A A H HARA

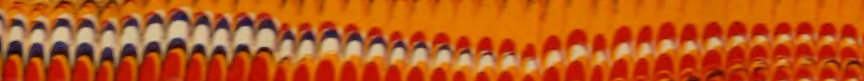

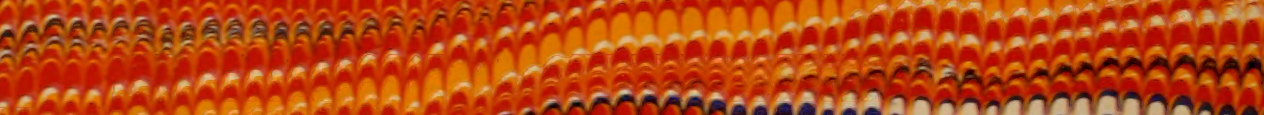

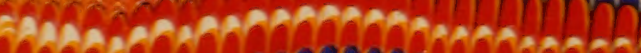

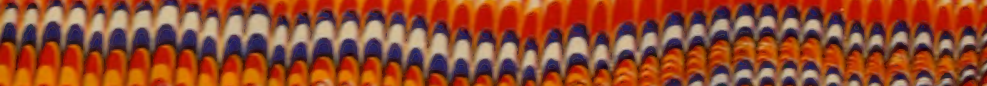

A H W

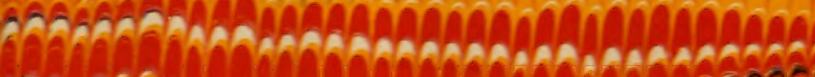

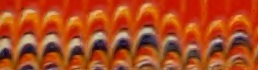
66-1

A

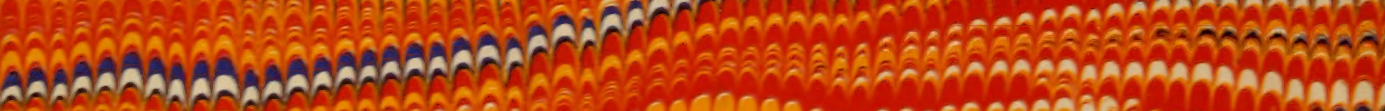

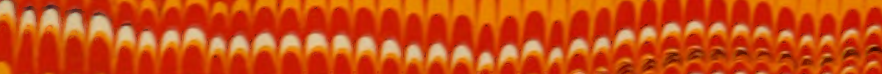

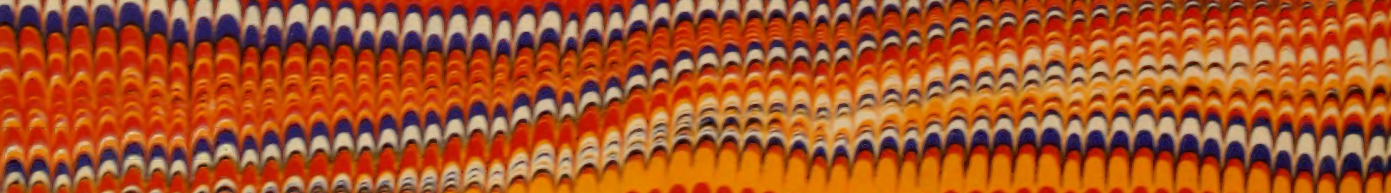

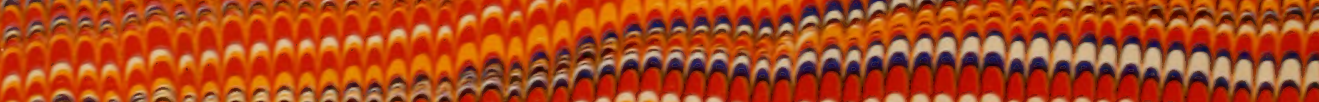

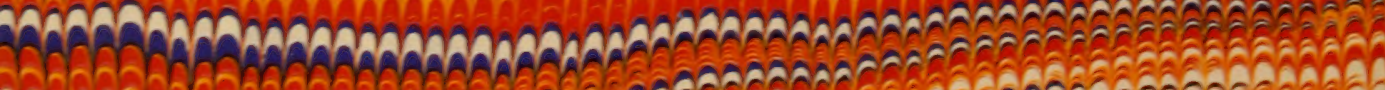
AmamaA

Ma

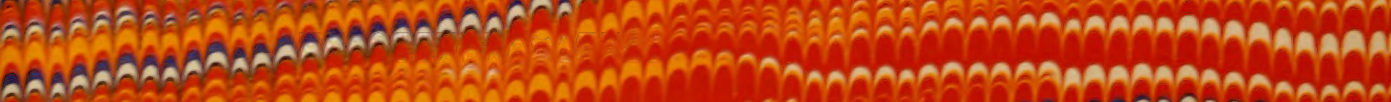

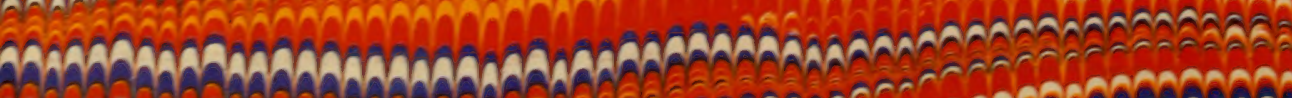
-

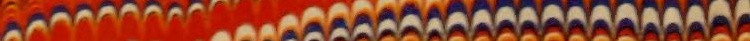







NOVA ACTA REGIAE SOCIETATIS SCIENTIARUM UPSALIENSIS SER. IV. VOL. 5. N:O 6 .

\section{THE CRINOIDS}

FROM

\section{DR. S. BOCK'S EXPEDITION T0 JAPAN 1914}

TORSTEN GISLÉN

WITH 2 PLATES AND 162 TEXTEIGURES

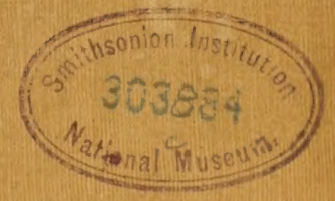

(Presemted to the Royal Sociefy of Science of Upsala November 4th 1921)

UPPSALA

EDV. BERLINGS BOKTRYCKERI A.-B.

1922. 

NOVA AOTA REGLAE SOCIETATIS SUIENTIARLM IPSALIENSIS SER. IV. VOL. 5. N:0 6.

\title{
THE CRINOIDS
}

FROM

\section{DR. S. BUCK'S EXPEDITION TO JAPAN 1914}

\section{TORSTEN GISLEN}

\author{
WITH 2 PLATES AND 162 TEXTFIGURES
}

(Presented to the Royal Soctery of Science of Upsala November 4th 1921)

UPPSALA

EDV. HERLINGS HOKTRYCKERI A,-B.

192.2. 



\section{The Crinoids}

from

\section{Dr. S. Bock's Expedition to Japan 1914.}

This systematic work is an investigation of the fine and very interesting Crinoid material that was brought home by Dr. Srxtex Bock's Japanese expedition of 1914 and which has kindly been delivered to me by $\mathrm{Dr}$. Bock for determination. On many occasions the determination has been facilitated by comparison with the crinoids that Dr. Mortensen of Copenhagen has collected in the same regions and also kindly delivered to me for determination.

I am much indebted to Mr A. H. CLark of Washington for the very valuable information he has always readily rendered me. 'T'o Professor A. Wirén of Uppsala I also wish to express my thanks for the kind interest with which he has followed my investigations.

The translation has been made by myself with the assistance of my sister Miss Märtha GrsLÉn. The work was afterwards revised by Mr Henry Alexander M. A. and to both these helpers I herewith offer my heartiest thanks.

Finally I beg to express my gratitude to Miss Sigrid OIrLsson and Miss A. Starup, who have kindly drawn in Indian ink the textfigures made by myself in peneil.

The points of view that I have followed in my investigation have chiefly been the same as I applied when revising the erinoid material brought home from Australia by Dr. NJöBerg, though I have been able to begin and complete the determination of the dapanese Crinoids with a deepened linowledge and also to apply a more tho- 
roughly worked out systematical method. 'Thus I have for each species given a more or less detailed deseription of a typieal specimen and for the rest of the individuals belonging to the same type I have given an account of the divergences from the normal type. I have also given numerical specifications for such characteristics as were the subject of statistical treatment.

What I have often felt as a defieiency is, that the authors of the species-descriptions within this group, especially during the last few years, have not given any specifications either as to which characteristics they have considered to be significant for the species or to which previously described species the newly described type might be most elosely related. It has therefore become unnecessarily tedious to find out from the multitude of the stated characters those which are specific for the species. Because of this I have added to the description of every new species or variety a short summary and discussion of the characteristics that I have thought to be distinguishing ones for the species, and a statement as to which previously described species the new one might be most closely related to.

Since the days of the Challenger papers there are few works that have given any figures of the newly described Crinoids and in the cases where this has been done it is almost without exception only habitus-figures that have been reproduced as drawings or photos. When it is necessary to reproduce a habitus-picture of a Crinoid a photo is doubtlessly most suitable, n. b. if well taken. A picture of an entire animal must always involve great sehematization, which becomes more visible in Crinoids than in other animals because the Crinoids consist of such an innumerable quantity of ossicles, the number, sculpture and form of which represent the proper genus and species characteristics. A good photo, on the contrary, can quite correctly reproduce a habitus-picture and, in addition, a good many of the more microscopical characters. But when it is a question of giving a complete picture of a newly described species the macroscopical photo is, however, not satisfactory alone, at least not in the case of a Comatulid species. Then one must also add to the habitus-picture drawings (or microphotos) to visualize the specific characters for the species. which one usually takes from the appearance, form, number and size of the $\mathrm{Cd}$ and cirrals; from the seulpture of the arms and especially 


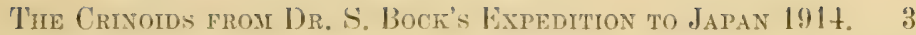

from their proximal parts; from the occurrence of the pinnules and their relative size and ornamentation. It will therefore be seen that in most species I have given drawings of Cirri, of the proximal and distal pinnules that are especially characteristic, and of Br joints and Centrodorsals, where they have any characteristic sculpture or otherwise show any appearance specific for the species.

As to the systematical classification I have followed A. H. CLARK's system. Though in some particular eases this perhaps needs criticizing, still it is certainly right in its principal traits. In his large work on the Comatulids of the Siboga Expedition, Cuark has brought together a good many of his systematical observations previously published in numerous investigations and now one can more easily estimate the value of the new system. In certain cases he has perhaps, however, gone too far in subdividing the genera; the recent known Crinoids comprising about 600 species are distributed in 132 genera. The apparent disproportion between the number of species and genera will in the future be diminished by new expeditions adding many new species to the small genera. By this the division into genera will certainly persist in many cases, but on the other hand I do not think that in course of time one will be able to keep apart genera in which for instance the difference in genus $A$ is only that $P_{1}$ is the longest pinnula, in $B: P_{2}$, in $C: P_{3}$.

Though I have studied about 40 of the above-mentioned genera, I do not consider that I have yet sufficiently detailed knowledge to put the system through a suitable criticism and apply new restrictions to certain genera. Besides, it seems to me as if the study of the inner anatomy (in the Comatulid genera and families still quite a terra incognita) ought to precede a discussion of the mutual relation between the different groups. I hope in the future to be able to begin this study and throw some light upon the matter.

Dr. Bock's Japanese Expedition brought home 53 different species and varieties of Crinoids, distributed in 29 genera. I have given below a list of the contents of the collection and at the same time the depths at which the specimens were swept. (In the case of the specimens from Kiu-Shiu there are sometimes no statements of the 
depths, but according to Dr. Bock they are said to be taken from at most a depth of 200 metres) ${ }^{1}$.

Comatella brachycirra n. sp. 145-209 metres

Comatella maculata (P. H. CARP.) 145-182 metres

Comatella stelligera (P. H. CARP.) 145-209 metres

Commissia peregrina var. maginifica n. var. 192 metres

Comissia parvula A. H. CLARK 209-728 metres

Comissia gracilipes A. H. Clark 728 metres

Comissia ignota var. minuta n. var. 127-209 metres

Comaster delicata var. grandis n. var. 72-182 metres

Comaster serrata A. H. CLARK 127-209 metres

Comantheria grandicalyx (P. H. CARP.) 54-72 metres

Comantheria grandicalyx var. flagellipinna $\mathrm{n}$, var. 20-63 metres

Comanthus solaster A. H. CLARK 2-4 metres

Comanthus pinguis A. H. CLARK 136 metres

Comanthus (Vania) annulata (BELL) 127 metres

Comanthus (Vania) parvicirra a comasteripinna (MüLLER) n, n, 0-63 metres

Comanthus (Vania) parvicira $\beta$ comanthipinna n. subsp. 63 metres Catoptometra Hartlaubi A. H. CLARK 245 metres

Catoptometra magnifica var. minor n. var. 127-182 metres

Eudiocrinus indivisus SeNPER 182 metres

Eudiocrinus gracilis var. pulchellus n. var. 127-182 metres Eudiocrimus Loveni n. sp. 145 metres

Liparometra grandis A. H. CLARK, ?-145 metres

Cenometra bella (HARTLAUB) 63 metres

Cyllometra disciformis (P. H. CARP.) 162-72S metres

Cyllometra manca (P. H. CARP.) 47 metres

Cyllometra albopurpurea A. II. CLARK 163-182 metres

Cyllometra pulchella n. sp. $136-163$ metres

Tropiometra afra var. macrodiscus (HARA) 3-5 metres

Tropiometra encrinus (LüTKEx) 163 metres

Neometra multicolor A. H. CLARK 163 metres

1 The statements as to the depths, according to Dr Bock, ought not to be taken too strictly, with the exception of the depths from the Kiu-Shiu locality. In other cases they only signify the length of the wire let out of the trawl. 
'The ('rinoms mon Dr. S. Bock's Expedttion to Japax 1914.

Pectinometre flewopurpured A. I. CLARK 36t-728 metres

Pteromelra trichopoda A. H. CLARK 145-182 metres

Asterometra macropoda A. H. CLARK 163 metres

Asterometra anthus A. II. CLARK 127-209 metres

Stenometra dentata n. Sp. 152-209 metres

Crossometra septentrionalis A. H. CLARK 364 metres

Perissometra aranea n. sp. 200 metres

Diodontometra Bocki n. gen. \& sp. 209 metres

Compsometra parviflora A. H. CLARK 127-145 metres

Compsometra serrata A. H. CLARK $0-3$ metres

T'oxometra aquipinna n. sp. 273 metres

Iridometra melpomene A. H. CLaRk 182-728 metres

Dorometra nana (HaRtLaub) Diver (about $0-5$ metres)

Dorometra briseis A. H. CLARK 728 metres

Dorometra parvicirra (P. H. CARP.) 145 - 163 metres

Psathyrometra Wireni n. sp. depth?

Enythrometra mora A. H. CLARK 163 metres

Clarkometra elegans n. gen. \& sp. 127-163 metres

Thaumatometra comaster A. II. CLARK 273-728 metres

Metacrinus nobilis var. tenuis $\mathrm{n}$. var. $182-400$ metres

Metacrinus rotundus P. H. CARP. 182-25t metres

Hotacrinus interruptus P. H. CARP. 145-400 metres

Metacrinus intervuptus form. ornatus new form 18\%-400 metres.

If I disregard Compometra serrata, which is also found on the shore at Shimonoseli, the above-enumerated speeies are seattered over 3 different localities. These 3 localities are the Sagami Bay, the district round the Goto Islands, and the Bonin Islands.

From Sagami the following speeies were brought home: 1) $\mathrm{Co}-$ missia parvula, 2) C. gracilipes, 3) Comanthus solaster, 4) C. parvicirra a comasteripinna, 5) Liparoinetra grandis, 6) Cyllometra disciformis, 7) Tropiometra afra macrodiscus, S) Pectinometra flavopurpurea, 9) Crossometra septentrionalis, 10) Compsometra serrata, 11) Toxometra cequipinua, 12) Iridometra melpomene, 13) Dorometra briseis, 14) Thanmatometra comaster and 15) Metacionus rotundus. Further there is a young Comasterid from a great depth, which is probably Comatulides decameros sp. juv. In all therefore 15 or 16 species from Sagami, one of which is new (N:r 11). 
From Kiu-Shiu and the Goto Island are collected: 1) Comissin parvula, 2) Comanthus pinguis, 3) Catoptometra Hartlaubi, 4) Cyllometra manca, 5) Cyllometra pulchella, 6) Neometra multicolor; 7) Asterometra macropoda, S) Perissometra aranea, 9) Psathyrometra Wireni, 10) Erythrometra mura, 11) Metacrinus nobilis temus; 12j H. intermutus, 13) M. internuptus form. ornatus and 14) $M$. rotundus or 14 species, including 3 new species and a new form. N:r 1 und 14 are common with the Crinoid fauna of the Sagami bay, n:r 11, 12 and 13 with that of the Bonin Islands.

From the Bonin Islands there are:

1) Comatella bractuycirra, 2) C. maculata, 3) C. stelligera. 4) Comissia peregrina magnifica, 5) C. ignota minuta, 6) Comaster delicala grandis, 7$) C$. serrata, 8) Comantheria grandicalyx, 9) C. grandicalyx fagellipinna, 10) Comanthus ammelata, 11) C. parvicirra a comasteripinna, 12) C. parvicirra $\beta$ comanthipinna, 13) Catoptometra magnifica minor, 14) Eudiocrinus indivisus, 15) Eu. gracilis pulchellus, 16) Eu. Loveni, 17) Liparometra grandis, 18) Cenometra bella, 19) Cyllometra albopurpurea, 20) C. (disciformis 21) Tropiometra encrinus, 22) Pterometra trichopoda, 23) Asterometra anthus,

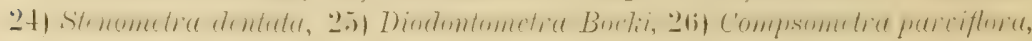
27) Dorometra nana, 28) D. parvicira, 29) Clartiometra elegans, 30) Meta. crinus nobilis temis, 31) MI. intermptus, 32) MI. intermuptus form. ornatus. Among these 32 species there are 2 belonging to new genera, 5 new species, 7 new varieties, and one new form. N:r 11 and 17 are also found in the Sagami-list, N:r's 30, 31 and 32 in the one from the Goto Islands.

As to the Sagami-species one can note some forms from a depth of $100-400$ fathoms (182-72S metres) which have not before been found north of the archipelago of the Sunda-Islands. Probably it is the warm Kuro-Shio stream which passes northwards along the eastern shore of Japan that has brought up the larva-stages of these southem species and that makes their duration in this northern waters possible. According to the statement of Mr A. H. CLARK and the holothurian specialist Dr. H. OHsmma a southern woof continues to assert itself in the marine fauna up to the Sendai Bay, i. e. somewhat north of the $38^{\text {th }}$ latitude. The prominent point and Kingwa-San here prevent further penetrating of the warm water and of southern forms and marlis the northern boundary of Indo-pacifie animals. Comissia parvula was previously found at the Philippine Islands and the smaller Sunda-lslands at a depth of $73-522$ metres. In the Bockian Collections the species 
was swept from Sagami at a depth of 209-728 metres. Comissia gretcilipes, collected at the Kei-Islands at a depth of $595-98+$ metres, is found at Sagami at 72s metres. Cyllometre disciformis oceurs at the Philippines from 0-325 metres, at Sagani the speetes is found from 182-728 metres and, finally, T'oxometre at the Philippines and the Sunda-lslands, where the genus is represented by the species panera, oceurring at a depth of $0-502$ metres, was brought home from Sagami from 273 metres.

A woof of southern forms is also visible at the Goto Islands by the occurrence of the species Cyllometra manca, Psallugrometra Wireni, Meterinus intermuptus and M. nobilis var. temuis.

The Crinoid fauna of the Bonin-Islands was quite unknown before. The 32 species that have been brought home from these islands, show that the crinoid fauna forms a mixture between the South Japanese fauna and that of the Sunda Islands and Oceania with a woof of some more peculiar and diverging forms. South Japanese species or ones closely related to these are Comatella brachycirra, Comaster serrata, Comantheria grandicalyx, Cyllometra albopurpurea, Asterometra anthus and Stenometra dentata. Nost of the rest are represented by the same or closely-related forms in the waters round the Sunda islands and the Philippines or belong to species with ubiquitous distribution. Eudiocrinus gracilis, formerly reported from Burma, is represented by a somewhat diverging form. Of the same genus there is a new species Eu. Loveni, which reminds one both of Eu. gracilis and vemustulus, but is otherwise a special type. It is strange that a variety of the Last African Comissia ignota is found at the Bonin Islands. As a parallel in the distribution one might quote Tropiometre afre and Tro. piometra afra macrodiscus. Both the new genera of the collection also originate from these islands. The genus Diodontometra is a Charitometrid form, most closely related to Charitometra, a genus known from great depths at the Kermadee and Fiji islands, though the new genus differs from Charitometra by having XX arms and a double opposing spine, an almost unparallelled condition, formerly observed only in the genus Epimetra fam. Colobometride. The new genus clartiometra is also interesting especially from an animal-geographical point of view. T'he genus belongs to the subfamily Perometrince of Antedonide and is most elosely related to the East Ameriean genus Ilypalometra, 
from which it differs, however, in several characteristics. A small number of genera from the Indian ocean are already known with corresponding types in the Caribbean sea. The above-mentioned genera still show a couple of these interesting correspondences.

Some of the species found at the Bonin islands (e. g. Tropiometra encrinus, Vania ammlata) are met with here at greater depths than those formerly reported in the literature.

A tendency to abbreviation of the cirri can be traced in several species from the Bonin islands. Thus Comutrlla brachyrima, Cutoptometru magnifica minor; Eudiocrinus gracilis pulchellus, and Stenometra dentata differ from closely related forms by the cirri being unusually short in comparison with the arms (compare several newly described species in Clark's Siboga work, where in forms from the Sunda islands an opposite tendency prevailed).

Some of the Bonin localities seem to have had a very rich crinoid fauna. From St. 59 one notes no less than 13 species. It may be of some interest to note that while the erinoid fauna from this rich locality only shows full-grown specimens, the list from e. g. St 47 only includes the young of large species and mature individuals of small forms. Obviously a current favourable for the one as well as for the other has brought larvæ of numerous forms. In the latter case quoted this has occurred rather recently and it is therefore only the small species that have reached maturity.

The collection as a whole gives a good idea of the abundance of crinoids that prevails in Japanese waters.

The family Comasteride is represented by 16 species, one of which is a new species, and 5 can be considered as new varieties. In the systematical investigation of this family I have discussed in special detail the forms of Comanthus (Vania) parvicirra and the value the characters may have in this sub-genus. The collection is rich in young forms and an especially great number of young comasterisk have been placed at my disposal. All these young forms, like all young forms of Comasterids, are exeeedingly difficult to identify and one may usually think oneself very fortunate if the young Crinoid is determinable as to genus. Hitherto deseriptions are chiefly published only for grownup forms and therefore the characteristies that might possibly be used to distinguish young ones are unnoticed or unknown. If the fauna 
at a certain place is approximately known and evolution-series are brought home, the prospects of identifying young forms are considerably brighter. I therefore considered it of a certain interest to make a combination of the young Comasterid forms from the Bonin Islands and, partly by comparing them with one another, partly by studying given evolution-series, try to prorluce the characteres that might be of systematical value. Thus, among other things, I think I have found that the appenrance of the disk ean give certain fixed points for judging the systematic position of the young Comasterids.

The family Zygometride is represented by 5 forms including one new species and two new varieties. As always, here too I have been very cautious in establishing new species and have preferred to set up a new form as a variety rather than as a species if the distinguishing characteristies have seemed to me to be less decided or I have otherwise had any doubt about the value of the distinguishing marks quoted. Therefore it is very possible that some of the new forms described as varieties will in future turn out to be new species.

of the families Mariametride, Colobometridce, Tropiometride and Calometridce there are, except Cyllometra pulchella n. sp., only previously known species with a number of species 1, 5, 2 and 2 respectively. Cyllometra disciformis is swept from greater depths than were previously known and because of this the cirrals are exceptionally short in correspondence with A. II. CLarks statement on the Siboga material. Antedon macrodiscus, described by the Japanese HARA 1895, I have put as a variety under Tropiometra afra, from which it only differs by having a greater number of cirrals, a character that in this case I cannot consider to have a species-distinguishing value, as it is the only differing one. The relation between the genera Calometra and Neometra I have discussed in connection with the description of specimens of Neometra multicolor.

The family Thalassometride appears with 4 species, one of which is new, Stenometra dentata, in a certain way intermediate between the genera Stenometra and Daidalometra. Of Asterometra anthus I have had an opportunity to study a very rich material, which has been subjected to statistical investigation. This has given the result that both the Clarkian species $A$. acerba and $A$. lepida cannot be considered as forms differing from the above-mentioned species but might become absorbed 
in A. anthus. Both in this and in the first-mentioned, newly described species there are some very tender young forms with defective pinnulation and orals not yet resorbed. I have also observed these ossicles in some small Comasterid youngs and in a young Compsometra serrata.

of Charitometridte there are 3 species, one of them belonging to a new genus, the above-mentioned Diodontometra. Moreover a new species of the genus Perissometra is also described.

The family Antedonide counts in the collection 12 species, distributed over 4 sub-families: 1) Antedonina: 7 species, including a new one, 2) Zenometrinc: one species (new), 3) Perometrince: 2 species (one new genus, the above-mentioned Clarkometra) and 4) Batymetrinc: 1 species.

Compsometra serrata as also the above-mentioned Cyllometra pulchella were brought home in great numbers and the statistical investigation that I have earried out shows here, as almost every where when one has to do with nearly fullgrown crinoids, an astonishing constancy in the number of cirri, cirrals, pinnulars, ete. A certain variability is, however, always visible and to establish its range seems to be of rather great importance. Psathyrometra Wireni is peculiar in so far as it has sexual products on $\mathrm{P}_{2}$, a character restricted otherwise to the subfamily Bathymetrince or occurring exceptionally in Antedonine.

Of stalked Crinoids there are only representatives for the Pentaerinoid genus Metacrimus, which is represented by 4 different species or forms (including a new variety and a new $\gg$ form»). Metacrinus Stewarti for reasons quoted is considered to be an unimportant form-deviation from the $M I$. rotundus type and is therefore treated as a synonym of this species. As to $M$. interruptus (P. H. CARP.) $I$ have on the contrary considered that there are reasons for not agreeing with Mr. Sperry's views as to the identity of this species with M. rotundus and I have therefore treated it as a separate species.

The material of Metacrinus-forms is extraordinarily fine and interesting from an ontogenetical point of view. A young specimen of $\lambda$. internutus may be the youngest known specimen of a Metacrinus species and shows many interesting conditions of organisation. In a couple of species it has been possible to follow the increase in the thickness of the stem and an estimate of the total length of the grow- 
ing stem has given figures from 2 to 2,5 metres. It is, however, to be noticed that large forms, such as $M$. rotundus, probably have stems which during their increase of thiekness become a good deal longer. Concerning both the first-mentioned species and the latter ones it is very possible that the length-increase of the stem is continued cven ufter the increase of thickness has ceased. A couple of measurements have shown that the thickness of the stem can even decrease proximally, which ought probably to be regarded as a phenomenon of old age. The study of the components of the division-series has led to interesting results which will be treated in a special investigation in connection with the question of the new formation and augmentation of the number of arms in the genus Metacrimes and in the discussion of the relation between pimnule and arms.

Concerning the terminology I have used the same names as in my work upon the Msöbergian Crinoids, i. e. about the same as Bather, A. I. Clark ete. have employed.

Thus $\mathrm{R}$ (the radial) is the first ossicle of the arm. The ossicles between the radial und the first arm-ramification are denoted as primibrachials 1, 2, ete. ( $\mathrm{I} \mathrm{Br} \mathrm{1,} \mathrm{I} \mathrm{Br} \mathrm{2).} \mathrm{The} \mathrm{last} \mathrm{ossicle} \mathrm{before} \mathrm{this} \mathrm{arm-}$ division is an axillary (I Brax), carrying on its distal surface two secondary arms. If the animal has only $\mathrm{X}$ arms there are no further arm-ramifications, otherwise after the I Brax the secundibrachials (II Br:s) follow with the $2 \mathrm{nd}, 4$ th or, among the stalked crinoids, even a more distal segment forming an axillary. On this a new division-series, the tertibrachial (III Br), may possibly arise, then perhaps a IV Br series and so on. The segments of the arm-branches that are not further divided are signified as brachials $(\mathrm{Br})$ with the number of the segments counted from the last axillary.

'The number of the Cirri (C) as well as of the arms is written in roman figures, the number of the segments in arabie ones. By the word »whorl» in the description of cirri I mean their arrangement in a horizontal line, but I speak of $\gg$ row» when referring to their arrangeement in a vertical line.

The pinnules (P) are denoted on the outside of the arm by ordinals, on the inside they are indicated by letters $(a, b, c)$. I Br (Costal), II Br (Distical), III Br (Palmar), and IV Br (prostpalmar) pinnules I 
have, however, contrary to my procedure in the Mjöbergian work, denoted by $\mathrm{P}_{\mathrm{I}}\left(=\mathrm{P}_{\mathrm{C}}\right), \mathrm{P}_{\mathrm{II}}\left(=\mathrm{P}_{\mathrm{D}}\right), \mathrm{P}_{\mathrm{III}}\left(=\mathrm{P}_{\mathrm{P}}\right)$ and $\mathrm{P}_{\mathrm{IV}}\left(=\mathrm{P}_{\mathrm{PP}}\right){ }^{1}$

In order to demonstrate the ramifications of the arms I have need the same schemes that I demonstrated in my Mjobergian investigation. In these schemes synarthries are indieated by hyphens, syzygies by the plus sign. Though synartries and syzygies have different marks they can, however, in certain species pass over to each other to an unlimited extent and in such dubious cases I have often put a query instead of one of the above-mentioned marks. The ppseudo-» syzygy when fully developed is denoted as a »true» syzygy. Roman numerals signify the number of division-weries. thus for instance II = II $\mathrm{Br}$, arabic ones $=$ the ordinals of the segments. Br as usual=brachial, $\mathrm{R}=$ radial. I have marked the regenerate by adding an index to the number of the segment. The index mark 1 forms the sign of a first regeneration, 2 of a second one and so on. The distribution of the pinnules is indicated by horizontal lines which are applied below or above the symbol of the segment according as the pinnula is fixed inside or outside the arm.

The abreviations that I have used are the following:

$$
\begin{array}{ll}
\mathrm{B}=\text { basal } & \mathrm{br}=\text { breadth } \\
\mathrm{Br}=\text { brachiale } & \mathrm{h}=\text { height } \quad \mathrm{D}=\text { Dorsal cirrus whorl } \\
\mathrm{C}=\text { cirrus } & \mathrm{L}=\text { length } \quad \mathrm{V}=\text { Ventral cirrus whorl } \\
\mathrm{Cd}=\text { Centrodorsal } & \mathrm{N}=\text { number } \\
\mathrm{IR}=\text { interradially } & \mathrm{S}=\text { number of segments } \\
\mathrm{P}=\text { pinnuld } & \mathrm{T}=\text { teeth. } \\
\mathrm{R}=\text { radiale } & \\
\hline \text { 'For the pronunciation of these symbols I suggest: primi-p., secundi-p., terli- }
\end{array}
$$


Comasteridæ A. II. Clark.

Subfam. Capillasterinæ A. H. Clark.

Comatella A. H. CL.IF,

C. brachycirra 11. sp.

Fig. 1-3. Photo 1.

From St. 53 ( 5 sp.), 55 (2 sp.), 56 (2 sp.), 59 ( 7 sp. $)=16$ specimens.

Sp. 1 (St. 56) Cd flattened, free dorsal surface small, smooth, peripherically somewhat furrowed, diameter $1,5 \mathrm{~mm}$.

Cirri XVIII, 10-12;5-7 mm. in a close, irregular whorl (most are broken). The first segment somewhat shorter than long, $2^{d}$ segment $\mathrm{L}=2 \times \mathrm{br}$, somewhat hour-glass shaped, $3^{\mathrm{d}}$ and $4^{\text {th }}$ segments $\mathrm{L}=3-3 \frac{1}{2} \times \mathrm{br}$. ( $t^{\text {th }}$ segment with the disto-dorsal part bent outwards), $5^{\text {th }}$ segment $\mathrm{L}=2 \times \mathrm{br}, 6^{\text {th }}$ and following segments $\mathrm{L}$ about $=$ br with unimportant, obtuse, dorsal spines. The dorsal spines of the two last segments more pointed: Terminal elaw strongly bent, quickly tapering, $\mathrm{L}=\underline{2} \times$ the penultimate segment.

$\mathrm{B}-\mathrm{S}$ appearing $\mathrm{IR}$ as knobs. $\mathrm{R}-\mathrm{S}$ almost hidden by $\mathrm{Cd}$ on the middle, or presenting themselves as narrow bands.

I $\mathrm{Br} \quad \mathrm{L} \mathrm{L}=1 / 3 \mathrm{br}$, laterally free, united with I $\mathrm{Br} 2$ by a synarthry. I Brax $h=2 / 3$ br, forming a low pentagon, the distal margins a little bent outwards. The II Br:s are 2, appearing in 2 cases fthe arms are partly broken). Arms at least XII, $50-60 \mathrm{~mm}: \mathrm{s}$.

$\mathrm{Br} 1$ on their inner side standing together or free, $0-7$ first Br-segments discoidal then oblique joints, $h$ (the longest) $=$ br. Syzygies $1+2$ on the inner side of the ramifications on the $\mathrm{Il} \mathrm{Br:s.} 3+t$ on the outer side, then $12+13 \cdot 17+18,21+22$ ete. with an interval of 3 oblique joints. The breadth of the arms is $0.8 \mathrm{~mm} .16 \mathrm{Br}$-segments pro $\mathrm{cm}(12$ if the syzygial pairs are counted as units) in lateral view not overlapping. The bases of the arms remarkably smooth. 
$\mathrm{P}_{1}-\mathrm{P}_{3}$ with a comb. $\mathrm{P}_{1} 22\left(+7 \mathrm{~T}\right.$, their $\mathrm{L}=1^{1 / 2} \times$ the br of the segment) $5,5 \mathrm{~mm}$. (Segments 1 and 2 short, the following ones $\geq \mathrm{br}), \mathrm{P}_{2} 17$ (6 T) $3,5 \mathrm{~mm} ., \mathrm{P}_{3} \pm 17$ (6 T) $3,5 \mathrm{~mm} ., \mathrm{P}_{4} 16 ; 4,5 \mathrm{~mm}$. a little spiny, $P_{6} 14 ; 3,5 \mathrm{~mm}$. Distal p-s. 18; $5-6 \mathrm{~mm}: \mathrm{s}$ (1 segment short, the following ones $L=1^{1 / 2}$ br; unimportant hooks on the last segments, compare the figure).

Mouth central. Disk $4 \mathrm{~mm}$, dark brown with lime-granules. Anal funnel short, 1,2 mm. The arms a lighter, uniform brown (in spirit).

Sp. 2 (St. 56) C. XV1, 11; 6,5 mm. The arms XV, 35- $40 \mathrm{~mm}$. $\mathrm{P}_{1} 24(8 \mathrm{~T}) 6 \mathrm{~mm} . \quad \mathrm{P}_{2} 19(6 \mathrm{~T}) ; \mathrm{P}_{3} 18(6 \mathrm{~T}) 4 \mathrm{~mm}$. The distal p. 15; $6 \mathrm{~mm}$. , Cd. peripherically rutty. Disk $3,5 \mathrm{~mm}$.

Sp. 3 (St. 59) C. XXV 11:6-7 mm. C. in two whorls. The arms XIV $+60 \mathrm{~mm}$. P ${ }_{1} 22-24$ (8 T) $7 \mathrm{~mm}$. The distal p. 20; 7,5 $\mathrm{mm}$. $P_{5} 15 ; 4 \mathrm{~mm}$. without a comb.

Sp. 4 (St. 59) C. XVII, 9-11;4-6 mm. The arms XIV or $\mathrm{XV}, 50 \mathrm{~mm} . \mathrm{P}_{1} 25(7 \mathrm{~T}) 5,5 \mathrm{~mm} . \mathrm{P}_{2}$ and $\mathrm{P}_{3}$ with $5-6 \mathrm{~T}, \mathrm{P}_{4}, 14 ; 3,5$ $\mathrm{mm}$. Distal p. 17;5,5 mm.

Sp. 5 (St. 59) C. XX $10-11 ; 4,5-7 \mathrm{~mm}$. The arms more than XII, broken. $P_{1} 23$ (7 T) $5,5 \mathrm{~mm}$.

Sp. 6 (St. 59) C. XII in a single whorl. The arms XII, $50 \mathrm{~mm}$. $\mathrm{P}_{1} 23$ (7 T) $5,5 \mathrm{~mm} . \quad \mathrm{P}_{2} 18$ (6 T) $3,2 \mathrm{~mm}, \mathrm{P}_{3} 18$ (5 T) $3,2 \mathrm{~mm} ., \mathrm{P}_{4} 14$. Distal p. 15; 5,5 mm. Disk $3,5 \mathrm{~mm}$. The specimen somewhat more slender than the foregoing ones. The Br-segments in the distal armpart $L=1 \frac{1}{2} \mathrm{br}$, somewhat spiny in the distal margin.

Sp. 7 (St. 59) C. XV 11; $5 \mathrm{~mm}$. The arms XIII, $45 \mathrm{~mm} . \mathrm{P}_{1} 2$ ? (S T) $5 \mathrm{~mm} ., \mathrm{P}_{2} 19$ (7 T) $3,5 \mathrm{~mm} . \mathrm{P}_{3} 6 \mathrm{~T}, 3 \mathrm{~mm}$. Distal $\mathrm{p} .18 ; 6,5 \mathrm{~mm}$.

Sp. 8 (St. 59) C. XXI, $10-11 ; 5-6 \mathrm{~mm}$. The arms $>$ XII. $\mathrm{P}_{1} 28$ (7 T) 5,5 mm. $\mathrm{P}_{2} 22$ (7 T), 3,7 mm., $\mathrm{P}_{3} 21$ (7 T) 3,5 mm., $\mathrm{P}_{4} 14 ; 3,5 \mathrm{~mm}$. Distal P. 12; $3,5 \mathrm{~mm}$. In this and the following specimen shorter $\mathrm{Br}$ segments which are bent more outwards.

Sp. 9 (St. 59) C. XVII, 10-11; $4-5 \mathrm{~mm}$. The arms XII +, 25-30 mm. $P_{1} 23$ (S T) 4,5 mm., $P_{2} 21 ; 3,5 \mathrm{~mm} . \mathrm{P}_{3} 20$ (7 T) $3,5 \mathrm{~mm}$. Distal p. $15 ; 5 \mathrm{~mm}$.

Sp. 10 (St. 55) Cirri XVIII $10-11 ; 0 \mathrm{~mm}$. The arms XIV, 70 mm. $\mathrm{P}_{1} 8 \mathrm{~T}, 6 \mathrm{~mm}, \mathrm{P}_{2} 2 \mathrm{I} ; 5 \mathrm{~mm}, \mathrm{P}_{4} 15 ; 4,5 \mathrm{~mm}$. Distal p. $18 ; 7 \mathrm{~mm}$. Spo 11 (St. 55) C. XVIII $10-11,5,5-6,5 \mathrm{~mm}$. The arms XIII, (50) mm. P 125 (8 T) $6 \mathrm{~mm} ., P_{4} 15 ; 4,5 \mathrm{~mm}$. Distal p. 20; $7 \mathrm{~mm}$. 
The Crinoins from Dr. S. Bock's Expentetox to Japax 1914. 15

Sp. 12 (St. 53) C. XIII 11; $7 \mathrm{~mm}$. The arms XVIII, 65-75 mm. $P_{1} 25-27$ (8-9 T) $6 \mathrm{~mm} ., \mathrm{P}_{2} 22, \mathrm{P}_{3} 21(6 \mathrm{~T})+\mathrm{mm}, \mathrm{P}_{4} 15$. Distal p. 18; $7 \mathrm{~mm}$. Oceasionally $\mathrm{P}_{4}$, with a comb 5 ' $\mathrm{T}, 17$ segments. The specimen is lighter coloured. Perhaps a hybrid with some of the following species. The Br-segments somewhat more spiny than those of the preceding specimens.

Sp. 13 (St. 53) C. XVII $10-11,5-6 \mathrm{~mm}$. The arms XV, t5 mm. $\mathrm{P}_{1} 7 \mathrm{~T}, \mathrm{P}_{2}-\mathrm{P}_{3}$ with teeth. Distal p. $16 ; 5 \mathrm{~mm}$. These sp. and the 3 following ones more redish-brown than the preceding.

Sp. 14 (St, 53) C. XIV $10-11,5-6 \mathrm{~mm}$. The arms XV, 50 mm.. $\mathrm{P}_{1} 7 \mathrm{~T}, \mathrm{P}_{2}$ (and $\mathrm{P}_{3}$ ) with teeth. Distal p. 17;5,5 $\mathrm{mm}$.

Sp. 15 (St. 53) C. XVII 10;6 mm. The arms $\mathrm{X}, 55 \mathrm{~mm}, \mathrm{P}_{1}-\mathrm{P}_{3}$ with teeth. Distal p. 19; $6 \mathrm{~mm}$.

Sp. 16 (St. 53) C. XIV 10; $5 \mathrm{~mm}$. The arms XV, $20 \mathrm{~mm} . \mathrm{P}_{1} 20$ (6 T) $3,5 \mathrm{~mm} ., \mathrm{P}_{2}$ is sometimes lacking, $\mathrm{P}_{3}$ always absent. Distal p. 12: $3 \mathrm{~mm}$. Disk $2,5 \mathrm{~mm}$.

An illustration of the division of arms from Sp. 2.

$$
\text { I } 1-2\left\{\begin{array}{l}
\text { II } 1-2\left\{\begin{array}{l}
\mathrm{Br} 1-23+4 \ldots 16+17 \ldots 21+2 \ldots 25+26 \ldots \\
\mathrm{Br}^{2} 1+2(4+5) \ldots 13+14 \ldots 17+18 \ldots 21+22 \ldots
\end{array}\right. \\
\text { II } 1-2\left\{\begin{array}{l}
\mathrm{Br} 1+2 \ldots 13+14 \ldots \\
\mathrm{Br} 1-23 \ldots 4 \ldots 13 \quad 14 \ldots
\end{array}\right.
\end{array}\right.
$$

In sp. 7 exceptionally one case with II $\mathrm{Br} 4(1-23-4)$

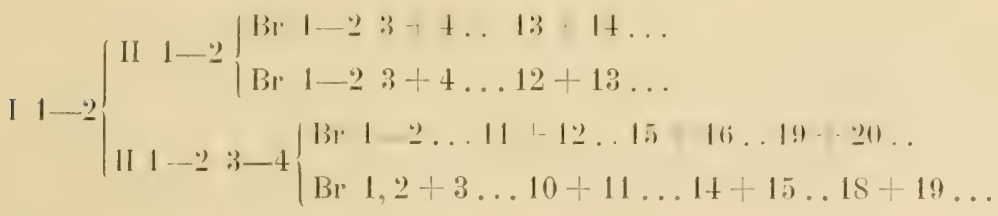

$\mathrm{Cd}$ varies in diameter between 1 and $2 \mathrm{~mm}$. Cirri appearing in one or two whorls. Cirrale $2: \mathrm{L}=1^{1 / 2}-2 \times$ br $^{2}$; Cirrale $3: \mathrm{L}=21 / 2$ $3 \times$ br'; Cirrale $4: L=31 / 2 \times$ br; Cirrale $5: L=1 \frac{1}{1} / 2-2 \times$ br.

This species is most elosely related to C. decora A. II. CLARK from Japan but is separated from this species, by 1): the eirri, which 
compared with the arms are much shorter and always have 10-11 segments (with very long $3^{\mathrm{d}}$ and $4^{\text {th }}$ segments) instead of $12-13,2$ ) never III Br:s, 3) syzygies between $\mathrm{Br} 1$ and 2 or 3 and 4, only exceptionally between 2 and 3,4$) P_{1}$ is much shorter and with fewer segments in $C$. brachycirre than in $C$. decora. Teeth $6-9$ instead of 12. 5) $\mathrm{P}_{1}-\mathrm{P}_{3}$ with a comb (C. decora has teeth on $\left.\mathrm{P}_{1}-\mathrm{P}_{6}\right)$.

Comatella maculata (P. II. CARP.).

Syyn.: see Siboga Exp. Vol. 42 B (A. H. Clark: Unstalked Crinoids) p. 7.

Fig. $4-6$.

From St. 53 (1 sp.) $59(2 \mathrm{sp})=$.3 specimens.

Sp. 1 (St. 59) Cd 3,5 mm., free dorsal pole $2,5 \mathrm{~mm}$. Cirri XXI, 19; 10-12 $\mathrm{mm}$, in a single or double whorl. First and $2^{\mathrm{d}}$ segments short, $3^{\text {d }}$ cubical, somewhat hour-glass-shaped, $4^{\text {th }}$ a little longer, $5-7^{\text {th }}$ segments $L=1^{1 / 2} \mathrm{br}$. Then shorter' segments again with dorsal spines. Penultimate segment $\mathrm{L}=\mathrm{br}$. Terminal claw coarse $\mathrm{L}=1^{1 / 2} \times$ the foregoing segment. A young cirrus has the $4-7^{\text {th }}$ segments somewhat longer, $\mathrm{L}=2 \times$ br.

$\mathrm{B}-\mathrm{s}$ and $\mathrm{R}-\mathrm{s}$ as in the preceding species. I $\mathrm{Br} 1 \mathrm{~h}=1 / 5 \mathrm{br}$. laterally free. I $\operatorname{Brax} h=1 / 3 \quad$ br, the border against II $\mathrm{Br} 1$ a little bent outwards. I $\mathrm{Br} 2$ forms with $\mathrm{I} \mathrm{Br}^{-} 1$ a small synarthrial tubercle. II Br:s are 2.

The arms are XV (or perhaps XVI), partly broken, $65 \mathrm{~mm}$. Primipostaxillaries inside for the most part united. Syzygies $1-2,3+4$, $14+15,23+24$ or $13+14,18+19$, then with an interval of 5 to 6 oblique artieulations. The proximal part of the arm not quite smooth. Br:s $1-8$ discoidal, then oblique joints. Distal segments tolerably short, the margins a little spiny and somewhat bent outward like a collar. 16-17 segments pro cm (If syzygial pairs are counted as units there are 14) Breadth of arms $1.2 \mathrm{~mm}$.

$\mathrm{P}_{1}-\mathrm{P}_{\mathrm{f}}$ with combs, $\mathrm{P}_{1} 36-38$ (18 T) 9 $\mathrm{mm}$. 'Teeth rather narrow, $1 / 2-1 / 3$ of the segment's breadth. $P_{2} \pm 30(15-17 \mathrm{~T}) 6,5 \mathrm{~mm}$., $\mathrm{P}_{3}-\mathrm{P}_{5}$ with decreasing length. $\mathrm{P}_{6} 22$ (12 T) $4,5 \mathrm{~mm}$. Distal p. 17-18: 5-6 $\mathrm{mm}$. 
The Crinotos rrom Dr. S. Bock's Expentmon to dapan 1914. 17

Disk $8 \mathrm{~mm}$. Anal funnel $1.5 \mathrm{~mm}$. Mouth and anus subeentral. Colour dark brown, regenerated parts white.

Sp. 2 (St. 59 ) Cd. $3 \mathrm{~mm}$, pentagonal, flat dorsal pole $2 \mathrm{~mm}$.

C. XXY $15-19 ; 9-11 \mathrm{~mm}$. The $4^{\text {th }}-5^{\text {th }}$ segments are the longest $\mathrm{L}=1 \frac{3}{4} \mathrm{br}$, $6^{\mathrm{th}}$ segment a little shorter, a transition segment. After this (as in sp. 1) highly polished segments.

The arms are XIII, 5.) $\mathrm{mm}$. Syzygies with an interval of $4-6$ oblique articulations.

$\mathrm{P}_{1} 38(19-22 \mathrm{~T}) 9 \mathrm{~mm}, \mathrm{P}_{4} 30( \pm 18 \mathrm{~T}) 7,5 \mathrm{~mm}, \mathrm{P}_{5} 17 ; 4,5 \mathrm{~mm}$. and $P_{6} 15 ;+m m$. without combs, but with dorsal hooks and as in the preceding p. with small spiny linobs on the outer side of the proximal segments. Distal p. 19; $6 \mathrm{~mm}$. 'The 6 last segments with dorsal hooks. 'The segments somewhat longer than broad, with spiny borders. Disk $6.5 \mathrm{~mm}$.

Sp). 3 (St. 53) C. XXIII 15-16 (D), 17-18 (V), 7-9 mm. The $4^{\text {th }}$ and $5^{\text {th }}$ segments longest, $L=2 \times b r$. From the $5^{\text {th }}$ segment a dorsal transverse crista.

The arms $\mathrm{X}, 40 \mathrm{~mm}$. +. Syzygies with an interval of 5 to 6 oblique joints. Axillary $h=1 / 2$ br. I $\mathrm{Br} \quad \mathrm{l} h=1 / 5 \mathrm{br}$. Primipostaxillaries free inside.

$\mathrm{P}_{1}-\mathrm{P}_{4}$ with a comb. $\mathrm{P}_{1} 30$ (18 T) $5 \mathrm{~mm}, \mathrm{P}_{2} \pm 13 \mathrm{~T}$, a little shorter. $P_{3}$ and $P_{4}$ with still shorter combs, $P_{5} 11 ; 3 \mathrm{~mm}$. Distal p. $13 ; 5 \mathrm{~mm}$.

Disk 5 mm. Mouth subcentral.

The base of the arms tolerably smooth. Synarthrial tubercles unimportant. The arms as in the preceding specimens rather coarse. Distal Br-segments a little overlapping, not bent outwards, with spiny borders.

The specimens agree with those of Carpexter and Cuare except that the joint between $\mathrm{Br} 1$ and 2 is of a synarthrial not of a syzygial nature and that the proximal pinnules are somewhat shorter. 
Comatella stelligera (I'. II. ('Mri').

Fig. $7-9$.

Syn.: sere sibogin Exp. t2 B, 1. II. Crank, Unstalked Cinoids, p. 5.

from St. $43(1$ sp.) $56(1), 59(2)=4$ specimens.

Sp. 1 (St. 59) Cd discoidal 3, $\mathrm{mm}$. Free dorsal surface $2 \mathrm{~mm}$. C. XXVIII 20-2t, $15-20 \mathrm{~mm}$. in two whorls. $1^{\text {st }}$ and $2^{\text {ll }}$ segments shorter than long, $3^{d}$ one somewhat longer, like the nearest one folfowing in the centre a little squeezed together, $t^{\text {th }}-{ }^{\text {th }}$ - segments $\mathrm{L}=$ $\pm 1 \frac{1}{2} \mathrm{br}, 7^{\text {th }}$ seginent a transition segment, the $8^{\text {th }}$ and the following ones highly polished. F'rom the $7^{\text {th }}$ segment a small dorsal spine. which at first consists of a minute, transverse, spiny erista, about the $1^{\text {th }} \mathrm{seg}-$ ment constricted to a simple spine protruding from the distal part of the segment. Distal cirrals $L=1 / 2-2 / 3 \times \mathrm{br}$. The height of the spine $=1 / 4-1 / 3$ of the breadth of the segment. Opposing spine more pointed and a little smaller than the preceding ones. Terminal claw eurved $L_{S}=12 / 3 \times$ the penultimate segment.

R-s visible as narrow bands. I $\mathrm{Br} I \mathrm{~h}=1 / 3 \times$ br, baso-laterally united, like all the following ossicles of the proximal part of the arm with the ends somewhat thiekened. bent outwards, and with small spines. A distinct synarthrial tuberele. I Brax triangular or low pentagonal, $h={ }^{1 / 3} \mathrm{br}$, laterally somewhat squeezed together. II Br-s are ?. appearing in 8 cases. II $\mathrm{Br} 1$ as $\mathrm{Br} 1$ on the inside united. $\mathrm{Br} I$ and 2 narrow, a little broader on the outside. After Br 7 oblique segments with the distal margins widened, overlapping and spiny. An example of the arm-ramification (a little differing in one branch) is giren below.

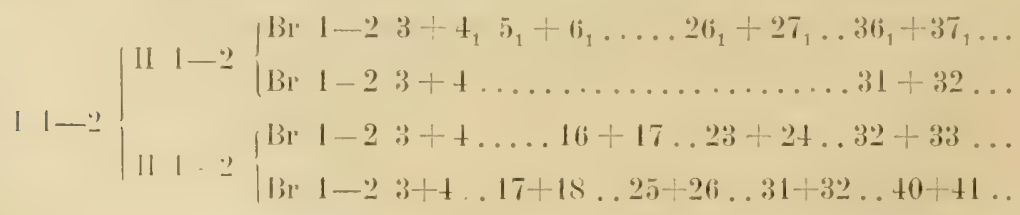


In some exceptional cases $13 r 1+2.3+4$ on the inner side of the dirisions. Syzygies distally with an interval of $5-6$ oblique joints. Arms XVIII. $80 \mathrm{~mm}$. 17-18 segments $\mu \mathrm{cm}$. (14-15 if the syzygial pairs are counted as units). Segments short, longest side $L=3 / 4 \times$ bre The breadth of the segments $0,8-1,4 \mathrm{~mm}$.

$P_{1}-P_{5}$ or $P_{6}$ with combs. $P_{1} \pm 37$ (17-18 T) 9,5 mm.. $P_{3}+35$ $(+20 \mathrm{~T}) \quad 6,5 \mathrm{~mm} . \mathrm{P}_{4}, 37$ (Teeth from $11^{\text {th }}$ segment), $\mathrm{P}_{5} \div 30$ ('T from

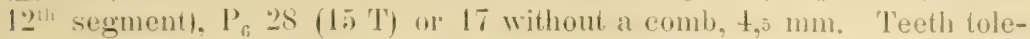

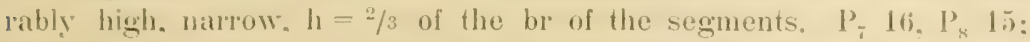
t.2 $\mathrm{mm}$. Segments not longer than broad. Proximal segments knobby and spiny, distally widened, not as in CARPEATER's figure with a small wing-like proeess but with a longitudinal spiny erista. Distal p. 18-20: $5 \mathrm{~mm}$. The last $4-5$ segments on each p. with paired dorsal hoolis.

Disk $10 \mathrm{~mm}$. Anal funnel 2.5 mm. Mouth and anus sub-central. Disk smooth without incrusted granules.

Sp. 2 (St. 59) C. XX 14-18, 6-12 mm, in a whorl only party double.

Arms IVI $65 \mathrm{~mm}$. (VI young regenerated arms). Syzygies most often $1-2.3+t \ldots$

$\mathrm{P}_{1}-\mathrm{P}_{4}$ with combs. $\mathrm{P}_{1} 31$ (15 T) is mm., $\mathrm{P}_{2} 30$ (17 T) 5 mmo, $\mathrm{P}_{4}$ 23 (1+ ' ' $)$ t,2 $\mathrm{mm}$. 'Teeth narrow, pointed. $P_{5} 13 ; 4 \mathrm{~mm}$. Distal $\mathrm{p}$. 16; $5 \mathrm{~mm}$., with small spines. The proximal parts of the arms somewhat smoother than in the preceding specimen.

Example of the arm-ramifications and distribution of syzygies in a somewhat abnormal arm.

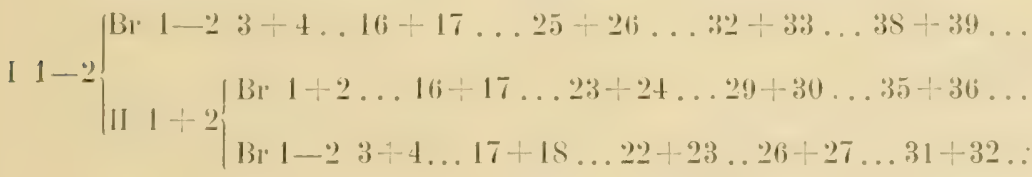

T'o this species 1 have also referred a X-armed specimen differing chiefly only by being smaller than the ones described above.

Sp. 3 (St. 56) Cd very slight vaulted, $1 \mathrm{~mm}$. C. XXV (III of them very small): 13 (D) $16(1), 6-9$ mm., usually in two whorls, $1^{\text {th }}$ and $2{ }^{d}$ segments short; $3^{d}$ one $\mathrm{L}=1 \frac{1}{1} / 2 \mathrm{br}$, a little hour-glass-shaped. $5^{\text {th }}$ and $6^{\text {th }}$ segments $\mathrm{L}=2 \times$ br with widened distal parts, $6^{\text {th }}$ segment with a 
spiny, transverse, dorsal crista which at the $10^{\text {th }}$ one is constricted to a simple spine ( $h=1 / 4$ of the br of the segment). Terminal elaw $L=1^{1} / 2 \times$ preceding segment, blunt, somewhat curved.

I $\mathrm{Br} \quad \mathrm{I} \mathrm{h}=1 / 3 \mathrm{br}$, laterally separated by the $\mathrm{R}-\mathrm{s}$, A weak synarthrial tubercle and a close articulation with the axillary. 1 Br. 2 $h_{1}={ }^{1} / 3$ br low pentagonal, distal margins form an obtuse angle. Arms X. about $35 \mathrm{~mm}$. Br 1 and 2 in close articulation with one another. B1. 1-6 discoidal, then oblique joints. Syzygies with an interval of 4-() oblique articulations. The outer margins of the distal segments very much bent outward and finely spinous.

$$
I 1-2\left\{\begin{array}{l}
\mathrm{Br} 1-23+4 \ldots 1+15 \ldots 19+20 \ldots 24+25 \ldots \\
\mathrm{Br} 1-23+4 \ldots 14+15 \ldots 19+20 \ldots 24+25 \ldots 31+32 \ldots
\end{array}\right.
$$

$P_{1}-P_{5}$ with combs. $P_{1} 32$ (18 $\mathrm{l}: \mathrm{h}=$ or $^{2 / 3}$ of the segment) 6,5 mm. $P_{2} 31$ (18 T) 5 mm., $P_{3} 2+(15 \mathrm{~T})+$ mm., $P_{4}$ similar, $P_{5} 2+(1+\mathrm{T})$ $3,5 \mathrm{~mm}$. Distal p. $\pm 17 ; 4,5 \mathrm{~mm}$. 3-5 distal segments with dorsal hooks.

Mouth and anus subcentral. Colour yellow-brown with white spots. Cirri white.

Sp. 4 (St. 43) C. XVIll $14-17,6-10 \mathrm{~mm}$. Dorsal spine from the $6^{\text {th }}$ segment.

Arms XII, $55 \mathrm{~mm}$. II Br:s are 2. Syzygies with an interval of $3-t$ oblique joints. The segments fairly strongly collar-shaped and spiny.

$P_{1}$ and $P_{2}$ with long combs composed of $15-20$ teeth. $P_{1} 5,5$ mm. $P_{2}+, 5$ mm., $P_{5}$ with $\pm 10 \mathrm{~T}$; $3 \mathrm{~mm}, \mathrm{P}_{6}$ without a comb. Distal p. $13 ;+\mathrm{mm}$.

Mouth and anus subcentral. Disk t-5 mm., brown-green. Calcareous parts lighter, olive-brown. Somewhat approaching C. maculculu but with more slender arms.

The young forms of the above-described species are very similar to one another and probably cannot be distinguished from each other. Presumably the two last-described species pass through a stage with cirri built as in C. brachycirra.

$\Lambda$ comparison between the characteristies for the species descrihed above also shows that $C$. maculata comes near to $C$. stelligera and 
The Crinoms fron Dr. S. Bock's Expedition to Japax 1914. 21

except for the number of cirrals ehiefly differs by having thicker and coarser arms, smoother arm-bases, and by having the distal Br-segments less bent outward.

It is to be supposed that the 3 species deseribed above make hybrids. A speeicimen (Sp. 12) of C. brachycima approaches the 2 other Comutellas by having somewhat spiny Br-segments. Compare also Sp. to of C. stelligeru.

Comissia A. H. Chark.

C. peregrina var. magnifica 11 . vall.

liig. 10, 11. Photo 2..

From St. 5y : 2 specimens.

Sp. 1. Cd pentagonal with somewhat prolonged corners. Diameter $5,5 \mathrm{~mm}$. Free dorsal part $2,5 \mathrm{~mm}$. Height $1,5 \mathrm{~mm}$.

Cirri thrown off, pits of XXXV-XL, in 2 whorls.

$\mathrm{R}-\mathrm{S}$ appearing as small flaps in the corners. I $\mathrm{Br} / \mathrm{h}=\mathrm{l} / 6 \mathrm{bl}$ laterally united with each other, forms with I Brax a low synarthrial tubercle as $\mathrm{Br} 1$ with $\mathrm{Br} \stackrel{2}{2}$. Axillary $h=1 / 3$ br, low pentagonal. $\mathrm{Br} 1$ grown together inside. Br 2 on the outer side $3 \times$ broader than on the inner side. $\mathrm{Br} 3+t$ narrow bands; $t^{\text {th }}$ and $5^{\text {th }}$ segments form a weak tuberele directed inwards, $5^{\text {th }}$ and $6^{\text {th }}$ give rise to a similar one directed outwards: $6^{\text {th }}-7^{\text {th }}$ and $8^{\text {th }}-9^{\text {th }}$ form inward directed, $7^{\text {th }}-8^{\text {th }}$ and $9^{\text {th }}-10^{\text {th }}$ outward directed knobs, then romded segments with more or less oblique articulations. Syzygies $3+4 \ldots 13+14 \ldots 17+18$ ete. With an interval of 3 to 4 oblique articulations. Distal Br-segments triangular, the long side $2 / 3 \times b r$. The arm-protile distally smooth, proximally somewhat serrate. Arms $\mathrm{X}, 150-170 \mathrm{~mm}$. 16 segments 1r. cm. (if syzygial pairs are counted as units 11 or 12). Breadth of the arms $2,5-1,3 \mathrm{~mm}$.

$P_{1} 50-55$ (22-25 last segments rolled in a double spiral with large rather pointed teeth, $h=$ the br of the segment. 2 $2^{\text {a }}-7^{\text {th }} \mathrm{or}^{\text {r }} 8^{\text {th }}$ segments with dorsal knobs, weakly projecting. The remaining segments smooth, though distally weakly collar-shaped, not at all or only a little longer than broad) $17 \mathrm{~mm}, \mathrm{P}_{2} 13 \mathrm{~mm} . \mathrm{P}_{3}$ and $\mathrm{P}_{4}$ still some- 
what shorter with combs which, as on all the comb-provided pinnules, are rolled a couple of turns; $P_{5} 27 ; 12 \mathrm{~mm}$. Without a comb. Distal p. 25-28; $12-13 \mathrm{~mm}$. The first $20-25$ pairs of pinnules with the proximal segments distally somewhat bent outwards and with small spines. The segments of the distal p-s somewhat hour-glass-shaped. their ends distinctly spine-crowned. Last pinnulars with weak hooks.

Iouth subcentral. Anal funnel lateral. small, short, 2 $\mathrm{mm}$. standing stiffly upright. Disk $11 \mathrm{~mm}$. with small caleareous granules. Colour (in formol) yellowish brown.

Sp. 2. Cd more flat and rounded than in the preceding speeimen. Diameter $5.5 \mathrm{~mm}$.

C. broken. Pits of $\pm \mathrm{XXX}$ ones in a single or double whorl. There are j segments of a cirrus left. These segments slowly increase in length, the $5^{\text {th }}$ segment $\mathrm{L}$ about $=2 / 3 \mathrm{br}$., a little hour-glass-shaped. Arms X, $145 \mathrm{~mm}$. most of them broken. Syzygies with an interval of 3 oblique articulations, 16 segments pr. $\mathrm{cm}$.

$\mathrm{P}_{1}-\mathrm{P}_{4}$ with a comb, $\mathrm{P}_{4}+0\left(22 \mathrm{C} \mathrm{T}^{2}\right) 12 \mathrm{~mm}$. Distal $\mathrm{p} . \pm 30 ; 1+\mathrm{mm}$. Though except for a small stump in Sp. 2- eirri are lacking, it is evident that both these specimens ought to be commected most closely with C. peregrina. From this species they differ, among other things, by having a more considerable size (Arm-length about $160 \mathrm{~mm}$. against $120 \mathrm{~mm}$, in the main species) and more cirri. Judging from the Clarkian deseriptions the proximal arm-parts and pinnules also seem to be considerably more spiny. C. peregrina has also cirral 5 indicated as at transition segment, while the above-described specimen has a $5^{\text {th }}$ cirral that does not show a trace of being a transition segment and has the br only $2 / 3$ of the L. Presumably therefore the cirri are also longer and composed of more segments. 
The ('rinoids fron Dr. S. Bock's Expedition to Japan 1914. 2:3

Comissia parvula L. II. Cr.iki.

lig. $12-14$.

Syn.: Comissie parule 1912 A. II. C'Lak Proc, Biol. Soc. Washington. Vol. 25, p. 19; 1918 A. H. Clark Siboga Exp. Bai t2 B, p. 2:3.

from St. $+(1 \mathrm{sp}),. 8(1), 36(1), 37(1)=+$ specimens.

Sp. 1 (St. 37) Cd discoidal, 2,5 mm., free part 1,5 $\mathrm{mm}$.

C. XXI 10-13; $6,5-8 \mathrm{~mm}$. in a partly double whorl. $1^{\text {st }}$ segment shorter than long, $2^{d} \mathrm{~L}=1^{1 / 2} \mathrm{br}, 3^{\mathrm{d}}$ longest and narrowest $\mathrm{L}=3 \times \mathrm{br}$. $4^{\text {th }}$ segment $\mathrm{L}=2 \mathrm{br}, 5^{\text {th }}$ and the following ones broader and shorter $L=1 \frac{1}{2}$ br. Antepenultimate segment $L$ about $=1^{1 / 5}$ br: A small dorsal knot from about the $5^{\text {th }}$ segment. Opposing spine inconspicuous. 'Terminal claw curved, pointed, somewhat longer than the preceding segment.

R-s concealed. I Br 1 slightly visible, narrow bands, h about ${ }^{1 / 0} \times \mathrm{br}$. Axillary low pentagonal or triangular, $h_{1}=1_{2} \times$ br. Br:s 1 almost free inside. Br 2 about twice as broad on the outer side. After Br 7 or 8 oblique articulations. Distal segments smooth, not overlapping. Syzygies for ex: $3+4 \ldots 11+12 \ldots 1+15 \ldots 18+19 \ldots 22+23$ etc. with an interval of 2 to 3 oblique articulations; 15 segments $\mathrm{pr} \mathrm{cm}$. (11 if the syzygial pairs are counted as units). Arms $X, 45-50 \mathrm{~mm}$. The breadth of the Bros at the middle parts of the arms about $1 \mathrm{~mm}$. 'The longer side of the distal segments $=\mathrm{br}$.

$$
\mathrm{P}_{1}-\mathrm{P}_{3} \text { with a comb. } \mathrm{P}_{1}+30(9-10 \mathrm{~T}) 7 \mathrm{~mm}, \mathrm{P}_{2} \pm 2(\mathrm{a} \text { (9) } \mathrm{T})
$$

(f) mm., $P_{3} \pm 25$ (9 $\left.\mathrm{T}^{2}\right) 4,5 \mathrm{~mm}$. with a genital gland to the $t^{\text {th }}$ segment. The height of the teeth about $=$ the br of the segment, $\mathrm{P}_{5} 13 ; 4,2 \mathrm{~mm}$. :3 to + last segments with dorsal prominences. Broad, coarse segments, the most proximal ones notehed on the distal side and somewhat widened in the distal part, by which the bases of the pinnules somewhat resemble those of Compsometra serralu. Distal $p .17 ; 5.5 \mathrm{~mm}$. The bases of the pinnules from $\mathrm{P}_{3}$ to $\mathrm{P}_{20}$ swollen by gonads.

Disk smooth, 5,5 mm. Mouth central.

Sp. 2 (St. 36) Cd 2.5 mm., free dorsal part 1,5 $\mathrm{mm}$. C. XXl1 12: $5 \mathrm{~mm}$. (only one cirrus left) in a single whorl, 3" segment longesi $\mathrm{L}=3^{1 / 2}$ br. Distal segments laterally compressed and shorter. Antepenultimate segment a little longer than broad. 
$\mathrm{R}-\mathrm{S}$ appearing as small flaps in the corners. I $\mathrm{Br} 1 \mathrm{~h}=1 / \mathrm{s} \mathrm{br}$, latero-basally mited with one another. I $\mathrm{Br} 2$ low triangular, $\mathrm{h}=1 / 3 \times \mathrm{br}$. A weak synarthrial tubercle with close articulation between $\mathrm{I} B \mathrm{Br}$ and 2. The arms $X$, smooth, broken, about $25 \mathrm{~mm}$. Syzygies with an interval of 3 oblique articulations.

$\mathrm{P}_{1}-\mathrm{P}_{3}$ with a comb. $\mathrm{P}_{1} 26(9 \mathrm{~T}) \pm 4,5 \mathrm{~mm}, \mathrm{P}_{2}+22$ (8 $\left.\mathrm{T}\right) \pm 3,5$ mm. $P_{3}$ similar, $3 \mathrm{~mm}$. Distal p. 1:3 segments. Disk $3 \mathrm{~mm}$.

Sp. 3 (St. 8) C. $\pm \mathrm{XX} \mathrm{12-13;} \mathrm{5-5,5} \mathrm{mm.} \mathrm{(some} \mathrm{of} \mathrm{the} \mathrm{dorsal}$ ones very small 9; $2 \mathrm{~mm}$; these have an antepenultimate segment whose $\mathrm{L}=1^{1} / 2 \times$ br), $2^{\mathrm{d}}$ segment $\mathrm{L}=2 \times \mathrm{br}, 3^{\text {"l }} \mathrm{L}=3 \times \mathrm{br}, 4^{\text {th }} \mathrm{L}=2 \times \mathrm{br}$; antepenultimate segment as in Sp. 2.

The arms $\mathrm{X}, 15-20 \mathrm{~mm}$. I $\mathrm{Br} 1 \mathrm{~h}=1 / 5 \mathrm{br}$. Axillary triangular $\mathrm{h}={ }^{1} / 2 \mathrm{br} . \mathrm{Br} 1+\mathrm{or}-2 . \mathrm{Br} 1 \mathrm{~h}={ }^{1} / 3 \mathrm{br} ; \mathrm{Br} \stackrel{2}{ } \mathrm{~h}={ }^{1} / 3 \mathrm{br}$ fon the outer side) or $1 / 5$ br (on the inner side). Syzygies with an interval of 3 oblique articulations.

$\mathrm{P}_{1}-\mathrm{P}_{3}$ with a comb. $\mathrm{P}_{1} \pm 2+4(10 \mathrm{~T})$ 5 mm., $\mathrm{P}_{3} 17$ (S T) $3,5 \mathrm{~mm}$. $P_{4}$ 11: 3,5 mm. The segments coarse, smooth, somewhat swollen.

Sp. 4 (St. t) A specimen corresponding to Sp. I which has crept into a calcareous sponge. C. $12 ; 5,5 \mathrm{~mm}$. Antepenultimate segment $\mathrm{L}_{1}=$ br. Arm-length about $30 \mathrm{~mm} . \mathrm{P}_{1}-\mathrm{P}_{3}$ with a comb.

Comissia gracilipes 1 . H. C'LAmK.

Fig. $15-17$.

Synn. Comissia gracilipes 1912 A. II. Cunk Proc, Biol. Soc. Washington. Vol. 25, 1). 19; 1918 1. H. Clink Siboga Exp. Vol. 42 B, p. 22.

From St. 35: 22 specimens.

Sp. 1. Cd $2 \mathrm{~mm}$. , free dorsal part $1.3 \mathrm{~mm}$. C. XVIII 9-12; $4-6 \mathrm{~mm}$. in a single whorl. $3^{\mathrm{d}}$ segment $\mathrm{L}=3 \times \mathrm{br}$, $4^{\text {th }}$ segment $\mathrm{L}=2 \times \mathrm{br}$, a transition segment. Antepenultimate segment $\mathrm{L}=11 / 2 \mathrm{br}$.

$\mathrm{R}-\mathrm{S}$ and $\mathrm{I} \mathrm{Br} 1$ almost completely hidden by $\mathrm{Cd}$. Axillary triangular $h=1 / 3 \times$ br. Br:s 1 united inside. $h=1 / 4 \times$ br, in close articulation with $\mathrm{Br} 2$, the height of which (on the outer side) is ${ }^{3} / 2 \times \mathrm{br}$. Arms $X, 35 \mathrm{~mm}$. 'The br of the Br:s at the middle parts of the arms 
$0,6 \mathrm{~mm}$. 16 segments pr $\mathrm{cm}$. (12, if the syzygial pairs are counted as units). The longer side of the distal $13 \mathrm{r}$-segments $=1^{1 / 3} \times$ br.

$P_{1} 25-27$ (9-11 T) 5 mm., P 23 (11 T). Teeth somewhat longer, narrower and more pointed than in C. parvula. $\mathrm{P}_{3}(16 ; 3 \mathrm{~mm}$. $)$ and the following ones without a comb with swollen pinnule-bases. Distal p. $13-15 ; 4-5 \mathrm{~mm}$. The segments are long $(\mathrm{L}=2 \times \mathrm{br})$, swollen into knots at the ends. Disk $3.5 \mathrm{~mm}$.

Sp. 2 Cd $1,8 \mathrm{~mm}$. C. $\pm \mathrm{XX} 9 ; 4 \mathrm{~mm}$. (only one cirpus remaining). Antepenultimate segment $\mathrm{L}=1^{1 / 2} \times \mathrm{br}$.

$\mathrm{R}-\mathrm{s}$ concealed. I $\mathrm{Br} 1$ appearing at the margin of $\mathrm{Cd}$. Axillary $h=1 / 3-{ }^{1} / 4 \times$ br, with strongly coneave distal sides. $\mathrm{Br} 1+\mathrm{or}-2$. Br. 1 only united by skin on the inside. Arms rather smooth, broken, $\mathrm{X}$, probably about $15 \mathrm{~mm}$. Syzygies with an interval of 3 oblique articulations.

$\mathrm{P}_{1}$ and $\mathrm{P}_{2}$ with combs. $\mathrm{P}_{1} 26(9 \mathrm{~T})+\mathrm{mm}, \mathrm{P}_{2} \pm 22(7-8 \mathrm{~T})$ $3 \mathrm{~mm} . \mathrm{P}_{3} 10-12 ; 2,5 \mathrm{~mm}$. Disk $2,5 \mathrm{~mm}$.

The specimens are habitually more slender and provided with more spiny distal pinnules than in C. parvula. A comb only occurs on $\mathrm{P}_{1}$ and $\mathrm{P}_{2}$. The genital glands are well developed in Sp. 1. Though $C$. gracilipes is rather elosely related to C. parvula, it can, however, scarcely turn out to be a young form of this species. For, in the first place, Sp. 1 of C. gracilipes described above is mature, secondly in this specimen Cd still hides more of the I Br-series than in C.parvula (If the first-mentioned species were a young form one might expect the opposite conditions). In other respects the above-deseribed specimens of $C$. gracilipes agree with A. II. CLARK's short diagnosis.

\section{Commissia ignota var minuta 11 . var.}

Fig. 18-20. Photo 3.

From St. 42 (1 sp). , 45 (9), 45 A (1), 47 (5), 55 (11), 61 (2) $=29$ specimens.

Sp. 1 (St. 45) Cd 1,5 mm. Free dorsal part $1 \mathrm{~mm}$. C. XV 10; 3,5 mm. $2^{3}$ segment hour-glass-shaped $\mathrm{L}=1^{1} / 2 \times$ the distal br, $3^{3} \mathrm{seg}-$ ment $\mathrm{L}=3 \times \mathrm{br}, 4^{\text {th }} \cdot \mathrm{L}=2 \times \mathrm{br}, 5^{\text {th }} \mathrm{L}=1^{3} / 4 \times \mathrm{br}, 6^{\text {th }}$ and $7^{\text {th }}$ segment

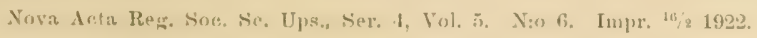


$\mathrm{L}=1^{1 / 3} \mathrm{br}$. Antepenultimate segment $\mathrm{L}=$ or somewhat larger than br; , last 3 to 4 segments with a small, dorsal spine. Terminal claw strongly bent, somewhat longer than the precering segment.

$\mathrm{R}-\mathrm{S}$ appearing as small corner-flaps. I $\mathrm{Br} / \mathrm{h}=1 / 6 \times \mathrm{br}$, laterally free, the angle between them about $45^{\circ}$. United with the axillary by syzygy. I $\mathrm{Br} 2$ triangular $h=1 / 2 \times$ br, with very concave distal sides. $\mathrm{Br} 1$ and 2 rather narrow, $\mathrm{h}=1 / 4 \times \mathrm{br}$, on the outer side twice as broad. Arms $\mathrm{X}, \pm 20 \mathrm{~mm}$. The arm-bases fairly smooth. Syzygies, for instance, $3+4 \ldots 11+12 \ldots 15+16 \ldots$ distally with an interval of 3 oblique articulations. The longer side of the distal segments $\mathrm{L}=2 \times$ br. $20 \mathrm{Br}$-segments $\mathrm{pr} \mathrm{cm}$. (15, if the syzygial pairs are counted as units). The br of the segments $0,5 \mathrm{~mm}$.

$\mathrm{P}_{1}-\mathrm{P}_{2}$ with a comb. Teeth $8-10 . \mathrm{P}_{1} 27 ; 4 \mathrm{~mm}, \mathrm{P}_{2} 23 ; 3,5 \mathrm{~mm}$. $\mathrm{P}_{3} 11 ; 2,5 \mathrm{~mm}$. with a genital gland. Distal p. $14 ; 4,5 \mathrm{~mm}$. 2" to $4^{\text {th }}$ pinnulars somewhat notehed on the outer side (especially on $P_{1}$ and $\mathrm{P}_{2}$ ). The bases of the $\mathrm{p}-\mathrm{s}$ however smooth beeause of connecting skin.

Disk smooth, $+2 \mathrm{~mm}$. Mouth central. Cushion-formed swellings along the ambulacral furrotvs. Anal funnel broad, coarse, short.

Sp. 2 (St. 45) $\mathrm{P}_{3}-\mathrm{P}_{12}$ with genital glands. For further details of these as well as the following specimens see the table.

Sp. 3 (St. 45) $\mathrm{P}_{2}$ very small. Disk $2 \mathrm{~mm}$.

Sp. 4 (St. 45) I Br. $1 \mathrm{~h}=1 / 5 \times$ br. $\mathrm{P}_{3}-\mathrm{P}_{9}$ with genital glands.

Sp. 5 (St. 45) Disk $3 \mathrm{~mm}$. Sp. 6 (St. 45) Disk $3 \mathrm{~mm}$. Speeimens $6-10$ young, more slender individuals.

Sp. 7 (St. 45) Antepenultimate cirral in the smallest cirri $\mathrm{L}=$ $1^{1 / 2} \times$ br. I Br 1 bent outwards almost at a right angle. Disk $2,5 \mathrm{~mm}$.

Sp. 8 (St. 45) Segments somewhat more spiny than in the preceding specimens.

Sp. 9 (St. 45) - Sp. 10 (St. 45) I Br $1 \mathrm{~h}=1 / 4 \times$ br. Disk $2 \mathrm{~mm}$.

Sp. 11 (St. 42) $1 \mathrm{Br}^{\cdot} 1$ almost completely hidden, $\mathrm{P}_{1}$ with 23 segments. Disk thrown off. Basal star visible.

Sp. 12 (St. 47) Ca 2 mm., free dorsal pole 1,5 mm. IV C. very small. I Br $1 \mathrm{~h}=1 / 8$ br. Usually $\mathrm{Br} 1+2,3+4 ; \mathrm{P}_{1}$ with $24, \mathrm{P}_{2}$ with 20 segments. The bases of the pinnules with strong genital swellings. Disk $3 \mathrm{~mm}$. Colour brown. 
Comissice ignota var. minuta.

\begin{tabular}{|c|c|c|c|c|c|c|c|c|c|c|c|c|c|c|}
\hline \multirow{2}{*}{$\begin{array}{l}\text { Xumber of Spe- } \\
\text { cimens and } \\
\text { Stations }\end{array}$} & \multicolumn{3}{|c|}{ Cirri } & \multicolumn{2}{|c|}{ Al'ms } & \multirow{2}{*}{$\begin{array}{l}1 \mathrm{Br} \\
\mathrm{h}: \mathrm{br}\end{array}$} & \multicolumn{2}{|l|}{$P_{1}$} & \multicolumn{2}{|l|}{$P_{2}$} & \multicolumn{2}{|c|}{$P_{3}$} & \multicolumn{2}{|c|}{ Dist. p. } \\
\hline & $\mathrm{N}$ & $\mathrm{S}$ & L & N & L & & $\mathrm{T}$ & L & $\mathrm{T}$ & L & $\mathrm{S}$ & L & $\mathrm{S}$ & L \\
\hline 1 & & & nm. & $\mathrm{X}$ & \pm 20 & $1: 2$ & $8-10$ & 4 & -10 & 3,5 & 11 & 2,5 & 14 & 4,5 \\
\hline$=2$ St. 4 & & & & $\mathrm{X}$ & & & $8-10$ & & -10 & - & & - & & \\
\hline 3 St. 45 & 1 & $9-10$ & $2,5 \cdot-3$ " & $\mathrm{X}$ & & - & $\mathrm{T}$ & - & $\mathrm{T}$ & - & & - & - & - \\
\hline 4 St. 4 & & & 8 & & & & $\mathrm{~T}$ & & $\mathrm{~T}$ & - & & - & & $\ldots$ \\
\hline 5 St. 4 & & 10 & & & & - & $8-10$ & - & $8-10$ & - & - & - & - & - \\
\hline 6 St. 1 & & $10-12$ & $3,4-4,5\rangle$ & $x$ & - & & $\mathrm{T}$ & - & $\mathrm{T}$ & $\cdots$ & & - & - & \\
\hline $7 s$ & & & & & 95 & & & & & - & - & - & - & \\
\hline $8 \mathrm{~S}$ & & & $2-3$ & & & & 1 & 3,5 & & 9 & & - & 19 & 3, \\
\hline $9 \mathrm{~S}$ & & & - & 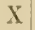 & 20 & & 7 & & & - & & $=$ & $\ldots$ & \\
\hline $10 \mathrm{~s}$ & & $9-$ & 3 & $\mathrm{X}$ & \pm 20 & $2: 3$ & 8 & & $\mathrm{~T}$ & - & & - & - & \\
\hline 115 & & & $4 \$$ & $X$ & \pm 20 & & & & & - & - & - & & 3 \\
\hline $12 \mathrm{~s}$ & & & $4 x$ & & & & & & & 3,5 & 11 & 3 & $4-15$ & 3,5 \\
\hline 135 & & & $2-3$ & & & & & & & - & $y$ & 3,5 & & \\
\hline$s$ & & & $3-4 »$ & 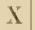 & 25 & & & 4 & 7 & 3,5 & 12 & 3 & 12 & \\
\hline : & & & $2-3 x$ & $\mathrm{X}$ & \pm 20 & & & & & - & - & - & - & - \\
\hline 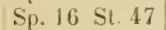 & & & $2,5-3$ » & & & & & & & - & 10 & 2 & - & \\
\hline s & & & 3 & & 25 & & & & & — & - & - & 12 & - \\
\hline$s$ & & $9-10$ & $3-4 \infty$ & & 30 & & & & & - & & - & - & - \\
\hline $19 \mathrm{~S}$ & & $8-9$ & 3 & & 18 & $1: 3$ & & & & - & 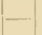 & -- & - & 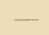 \\
\hline $20 \mathrm{~s}$ & - & - & - & & 22 & - & & & & - & — & - & 10 & - \\
\hline S & & - & - & & & & & & & - & - & + & -- & - \\
\hline 25 & XVI & 8 & 2 & & & - & & & & - & - ! & - & - & \\
\hline $\mathrm{S}$ & & - & - & & - & & & & (T) & - & - & - & - & - \\
\hline 24 St. : & & 9 & 3 & & 18 & & & & & - & - & - & - & $=$ \\
\hline $25 \mathrm{St}$ & & 9 & $1,52,5$; & & 12 & $1: 9$ & & - & - & - & - & - & - & \\
\hline $26 \mathrm{St} .5$ & & 10 & $3 »$ & & - & - & & & & - & - & $\ldots$ & - & \\
\hline $27 \mathrm{~s}$ & & 9 & $2,5 \gg$ & & \pm 15 & & & & (T) & - & - & - & - & \\
\hline $\mathrm{S}$ & & & 3 & & 15 & & & & & - & - & - & 12 & 3 \\
\hline Sp. 29 St. 61 & $X \| I$ & $8-9$ & $2-2,6 \geqslant$ & & 12 & $2: 3$ & & -. & - & - & - & - & - & - \\
\hline
\end{tabular}

Catoptometra magnifica minor Sp. 5-8.

\begin{tabular}{|c|c|c|c|c|c|c|c|c|c|c|c|c|c|c|c|}
\hline \multirow{2}{*}{$\begin{array}{l}\text { Number of Spe- } \\
\text { cimens am? } \\
\text { Stalions }\end{array}$} & \multicolumn{3}{|c|}{ Girri } & \multicolumn{2}{|c|}{ Arms } & \multirow{2}{*}{$\begin{array}{r}\mathrm{I} \mathrm{Br} \cdot 2 \\
\mathrm{~h}: \mathrm{l},\end{array}$} & \multicolumn{3}{|c|}{$P_{1}$} & \multicolumn{3}{|c|}{$\mathrm{P}_{2}$} & \multicolumn{3}{|c|}{$\mathrm{P}_{3}$ List. p. } \\
\hline & N & $\mathrm{S}$ & L & $\mathrm{N}$ & L. & & $\mathrm{S}$ & $\mathrm{T}$ & $\mathbf{L}$ & $\mathrm{S}$ & $\mathrm{T}$ & L & $\bar{S}$ & $\mathrm{~L} \mid \mathrm{S}$ & $\mathrm{L}$ \\
\hline 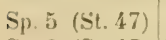 & & & & & 35 & & - & & & 1 & & 4,5 & & -18 & \\
\hline Sp. 6 (St. 47) & XXIII & $11-13$ & $3-4,5$ & XI & 28 & $1+: 1$ & & & 3 & - & - & 3 & - & -14 & 6 \\
\hline Sp. 7 (St. 47) & $\mathrm{XIX}$ & $11-14$ & $5-8$ & $\mathrm{X}$ & 35 & $2: 3$ & \pm 20 & & $3,5-4$ & $16-19$ & - & $3,5-5$ & 16 & $4-$ & \\
\hline Sp. 8 (St. 61) & $\mathrm{XXV}$ & $11 \cdot 14$ & $4-8$ & XI & 45 & $2: 3$ & - & - & 4 & - & - & 5 & - & -18 & 6,5 \\
\hline
\end{tabular}




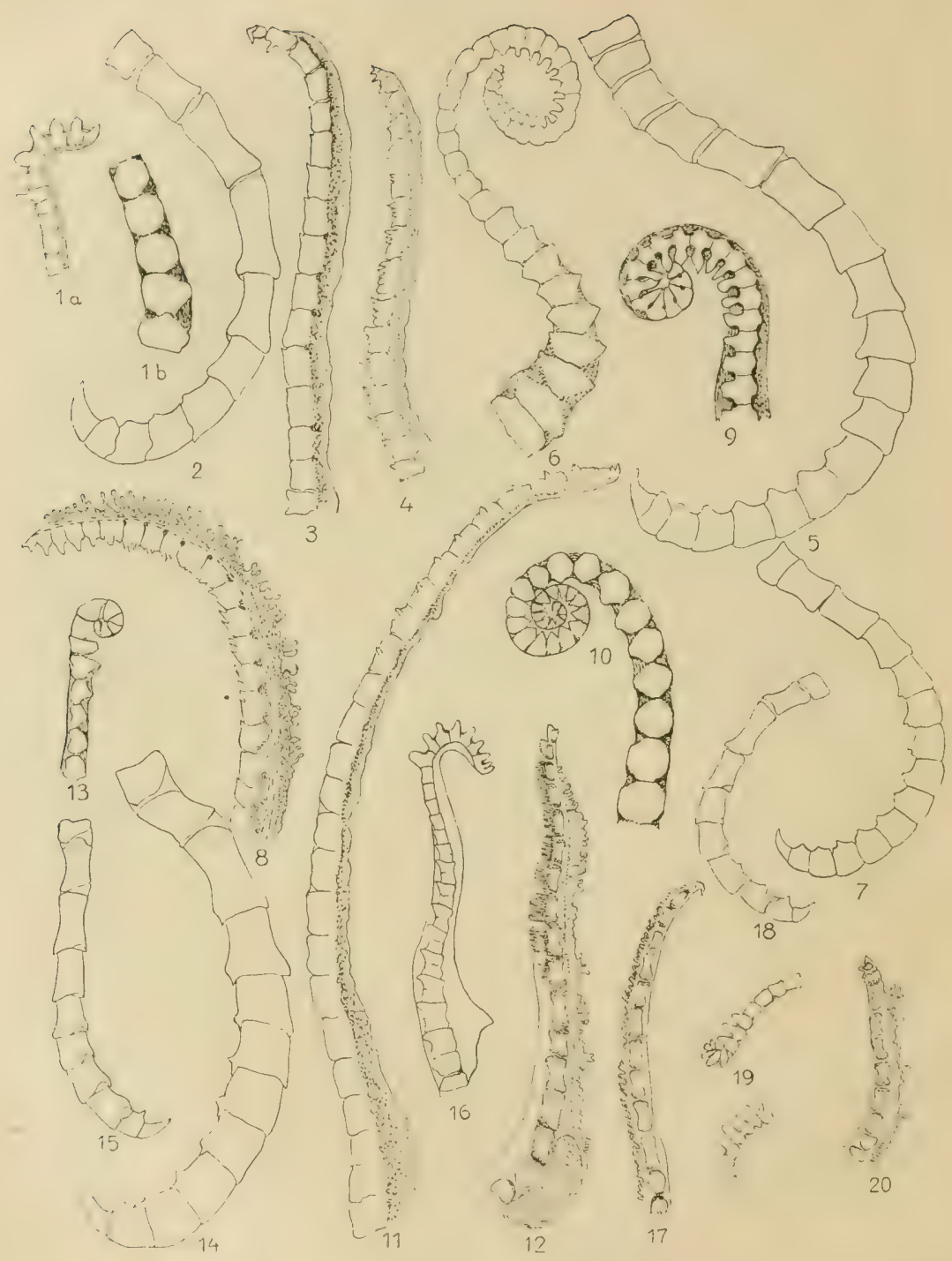

Fig. 1-3, Comatella brachycirra (St. $56 \mathrm{Sp}$. 1) 1 a) The comb on the distal part of $\mathrm{Y}_{1}, \times 17^{1 / 8}$, 1 b) The proximal part of $P_{1} \times 17 \frac{1 / 2,2)}{A}$ cirrus $\left.16 / 1,3\right)$ A distal pintule $16 / 1$; Fig. 1 - b Comatella

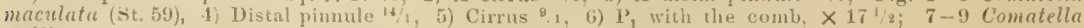

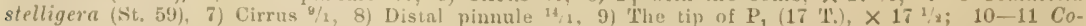
nissia peregrina magnifica (St. $59 \mathrm{Sp}$. 1) 10) The tip of $\mathrm{P}_{1} 1 \mathrm{~s} / \mathrm{s}, 11$ ) Distal pimule $1 \mathrm{t} / 1$; $12-14$ Comissia parvula (St. $37 \mathrm{sp}, 1$ ) 12) Distal piumle with a smull genital gland 14,1, 13) The tip of $\mathrm{P}_{1}, \mathrm{X}_{17} 1 / 2$, 14) Cirrus 14/x; $15-17$ Comissia gracilipes (St. $35 \mathrm{Sp}, 1)$ 15) Cirrus 14/1, 16) $\mathrm{P}_{1} 14 / 1,17$ ) A distal pinnule $14 / 1 ; 18-20$ Comissia ignota minuta (St. 55) 18) Cirms 14/2, 19) The tip of $P_{1} \times 171 / 2,20$ ) Digtal pinuule $14 / 1$. 
Sp. 13 (St. 47) I Br 1 as in the preceding specimen.

Sp. 14 (St. 47) I Br $1 \mathrm{~h}=1 / 8 \mathrm{br} ; \mathrm{Br} 1$ and 2 each $\mathrm{h}=1 / 4 \times \mathrm{br}$. $\mathrm{P}_{1}$ with about 25, $\mathrm{P}_{2}$ with 20 segments. This and the two following specimens young individuals with gonads only slightly prominent.

Sp. 15 and 16 (St. 47) I Br $1 \mathrm{~h}=1 / 3$ br. Cd $1.8 \mathrm{~mm}$.

Sp. 17 (St.55) With genital glands well developed like both the following specimens.

Sp. 18 and 19 (St. 55) I Br 1 almost completely hidden.

Sp. 20 (St. 55). Fixed on a worm-tube. Sp. 21 and 22 (St. 55) Pinnules a little swollen by genital glands.

Sp. 23 (St. 55) $\mathrm{P}_{2}$ sometimes lacking. Sp. 24 (St. 55) R--s somewhat visible. $\mathrm{I} \mathrm{Br} 1 \mathrm{~h}=1 / 6 \times \mathrm{br}$.

Sp. 25 (St. 55) $\mathrm{R}-\mathrm{s}$ narrow bands. $1 \mathrm{Br} 1 \mathrm{~h}=1 / 6 \times$ br. $3^{\mathrm{d}}$ cirral the longest $\mathrm{L}=3^{1 / 2} \mathrm{br}$. Antipenultimate cirral $\mathrm{L}=1^{1 / 3} \times \mathrm{br}$. $\mathrm{P}_{2}$ lacking.

Sp. 26 (St. 55) Pinnules genitally swollen. Sp. 27 (St. 55) Antipenultimate cirral $\mathrm{L}=1^{1 / 3} \times \mathrm{br}$. I Br $1 \mathrm{~h}=1 / 6 \times \mathrm{br}$.

Sp. 28 (St. 61) R-S concealed. I Br $1 \mathrm{~h}={ }^{1} / 4 \mathrm{br}$. Syzygies with an interval of 3 oblique articulations. $P_{2}$ inconspicuous or lacking.

Sp. 29 (St. 61) I Br $1 \mathrm{~h}=1 / 2 \times$ br. $\mathrm{P}_{2}-\mathrm{P}_{1}$ lacking.

As is evident from the comparison given above, the number of cirri varies between XII and XX (usually XV--XVI) and the number of cirrals between 8 and 12 (usually 9-10). The specimens seem to be mature at an arm-length of $25-30 \mathrm{inm}$., as in such specimens the pinnules are strongly swollen, but even with shorter arms the genital gland is quite visible. All specimens with complete pinnulation have combs on $P_{1}$ and $P_{2}$ but no teeth on $P_{3}$. The number of teeth varies between $7-10$ and is usually 8 . - It is interesting to observe the relation between the length and breadth of the most proximal BI'-segments. The smallest specimens (e.g. Sp. 25 and 29 ) have the R-s plainly visible. I $\mathrm{Br} 1$ is rather long in minor specimens $(h=1 / 2-$ $1 / 3 \times \mathrm{br}$ ), but becomes more and more short during growth (in fullgrown specimens the $h$ is $=1 / 6-1 / 8 \times$ br or the ossicle is almost completely hidden by $\mathrm{Cd}$ ). The length of the axillary also usually decreases (from $\mathrm{L}=2 / 3$ to ${ }^{1} / 5 \times$ br) but is never hidden by $\mathrm{Cd}$.

The specimens approach $C$. ignota, from which they differ by having, on an average, more eirri, by some differences in the conditions of length of the eirrals, by smaller size etc. 
Finally a few words about the relation between the genera $\mathrm{Co}-$ matella and Comissia. When A. H. CLARK in 1909 proposed these two genera he characterized the first-mentioned one (Smiths. Misc. Coll. Vol. 52 p. 207) thus, that species belonging to this genus should have the first syzygy between $\mathrm{Br}^{\circ} 3$ and 4 in arms situated on I Brax, but the first syzygy between $\mathrm{Br} 1$ and 2 in arms coming from axillaries of higher numbers. Aceording to CLARK's view some arms should therefore be divided by »extraneous» some other's by »intraneous division» and thus one might in this genus have crinoids with so-called 》compound arms». In the later proposed species Comatella decora CiarK has found a syzygy between $\mathrm{Br}^{\circ} 2+3$ ol on the outer side of the armdivisions between. $\mathrm{Br} 3+4$. Comatelle brachycirra mus usually, but far from always, has $\mathrm{Br}^{\circ} 1+2$ on the inner side, $3+4$ on the outer side of the arm-divisions. The specimens of $C$. maculata and $C$. stelliger that I have investigated usually have $\mathrm{Br} 1-23+4$, in the case both of the inner and outer side of the division-series; in a few cases, however, we find $\mathrm{Br}^{2}+2$. - Most often, therefore, the »compound» nature of the arms is visible, but by no means always. From what is mentioned above it is evident that the compound nature never appears in Xarmed young Comatellas. How are then the latter to be distinguished from the genus Comissia, the species of which always have $\mathrm{I}$ arms? As to this A. II. Crark in the Siboga Exp. Vol. 42 B, p. 23 has remarked that the young of Comissia can be distinguished from the Xarmed young of other genera by very short and broad I Br-series, the ossicles of which are said to be united in very close articulation. As I have tried to show in deseribing Comissia ignota minuta this only holds good in full-grown specimens of the species. 'The small young of large Comissia-species might therefore have rather long I Br-segments and are consequently similar to young Comatellas. Just as the immanent tendency to »compound arm-division» did not appear in $\mathrm{X}$-armed young Comatellas it cannot, if it exists, assert itself in Comissiu-species which never reach beyond the X-armed stage. In reality, therefore, the difference between the genera turns out to be a difference between a group of X-armed and a series of multibrachiate forms of Capillasterima. Joint characteristies by which both the genera are distinguished from other genera within the subfamily are as follows: $P_{1}$ on $\mathrm{Br}_{2}^{2}$, short Br-segments, complete pinnulation, cirri of normal comasterid type, at 
least $\mathrm{P}_{1}$ and $\mathrm{P}_{2}$ with a comb, proximal pinnulars never with strong prominences. - Whether the limit between the genera Comatella and Comissin is a natural one I must leare an open question.

This seems to be the place to mention a young Comasterid swept from a depth of 400 fathoms in Sagami Bay (St. 37). If this young specimen deseribed below belongs to any previously known Comasterid species there are only a few of which one might expect that it may be a young form, for the number of Comasterids found at a depth of more than 150 fathoms is only about 10. Since the proximal segments are rather high and narrow and the arm-bases widely separated, one can eliminate both the above-described Comissiaspecies (which are deep-water forms); of the remaining ones it approaches closest to Comatulides decameros, known from great depths off Japanese coasts. There is, however, in the young specimen an important difference from this species: there are dorsal spines on the cirrals. It is however, rather likely that the absence of dorsal spines is not a primary feature in Comactinina. Under such eircumstances it is possible that dorsal spines can appear in the young specimens and then again disappear. The formation of the cirrals in the other Comatulides-species (C. australis) perhaps also points in this direction: A. H. CLark remarks that: $»$ the last + or 5 segments before the penultimate have their distal dorsal margin very slightly thickened.» Deseription as follows:

C. XIX $11-14 ; 5-6 \mathrm{~mm}$. 'The $\mathrm{t}^{\text {th }}$ segment longest $\mathrm{I}_{4}=2{ }^{1 / 2} \times \mathrm{br}$. $3^{\text {t }}$ and $5^{\text {th }}$ somewhat shorter. From the $7^{\text {th }}$ segment a weak dorsal prominence. Terminal claw curved, pointed, somewhat longer than the preceding segment.

$\mathrm{R}-\mathrm{S} \mathrm{h}=1 / 5 \mathrm{br}$, at the middle hidden by $\mathrm{Cd}$. I $\mathrm{Br} \quad \mathrm{l} \mathrm{h}=1 / 3 \times \mathrm{br}$, laterally free, united with $\mathrm{I} \mathrm{Br} 2$ by synarthry. This ossicle low pentagonal, $\mathrm{h}=1 / 2 \mathrm{br}$. Br 1 free inside, like the following ossicle on the inner side somewhat narrower. Br 1 and 2 united by a close articulation. All the segments after $\mathrm{Br}^{\prime} 4$ somewhat hour-glass-shaped, distally bent outwards and spiny. A I ms X, $35 \mathrm{~mm}$., proximal parts rather narrow, well separated from each other. Syzygies $3+t \ldots 11+12 \ldots$ $15+16$ ete. with an interval of 3 oblique artieulations. Segments distally somewhat longer than broad. 
$P_{1} 25,5 \mathrm{~mm}$. with $\mathrm{S}-10 \mathrm{~T}$, the tip smooth. $\mathrm{P}_{2}$ and $\mathrm{P}_{3}$ with combs. $P_{n} \&$ T. $P_{4} 11 ; 3 \mathrm{~mm}$. without a comb. $P_{7} 14 ; 4,2 \mathrm{~mm}$. Distal p. $\pm 15 ; 5 \mathrm{~mm}$. Basal segments short, spiny, the distal ones longer $\left(\mathrm{L}=\mathrm{L}^{1 / 2} \mathrm{br}\right)$.

Disk $5 \mathrm{~mm}$., swollen, somewhat cushion-formed, without granules; clearly visible from the dorsal side in the broad interspaces between the arms, reaching to $\mathrm{Br}$. Mouth and arms subcentral. Anal funnel $2.5 \mathrm{~mm}$.

Subfam. Comasterinæ A. H. Clark.

Comaster (L. Agassiz) A. H. Chanir.

Comaster delicata var grandis n. var.

Fig. 26-29. Photo 4 .

From.St. 45 (3 sp.), 51 (1), 59 (1), $60(1)=6$ specinens.

Sp. 1 (St. 51) Cd thickly discoidal, $10 \mathrm{~mm}$., free dorsal pole $5 \mathrm{~mm}$., flat with somewhat raised margins.

C. XLII $27-28$ (D) $30-32$ (V) $35-40 \mathrm{~mm}$. in 2 to 3 whorls. $1^{\text {st }}$ and $2^{\mathrm{d}}$ segment shorter than long, $3^{\text {th }}$ and $4^{\text {th }}$ cubical, $5^{\text {th }}-9^{\text {th }}$ somewhat longer than broad to $L_{4}=1^{1 / 2} \times$ br. Dorsal spine from the $11^{\text {th }}$ segment (Length of this segment $=$ br). From about the $15^{\text {th }}$ segment $\mathrm{L}=1 / 2 \times \mathrm{br}$. Dorsal spines and opposing spine very small, $h=1 / 6 \times$ the breadth of the segment. 'T'erminal elaw $L=1^{1 / 4} \times$ preceding segment.

I Br 1 almost completely hidden by $\mathrm{Cd}$. I Brax pentagonal $\mathrm{h}=1 / 2 \mathrm{br}$ : distal margins weakly concave. 'The disk visible in the narrow interspaces between the outer sides of the II Br:s and I Brax. II Br:s are $4(3+4)$. II Br 1 and 2 with distinet synarthrial tubercle. Primipostaxillaries completely grown together inside. From II $\mathrm{Br} 2$ the distal margins of the segments are somewhat collar-shaped, bent outwards and provided with small spines. 111 Br:S me $2(1-2)$ in 8 cases of 13. IV Br:s: 4 (in all 13 cases). Arms XLVI $130 \mathrm{~mm}$. Br $1-7$ discoidal, then oblique joints. Syzygies for instance: $3+4 \ldots 12+13 \ldots$ $. .17+18$ ete. with an interval of + to 5 oblique artieulations. The 
The Crinotds from Dr. S. Bock's Expenttion to Japax 1914. 33

height of the segments $=1 / 2-1 / 3 \times$ br. $13-14$ segments $\mathrm{pr} \cdot \mathrm{cm}$. (11, if the syzygial pairs are counted as units). The breadth of the arms proximally $3-3,5 \mathrm{~mm}$. In the middle arm-parts $2 \mathrm{~mm}$.

$P_{\mathrm{II}} \pm+0\left(6-\mathrm{S}^{\mathrm{T}}\right) \quad 1+-17 \mathrm{~mm}, \mathrm{P}_{\mathrm{IV}} 32$ (5-6 T) $10 \mathrm{~mm} ., \mathrm{P}_{1}$ and $\mathrm{P}_{2}$ decreasing, $\mathrm{P}_{3}$ about 20 (5 'T) $5 \mathrm{~mm}$. This, however, not always so decided, but $\mathrm{P}_{2}$ or $\mathrm{P}_{3}$ are most often the shortest. In the posterior arms the pinnules are genitally swollen after $P_{\text {IV }}$. Combs to $P_{20}-P_{2,5}$, most often on every two p., here and there even to $\mathrm{P}_{30}$. The basal segments of the pinnules distally somewhat bent outwards and bordered with spines. Genital p. $7 \mathrm{~mm}$. Distal p. 20 - 25:9 mm. Dorsal hooks on the last $9-12$ segments.

Disk smooth, without calcareous granules or papillæ, $25 \mathrm{~mm}$. Anal funnel central, short, verruciform, $\mathrm{L}=4 \mathrm{~mm}$. Colour yellowbrown. Cirri whitish with brown transverse bands.

In the pinnules and arms an ento-parasitic new myzostomid. compare Protomyzostomum.

Sp. 2 (St. 45) The free dorsal surface of $\mathrm{Cd} 4 \mathrm{~mm}$. C. XXVII $23-25$ (D) $25-27$ (V), 25-30 mm. in 2 whorls.

$\mathrm{R}-\mathrm{S}$ appearing in the corners. I $\mathrm{Br} 1 \mathrm{~h}=1 / 4 \times \mathrm{br}$, united by synarthry with I Brax. Laterally of half their height fused with each other. Disk somewhat more visible in the interspace between the arms than in the preceding specimen. I Brax flattened pentagonal, $\mathrm{h}=2 / 3 \times$ br. Primipostaxillaries united inside for the most part. II Br:S are $4(3+4) 9$ cases, III Br:s: 2,13 cases, IV Br:s: 4,3 cases. Synarthrial tuberele between II and III Br 1-2. Arms XXXV + (probably XXXIX in the complete specimen) $125 \mathrm{~mm}$. Arm-bases in this and the following specimen smoother than in the preceding one. The breadth of the arms proximally $2,2 \mathrm{~mm}$., in the middle of the arm $1,7 \mathrm{~mm}$.

$\mathrm{P}_{\mathrm{II}} \pm 40(7 \mathrm{~T}) 16 \mathrm{~mm} . \mathrm{P}_{\mathrm{IV}} \pm 38(7 \mathrm{~T}) 15 \mathrm{~mm} . \mathrm{P}_{1} \pm 25(6 \mathrm{~T}) 5 \mathrm{~mm}$. $\mathrm{P}_{2} 18 ; 3 \mathrm{~mm}$. Then longer $p$. again; combs here and there at least to $\mathrm{P}_{25}$. Distal p. $18 ; 7 \mathrm{~mm}$.

Disk $18 \mathrm{~mm}$. Anal interradius large, swollen, with calcareous papillæ. Colour grey-yellow.

Sp. 3 (St. 45) C. XX 19-20 (D), 26-27 (V), 12-25 mm. II Br:s are 4 (9 cases), III Br:s:2, IV Br:s: 2, V Br:s: 2 (1 case). Arms XISII $105 \mathrm{~mm}$. 
$\mathrm{P}_{\text {II }} 24-37(6-7 \mathrm{~T}) 11-13 \mathrm{~mm}, \mathrm{P}_{1} 20-35 ; 5-9 \mathrm{~mm} ., \mathrm{P}_{2}$ and $\mathrm{P}_{3}$ very short $(4-6 \mathrm{~mm})$. Combs here and there to $P_{25}$ or $P_{30}$. Distal p. $16-18 ; 6 \mathrm{~mm}$.

Disk $14 \mathrm{~mm}$. Anal interradius with coarse and large calcarious plates.

In this specimen there is a fine example of $\gg$ multiplicative» armregeneration. Instead of the usual method of arm-division in this genus with an undivided arm now on the right now on the left from a II Brax, we have in this case a type of arm-division that continually gives unramified arms to the inner side, but which on the outer side contimues to ramify.

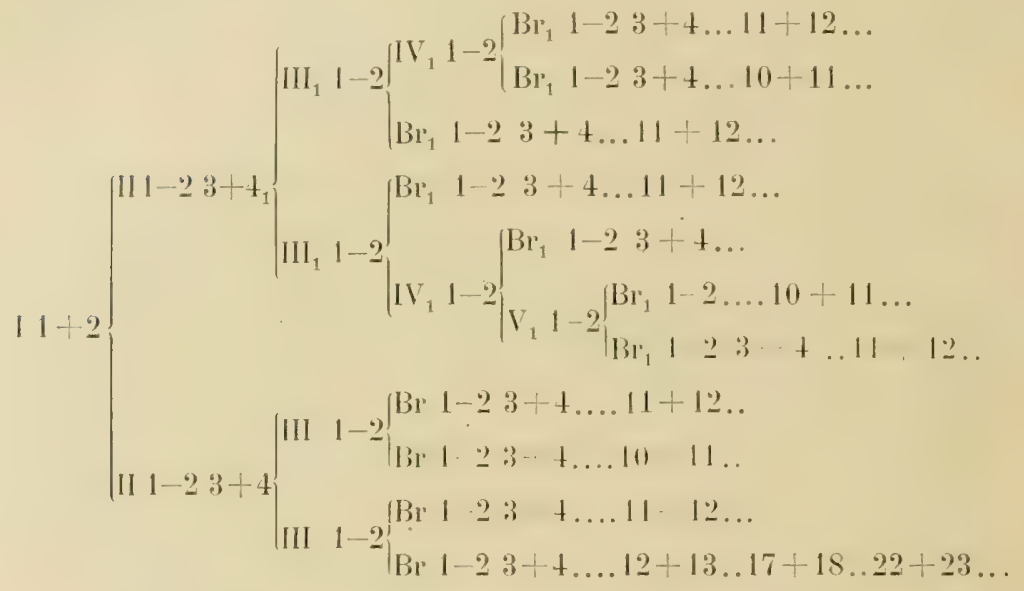

Sp. 4 (St. 60) Cd $4 \mathrm{~mm}$. free dorsal surface $1,5 \mathrm{~mm}$. C. XXII 20-21 (D) $26-30$. (V) $13-26 \mathrm{~mm}$. i 2 whorls. $4^{\text {th }}$ segment a little longer than broad, $5^{\text {th }}$ to $7^{\text {th }}$ or $8^{\text {th }}$ one $L=1^{1 / 2} \times$ br, then shorter again. From the $7^{\text {th }}$ or $8^{\text {th }}$ segment polished segments with transverse cristas with small spines. Opposing spine $h=1 / 4 \gtrless$ the br of the segment. $\mathrm{R}-\mathrm{S}$ visible in the corners. I $\mathrm{Br} \perp \mathrm{h}=1 / 3 \mathrm{br}$, laterally free from each other. I Brax pentagonal $h=1 / 2 \times$ br. Lateral margins form an obtuse angle with I Br 1. Distal borders with small spines as in the following ossicle: for the rest the arm-bases are rather smooth. 


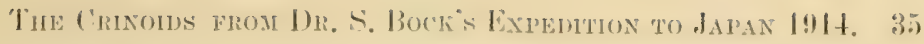

Primipostaxillaries united inside. II Br:s are t, III Br:s: 2 (in 4 cases) Arms XI $90 \mathrm{~mm}$. Syzygies as in Sp. 1. 14 segments $\mathrm{pl} \mathrm{cm}$. (11, if the syzygial pairs are counted as units). Breadth of the segments $1,2 \mathrm{~mm}$.

$\mathrm{P}_{\mathrm{II}} 35$ (8 T) $10 \mathrm{~mm} ; \mathrm{P}_{1} 3 \mathrm{l}$ (6 T) $9,5 \mathrm{~mm}, \mathrm{P}_{2}-\mathrm{P}_{4}+4-3,5 \mathrm{~mm}$., decreasing, with 5 ' $\mathrm{T}$ and $15-20$ segments. A short comb here and there to $P_{25}$; the interspaces are, however, very large after $P_{15}$. Distal P. $17 ; 0,5 \mathrm{~mm}$.

Disk 11 mm., finely papillous. Anal funnel central. Colour yellow-red. A Protomyzostomem incysted.

Resembles Comantheria grandicalyx var. Sp. 1 in general appearance.

Si). 5 (St. 45) Cd covered with small eavities, $2,5 \mathrm{~mm}$. free dorsal pole 1,5 mm. C. XVII $15-20 ; 10-19 \mathrm{~mm}$. $6^{\text {th }}$ to $8^{\text {th }}$ segments the longest ones, $L=!^{1} / 2 \times$ br; $9^{\text {th }}$ segment a transition segment. Opposing spine $h=1 / 3-{ }^{1} / 4 \times$ br of the segment.

I $\mathrm{Br}$ I h $={ }^{1 / 4} \times \mathrm{br}$, laterally free from each other, a weak synarthrial tubercle with I $\mathrm{Br}^{2} 2$. II Br:S are $4(3+4)$. Arms XIII 65 mm. Syzygies with an interval of 3 to $t$ oblique articulations.

$\mathrm{P}_{1} 25(6-7 \mathrm{~T}) . \mathrm{P}_{2} 5 \mathrm{~T} ; 5,5-9 \mathrm{~mm}, \mathrm{P}_{3}$ and $\mathrm{P}_{4}+\mathrm{T}^{\mathrm{T}}: 4,5 \mathrm{~mm}$. $P_{1}-P_{5}$ with small, spiny, dorsal processes on the $2^{\text {al }}$ to $5^{\text {th }}$ segment. A comb here and there to $P_{15}$.

Disk $9 \mathrm{~mm}$. Anai interradius with large calcareous papillo. Mouth marginal. Colour (in spirit) white.

sp. 6 (St. 59). C. XXIV $11-15 ;(4)-10 \mathrm{~mm}$. 3' segment $\mathrm{L}=$ $1^{1} / 2 \times$ br. $\quad 4^{\text {th }}$ and $5^{\text {th }} \mathrm{L}=2 \times$ br. $6^{\text {th }}$ or $7^{\text {th }}$ a transition segment. Dor'sal spine very indistinct. Opposing spine $h={ }^{1}+\times$ the br of the segment.

R-s nearly hidden by Cal. I Br I $h=1,3 \times$ br, laterally almost free. Axillary $\mathrm{h}=1,2 \times \mathrm{br}$, its lateral sides bent sidewards at an angle to $1 \mathrm{Br}$ 1. Primipostaxillaries mited inside. Il Br:s are 4, III Br:s:4 (in one case on an inner arm). Arms XXI $55 \mathrm{~mm}$. Syzygies as in the preceding specimen. Distal segments $L=I^{1} .2 \times$ br, narrow, almost smooth, somewhat overlapping distally.

$P_{11}+30$ (7-8 T) mm. $P_{1} \pm 30$ (T T) $7 \mathrm{~mm}$. or shorter, $P_{2} 21$

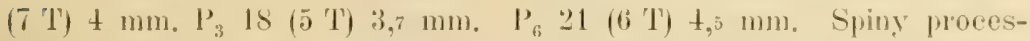
ses on the proximal segments. Combs with $5-6$ 'T here and there at least to $\mathrm{P}_{13}$. Distal 1. $16-17 ; 5,5 \mathrm{~mm}$. The last two segments with dorsal hooks. 
Disk $7,5 \mathrm{~mm}$, papillous. Nouth marginal. Anus central.

To this species one might also assign a very young specimen from St. 4t, deseribed among the young ones (see below).

An examination of the occurrence of the combs gives the following result:

Sp. 1 On an arm situated on III Brax: $\begin{array}{llllllllllll}P_{1} & P_{2} & P_{3} & P_{4} & P_{5} & P_{6} & P_{8} & P_{10} & P_{11}\end{array}$ $P_{15} P_{17} \quad\left(P_{18-19}\right.$ are lacking $)$ $\begin{array}{lllllll}\mathrm{P}_{21} & \mathrm{P}_{23} & \mathrm{P}_{25} & \mathrm{P}_{27} & \text { (After } \mathrm{P}_{30} & \text { no }\end{array}$ comb).

The same arm on the other side $\mathrm{P}_{1}-\mathrm{P}_{6} \mathrm{P}_{8} \quad \mathrm{P}_{10} \mathrm{P}_{12} \mathrm{P}_{14} \mathrm{P}_{16} \mathrm{P}_{17}$ $P_{19}$ then usually more sparse. Sp. 2 On an arm situated on III Brax $P_{1}-P_{5} \quad P_{7} P_{9} P_{11} P_{13} P_{15} P_{17}$ $\begin{array}{lllll}\mathrm{P}_{18} & \mathrm{P}_{20} & \mathrm{P}_{22} & \mathrm{P}_{24}\end{array}$

Sp. 3 》 》 》 》 》 $\mathrm{P}_{1}-\mathrm{P}_{4} \mathrm{P}_{6}\left(\mathrm{P}_{8}\right.$ broken) $\mathrm{P}_{10} \mathrm{P}_{12}$ $\mathrm{P}_{13} \ldots \mathrm{P}_{19} \quad \mathrm{P}_{21} \quad\left(\mathrm{P}_{20-30}\right.$ broken) $\mathrm{P}_{31}$.

$S p .4 \gg \gg \geqslant \quad \gg \quad \mathrm{I} \operatorname{Brax} \mathrm{P}_{11} \mathrm{P}_{1}-\mathrm{P}_{5} \mathrm{P}_{7} \mathrm{P}_{9} \mathrm{P}_{14} \mathrm{P}_{20}$.

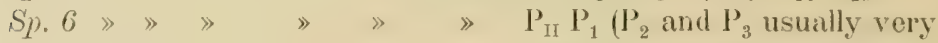
small, sometimes without a comb) $P_{4} P_{6}\left(P_{7-11}\right.$ broken) $P_{14}$.

Other arms of this specimen show that more than $6-8 \mathrm{p}$. on each side of the arm do not occur.

Example from sp. juv. St. 44: $\mathrm{P}_{1}\left(\mathrm{P}_{2} . \mathrm{P}_{4}\right.$ are lacking), no more combs. -

This species is most closely related to $C$. delicata but differs by having larger dimensions and more cirri and cirrals, as well as by the abundant occurrence of 4 IV Br:s. 
The Crinoms from Dr, S. Bock's lixpedition to Japan 1914. 37

Comaster serrata $\Lambda$. II. CLINK.

Fig. $21-25$. p. 154.

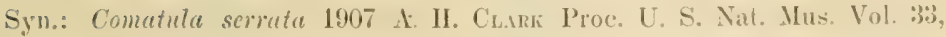

Comaster serrate 1908 A. II. ChanK Proc. U. S. Nat. Llus. Vol. 333, p. 686; 1912 Crin. Ind. Oc. p. 89; 1915 Journ. Aead. Sei. Vol. 5, p. 214; 1918 Siboga Exp. 42 B, p. 37.

Comaster parvicirra 1908 A. H. Clamk Proc. U. S. Nat Mus. Vol. 34, p. 306.

From St. 45 (1 sp.) $55(1), 59(1)=3$ specimens.

Sp. 1 (St. 59) Cd 2,2 mm., free dorsal pole $1 \mathrm{~mm}$. C. XVil, $10-11 ; 5-7 \mathrm{~mm}$. in a single or double whorl; $1^{\text {st }}$ segment short, 2 strongly hour-glass-shaped $\mathrm{L}=1^{1 / 2} \times \mathrm{br} ; 3^{\mathrm{d}} \mathrm{L}=3 \times \mathrm{br}$, $4^{\text {th }}$ somewhat shorter $\mathrm{L}=2^{1 / 2} \times$ br. $5^{\text {th }}$ segment a transition segment. Dorsal spine small, indistinct, on the distal part of the segment. Penultimate segment $\mathrm{L}=\mathrm{br}$ with opposing spine; $\mathrm{h}$ of this one about $=1 / 5 \times$ the br of the segment. Terminal elaw $\mathrm{L}= \pm 2 \times$ the preceding segment, strongly curved.

$\mathrm{R}-\mathrm{s}$ concealed. I Br $1 \mathrm{~h}={ }^{1 / 4} \times \mathrm{br}$, partly hidden by $\mathrm{Cd}$. I Brax $\mathrm{h}=1 / 3 \times \mathrm{br}$, almost triangular. A syzygy between $\mathrm{I} \mathrm{Br} 1$ and "2. All the way from I Brax the margins of the segments are distally bent outwards and very spiny. II Br:s are 4 , III Br:s $2(1+2)$. Arms XXVIII $50-70 \mathrm{~mm}$. Br: $1+2$ except when the arm originates from a I Brax; then occur's $\mathrm{Br} 1-23+4$. $\mathrm{Br} 1-7$ discoidal, then oblique joints. 16 segments $\mathrm{pr} \mathrm{cm}$. (12 if the syzygial pairs are counted as units). The breadth of the arms $0,7 \mathrm{~mm}$. Segments distally: $L_{L}=1^{1 / 2} \times$ br, slender, hour-glass-chaped.

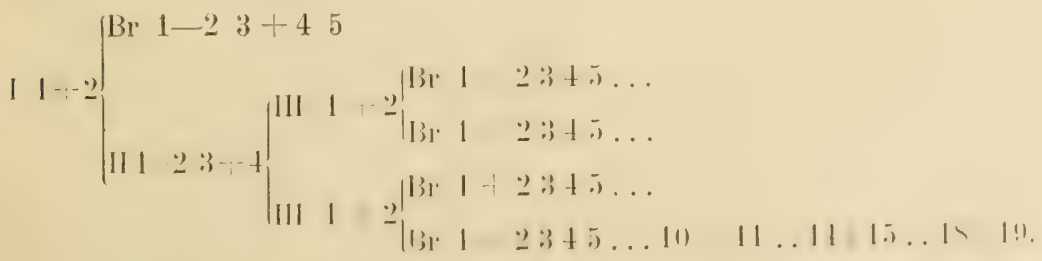


$P_{\mathrm{II}}$ and $\mathrm{P}_{1} 25-30(6 \mathrm{~T}) 6 \mathrm{~mm} ., 11-13$ first segments with very spiny distal collars, $P_{2} \pm 23 ; 5 \mathrm{~mm}$. (The 7 most proximal segments spiny), $\mathrm{P}_{3} \pm 20 ; 3 \mathrm{~mm} ., \mathrm{P}_{4} \pm 15(5 \mathrm{~T}), 2,5 \mathrm{~mm}$. $\mathrm{P}_{1}-\mathrm{P}_{4}$ or $\mathrm{P}_{5}$ with combs, then on every two or three pinnules to about $\mathrm{P}_{20}$. The teeth of the combs: $\mathbf{h}=1^{1} / 2 \times$ the $b r^{\circ}$ of the segments. Distal p. 20;6,5 $\mathrm{mm}$. the segments (except the most proximal): $\mathrm{L}=2 \times \mathrm{br}$, at the ends linotty swollen and spiny.

Mouth central. Anal funnel lateral, papillated. Disk smooth without granules, $6 \mathrm{~mm}$. Colour brownish. $\mathrm{L}=3 \times \mathrm{br}$.

Sp. 2 (St. 55) C. XIV, 9-10, 4-6 mm. $3^{31}$ and $4^{\text {th }}$ segments

$\mathrm{R}-\mathrm{s}$ narrow bands. I Br:s 1 laterally free, $\mathrm{h}=1 / 3$ br. I Brax $\mathrm{h}=1 / 2 \mathrm{br}$, pentagonal. Primipostaxillaries united inside. II Br:S are 4 (3 cases); III br:s: 2 (2 cases). The arms are XV $45 \mathrm{~mm}$. Syzygies with an interval of 3 oblique articulations.

$\mathrm{P}_{1}-\mathrm{P}_{4}$ with combs; afterwards here and there but scarcely farther than to $P_{10}$. Example $P_{1} P_{2} P_{3} P_{4} P_{6} P_{9}$. $P_{1}$ with $5, P_{2}$ with $4 T$.

Mouth subcentral. Anal funnel large, papillated, swollen, 1,5 $\mathrm{mm}$. Disk $3 \mathrm{~mm}$., dark brown. Colour for the rest light grey-brown. 3) $\times$ bir.

Sp. 3 (St. 45) C. IVI 8-9;2-3 $\mathrm{mm}$. $3^{\mathrm{d}}$ and $4^{\text {th }}$ segment $\mathrm{L}=$

I Br 1 laterally free, $h=1 / 3$ br. Axillary $h=1 / 2 \times$ br. Primipostaxillaries free inside. II Br:s are 4, III Br:s:2. Arms XIII $25 \mathrm{~mm}$. Br-segments strongly bent outwards and serrate. Syzygies as before. (After III Brax $1+23+5 \ldots$.). Length of the distal segments $=1^{1 / 2}-$ $\underline{2} \times \mathrm{br}^{2}$.

$\mathrm{P}_{1}-\mathrm{P}_{3}$ or $\mathrm{P}_{4}$ with short, high combs of $4-5 \mathrm{~T}, \mathrm{P}_{1} \pm 25 ; 2,5-3$ $\mathrm{mm}$. No distal pinnules with combs. Distal p. 12--14; $4-5 \mathrm{~mm}$.

Disk 2,5 mm., a little cushion-shaped. Mouth central. Anal funnel short, coarse, smooth, length $0,8 \mathrm{~mm}$., breadth about the same.

See for the rest the description of the young forms from Bonin Island (p. 58), some of which certainly belong to this species.

As in the preceding species, the young forms of this one scom to lack combs on distal pinnules. The finest example of this is Sp. 3 of Comaster serrata. The specimen in question is a connecting link between the X-armed young forms (it has like these only a couple of proximal pinuules provided with combs) and the full-grown specimens 
'The Crtwotns from Dr. S. Bock's Expentrox to dapan 1914. 39

(in conformity to which it has the III $\mathrm{Br}$ ' series with following $\mathrm{Br} 1+2$ developed and is therefore certainly determinable). - The combs oceur more and more abundantly on larger specimens and, finally. in full-grown specimens reach far out on the distal parts of the arms. Usually a comb occurs on every seeond pimule. - The late ontogenetical oceurence of combs on distal pinnules probably has a correspondence in the phylogenetical evolution and might stand in a certain relation to an altered manner of living and a different mode of catching the food, a question that 1 shall discuss in another connection.

Comantheria A. II. Cr.ивк.

C. grandicalyx (P. H. C.RrR)

Fig. 30,31 .

Syn.: Actinometre grandiculyx 1852 P. II. Carpexten Journ. Linn, Soe. Vol. 16, p. 520

Commentheria grandicalyx 1912 A. H. CLark C'rin. Ind. Oe. p. 90; Smithson. Mise. Coll. Yol. 60, N:o 10, p. $\overline{7}$; 1915̃ Journ. Acall. Sci. Yol. j, p. 214; 1918 Siboga Lxp. Vol. 4 t2 B, p. 43 .

From St. 52: 2 specimens.

$S p .1 \mathrm{Cd} 10 \mathrm{~mm}$. in diameter, the dorsal surface very concave, free dorsal pole $6 \mathrm{~mm}$.

C. + LXXY 26 (D) $25 \mathrm{~mm} ., 30-31$ (V) $29-34 \mathrm{~mm}$., in about :3 close whorls. $1^{\text {st }}$ to $5^{\text {th }}$ segments shorter than long to cubical. $6^{\text {th }}$ to $11^{\text {th }}$ or $14^{\text {th }}$ a little longer than broad, the following segments decreasing, $\mathrm{L}={ }^{2 / 3}--^{1 / 2} \times \mathrm{br}$. From the $20^{\text {th }}$ or $25^{\text {th }}$ segment a very weak and indistinct dorsal spine. Opposing spine a little stronger. T'erminal claw rather coarse, somewhat longer than the penultimate segment.

I Br 1 almost concealed. I Brax low pentagonal $L_{2}=1_{3} \times b_{1}$, the distal margins coneave. II $\mathrm{Br}^{\circ} \mathrm{I}$ basally united in pairs inside. $111 \mathrm{IB} \cdot 1$ and 2 and sometimes also $\mathrm{Br} 1$ and 2 fused in pairs on the inner side. II Br:s:t $(3+4)$, 111 Br:s: 2 (1-2, a weak synarthrial tubercle), II Br:S: $4(3+4)$. The components of the division series smooth, broad, 
tolerably flat. Disk only appearing slightly between the inner sides of the II $\mathrm{Br}$ series. Arms LVIII $120 \mathrm{~mm}$. Syzygies for instance $3+4 \ldots 16+17 \ldots 22+23 \ldots$, distally with an interval of 4 oblique articulations. 16 segments $\mathrm{pr} \mathrm{cm}$. (13 if the syzygial pairs are counted as units). The breadth of the arms at the middle $2,2 \mathrm{~mm}$. $\mathrm{Br}$ segments very short, $L=1 / 3-{ }^{1 / 4} \times$ br.

$\mathrm{P}_{\mathrm{II}}+60 ; 30 \mathrm{~mm}$, about 20 ' $\mathrm{I}$ ' ( $37^{\text {th }}$ to $5 \mathrm{~S}^{\text {th }}$ segment) the tip smooth; the teeth rather thin, low, $h=1 / 2$ of the br of the segments. $P_{\text {IV }}$ or $P_{1} 22-28 \mathrm{~mm} ., \pm 20 \mathrm{~T}$. $P_{2} \pm 15 \mathrm{~mm}$. with about $15 \mathrm{~T}$. $\mathrm{P}_{3} 6 \mathrm{~T}$, $11 \mathrm{~mm}$. If $\mathrm{P}_{I V}$ is lacking only 4 pinnules $\left(\mathrm{P}_{I I}-\mathrm{P}_{3}\right)$ with teeth, $\mathrm{P}_{6} \quad 9,5$ mm. Genital p. $14 \mathrm{~mm}$. Distal p. 25; $11 \mathrm{~mm}$., the 3 last segments with small dorsal hooks. The proximal pinnules have the first $5-12$ segments provided with small prominences; the notehes between these partly filled up by skin.

Disk $40 \mathrm{~mm}$. Mouth marginal. Anal funnel central, sharply set off from the anal interradius, $L=14 \mathrm{~mm}$. No calcareous granules or papillo in the skin. Colour brown; a somewhat lighter middle-line on the dorsal side of the arm. On about 10 of the posterior arms 25-30 pairs of pinnules are without ambulacral furrows. The ambulacral furrow of the arm, however, always remain.

Sp. 2 The dorsal free surface of Cd slightly concave, $9 \mathrm{~mm}$. $\mathrm{C} \pm$ LXX 27 (D) 30 (V) $25-30 \mathrm{~mm}$.

II $\mathrm{Br}-\mathrm{S}: 4(3+4)$, III $\mathrm{Br}-\mathrm{S}: 2$ (20 cases), IV $\mathrm{Br}-\mathrm{s}: 4(3+4)$ 26 cases, V Br-s:2 (2 cases). Arms LXVIII, $130 \mathrm{~mm}$. or shorter. The formation of the arms as before.

$\mathrm{P}_{\pi}>35 \mathrm{~mm} .,>80$ segments. Teeth from the $40^{\text {th }}$ or $55^{\text {th }}$ to the $75^{\text {th }}$ seginent. Comb best developed about the $60^{\text {th }}$ segment. $\mathrm{P}_{1 Y}-\mathrm{P}_{3}$ decreasing, with teeth. All the arms with ambulacral furrows.

Disk $42 \mathrm{~mm}$. Anal funnel $17 \mathrm{~mm}$. 
The Crixoms from Dr. S. Bock's Expentrox to Japax 191t. H

Comantheria grandicalyx var. Hagellipinna H. var.

lijg: : :

From St. 5l (1 sp.), 62 $(1)=2$ specimens.

Sp. 1 (St. 51) Cd l:2 mm., free dorsal surface 9 $m m$. $\mathrm{Y}_{1}=3 \mathrm{~mm}$.

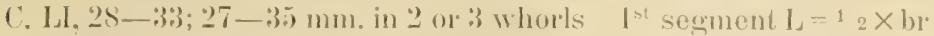
$2-11^{\text {th }}$ enbical, a little thicker at the ends, $12^{\text {th }}-1 f^{\text {th }}$ somewhat longer fhan broad. About the $20^{\text {th }}$ segment a trumsition-segment. Dorsal spine weak, but rather distinct. The spines on the distal cirrals pointed. Terminal cha curved, $L=1^{1 / 2} \times$ the penultimate segment.

I Brax h $=1 / 2$ br, distally protracted at an acute angle. II Br I inside almost completely free. II $\mathrm{Br}-\mathrm{s}: 4$, III $\mathrm{Br}-\mathrm{s} 2$ (20 cases) I Br-s + (2)+ cases). Arms LXIV $1+0-190 \mathrm{~mm}$, dimorphous. Example of armdivision:

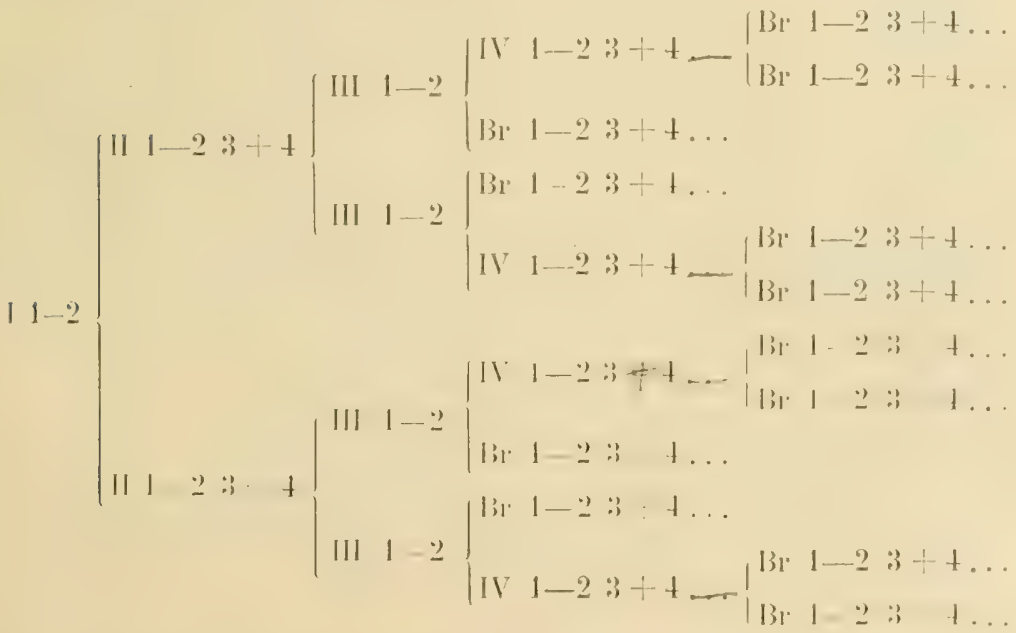

$2^{\text {d }}$ syzygy at the $22^{4}-24^{\text {th }}$ segment, $3^{\text {d }}$ at $28^{\text {th }} 01^{\circ} 30^{\text {th }}$ segment then with an interval of 4 (to 5) oblique articulatious. $19-23$ segments pr em. (15-17, if the syzygial pairs are eomited as units). Jova Acta lieg. Soc. Sc. Vps., Sert. 1, Vol. 5. N:o f. Impr. 18,2 192.2. 
Breadth of the $\mathrm{Br}-\mathrm{s} 50 \mathrm{~mm}$. from the base of the arms $1.8 \mathrm{~mm}$. Distally $0.6 \mathrm{~mm}$. The joints very swollen, thick and coarse.

$P_{\text {II }} 75-80 ;: 30-33 \mathrm{~mm}$. with a very indistinct comb, partly hidden by skin; +12 T, the tip of the pinnula smooth. $P_{1 V}+12 \mathrm{~T}$ similar to the preceding p. P' with 18 ' $\mathrm{T}$, which are more strongly developed, $+23 \mathrm{~mm} . \mathrm{P}_{2}+40$ (6 T) $16 \mathrm{~mm}$. the tip smooth. $\mathrm{P}_{3}$ shorter with some few, small teeth, $P_{4}+25$ (no T) $6 \mathrm{~mm}$. Genital p. $12 \mathrm{~mm}$. Basal segments as in the chief species. Distal p. $+30 ; 14 \mathrm{~mm}$, Length of the pinnulars $=1^{1 / 2} \times \mathrm{br}$. Dorsal hooks indistinet. Distal p. spirally rolled.

Disk $38 \mathrm{~mm}$. Colour red-yellow.

Sp). 2 (St. 62) Cd $11 \mathrm{~mm}$, free dorsal pole $7 \mathrm{~mm} . \mathrm{C}+\mathrm{L}, 27-32$; $24-29 \mathrm{~mm} .13^{\text {th }}-18^{\text {th }}$ segment a transition segment.

II $B r-s: t$, III $B r-s: 2$, II $B r-s: 4(3+t)$, in one case 2; V Br-s 2 (one case). Arms LXVIII $90-110 \mathrm{~mm}$. 19 segments pr cm.

$P_{I S}+65(10-17$ indistinct $T) 32 \mathrm{~mm}, P_{\mathrm{IF}} 28 \mathrm{~mm} .+5$ ร $(12 \mathrm{pin}-$ nules with small T), $P_{2} 31$ (ST) 12 mm., $P_{3} 25$ (5 T) 8 mm., $P_{4}$ no $T$, $6 \mathrm{~mm}$. Genital p. $+20 ; 8,5 \mathrm{~mm}$. Distal p. $\pm 25 ; 11 \mathrm{~mm}$.

Disk $33 \mathrm{~mm}$. Anal funnel 12 $\mathrm{mm}$.. somewhat swollen but well marked out from the disk. Mouth adradial, marginal. Colour brownorange to grey-brown.

Both these specimens are distinguished from the chief species by the nearly smooth distichal pinnule, by very short Br-segments, by a more slender constitution and by the trilling size of the disk when compared with length of the arms. (The last-described specimen, however, somewhat approaches C. grandicalyx). 
Comanthus A. II. Ciratil.

C. solaster A. H. Ch.skli.

lig. $33,34$. 1). 153.

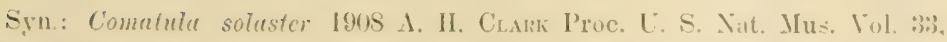

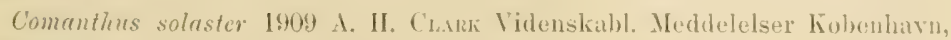
1). 147; 1912 Crin. Ind. Oe., p. 94; 1915, Journal Acatl. Sci. Vol. 5, p. 214; 1915 Sibogra Exp. Vol, 42 B, p. 49.

From St. $20(1$ sp.). 28 (1) $38(\underline{y})=4$ specimens.

Sp. 1 (St. 38) Cd $11 \mathrm{~mm}$, free dorsal pole a little concave $7.5 \mathrm{~mm}$. ( + LXX 18-23; 12-21 $\mathrm{mm}$. in 20 or 3 whorls. Cirri very diversiform in appearance, often slender, straight, weak; sometimes of the usual type; coarse, thick and strongly curved (compare lijg. 34). 'The firstmentioned ones have the $1^{\text {st }}$ segment short, $2^{\mathrm{d}}-3^{\text {th }}$ or $4^{\text {th }}$ cubical or a little longer. $5^{\mathrm{d}}-\mathrm{S}^{\text {th }}$ segment $\mathrm{L}=+\underline{2} \times$ br (when the $\mathrm{C}$ are of the later type these segments have only $\left.\mathrm{L}=1^{1 / 4} \times \mathrm{br}\right)$. From about the $10^{\text {th }}$ segment $L={ }^{1 / 2} \times$ br. Dorsal transverse ribbon or knot occurs from 12 $2^{\text {th }}$ or $16^{\text {th }}$ segments. Terminal claw rather coarse, somewhat longer than the penultimate segment.

I Br I hidden by Cd. I Brax trangular $h=1 / 2 \times \mathrm{br}$, distal angle very acute, separating II $\mathrm{Br}-\mathrm{S} 1$, which are only narrow tips inside. The other primipostaxillaries united inside. Il Br-s: $t$, III Br-s: $t$, IV Br-s:t. Arms L $110-130 \mathrm{~mm}$. Division series smooth, very close. From the dorsal side only the bases of the distichal pimules visible (the first 6 segments). Disk concealed in dor'sal view. Syzygies: $3+t \ldots 17+18 \ldots 23+2 t$ or $3+t \ldots 1+15 \ldots 18+19$ etc, with an interval of $t$ oblique articulations. $\mathrm{Br}+- \pm \mathrm{Br} 70$ with distally orerlapping, thickened segments with small spines, then smooth arms. $20-21$ segments pr em. $(15-16$ if the syzygial pairs are counted as units). II $\mathrm{Br}-\mathrm{s}: \mathrm{br}^{\mathrm{r}}=4 \mathrm{~mm}$. Br $\mathrm{L} \quad \mathrm{br}=2,3 \mathrm{~mm}$; $50 \mathrm{~mm}$. from the arm-base the $\mathrm{br}^{\circ}$ is $=1.3 \mathrm{~mm}$.

$\mathrm{P}_{\mathrm{II}} \pm 60$; about $25 \mathrm{~mm}$. with $8-16$ weak leeth, 2) to 5 last pinnulars smooth, the basal segments angular, a little knotty. $\mathrm{P}_{\mathrm{In}}$ similar somewhat shorter. $P_{T Y}$ or $P_{1}$ about $20 \mathrm{~mm}$. (11 l'). $P_{2}$ with 8 madi- 


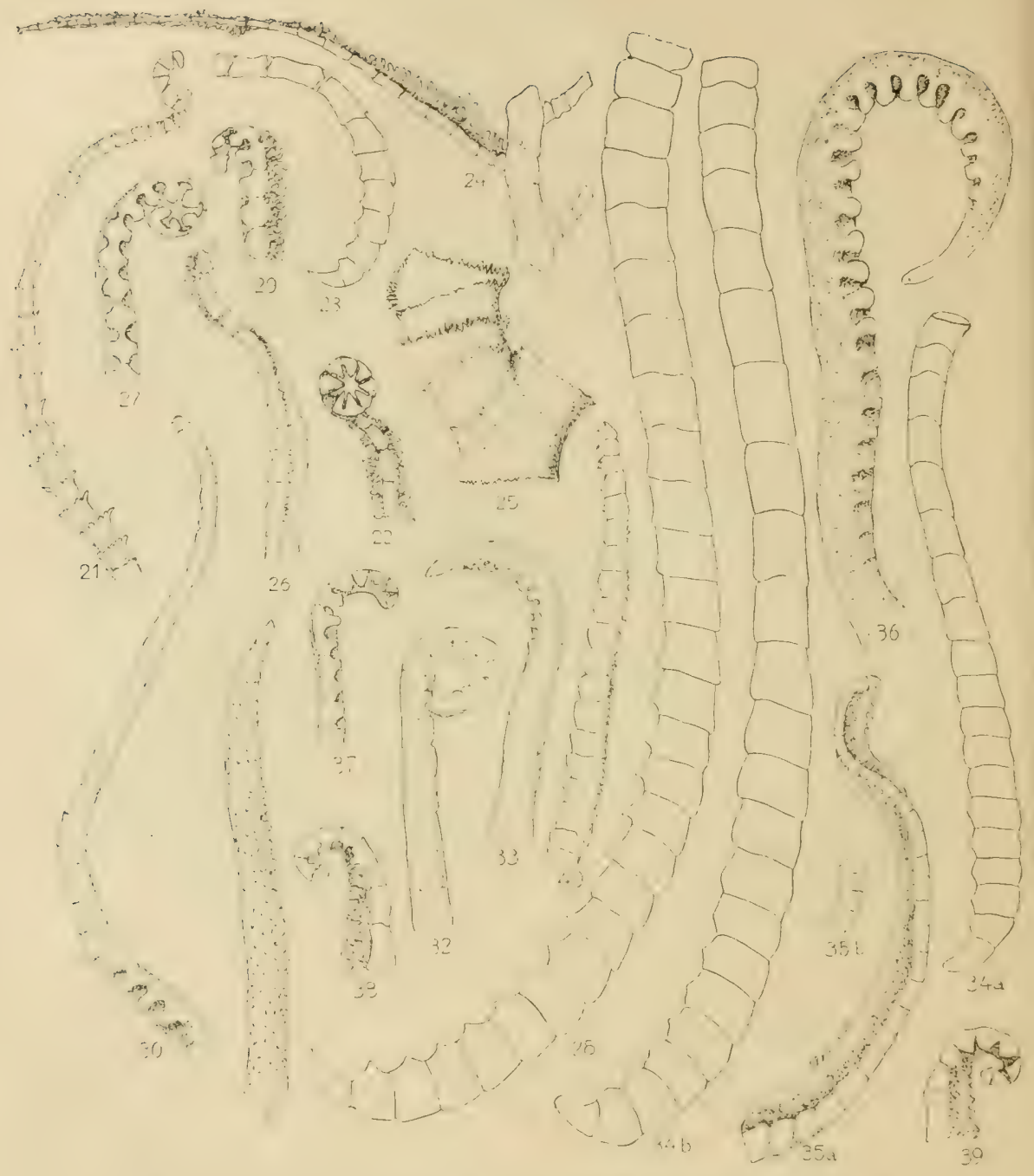

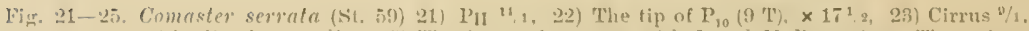
24) An arm-stump with histal $\left.p-s{ }_{1}, 25\right)$ 'The base of an arm with I null 11 I3r series. The spines which necur at the-distal margins of the segment are mast often broken ${ }^{4}{ }_{1}$; $26--29$ Comaster ileli-

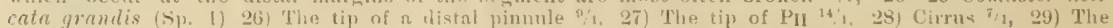
tip of a genital j. with a comb, $\times 17 \frac{1}{2} ; 30,31$ Comnntheria grandicalyx (nt. 52) 30) Distal pin- 
mentary teeth, still shorter. $P_{3} \quad 6_{2} 5 \mathrm{~mm}$. without a comb. Genital p. 11-12 mm. Distal p of about equal length. On all pinnules 2-5 or $7^{\text {th }}$ segments with small prominences.

Disk $30 \mathrm{~mm}$., without granules. Mouth admarginal. Anal funnel subcentral, $7 \mathrm{~mm}$.

Sp. 2. (St. 38 A). Cal $10 \mathrm{~mm}$. dorsal pole a little concure, $6,5 \mathrm{~mm}$. C. LXV 22-24; 12-25 $\mathrm{mm}$.

I Br $1 \mathrm{~h}={ }^{1} / 10 \times$ br. I Brax $h={ }^{1 / 2}$ br. II, III and IV Br-s: + (the last-mentioned division-series appearing in 2 cases). Arms XLII $125-15.5 \mathrm{~mm}$.

Disk :32 $\mathrm{mm}$. Anal funnel $8 \mathrm{~mm}$. Colour as in the preceding specimen violet-brown. Cirri and regenerated parts somewhat lighter.A splendid specimen.

Sp. 3 (St. 2S) Ca $10 \mathrm{~mm}$., free dorsal pole $7 \mathrm{~mm}$. C. LV 20-26: $12-20 \mathrm{~mm}$.

I $\mathrm{Br}$ I slightly visible. Axillary almost triangular $h=2 / 3 \times b$ r. II and III Br-s: 4. Arms XL 105-125 mm. Sutures between the distichal and palmar segments slightly visible, division-series not quite so smooth as in $\mathrm{Sp}$. 1.

$\mathrm{P}_{\mathrm{II}} \pm 55 \quad(10-12 \mathrm{~T}) 24-25 \mathrm{~mm}$. 'T' indistinct, h about ${ }^{1 / 3}$ of the br of the segment. $P_{\mathrm{II}}$ to $P_{2}$ shorter; also $P_{3}$ with $a$ small comb. Genital p. $10 \mathrm{~mm}$. Distal P. $11-12 \mathrm{~mm}$. - Disk $32 \mathrm{~nm}$. Anal funnel if $\mathrm{mm}$.

Sp. 4 (St. 20) Ca $10 \mathrm{~mm}$. Alorsal pole $8 \mathrm{~mm} . \quad$ C. + LX 20-24. $14-23 \mathrm{~mm}$. in 2 whorls. A great many empty joint-carities.

II and III Br-s:t. Arms XL 105-120 mm. Division series and arms as in Sp. I,

$\mathrm{P}_{\mathrm{II}}+50 ; 2 \mathrm{~S}$ mm. $\mathrm{P}_{\mathrm{II}}$ with 6 - $\mathrm{S}$ very low T.; j to 6 top-segments smooth; +20 mm.. $\mathrm{P}_{1}-\mathrm{P}_{3}$ decreasing $\left(\mathrm{P}_{2}-10\right.$ mm.. $\mathrm{P}_{33} 7 \mathrm{~mm}$. without a comb.) Distal. p. $9 \mathrm{~mm}$. - Disk $28 \mathrm{~mm}$. Anal funnel (j) $\mathrm{mm}$.

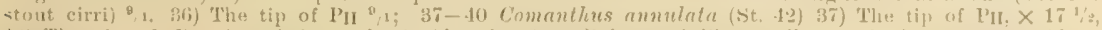
(3) 'The tip of $l^{\prime} z$, riewed from tho inside, slowing slight teoth-like swellings which constitute ridges supporting the teeth on the outsiele of the piumule, $\times 17$ 1/3. 34) The same pinnule viewed from the ontside with 7 stout teeth, $\times 171 / 2,40$ ) Distal pinmule with stout dorsal hoolis (obserre small cirri) ${ }^{\circ}$. 
In all these specimens one finds the variable appearance of the cirri peculiar to $C$. solaster. 'The only difference from the specimens described by A. II. Crank is the number of $\mathrm{C}$, which in the Bockian species are more numerous and arranged in 2 to 3 whorls. The abovedescribed specimens might perhaps therefore be characterized as a forma multicina.

\section{Comanthus pinguis 1 . II. Ci.ARK.}

lig: 35,36 .

Syn: Comanthus pinguis 1919 1. II. Craki Proc. U. S. Nat. Mus. Vol. 37, p. 29; 1912 Crin. Ind. Oc. p. 94; Smiths. Misc. Coll. Vol. 60, N:o 10, p. 9; $191 \tilde{5}$ Jonograph; Journ. Acad. Sci. Vol. 5, p. 214; 1918 Sibnga Lxp. Vol. 422 B, p. 49.

From St. 14 (2) sp.), 15 (1) $[18(1)]=4$ specimens.

Sp. 1 (St. 14) Cd almost hemispherieal, $9 \mathrm{~mm}$, free dorsal pole 5 mm.a a little hollowed in the middle. C. XXXVIII 28-33: 30-36 $\mathrm{mm}$. in 2 whorls. $1^{\text {st }}$ and $2^{\mathrm{d}}$ segments short, $3^{\mathrm{d}}$ to $5^{\text {th }}$ cubieal or somewhat longer., $6^{\text {th }}-10^{\text {th }}$ segment $\mathrm{L}=1^{1 / 2}$ br. Distal ones $\mathrm{L}={ }^{1 / 2} \times \mathrm{br}$. Dorsal prominences from the $15^{\text {th }}$ to $20^{\text {th }}$ segments, $\mathrm{L}= \pm^{1 / 5}$ of the br of the cirral: A weak opposing spine. Terminal claw slightly curved. $\mathrm{L}=1^{1 / 2} \times$ the preceding segment.

$\mathrm{R}-\mathrm{S}$ slightly visible at the corners. I $\mathrm{Br} 1 \mathrm{~h}=1 / 4 \mathrm{br}$, in the basal half united with each other. Between them a depression in the perisome. I Brax $\mathrm{h}={ }^{1} / 3 \times$ br, pentagonal, the distal margins slightly concave. The br $6,5-7 \mathrm{~mm}$. Primipostaxillaries united inside. On their distal, interdistichal side a depression as between the primibrachial series. Divisions-series broad, smooth, flattened, but the perisome between them is quite visible. The distance between $1 \mathrm{H} \mathrm{Br}^{\circ} 3$ in two different division-series is $3,5 \mathrm{~mm}$. Disk reaching to $1 \mathrm{ll} \mathrm{Br}^{\circ} 2$ or 3 . II and III Br-S:4 (3+4). Arms XXXVIII $125 \mathrm{~mm}$. +, very fragile. Br-segments distally somewhat, but only slightly, thickened. Syzygies distally with an interval of 4 oblique articulations. Example of armramification and proximal syzygies: 
The Crinoids from Dr. S. Boctís Expedrtion to Japax 191.t. 47

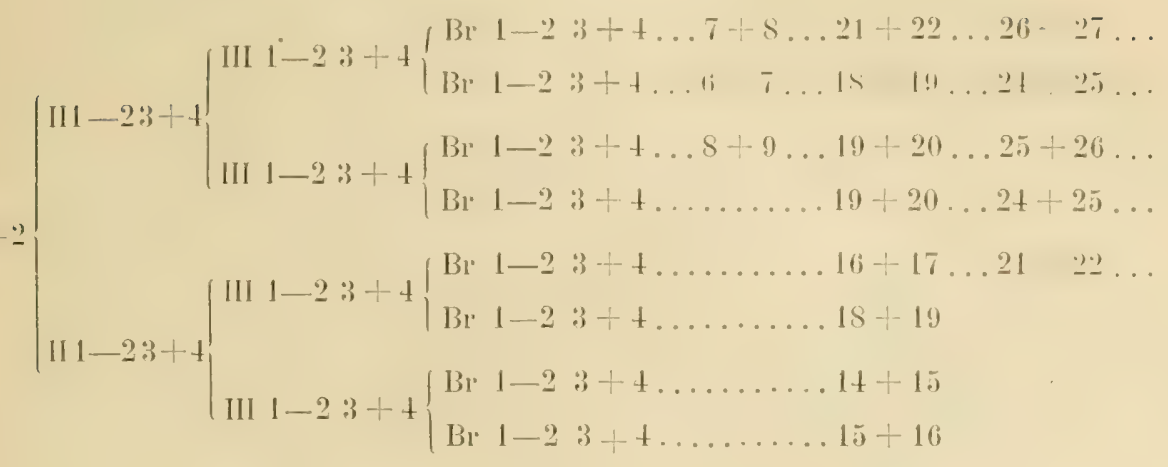

16 segments $\mathrm{pr}^{\mathrm{cm}}$. (13, if the syzygial pairs are counted as units).

$\mathrm{P}_{\mathrm{II}} 50-5 \overline{5} ; 30 \mathrm{~mm}$., last 5 segments smooth. T' 20 low, thin. $h=+{ }^{1}{ }_{4}$ of the br the pinnular, $P_{I I I}$ t5, last 6 segments smooth, $15 '$ '. $\pm 25 \mathrm{~mm}$. $\mathrm{P}_{1} 45$ (15 T) $22 \mathrm{~mm}$. (last j segments smooth), $\mathrm{P}_{2} \mathrm{~S} \mathrm{~T}, 10$ mm., $\mathrm{P}_{3} 6 \mathrm{~T}, 8 \mathrm{~mm}$. (h of $\mathrm{T}={ }^{1}, 2-{ }^{1 / 3}$ of the br of the segment. One or two distal segments without teeth), $P_{4}$ and $P_{5}$ usually with a rudimentary comb. Distal p. $\pm 25 ; 10 \mathrm{~mm}$. $3^{\mathrm{d}}$ to $5^{\text {th }}$ pinnular with skin connecting the knots as in Comantheria grandicalyx, most distinct on proximal p.

Disk $32 \mathrm{~mm}$. without granules. Mouth adradial. Anal cone 6 mm. Colour: dorsally light yellow, ventrally yellow-red with a sharp colour-border, especially on the lateral sides of the division-series.

Sp. 2. (St. 14) Cd $9 \mathrm{~mm}$, free dorsal pole rather flat, $6 \mathrm{~mm}$. $\mathrm{h}=2 \mathrm{~mm}$. C. XXXIV 28-31: 30 -38 $\mathrm{mm}$.

Arms XXXVlll $140 \mathrm{~mm}$. The components of the division-series a little thickened in the articulations and therefore the arm-bases are not quite as smooth as in. Sp. 1.

$\mathrm{P}_{\mathrm{II}} \pm 50(16 \mathrm{~T}) 35-\mathrm{t}^{2} \mathrm{~mm}$. $\mathrm{P}_{\mathrm{III}}$ 12 $\mathrm{T}$, 5 to 6 top-segments, as usual, smooth, $30 \mathrm{~mm}^{\circ} \mathrm{P}_{1} 13^{\mathrm{T}}$ (3 top-segments smooth), $\pm 25 \mathrm{~mm}$. $P_{2} 8 \mathrm{~T}, \mathrm{P}_{3} 6 \mathrm{~T} ., 7 \mathrm{~mm} . \mathrm{P}_{4}$ and $\mathrm{P}_{5}$ still a little shorter also with combs. - $P_{6}$ longer without a comb.

Disk $32 \mathrm{~mm}$. Anal funnel $5 \mathrm{~mm}$. Colour as in Sp. 1. Disk, however, spotted with olive-brown. 
Sp. 3. (St. 15) Cd $8 \mathrm{~mm}$., free dorsal pole $5 \mathrm{~mm}$. C. XXXII 23-28, 18-25 mm. Dorsal spines a little stronger than in the preceding specimen.

I $\mathrm{Br} 2 \mathrm{~h}=1 / 3 \mathrm{br}$, the distal angle somewhat prolonged, $\mathrm{br}=6 \mathrm{~mm}$. Arms XXXII $115 \mathrm{~mm}$. The interspaces between II $\mathrm{Br} 3: 2.5 \mathrm{~mm}$. 'The arm-branches somewhat more slender than in the preceding specimens. $P_{I I}+45$ (5 to $14 \mathrm{~T}$, , the tip smooth) 26 - $33 \mathrm{~mm}$. $\mathrm{P}_{\mathrm{III}}$ or $\mathrm{P}_{1}$ $\left.(+10 \mathrm{~T}) 23 \mathrm{~mm}, \mathrm{P}_{2} \mathrm{~S}-9\right) \mathrm{T}, 18 \mathrm{~mm} . \mathrm{P}_{3}-\mathrm{P}_{5}$ with a small, short comb $(3-5 \mathrm{~T}): \mathrm{P}_{6}$ without a comb $18 ; 5,5 \mathrm{~mm}$.

Disk $28 \mathrm{~mm}$. Anal cone $t .5 \mathrm{~mm}$. Colour a little more greybrown than in the foregoing specimens.

One may possibly also assign a young Comasterid (St. IS) to this species.

Sp. 4 ? (St. 18) C. XIII $10-12 ; 2,5-3 \mathrm{~mm}$. $3^{\text {d }}-5^{\text {th }}$ segment longest $\mathrm{L}=1^{1 / 2} \times \mathrm{br}$.

$\mathrm{R}-\mathrm{S} \quad \mathrm{h}=1 / 3 \times \mathrm{br}$. I Br $\mathrm{I} \quad \mathrm{h}=1 / 2 \times$ br: latterally free. I Brax $\mathrm{h}=2 / 3 \times \mathrm{br}$, pentagonal, the distal margins straight. $\mathrm{Br} 1$ inside almost free. Arms X, T mm. $1^{\text {st }}$ syzygy between $\mathrm{Br} 3$ and $t$. The segments distally collar-shaped, spiny, and overlapping.

$\mathrm{P}_{1}$ with an indistinct comb, the tip is smooth, the pinnule rolled. T 7 low, sparse, obtuse. $P_{2}-P_{4}$ to $P_{5}$ are lacking.

Disk $2.3 \mathrm{~mm}$. Mouth and anus subeentral. Anal cone $1 \mathrm{~mm}$. Disk rather »leain», wealis papillated.

A comparison with specimens in Dr MorTensex's collection from Japan showed that it is only the very largest specimens of $C$. pinguis that have the ossicles of the division-series so broad that they grow together laterally. The division-series are, however, always (even when not in lateral contact) strikingly broad and flat. C. japonica, according to the scheme in the Siboga volume, has narrow divisionseries, leaving broad parts of the perisome unprotected. Nerertheless A. H. CLARK says about the original specimen (Leyden Mus. Vol. 33, p. 181) that $>$ the division-series are rather broad». The formation of I Brax seems to be a charac-teristic of species more certain than this one. While $C$. pinguis has an axillary that in old specimens gets almost straight distal margins, these in $C$. japonica are very concave, and therefore the distal angle of the axillary becomes very prolonged (As also in C. solaster). 


\section{Comanthus (Vania) annulata (BELL)}

Fig. $37-+0$.

Syn: See 1918 A. II. Chark Sibogal Exp. Vol. 42 B, p. 53.

From St. $42 \Lambda=1$ specimen.

Sp. 1 Cd flattened, $4 \mathrm{~mm}$. Dorsal pole $3 \mathrm{~mm}$. C. $\mathrm{Xr} 15$; $9-10$ $\mathrm{mm}$. in a single whorl. $1^{\text {st }}$ and $2^{\mathrm{d}}$ segment shorter than long, $3^{\mathrm{d}} \mathrm{seg}$ ment cubical, $4^{\text {th }}$ and the following ones longer, a little hour-ghassshaped, $6^{\text {th }}$ segment the longest, $L=1^{1 / 2} \times$ br. From $7^{\text {th }}$ or $8^{\text {th }}$ segment a weak and indistinet dorsal prominence. The $\mathrm{L}$ of distal segments = $2 / 3 \times$ br. The eirrus in the distal part somewhat pressed together and in lateral view somewhat thickened. The terminal claw short, coarse. a little longer than the penultimate segment. Cirri weak, small.

$\mathrm{R}-\mathrm{s}$ somewhat projecting at the corners. I Br I laterally fused with each other, distally broader, $h=1 / 5 \times$ br. I Brax low pentagonal, $\mathbf{h}={ }^{1} / 3 \times \mathrm{br}$, laterally united as usually also II Br:S 1. Primipostaxillaries fused inside. Bases of the arms smooth. The branches of the arms close together. Syzygies $3+4,11+12,16+17$ ete. with an interval of 4 oblique articulations. $\mathrm{Br} 1-7$ discoidal, then oblique joints. II $\mathrm{Br}-\mathrm{s}: 4(3+4)$, III $\mathrm{Br}-\mathrm{s}:(3+4)$. Arms XL $80-120 \mathrm{~mm}$. dimolphous. Distal segments slightly thickened at the distal ends. $14 \mathrm{Br}$ segments pr. em. (11, if the syzygial pairs are counted as units). The br. of the arms proximally $2,5 \mathrm{~mm}$., distally $1 \mathrm{~mm}$. or less.

$\mathrm{P}_{\mathrm{II}} \pm 50(6-8 \mathrm{~T}) 16-18 \mathrm{~mm}, \mathrm{P}_{\mathrm{III}} 45(5-6 \mathrm{~T}) 12 \mathrm{~mm}, \mathrm{P}_{1} \pm 35$ $(7 \mathrm{~T}) 10 \mathrm{~mm} . \mathrm{P}_{2} \pm 20$ (7 T) $6 \mathrm{~mm}$., sometimes without a comb, $\mathrm{P}_{3}$ with or without a comb. Teeth then on every second or third pinnule to $\mathrm{P}_{11}$. Distal p. $\pm 20 ; 8 \mathrm{~mm}$. ( $1^{\text {st }}$ and $2^{\mathrm{d}}$ segments short, the rest longer than broad, the last 4 to 5 segments with dorsal hooks). The bases of the p. rather smooth.

Disk $20 \mathrm{~mm}$. Anal funnel central. Mouth interradial. Colour (in spirit) grey-brown. 'The shorter, posterior arms coarser, their p. often without ambulacral furrow. 
Comanthus (Vania) parvicirra (J. Möll:ki).

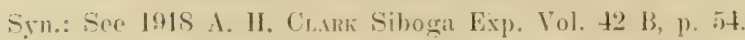

C. parvicirra \& comasteripinna n. subs\}.

Fig. $41-43$.

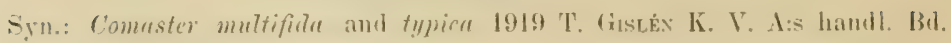
5), N:0 4. p, 14 and 9.

From St. 40 (1), 49) (broken arms), 6:3 (1) = 2 specimens + .

Sp. 1 (St. 40) Cd $3 \mathrm{~mm}$., only sligihly raised above the dorsal surface. C. IX $13-15 ; t-7 \mathrm{~mm}$., in a single, incomplete whorl. $1^{\text {st }}$

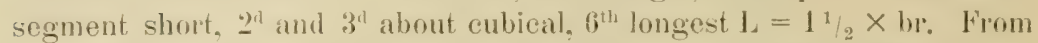
the $7^{\text {th }}$ segment a weak dorsal prominence. Opposing spine $h=1 / 5$ of the br of the segment. 'Teminal claw eured, $I_{\alpha}=1_{1 / 2}^{1} \times$ penultimate segment.

$\mathrm{R}-\mathrm{s} \mathrm{h}=1 / 6$ br. I Br. I $\mathrm{h}=1 / 4 \mathrm{br}$, Jaterally united. I- Brax $\mathrm{h}=1 / 3$ br, laterally free, low pentagonal. Primipostaxillaries united inside. II Br-s 4 (9 cases), 2 (1 case). III I3r-s 4 ( $t$ cases). Arms XXIV 90 mm. Division-series smooth. The basal arm-segments somewhat $\gg$ chubby, then slightly overlapping and with small spines distally. The br. of the arms proximally $1,8 \mathrm{~mm}$. Syzygies $3+4$ (sometimes $4+5$ or still later).. $11+12 \ldots$ etc. with an interval of 4 oblique articulations. $14-15$ segments $p r$ cm. (11. if the syzygial pairs are counted as units).

$$
\mathrm{P}_{\mathrm{II}}+45(9-10 \mathrm{~T}) 12 \mathrm{~mm} . \mathrm{P}_{1} \mathrm{~s}-1 \mathrm{I}^{\prime} \mathrm{T} ; 10 \mathrm{~mm} ; \mathrm{P}_{2} \mathrm{~s}-9 \mathrm{~T}, 20-
$$

25: 5-7 mm. $P_{2}$ or $\mathrm{P}_{3}$ shortest, the latter with 15 segments (8 $-9 \mathrm{~T}$ ) $+-\bar{m} \mathrm{~m}$. Combs on about every second $\mathrm{p}$ to $\mathrm{P}_{2.5}$ or $\mathrm{P}_{30^{\circ}}$. Example $\mathrm{P}_{4} \mathrm{P}_{5} \mathrm{P}_{7} \mathrm{P}_{9} \mathrm{P}_{11} \mathrm{P}_{13} \mathrm{P}_{15} \mathrm{P}_{17}$ ete. Distal combs with about $10 \mathrm{~T}$. Distal p. 22-2s; $10 \mathrm{~mm}$.

Disk $15 \mathrm{~mm}$.. without granules, hemispherieally swollen. Anal funnel central, 3 mm. Colour: dark sepia. Disk in dorsal view somewhat visible between the arms, not reaching farther than to III Brax.

S\%. 49 (Brolien arms) Arms $100-140 \mathrm{~mm}$. The proximal parts of the arms br $=2.2 \mathrm{~mm}$. Syzygies as before 16 (resp 13) segments $111^{\circ} \cdot(\mathrm{m})$

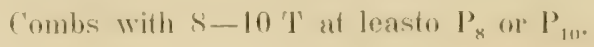




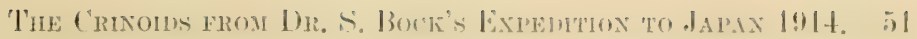

To this species there also belongs rery probably a young specimen from Sagami which shows a great resemblance to larger individuals in Dr Mortexsex's collection from the same locality referable to C. parvicira. Description as follows:

Sp. 2 (St. 63) Cil $1.9 \mathrm{~mm}$. free dolsal part 1.6 $\mathrm{mm}$. C. lacking. Pits of XVII in a single whorl.

R-s narow, at the middle almost coneealed bands. I Br. I h $=$ $1_{1 / 3}$ br, laterally free. I Brax $h-{ }_{1 / 2} \times b_{r}$, pentagonal, br $-1,3 \mathrm{~mm}$. Disk visible in the interspaces (br $-0,5 \mathrm{~mm}$.) between the arms. II Br-s:t (t cases). Arms XII $20 \mathrm{~mm}$. P'rimipostaxillaries united inside basally. II Br. $1 \mathrm{~h}=1 / 5 \mathrm{br}$. II Br. 2 and Br.2 distally and dorsolaterally broader. Syzygies $3+4 \ldots 10+11$ ete. with an interval of 3 to + oblique articulations. Arm-segments after Br 4 distally bent ontwards and a little small-spiny 20 (resp. 16) segments prem.

$P_{1}$ with $S-10$ large 'T., tip not smooth. $P_{2}$ similar', somewhat shorter, 3 mm., $P_{3} 12$, 3 mm., basally a little swollen (by a gonad? Basal pinnulars weakly carinate. Distal p 12-14, 3,5 m. coarse, short segments, distally dorsal hooks (cf. fig.)

Disk $5 \mathrm{~mm}$. Anus central. Colour yellow-brown. The last mentioned specimen most probably referable to the $3^{\text {U }}$ subspecies $(\gamma$. vanipinna represented in Dr. Mortexses's collection from Sagami; otherwise (f. p. 52).

Comanthus (Vania) parvicirra $\beta$ comanthipinna 11. subsp.

lig. 44,45 .

from st. $40 \ldots 1$ specimen.

Sp. 1 Cd $3 \mathrm{~mm}$. C. VIl 13-14; $8-9 \mathrm{~mm}$. coarser and more curved than in the preceding sub-species.

B--s projecting IR. II Br-s:t (t cases), 2 (6 cases), III Br--s: + (2 eases). Arms XXII 105 mm.. most of them loose, broken. Syzygies with an interval of + oblique articulations. 12-13 segments pre $\mathrm{em}$ (10, if the syzygial pairs are counted as units). Breatlh of the arms $2,3 \mathrm{~mm}$.

$\mathrm{P}_{\mathrm{TT}}+-40$ 183 mm. with a comb as in typical Comenthus-Cenolucspecies, that is in this case 12 low, thin teeth which om both sides 
(proximally and distally on the pinnule) obliterate. The tip of the p. with 2 or 3 smooth segments. $P_{1} \pm 12 \mathrm{~mm} . P_{2} 5,5 \mathrm{~mm} . P_{3}$ and the following ones without a comb. Distal p. $27 ; 11 \mathrm{~mm}$. The segments: $\mathrm{L}=1^{1 / 2} \times \mathrm{br}$, the 4 outermost ones with distal hooks.

Disk thrown off. The pinnules of some arms without ambulacral furrows.

Both these newly proposed sub-species of the polyform C.parvicirra differ in many characteristics from each other. Thus for instance $\beta$ has coarser arm-bases and somewhat fewer Br-segments $\mathrm{pr} \mathrm{cm}$. but it is chiefly the different appearance of the comb that has caused me to separate these two types and to denote them by different names.

Within the sub-fam. Comasterince of the fam. Comasteride one can distinguish chiefly 3 different types of combs. The first of these, which I should like to call the Comaster-type, is characterized by a short, strongly rolled comb, with some few, large and close teeth. The combs occur on every second or third p. to rather far out on the arm. The second, the Comanthus-type, has combs with a greater number of teeth, which are small and low, and therefore thinly placed. They become smaller proximally and distally and obliterate towards the tip of the pinnule, leaving the latter smooth. 'The combs occur on at very few proximal pinnules (never farther than $P_{6}$ ) and in an unbroken series, that is never on every second or third $p$. as in type 1 . The $3^{d}$ type - to a certain extent an intermediate one - is the Vania-type, which has rather high and large teeth right out to the tip of the pinnule. Combs occur as in type 2 in an unbroken series.

Both the first-mentioned types are usually very regularly associated with certain genera within the above-mentioned sub-family Comasterince. Type 1 is found in the genus Comaster, type 2 is, as far as I have been able to verify, characteristic of the genera Comantheria, Comanthina (?), and Comanthus (Cenolia). In the genus Comanthus (Vania) the use of this characteristic, like so very many others, becomes, however, impossible in the diagnosis. 'T'o Comanthus-Vania are assigned two species distinguished from each other by such an artificial character as the number of arms. The facts of the matter are undoubtedly, however, that Comanthus (Vania) ammlata represents one group of forms 
The Chinoms from Dr. S. Bock's Expentrion to Jalan 1914. $5 \%$

with a generally greater number of arms which are longer and coarser, C. (Vania) parvicirra another one with a smaller number of more slender arms. Nevertheless, both the »species» vary so considerably that they often intrude upon each other's spheres.

The specimens obtained by the Bockian expedition, show that within the subgenus Vania there occur types of combs of both the Comaster-, Comanthus- and fof this I have been convineed by observations on Di. Mortensex's Japanese specimens of this species) of the Vania type too. In revising the Bockian collection I have distinguished type 1 and 2 in $C$. (Vania) parvicirra by ranging them in two different sub-species. I have been neither able nor' willing to discuss the innumerable synonyms of this species - A. 11. CLARK has given an imposing synonym list in Siboga Exp. Vol. 42 B. It is not possible to distribute the names of this list among the 2 new sub-species because most of the authors have given no information about the occurrence and appearance of the combs. Even A. H. CuARK, who has described hundreds of specimens belonging to this species, has hardly given any other information except about cirri and division-series. It is therefore natural that he has escaped making the observation that a comb of the Comaster-type also occurs in the sub-genus Vania. Already in my work upon the crinoids of Dr IJöвERG's expedition I recorded the statement of P. H. CARPEnTER about the occurrence of the Comastertype in 3 of the species referred by A. H. CLaRK to the parvicirragroup, viz. Actinometra elongata, simplex and quadrata. All the Mjöbergian specimens, however, had 4 components in the II Br-series and the Comaster-type in respect of the distribution of pinmules, and consequently, trusting to the Clarkian genus-diagnosis, I referred the abovementioned species, most suitably referable to Vania parvicira, to the genus Comaster and assigned the specimens with coarser cirri to $C$. multifida and those with rudimentary cirri to C. typicu. Since then I have had an opportunity to establish that the occurrence of combs far out on the arms is not exclusive to the genus Comaster but is also found in the genus Comanthus subgenus Vania.

It is not curious that both these species of the subgenus. Vaniu have caused great trouble to all authors by their extreme variability in practically all distinguishing characteristics otherwise succesfully used. Not only are cirri and cirrals, division-series and Bl-segments 
very variable in appearance and number; to this is added, as mentioned above, the varying development and distribution of the pinnulecombs. In Vania ammlatu the combs in the above-described speeimen reached as far as $P_{11}$. In a specimen from Java of the same formseries istill not described; possibly, however, belonging to a new species on account of the rery long. slender and well-separated arms) the combs occurr on every second pinnule and reached at least $P_{35}$. As to Vaniu parvicira I refer to the deseriptions given above.

1. H. Clark in a letter to me writes about both these species as follows: »The species of Comasterince are the most difficult of all Crinoids - I may even say of all the lichinoderms - to determine. The two species which I call parvicirra and amnulutu are very likely arbitrary divisions of one type; but it is convenient to call the smaller individual with 30 or fewer arms parvicirra and the larger with 30 70 arms $^{1}$ ammlatu. Many specimens of the latter with the III $\mathrm{Br}$ series 2 are practically indistinguishable from certain species of Comantherict. .»

Aceording to this division Comaster typice Sp. 2 Mihi 1919 would be assigned to Vanic ammlata. Nevertheless it corresponds closely with the other specimens in the Mjubergian collection and has also unusually short arms and therefore I should be disposed to include it in Vania parviciria.

As to the reason of the polyformity of this subgenus I will only point to the following:

It is possible that the two species of Vanich have become a rubbish heap for diver's species difficult of solution or types inconvenient for the systematist. In such a case it would be prossible to put order into the now confusing multitude and to get a survey over the existing types by a detailed description of specimens. ('haracteristies that might perhaps be applied would be the number, presence or absence of cirri, the br of the arm-bases. the appearance and formation of the Br--segments, of the division series, of the proximal (and also (listal) pinnules and pinnulars, of the disk and eventually of caleareous spicules, that is to say the inclusion of all characteristies and then an examination of a large material. 
Further it may be that these possibly existing small species party make hybrids between themselves and perhaps partly atso form crossings with proximal speries in the genera Comaster. Comantheria and Comanthus. If these hybrids are fertile they will after a couple of generations be split into countless different types. Supposing. for instance, that a form without cirri, with III and IV BP-s: t, and with a Comanthus-comb (restrieted to proximal pinnules) were crossed with a form with cirri. with III and II BR-S:20, and with Comaster-comb (that is short, high combs dispersed to distal pinnules). Further. supposing that such a hybrid were fertile and therefore in the generation was normally split in the different possibilities of combination. Then one would get forms that might be referred to all the genera known within the sub-fam. Comasterine. (If, e. g., the first : gens as heterozygotic might be represented with different forms: rudimen. tary cirri, mixture of 2 and + eomponents in the III and IV divisionseries, one would get $10 \mathrm{~s}$ different possibilities). The great variability in the division-series even in the same specimen seems to be a proof of the probability of the heterozygotical nature of certain specimens of C. parvicirra.

In a special paper 1 will treat a $3^{\prime \prime}$ possible influencing eause, viz. alteration in the mode of eatching food.

Though in many cases the Comasterids show primitive characeristics such as elumsy formation, frequently (in the genus Comaster) a primitive way of arm-division, a number of components in the division-series that is rery indefinite, it is evident that in other characteristics the family is in fast development and has entered quite a speeifie direction of evolution. A lot of the characteristies which are engaged in such a development have this apparently caused by the changed manner of eatching food and are treated in connection with this question.

'The variability of the cirri is probably caused by another' factor and their regression, which is observable in different species of the Comasterid family, I suppose to be caused by the dorsal hooks on the distal pinnules having taken over the anchoring function that otherwise falls upon the cirri. These dorsal hooks are to be found in most of the Comatulits, though usually visible only by strong magni- 
fication. In the Comasterids they are large and well developed, they appear smallest in species with powerful cirri as in Comanthus pinguis. Everyone who has worked somewhat with species of this genera. knows that for instance a Comaster or Vania parvicirra has a strong power of attaching itself by means of the dorsal hooks of the distal pinnules. Consequently the cirri will become superflous or perhaps even be a hindrance if the animal wishes to creep about, which by the observations of H. L. CLARK is proved to be the manner of locomotion of some Comasterids. Because of this they become reduced and in many genera they have totally obliterated (as in species of Capillaster, Comatula, Comaster, Comantheria, Comanthina and Vania).

As appears from the above investigation the subgenus Vania is a very critical genus, forming to a certain extent a middle link between Comantheria-Comanthus and Comaster. The reason why I have not united all these genera is that I perceive the possibility of Vrmia representing a rallying group of hybrids and hybrid-splittings with combinations of characteristics from different form-eireles. I should have liked to put Vanic as a separate genus between Comaster and Comantheria-Comanthus. In this case I would have distinguished it from the the first-mentioned genus by the III $\mathrm{Br}-\mathrm{S}$ chiefly consisting of $4 \mathrm{com}-$ ponents, from the two latter ones by comb-provided pinnules often occurring far out on the arms. Nevertheless the characterizing in such a case is not satisfactory, if one does not transfer all the Vanias of comanthipinna-type to the genus Comanthus (Cenolia). Perhaps therefore, it is for the present quite as good to keep the classification made by A. H. CLarK and put Vania as a sub-genus under Comanthus. Still it is then to be observed that, according to his scheme of examination, $V$. parcicire a comasteripinna ought to be referred to Comanthus if one pays attention to the division-series, to Comaster if one takes into consideration the oceurrence of the combs. Compare also in this connection the above quoted statement of A. H. CLark. Another solution, and this a rather good one, might be possible. This would be to subdivide Comasterince into 2 genera: Comaster and Comanthus, the first one characterized by comb-provided pinnules occuring distally on every second or third pinnule, the latter one with combprovided pinnules in an unbroken series. With such a division the 


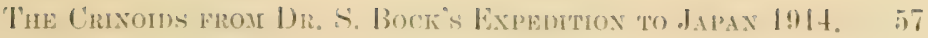

two types would also be easy to keep apart if it were a question of systematically proximal forms, for, its is shown above, such forms are to be found. no matter how the division is made. On the same specimens the combs seldom or never vary in occurence on different arms and so to this extent they offer a better distinguishing feature than the division-series. The sub-division proposed above is still, however. impossible to carry out becanse of the incompleteness of the preceding species-deseriptions in the statements as to the appearance and oecurence of combs. So much, however, can be said, that to the first mentioned genus might be referred the genus Comaster sensu A. II. CLARk, Vamil (pro parte) and eventually Comanthine fand Comantheriu) pro parte. To Comunthus sensu nova should be referred Comuntherie, Comanthina (p.p.), Comanthes (Cenolie) and Vonia p.p.

Young, Comasterids from the Bonin Islands:

From St. $4+(1), 45(15), 47(6), 50$ (1), 53 (1), $5+(1)$, $61(1)=26$ specimens.

Comatella sp.

Sp. 1 (St. 53) C. XI $8-9 ; 2-2,5 \mathrm{~mm}$. 33 segment $\mathrm{L}=\underline{2}{ }^{1 / 2} \times$ bl. T'erminal claw curved, longer than the penultimate segment.

$B-s$ projecting between the $R-s$ as small corners. $R--s$ narlow bands. I $\mathrm{Br} \perp \mathrm{h}-1 / 3 \times$ br. Arms $\mathrm{X}$, $\pm 15 \mathrm{~mm}$. Syzygies with an interval of 3 oblique articulations. The segments somewhat folded outwards and spiny.

$P_{1}$ with a comb of $5-6$ T. $P_{2}$ and $P_{3}$ absent.

Disk smooth, dark-brown, Mouth central. Anal funnel small. not papillated.

Comatella sp. juv. or the young forms of a large Comissia sp.

Sp. 1 (Si. 45$)$ C. XIX $14-16 ; 6-8 \mathrm{~mm}$. $4^{\text {th }}$ segment the longest, $\mathrm{L}=21 / 2 \times$ br. Dorsal spine from the $t^{\mathrm{th}}$ segment. - R-s narrow bands. I Br I h-1/4 br. laterally free. Axillary $\mathrm{h}-1 / 2 \times$ br, forms with the preceding segment a low synurtrial tuberele. B1 22 on the outer side Nova Acta keg. Soc. Sc. Ups., Ser. 4, Vol, 5. X:o 6. Impr. ${ }^{2 y / 2}$ 192.2. 
twice as broad. Arms $\mathrm{X}, 45 \mathrm{~mm}$. Syzygies with an interval of 3 oblique articulations. Distal segments $\mathrm{L}=1^{1 / 2} \mathrm{X}$ br, weakly spiny, but not bent outwards. - $P_{1}$ and $P_{2}$ with a comb; $P_{3}$ usually, $P_{4}$ always absent. $P_{1} 25-30(10 \mathrm{~T}), 5,5 \mathrm{~mm}$. strongly rolled at the tip. - Mouth subcentral. Anal cone, small, marginal. Disk $4 \mathrm{~mm}$.

Probably a young form of Comissia peregrina magnifiea like both the following ones.

Sp. 2 (St, t5) C. YIII 12-1t: $4-5 \mathrm{~mm}$. $3^{\text {th }}$ and $t^{\text {th }}$ segment $\mathrm{L}=2 \times$ br. Arms $\mathrm{X}, 25 \mathrm{~mm} . \mathrm{P}_{1}$ and $\mathrm{P}_{2}$ with a comb. $\mathrm{P}_{4}$ and usually $\mathrm{P}_{3}$ absent. $\mathrm{P}_{1}$ with $9 \mathrm{~T}$. Nouth central. Disk $2,5 \mathrm{~mm}$.

Sp. 3 (St. t5) C. XII 10-11; 2, mm. Arms X, $15 \mathrm{~mm}, P_{1}$ with a comb, then a gap to $\mathrm{Br} 11$ or 13 . Nouth central. Disk $2,5 \mathrm{~mm}$.

Sp). 4 (St. 47) C. XVII 12-15; 6-7 mm. $3^{\text {th }}$ and $4^{\text {th }}$ segment $\mathrm{L}=\mathrm{I}^{1 / 2}-\stackrel{2}{\mathrm{2}} \times \mathrm{bl}$

I Br $1 \mathrm{~h}=1,3 \mathrm{br}$, laterally free. Axillary $\mathrm{h}={ }^{2} / 3 \mathrm{br}$, pentagonal. $\mathrm{Br}, \mathrm{h}=1 / 4 \mathrm{br}, \mathrm{Br}^{\circ} 2 \mathrm{~h}=1 / 3 \mathrm{br}$. Arms $\mathrm{I}, 30 \mathrm{~mm}$. Arm-bases smooth. Syzygies as in Sp. 1 (St. to). $P_{1}-P_{3}$ with a comb $\left(P_{1} \pm 15\right.$ T.. $P_{3}$ S-11 T), $P_{4}$ lacking. Distal p. 12-14; 3,5 mm. Strong dorsal hooks on the 3 last segments. Disk smooth, dark-brown, 3,5 mm. Mouth subcentral. Anal funnel short. (Disk half thrown off, under this a new regenerated one).

Sp. 5 (St. 47) C. XI 8-9); 2 mm. $3^{4}$ segment the longest $L=$ $3 \times \mathrm{br}$. - I Br $1 \mathrm{~h}={ }^{1 / 4} \mathrm{br}$. Axillary triangular with very concave distal matgius forming an acuie distale angle, $h=1 / 2 \mathrm{br}$. Br-segments spiny and bent outwards. Arms X, $10 \mathrm{~mm}$. $\mathrm{P}_{1} 7 \mathrm{~T}, 2,5 \mathrm{~mm}$. $\mathrm{P}_{2}$ absent. $\mathrm{P}_{3}$ without a comb.

Sp. 4 and 5 perhaps young Comatella maculate (or slelligera).

Sp. 6 (St. 61) C. XV 9-12; 2- 3,5 mm. - R $-\mathrm{s} \mathrm{h-1/4br.} \mathrm{I}$ $\mathrm{Br} 1 \mathrm{~h}=1 / 3$ br. Axillary $\mathrm{h}=1 / 2 \mathrm{br}$. Syzygies as in Sp. 1 (St. 45 ). Arms X, $20 \mathrm{~mm}-\mathrm{P}_{1}$ with 9 sparse ' $\mathrm{T}$. $\mathrm{P}_{2}-\mathrm{P}_{4}$ lacking. Mouth central. Disk $2 \mathrm{~mm}$., dark-brown, pentagonal. Anal funnel small.

Young Comaster serrata, the two last ones probably C. delicata grandis. Sp. 1. (St. 45) C. XIV 9; 2 mm. R-s h=1/4 br. I Br $1 \mathrm{~h}$ $1 / 3$ br. Arms X, $10 \mathrm{~mm}$. Br-segments strongly sermate and bent outwards. $P_{1}$ (and $P_{2}$ if not absent) with a short high comb; $P_{3}$ and $P_{4}$ lacking. Nouth eentral. For the rest like Sp. 3 of Comaster serrata. 


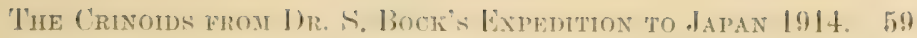
$2{ }^{1 / 2} \times \mathrm{br}^{2}$

Sp. 2 (St. 47 ) C. XIII $9 ; 2.5-3 \mathrm{~mm} .3^{\text {d }}$ and $4^{\text {th }}$ segments $\mathrm{L}=$

Arms $\mathrm{X}, 1520 \mathrm{~mm}$. The arm-bases rather serrate. Between $\mathrm{Br} 1$ and 2 a close synarthy. Syzygies with an interval of 3 oblique articulations. $P_{1}$ (and $P_{2}$, when present) with a short, high comb of $4-5 \mathrm{~T} . \mathrm{P}_{3}$ lacking. No distal pinnules with combs

Mouth central. Disk $1,2 \mathrm{~mm}$. Anal funnel short, wart-shaped; the anal interradius with calcareous plates in the slin, but no papillae. Sp. B (St. $4 t$ ) C. XIll $9-10: 3-4 \mathrm{~mm}$. $3^{\mathrm{a}}-5^{\mathrm{th}}$ segments $\mathrm{L}_{2}=$ $2 \times \mathrm{br} .-\mathrm{R}-\mathrm{s} \mathrm{h}=1 / 7 \mathrm{br}$. I $\mathrm{Br} \cdot \mathrm{I} h=1 / 3 \mathrm{br}$, laterally free, articulafing closely with the axillary, which is pentagonal $h=-2 / 3$ br. Br 1 basally united inside. Syzygies as in S\%. 2 (St. 47) Arms X, 22 mm. Brsegments rather long, distally somewhat bent outwards and spiny. Proximal parts of the arms well separated. Disk reaching to Br 2.

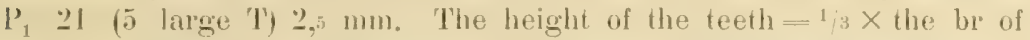
pinnular: $P_{2}, P_{3}$ and sometimes $P_{4}$ absent. Pinmulars very spiny. Distal p. $14: 3 \mathrm{~mm}$. (The $3^{4}$ and following segments $\mathrm{L}=t \times \mathrm{br}$ ). No combs on the distal $p$.

Disk 3 mm. Anal cone subeentral, swollen, papillated.

Young forms of Comantheria (doublut whether sp. 2 belongs to this genus).

Sp. 1. (St. t5) C. XIV 11-17:-3-6.5 mm. $4^{\text {th }}$ segment the longest. $L=1^{1 / 3}-1^{1 / 2} \times$ br. From the $7^{\text {th }}$ segment a dorsal prominence fixed a little before the distal margin. Opposing spine $h=1 / 3$ of the br of the segment, courser and more pointed than the preceding ones. Cirri from the dorsal whor considerably more tender.

$\mathrm{R}-\mathrm{S} \mathrm{h}-{ }^{1 / 7} \mathrm{bl}$. I $\mathrm{Br} / \mathrm{h}-{ }^{1 / 3} \mathrm{br}$, laterally free, a weak synarthrial tubercle with the axillary, which has the $\mathrm{h}=1 / 2 \mathrm{br}$, with somewhat concave distal margins. Syzygies $3+4,11+12,16+17$ etc. with an interval of + oblique arliculations. Br:s 1 united inside to ${ }^{2} / 3$. Arms $\mathrm{X}$, broken, $15 \mathrm{~mm}$. +. The arm-bases tolerably smooth, after 13. 7 with the distal margins a little bent outwards and spiny. Breadth of the arms proximally $0,6-0,8 \mathrm{~mm}$.

$P_{1} 27$ (!)-11 rather low, triangular T, h $\ldots{ }^{3} / 4$ of the segment) $5,5 \mathrm{~mm}, \mathrm{P}_{2} 6 \mathrm{~T} ; 3 \mathrm{~mm}, \mathrm{P}_{3}$ rudimentary, $\mathrm{P}_{4}$ without a comb $11 ; 1,5 \mathrm{~mm}$. 
Disli $t$ mm. Anal tube chimney-shaped, $1.5 \mathrm{~mm}$., subcentral The skin smooth, without papillae. Nouth somewhat marginally displaced.

Sp. 2 (St. 45) C. XIX 9-12: 2-t,5 mm. - B-s visible in the corners. $\mathrm{R}-\mathrm{s} \mathrm{h}={ }^{1 / 5} \mathrm{br} . \quad$ I $\mathrm{Br} 1 \mathrm{~h}-{ }^{1 / 2} \mathrm{br}$. Arms $\mathrm{X}$, $25 \mathrm{~mm}$, 'The distal borders of the axillaries spiny and bent outwards. Syzygies $3+t, 11+12$, distally with an interval of usually $;$ oblique articulations. Distal Br-segments $\mathrm{L}=\underline{2} \times \mathrm{l}$ )r, strongly hour-glass-shaped and spiny.

$P_{1} \pm 20$ (about 5 coal'se 'T) $3 \mathrm{~mm}^{3}, \mathrm{P}_{2}$ absent, $\mathrm{P}_{3}$ without a comb $7 ; 1,5 \mathrm{~mm}$. Distal p. + : 2,2 $\mathrm{mm}$. - Disk $2,5 \mathrm{~mm}$. Anal funnel $1 \mathrm{~mm}$. Mouth somewhat dislocated.

\section{A young form of Vania.}

sp. 1 (St. 50) C. XII 9: 2-3 mm. slender, in a single whorl $t^{\text {th }}$ segment the longest $\mathrm{L}=2 \times \mathrm{br}$. Cd low; flattened. $-\mathrm{R}-\mathrm{s}$ narrow bands $\mathrm{h}=1 / 5$ br. I Br $1 \mathrm{~h}=1 / 2 \mathrm{br}$, laterally free. Axillary $\mathrm{h}-2 / 3 \mathrm{br}$, pentagonal. Primipostaxillaries well separated inside. The synarthry between $\mathrm{Br}^{\circ} 1$ and 2 usually rather similar to the syzygy between $\mathrm{Bl}^{\circ}$ 3 and 4 . Br 1 and $2 \mathrm{~h}=1 / 3$ br, the outside somewhat broader. Arms $\mathrm{I}, 12 \mathrm{~mm}$. Br-segments serrate, only slightly overlapping. Syzygies with an interval of 3 oblique articulations, $-P_{1} \pm 6 \mathrm{~T}, \mathrm{P}_{2}$ and $\mathrm{P}_{3}$ rudimentary or lacking. The following pinnules without a comb. Distal P. 2.5 $\mathrm{mm}$. - Disk 2,5 mm., reaching to Br 1. Anal cone smooth, $1,2 \mathrm{~mm}$., sharply set off with a papilla whorl round the opening. Mouth marginally displaced. Colour yellow-brown.

\section{Unrecognisable Comasterid young forms.}

Sp. I (St 47) C. XVIII 12-17 (usually 15-17), $t-8 \mathrm{~mm}$. Opposing spine a little longer than the preceding ones. - Axillary $\mathrm{h}=1 / 2$ br. II Br-s in a regenelate 2 (2 cases). Arms XIl, 30 mm. Syzygies with an interval of 3 or 4 oblique articulations. $-\mathrm{P}_{1}-\mathrm{P}_{4}$ with a

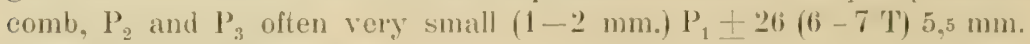
Distal p, $12-1: 3 ; 4,5 \mathrm{~mm}$.

Disk $3,5 \mathrm{~mm}$. Anal tube papillated, subcentral, narow, 22 mm. sharply set off from the disk. Mouth marginal. 


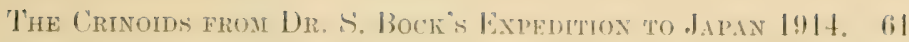

Differs by the formation of the disk from the above-deseribed Comutellas.

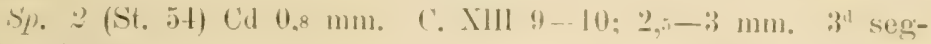
ment $\mathrm{L}=2{ }^{1}+\mathrm{i}+\mathrm{bl}$.

$R \rightarrow s$ h $\ldots 1 / 4$ bre partly concealed by the angular Cd. I Br I $\mathbf{h}={ }^{1} / 2$ br. Axillary $\mathbf{h}-2 / 3$ br. Distal margins somewhat concave. Arms $\mathrm{X}, 15 \mathrm{~mm} . \mathrm{Br} \mathrm{l} \mathrm{h}={ }^{1} / 2 \mathrm{br}$, contigueus in pairs inside, not broader on the outside. Br $20 \mathrm{~h}-{ }^{1} / 2 \mathrm{br}$, a litfle bronder on the outside. Syzygies usually 1-2, $3+4$; Distally with an interval of 3 oblique articulations. Br-segments long, serrate and bent outwards. $-P_{1}$ with 8 heart-shaped T. $P_{2}$ and $P_{3}$ wanting. Distal P. 3) mm. - Disk 2,2 mm. Anal funnel $1 \mathrm{~mm}$. I $R$ calcareous plates.

Sp. 3 (St. 47) C XI 8-9: 2,5-3 mu. - R-s h . ${ }^{1} / 4$ br. I Br I $h=1 / 2$ br. Axillary $h={ }^{2} / 3$ br. Arms Xl. Il Br-s $t(1$ case $)$. The segments very serrate.

$\mathrm{P}_{1}$ with t-5'T'. $\mathrm{P}_{2}$ missing - Disk coarsely granulated with calcareous grains and plates. Small oral plates. Probably a $\mathrm{Co}_{0}$ muster.

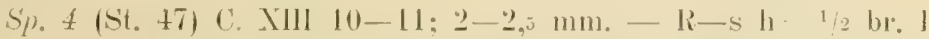
$\mathrm{Br} 1 \mathrm{~h}={ }^{2} / 3 \mathrm{br}$. The arm-bases serrate. Arms $\mathrm{X},+10 \mathrm{~mm}-\mathrm{P}_{1}$ with some few T' (probably 5 to (i) rolled to a close globe. $P_{2}-P_{4}$ wanting. - Mouth central. Disk $1,3 \mathrm{~mm}$. Orals!

From St. 45 there are, besides, o small young Comasterids. Some of these specimens apparently belong to the sub-family Comasterince (Comaster and Comantheria), but some of the others are practically impossible to determine either with regard to subfamily or to genus.

Sp. 5 (St. 45) C. XIV, 9, strongly bent. Arms XII. $15 \mathrm{~mm}$. II Br-s 4. III Br-s 2. $P_{1}$ and $P_{2}$ and perhaps $P_{3}$ with a short comb. Mouth central. Anal cone smooth (a Comuntheric or Comaster).

Sp. 6 (St. 45) C. XII $8-9 ; \pm 2 \mathrm{~mm}$. $4^{\text {th }}$. segment the longest $\mathrm{L}=3 \times \mathrm{br} . \quad 5^{\text {th }}$ and $6^{\text {th }}$ segment $\mathrm{L}=2 \times \mathrm{br}$. Antepenultimate one $\mathrm{L}=$ $\mathrm{I}^{1} / 2-2 \times \mathrm{br} .-\mathrm{R}-\mathrm{s}$ band-shaped, $\mathrm{h}=1 / 4 \mathrm{br} .1 \mathrm{Br} 1 \mathrm{~h}=1 / 3 \mathrm{br}$, laterally free. Il Br-s:t. Arms XII, $14 \mathrm{~mm}$. - $P_{1}$ with if high T', 3 mm. P. and $P_{3}$ usually absent. $P_{a}$ with $+T$. No distal combs on the distal pinnules. - Mouth and anus subeentrat. Disk 22 mm. Anat fumnel papillated. - (Probably as sp. 7 a Comuster). 
Sp. 7 (St, 45) C. XII 9-10; 2,5-4 mm. Arms X, $20 \mathrm{~mm}$. somewhat smoother than in the preceding sp. - $\mathrm{P}_{1} 7 \mathrm{~T}, \mathrm{P}_{\mathrm{a}} 6 \mathrm{~T}, \mathrm{P}_{2}$ and $P_{3}$ wanting. - Mouth a hittle displaced. Anal cone strongly papillose.

S\%. 8 (St. 45 ) C. XIV $8-11 ; 2,5-4 \mathrm{~mm}$. Arms XII, $16 \mathrm{~mm}$. II Br-s 2. - $\mathrm{P}_{1} T \mathrm{~T}, \mathrm{P}_{2}$ and $\mathrm{P}_{3}$ missing. Anal cone papillated.

$5 \%$ 9. (St. t5) ( . XVII 10-14:3-4, $\mathrm{mm}$. $3^{d}$ and $t^{\text {th }}$ segment. $\mathrm{L}=\underline{2}$ br. Arms $\mathrm{X}, 15 \mathrm{~mm}$. of serrate type. $\mathrm{P}_{1} 5$ high $\mathrm{T}, \mathrm{P}_{2}$ and $\mathrm{P}_{3}$ absent.

SP. 10 (St. 45) C. IX 7-9); 2-2.5 mm. Arms X, $12 \mathrm{~mm},-\mathrm{P}_{1} \pm$ 6 T. $P_{2}$ and $P_{3}$ wanting. Nouth central.

S1\% 11 (St. 45) C. XVI 10. Arms X, $10 \mathrm{~mm}, \mathrm{P}_{2}-\mathrm{P}_{4}$ wanting.

Sp. 12 (St. 45 ) C. XVII 8-9. Arms X, +15 mm. P 9 T'. Pa mis$\operatorname{sing}, \mathrm{P}_{3}$ without a comb. - Anal lube smooth. - Perhaps Commissia ignota minuta.

Sp. 13 (St. 45) C. XIII 9-10; 3 mm. Arms X, broken. R-s concealed. $-P_{1} \pm 6 \mathrm{~T}, \mathrm{P}_{2}$ rudimentary.

Above I have brought together all the young Comasterids from the Bonin Island that I have not been able without doubt to identify to a certain species. With regard to some specimens, however, I am rather sure as to which species they belong by comparison with somewhat larger, systematically determinable specimens from the same locality. (This is for instance true of Comaster servala sp. juv 1).

At the same time as the investigation made above I also tried to establish some characteristics of systematical value for the determination of the young Comasterids. Even a hasty reflection tells us at once that this is a very difficult task. For the systematical characteristics in the Comasterids, as in all Comatulids, are taken from the length, breadth, appearance and order of magnitude of the calcareous ossicles which combine to constitute the animal, and these are very different in young specimens and in full-grown ones. - If guided by the figures and statements given above one examines the characters, the following facts are evident.

1) The cirri in all young forms correspond to a type about the same as the one in Comaster servatu or Comatella brachycirra, that is to a number of segments of +10 . where the $3^{\text {th }}$ and $f^{\text {th }}$ segments are the longest, $L=2$ or $: 3 \times$ br: 


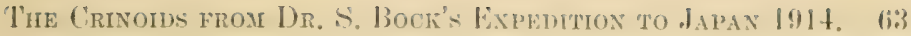

2) The higher division-series, which are an important characteristic of elassitication, have not yet appeared.

3) The proximal ossicles of the arm become longer compared with the breadth, the younger the animal is. This is also applicable to a still greater extent to the distal-Br-segments. 'The distal ends of the Br-segments are serrate and bent outwards.

4) The comb on the proximal pinnules, a very reliable characteristic in adolescent and full-grown specimens, tends at an enrly stage to a uniform type and therefore all small young forms have combs with a few, high, rather large teeth. The young forms of the Comaster-genus only have combs on the proximal pinnules.

j) In the very earliest stages the disk has a central mouth and a marginal anal tube.

As a general mule one can say that young Comasterids which have a pinnule-gatp on the proximal arm-parts (here of course excluding Comasterids of the Comatilia type) are impossible to determine even with folerable certainty.

The comparison between the appeal'ance of the disk shows. however, that here perhaps, one might get certain fixed points for the judgement of the systematical position of the animal.

The young of the species of Comatellu and large Comissic have a central or subcentral mouth and a short, narrow, inconspicuous anal tube. The skin is tightly stretched on the ventral side between the arms so that the disk gets a characteristically lean appearance.

The young forms of Comissia ignola minutu are also in the early stages recognized by having the ambulactal furrows surrounded with cushion-shaped slopes, probably marking the extension of the gonads on the disk, and this condition together with the eharacteristic proximal Br-ossicles (already at an early stage very short), the coarse pinnule-bases, soon thickened by the genital glands, and the smooth proximal arm-parts make them fairly easy to distinguish from young forms of other species in the collection.

The young forms of Comaster and Comantheria in the early stages also have a pat» (swollen) disk. The anal tube is large, thick and coarse, a little swollen, often (especially in Comuster delicutu granais) strongly papillated or plated. In Comaster - species the lengthgrowth of the anal tube soon censes, and in larger individuals the tube 
gets a characteristic wart-shaped appenrance. while in Comanherin it continues to lengthen to a long, large chimney. In smaller young forms the mouth is central, but except in Comaster serrata it is soon dislocated marginally.

The young of Vumic has, if my determination is correct. a rather long unswollen anal cone, and a tolerably »lean» disk.

Naturally the fixed points obtainable by an examination of the disk, are only to be used together with the other characteristies which are found. If, howerer, in the comparison and systematizing of the Comasterid youngs one takes into consideration the appearance and formation of the disk, I believe that we will be able to predict with greater probability than otherwise to which species or genus the young Comasterid in question might be referred.

\section{Zygometridæ A. H. CLARK.}

\section{Catoptometra A. II. Ci.LKK. \\ C. Hartlaubi $A$ II. Cr.ım.}

Fig. 48-51. p. 72 :

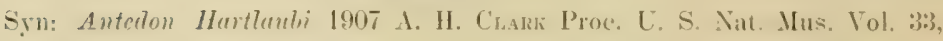

Zygometru Kochleri 1907 A. II. Clark Smiths. Misc. Coll. Vol. 50, p. 339!;

Catoptometru Hartlauli 1908 A. II. C'sakk Proc. U. S. Nat. Mlus. Vol. 34, p. 317; 1912 Crin Ind. Ocean, p. 106; 1915 Monograph pp.; Journ. Acat. Sci. Vol. 5, p. 214; 1918 Siloga Exp. Vol. 42 13, p. 63.

From St. $5=1$ specimen.

Sp. I Cd. large, flattened, a little deepened in the centre, with calcareous granules which towards the margin are arranged in about 10 rays. Diameter $5 \mathrm{~mm}$. free dorsal pole $3,5 \mathrm{~mm} . \mathrm{h}=0,8 \mathrm{~mm}$.

C. XXVIII 14-15 (D) 16-17 (V). 11-17 mm, in two close, alternating whorls, $2^{\mathrm{d}}$ segment cubical, $3^{\mathrm{a}}$ a little longer, slightly hour-glassshaped $\left(=\right.$ most of the following eirrals), $5^{\text {th }}-7^{\text {th }}$ segment $\mathrm{L}=2 \mathrm{br}$ : then shorter again $\mathrm{L}=1 \frac{1}{2}-1^{1 / 4} \mathrm{br}$, without dorsal spines, Penultimate segment $L=1 \frac{1}{5}$ br with dorsal medially placed, very weak opposing spine, h about $1 / 5$ of the br of the segment. Terminal claw narrow, somewhat curved, longer than the preceding segment. 
$\mathrm{R}-\mathrm{s}$ and $\mathrm{l} \mathrm{Br} \cdot \mathrm{I}$ eoncealed by the overlapping Col. The distal margin of $1 \mathrm{Br}$ I, however, visible, in syzygial atteulation with I $\mathrm{Br}$

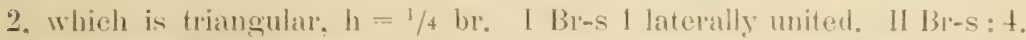
Primipostaxillaries united inside. twice as broad on the outside. II Br. I $\mathrm{h}=1 / 2 \mathrm{br}$, forms with the somewhat broader II Br 2 a projecting synarthrial tubercle. An inconspicuous similar one also between Br I and 2. Arms XX (or XIX, one arm broken in $11 \mathrm{Br} \cdot 3+$ ). $70 \mathrm{~mm}$. B1. $1-8$ discoidal. All the distal segments somewhat squeezed together at the middle with the ends furnished with small spines and bent outwards. Proximal segments short. Distal segments $\mathrm{L}_{2}=+$ br. Lxample of syzygies: $3+4,11+12,21+22,30+31 \ldots$ distally with an interval of about 7 oblique articulations. 17 segments per $\mathrm{cm}$. $(15$, if the syzygial pairs are counted as units).

$P_{\mathrm{II}} 29,+7 \mathrm{~mm}$. (7 first segments coarse, then more narrow). $P_{1}$ 33: $13 \mathrm{~mm}$. (The segments a little longer than broad, 2 th $-4^{\text {th }}$ with small prominences resembling those on the proximal pinnules of, for instance. Comatula pectinata, but very much less developedi). $P_{2}$ of about the same length. $P_{3}+10 \mathrm{~mm}$. $P_{i}+20: 5,5 \mathrm{~mm}$. Genital pinnules 12 $\mathrm{mm}$. Distal p. 20; $8 \mathrm{~mm}$. (Basal pinnulars especially on proximal p. with small, spiny prominences). 3 pairs of small sacculi per segment. - Disk thrown off. Colour (in formol) white.

Closest to C. Hartlaubi, from which it differs by the occurrence of an opposing spine and the pinnules which, compared with the armlength, are somewhat longer.

\section{Catoptometra magnifica var. minor 11 . var.}

Fig. 46,47 .

From St. $46(1), 47(3), 59(3), 61(1)=8$ specimens.

Sp. 1 (St. 59) Cd tlat, dorsal free pole gramular, 3,5 mm. C. XXV $20-21 ; 17-22 \mathrm{~mm}$. in a partly double whorl. $1^{\text {st }}$ and $2^{\mathrm{d}}$ segments short, $3^{\text {a }}$ enbical, $t^{\text {th }}$ a little longer, $5^{\text {th }}$ and $6^{\text {th }}$ segment $L=a b o u t$ $1 \frac{1}{3} \times$ the distal br, the length then slowly decreasing. l'roximal segments hour-glass-shaped with the distal ends especially widened. Usually no dorsal spine except on the antepenultimate segment. This cirral $\mathrm{L}_{4}=1 \frac{1}{1} / 4$ br. Opposing spine inconspicuous $\mathrm{h}_{\mathrm{H}}=1 / 4$ of the br of

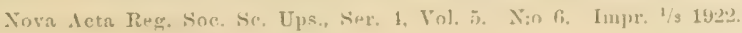


the segment. Terminal elaw pointed, L about the same as the preceding segment.

$R-s$ very narrow bands, partly hidden by the able-formed Cd. I Br I laterally free $\mathrm{h}=1 / 4$ br, in syzygial articulation with I Brax, which is low pentagonal $\mathrm{h}=1 / 3 \mathrm{br}$. II and III Br-s:2. Arms XXIV, broken. II Br I and 2 with a weak synarthrial tubercle. Ex. of syzygies: $3+4,8+9,14+15 \ldots$ then with an interval of $t$ to 5 oblique articulations. Br $1-10$ discoidal, then oblique segments, distally with small spines and somewhat overlapping.

$\mathrm{P}_{1} 22 ; 5,5 \mathrm{~mm} . \mathrm{P}_{2} 36 ; \pm 10 \mathrm{~mm}, \mathrm{P}_{3} 40 ; 13 \mathrm{~mm}, \mathrm{P}_{5} 29, \pm 9$ mm., $P_{10} 15 ; 0^{6} \mathrm{~mm}, \mathrm{P}_{1}$ to about $\mathrm{P}_{\bar{i}}$ with $1^{\text {st }}$ to $5^{\text {th }} \cdot$ or $6^{\text {th }}$ segments provided with large prominences. $h=1,3-{ }^{1 / 4}$ of the br of the segment. Distal p. $+20 ; 6 \mathrm{~mm}$. Proximal segments distally somewhat serrate and widened.

Disk incised, largest diameter 13, shortest $8 \mathrm{~mm}$., with fine calcareous granules. Mouth central.

Sp. 2 (St. 59) $\mathrm{Cd}$ as before, $+\mathrm{mm}$, dorsally with small papilla?. Free dorsal pole $3 \mathrm{~mm}$. C. XXIV 15-19: $11 \mathrm{lmm}$. Opposing spine $h=1 / 3$ of the br of the segment.

II and III Br-s:2. Arms partly broken, XXI (perhaps still II) arms, $60 \mathrm{~mm}$. I $\mathrm{Br} \cdot \mathrm{l} \mathrm{h}=1 / 3 \mathrm{br}$. Lateral borders of the $\mathrm{I}$ and $\mathrm{II} \mathrm{Br}$ series a little spiny. Syzygies with an interval of 4 to 5 oblique articulations.

$\mathrm{P}_{1} 22-24 ; 3,5-4 \mathrm{~mm}, \mathrm{P}_{2}$ (in a regenerate) $25 ; 5 \mathrm{~mm}, \mathrm{P}_{4} 22$ : $6 \mathrm{~mm}$. The carination on the proximal $\mathrm{P}$. only from $\mathrm{P}_{1}-\mathrm{P}_{3}$. Distal p. $t, 5 \mathrm{~mm}$. (The tength of the segments $=3 \times \mathrm{br}$ ). Disk $6 \mathrm{~mm}$. Anal cone $1.7 \mathrm{~mm}$.

Sp. 3 (St. 59) Cd $5 \mathrm{~mm}$.. free dorsal surface $3,5 \mathrm{~mm}$.. radially furrowed. (: XXII 19-20: 16-18 mm, in a double-whorl. - Arms XXIII, broken. I Br $1 \mathrm{~h}={ }^{1} / 8$, br, laterally free. I Brax $h=1 / 3$ br. II and III Br-s 2, in one case, however, II Br 3 (1-2-3, without a p.). Proximal segments with $3-t$ small lateral knots, which on I Br I ornament the whole proximal margin, a similar ornation, though less distinet, on II and III $\mathrm{Br}$ 1. P'rimipostaxillaries grown together inside in $3 / 4 .-P_{1} 25, \pm 5 \mathrm{~mm}$.

Disk incised. Longest diameter 12, shortest $6 \mathrm{~mm}$.

This sprecimen differs from the preeeding ones by its lighter colour and by the ornation of the proximal ossicles. 
The Crixoms from Dr. S. Bock's Expentrox to Japax 1914.

To this species belong a number of young forms with $\mathrm{X}$-XII arms, of which I describe a specinen from St. 46 :

Sp. 4 (St. 46) Cal almost hidden by Cirri. (. XXIII 10-14;

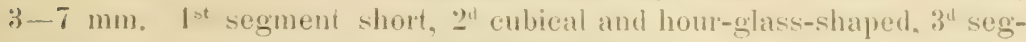
ment $\mathrm{L}_{2}=11,2 \mathrm{br}, f^{\mathrm{th}} \mathrm{L}=2 \times \mathrm{br}$, strongly hour-glass-shaped. then shorter segments. Antepenultimate one $\mathrm{L}=\mathrm{L}^{1 / 4} \mathrm{br}$. Opposing spine $h=1 / 3$ of the br of the segment. Terminal claw a litle shorter than the preceding segment.

$\mathrm{R}-\mathrm{s}$ rounded, smooth, disto-laterally well separated. I Br I $\mathrm{h}=1_{13} \mathrm{br}$, wnited with I Brax in syzygial articulation. $1 \mathrm{Br} 2 \mathrm{~h}=1$, br. Example of syzygies: $3+4,10+11$ ete. with an interval of 6 oblique articulations. II Br-s 2 (a very young regenerate). Arms XII, 35-40 mm., slender. The segments smooth, rather long, and a little hourglass-shaped. The arm-bases well separated, leaving broad spaces of the perisome visible.

$\mathrm{P}_{1} 22 ;+$ mm., $\mathrm{P}_{2} 20 ; 4,2-5,5$ mm., $\mathrm{P}_{3} 19 ; 4,3 \mathrm{~mm} ., \mathrm{P}_{4} 15 ; 3,8 \mathrm{~mm}$. $P_{6}$; mm. Basal segments with weak prominences. The $L$ of the distal segments $=2 \times$ br. Distal p. $18 ; 5 \mathrm{~mm}$. with very long pinnulars, $\mathrm{L}=4-5 \times \mathrm{br}$.

Disk incised, with calcareous granules at the ambulacral furrows. Anal cone long, narrow, $1,5 \mathrm{~mm}$.

Sp. 5 (St. 47) I Br $1 \mathrm{~h}=1 / 2 \mathrm{br}$. Syzygies with an interval of \#- $t$ oblique articulations. Otherwise as for the following sp. see the scheme p. 27 .

Sp. 6 (St. 47) \& Br $1 \mathrm{~h}={ }^{3} / 4$ br. Syzyeies with an interval of +-8 oblique articulations.

Sp. 7 (St. 47) $1 \mathrm{Br} \perp \mathrm{h}=1 / 2$ br. Syzygies with an interval of 0 oblique articulations. $P_{4} \quad 14 ; 3,5 \mathrm{~mm}$. Disk $\gg$ lean», incised 2-3 $\mathrm{mm}$. Anal funnel $1.5 \mathrm{~mm}$.

Sp. 8 (Si. 61) I $\mathrm{Br} 1 \mathrm{~h}=\mathrm{I}_{/ 2} \mathrm{br}$. Syzygies with an interval of 5 - 7 oblique articulations. In these small specimens the prominences on the proximal p-s are indiscernible.

The above-described specimens differ from C. magnifica by having fewer arms, shorter cirri, and very much shorter proximal pinnules. These differences are also to be found in specimens in Dr. MonTEnstes's collection, and therefore I wish to separate the form as a new variety: minor. 
Eudiocrinus P. H. Cinr.

Eu. indivisus (SEMFLr).

Fig. 52.

Syln: Ophiocrinus indirisus 1868 Scsmen Arch. Nalurgesch. I. p. 65.

Eudiocrinus indirisus 1S52 P. H. Cinpexter Journ. Lill. Soc. (Zö̈l.) Vol. 16. p. 495; 1588 Chall. Rep. Tol. 26 p. 81 ff.; 1912 A. H. Chank Crin. Ind. Oc., 1). 102; 1915 Monograph. p. 37, 42, 50; 1918 Siboga Exp. Vol. 42 B, p. 65.

? Eudiocrinus granulatus 1894 BeLL. P. Z. S. p. 397; 1913 . I. II. CL.MK Smiths. Misc. Coll. Vol. 61: 15, p. 21

\section{From St. 5\%: 1 specimen.}

Sp. 1 Cd $3 \mathrm{~mm}$. free dorsal pole 2 mm.. flattened, with a somewhat arched dorsal suface.

( . XIX 19-21; $11-15 \mathrm{~mm}$. in a single or double whorl. $1^{\text {st }} 3^{4}$ segments short, $t^{\text {th }}-7^{\text {th }} \mathrm{L}=1^{1} / 2-2$ the median br, like the following cirrals strongly hour-glass-shaped. 'The distal segments shorter. Antepenultimate one not very much longer than broad ( $\mathrm{L}=1 / 5 \mathrm{br})$. $14^{\text {th }}$ $15^{\text {th }}$ segments less swollen at the ends. Opposing spine $h=1,3$ of the br of the segment. Terminal claw somewhat longer than the preceding segment.

$R$-s nearly concealed, the visible horder adorned with small knots. I $\mathrm{Br}^{\mathrm{C}} 1+2$ with a weak median prominence. The arm-bases smooth, without longitudinal prominences as in Eu. variegutus. A prominence between $\mathrm{Br}$ ? and 3 formed in the oblique articulation on the right. A similar knot on the left between $\mathrm{Bl}^{\circ}+$ and 5 , and one more on the right between $\mathrm{Br} 5$ and 6 , then less pronounced. Arms $\mathrm{V}$. broken. Breadth of Br 1:1,9 mm. Ex. of Syzygies: $3+4,8+9 \ldots$ After $\mathrm{Br} 10$ oblique articulations. Out to $\mathrm{Br}^{*}+$ small, ventro-lateral rows of knots.

$P_{I} 10:+m m . P_{1} 10 ;+m m, P_{a} 10 ; 7.5 \mathrm{~mm} . P_{2} 11 ; 8$ mm. 'These p. extraordinarily coarse and thick, sharply triangular; $3^{d}$ segment on $P_{1}$ and $P_{a}$ about cubical. The distal segments. $L=1^{3}+b r$, without distal, spiny borders. $P_{1}$ and $P_{3}$ much more slender, the latter 17: 8 mm. Is of the segment $21 / 2-3 \times$ br:

Disk thrown off, probably about $3 \mathrm{~mm}$. Colour yellow-brown.

This specimen is closest to Eu. indivisus, though the longest cirraks are rather short to belong to this species. Nevertheless it has 


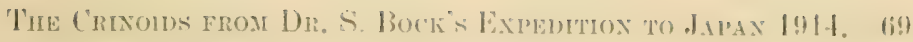

considerably longer cirri than the above-mentioned species and in this respeet approaches Eu. gramelalus BEL which, according to A. II. Ctark, is synonymous with the first-mentioned species. On the ligure of E'te. gromelatus by BEL, $\mathrm{P}_{\mathrm{h}}$.? $\mathrm{P}_{2}$, for, though the arm is drawn from the left side, still the pinnules stand on ossicles corresponding to P' and $P_{2}$ : a faulty drawing?) has 26 segments and hats a lengih of 2.0 mm. $P_{a}\left(P_{1}\right)$ has 16 segments. If the figure is correctly drawn. the existence of gramulutus ought to be authorized at least as a rariety.

Eudiocrinus gracilis var pulchellus 11. vill.

Fig. (60-63). Photo 5.

firom si, $45(5), 46(2), 47(2), 48(1), 53(1)=11$ specimens.

S\%. I (St. tb) Cil flattened $1,5 \mathrm{~mm}$., free dorsal pole $1 \mathrm{~mm}$.

C. XIX $13-15 ; 5,5-6,5 \mathrm{~mm}, \mathrm{I}^{\text {st }}$ and $2^{\mathrm{a}}$ segments shorter than long, $3^{\text {d }} \mathrm{L}=\mathrm{br}$, $4^{\text {th }}-6^{\text {th }}$ segment $\mathrm{L}=+2 \underline{\times}$ the median br, then the segments shorter again. Antepenultimate cirral $L$ about $=$ br:

$\mathrm{R}-\mathrm{s}$ smooth I Br $1 \mathrm{~h}=\mathrm{br}$. Br-s not overlapping eren in distal segments. The proximal muscular articulations dark-coloured. From B1. 7 oblique joints with a couple of datk longitudinal bands. Syzygies: $3+4,9+10,13+1+$ ete. with an interval of $:$ oblique articulations. Arms $V, 40 \mathrm{~mm}$. Breadth of $B \mathrm{r}^{\circ} \mathrm{L}=0.8 \mathrm{~mm}$.

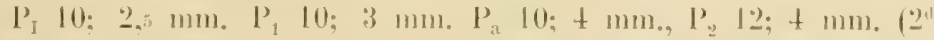
segment of $P_{a}$ and $P_{2} I_{1}$ not fully as large as br, $3^{d}$ segment somewhat longer than broad $-L=1^{1} / 3-I^{1 / 2}$ br - distal segments $L=$ $3 \times \mathrm{br}$, a little widened at the distal ends but only slightly spiny), P', 11: $3,5 \mathrm{~mm} . \mathrm{P}_{3}$ 12: $3,5 \mathrm{~mm}$. Distal p. 15-16;5,5 mm. (The L of the pinnulars $=3-4 \times$ br. The last segments with dorsal hooks. "3 pairs of large saceuli per segment).

Disk thrown off, has been about $2 \mathrm{~mm}$.

Sp. 2 (St. 46) $3^{d}$ segment on $P_{1}$ and $P_{n} L_{1}=1^{1} / 3 \mathrm{br}$. Anal funnet $0,8 \mathrm{~mm}$. Disk $1,5 \mathrm{~mm}$. For further details see the table as for the following specimens.

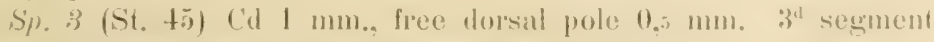
of $P_{1}$ and $P_{i 1}$ as in sp. 2. Disk 2 mm. 


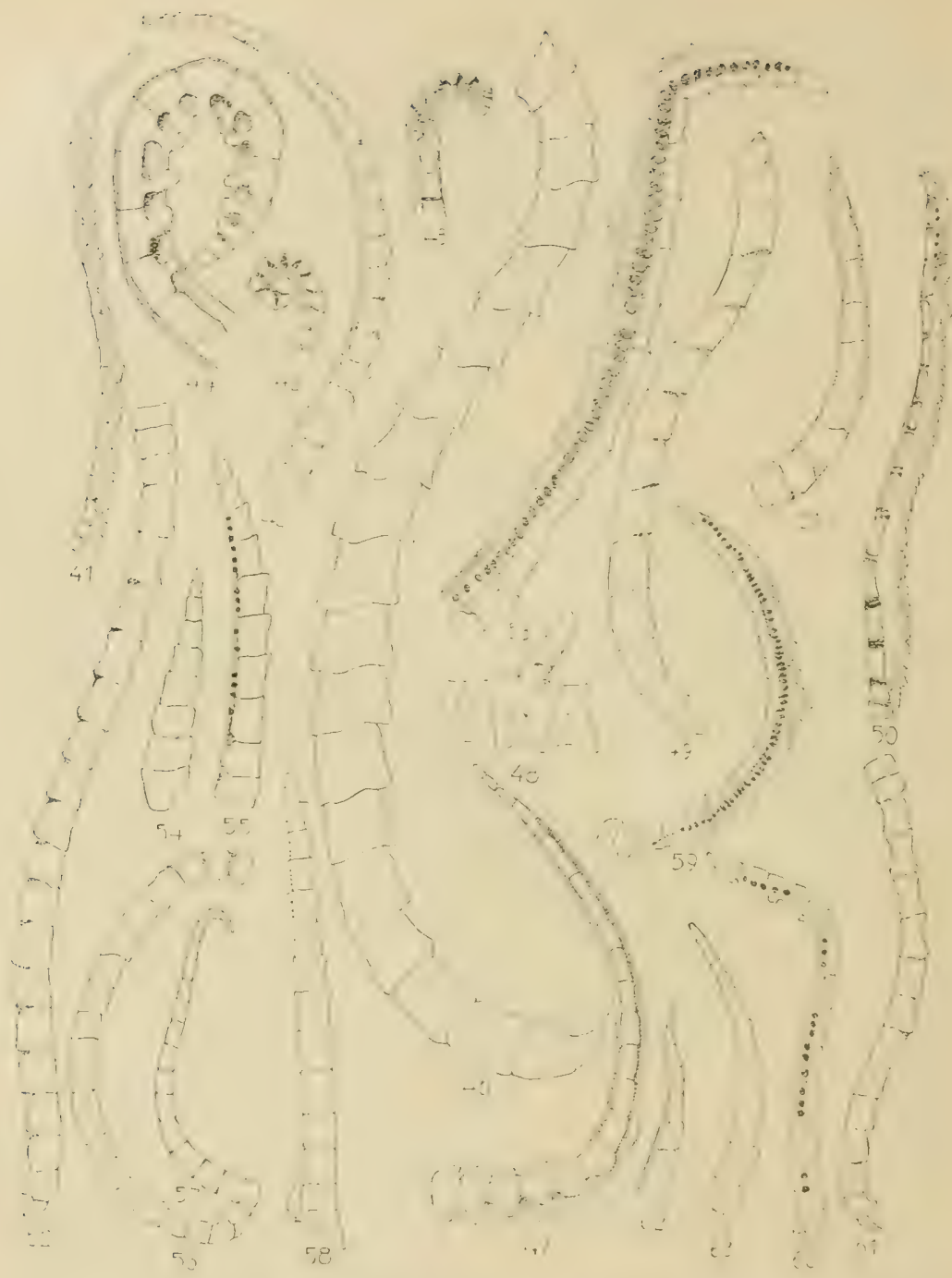

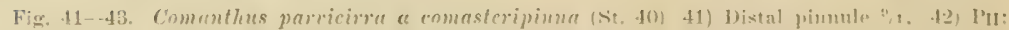

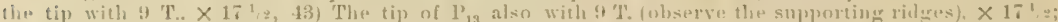

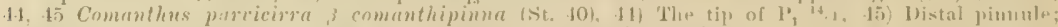
coarse, short secrutents 14, 16,17 Catoptometra maynifica minor (St. 509). 16) ('irrus "1, 17 ) 
Sp) 10 (St. 45) $3^{\mathrm{d}}$ eirral: $\mathrm{L}=1^{1}{ }^{4} \times$ the distal widened part of the segment, $t^{\text {th }}$ segment, strongly hour-glass-shaped, $\mathrm{I}_{2}=\underline{2} \times$ the diameter of the distal part. $5^{\text {th }}$ and ith $^{\text {th }}$ segment proximally a little narrower. $7^{\text {th }}$ to antepenultimate one laterally compressed $\mathrm{L}=\mathrm{I}^{1 / 2} \mathrm{bl}$. Opposing spine sharp, $h=1 / 2$ of the br of the segment. Terminal elaw pointed, curved, somewhat longer than the preceding segment.

$R$ a narrow band with a median prominence, separated at the corners by the $\mathrm{B}-\mathrm{S}$. I $\mathrm{Br}$ I proximally bent outwards with a median keel, $\mathrm{h}=1 / 3$ of the thickness of the segment, laterally viewed. $\Lambda$ similar prominence or the distal part of $\mathrm{I} \mathrm{Br}, 2$ and $\mathrm{Br} \perp$ and 2 . where laterally, however, it has no distinct border. 'The ends of the segments a little bent outwards. From $\mathrm{Br}^{\circ} \mathrm{S}$ oblique joints. Ex of syzygies: $3+4,13+14$ and then with an interval of 3 (to 4) oblique articulations. Arms $\mathrm{V}, \pm 20 \mathrm{~mm}$., distally tolerably smooth.

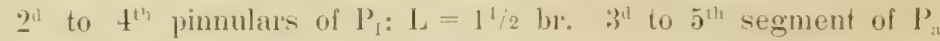
$L=2 \times b r$. The distal ends of the segments spiny and somewhat bent outwards. The pinnulur's of the distal pinnules very long $(\mathrm{L}=t-$ $5 \times$ br\%. - Disk $1 \mathrm{~mm}$. Colour (in spirit) yellow-white. The sacculi are dark. The anal cone smooth, subcentral. Nouth subeentral.

Sp. 11 (St. 53) Strong prominences on the proximal ossicles ats in Sp. 10. $3^{d}$ segment of $\mathrm{P}_{\mathrm{a}} \mathrm{L}=\mathrm{I}^{1 / 2} \times 1^{3 / 4} \mathrm{br}$.

The two last-described specimens are of an ormate type but evidently young forms of the preceding specimens.

The full-grown specimens differ from Eu. gracilis by their smatler size, by having more but shorter cirri, and by $P_{1}$ and $P_{2}$ being not much longer or more slender than the rest of the proximal pinnules.

Eudiocrinus Loveni n. sp.

Fig. 53 -56. Photo 6 .

From St. $47=1$ specimen.

Sp. 1 Cd 1,8 mm. C. XX 20-21: 9-10 mm. $1^{\text {st }}$ and $2^{\text {d }}$ segments shorter than long. $3^{\text {d }}$ cubical, $5^{\text {th }}-7^{\text {th }} \mathrm{L}=1^{1} / 4 \times$ br. The segments are smooth, slightly hour-glass-shaped, rather coarse. Opposing spine $h=2 / 3$ of the br of the segment. Terminal claw curved, $\mathrm{L}=$ the preceding segment. 


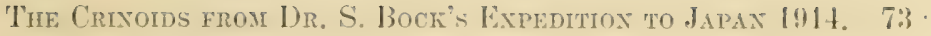

$\mathrm{R}-\mathrm{s}$ narrow, smooth bauds, $\mathrm{h}=1 / 5 \mathrm{br}$. I $\mathrm{Br} \mathrm{I}+2 \mathrm{~h}=\mathrm{br}$, as $\mathrm{Br}^{\circ} 1$ and 2 with ventro-lateral, rather pronounced ledges, $\mathrm{Br}^{\circ} \mathrm{l}$ br $=$ 1,4 mm. Syzygies: $3+4,8+9,12+13$ ete, with an interval of 3 oblique articulations. Arms $V, 40-45 \mathrm{~mm}$. smooth.

$\mathrm{P}_{\mathrm{I}}$ 9: $3,5 \mathrm{~mm}$. (1-3 or 5 segments with a distally directed crista. $I^{\text {st }}$ segment much decreasing proximally, 20 segment broadest. The h of the crista $=1 / 3$ of the br of the segment, compare the figure), $\mathrm{P}_{1}$ $10 ; \pm \mathrm{mm}$, similar to the preceding. $\mathrm{P}_{\mathrm{a}} \quad 11 ; 5 \mathrm{~mm}$. $(3)^{\prime \prime}$ segment $\mathrm{L}=1^{1 / 2}$ br, distal segments with a somewhat spiny border, $L=22-2^{2} / 2$ br), $\mathrm{P}_{2}$ 11; $5 \mathrm{~mm} ., \mathrm{P}_{1}, 12 ; 5 \mathrm{~mm}, \mathrm{P}_{3} 11 ; 5 \mathrm{~mm}$. (with a small spiny garland on the distal segments). Distal p. I6-17; 4,5 mm. (the segments $\mathrm{L}=3 \mathrm{br}$, the 3 last ones with dorsal hooks; 4 pairs of large sacculi per segment).

Colour: Cirri white. Arms dorsally brown with white transverse spots. The pinnulars whitish, the sacculi dark-coloured (in alcohol).

At first I had some doubt whether this specmen was not only a full-grown specimen of those described as Fu. gracilis pulchellus. Nevertheless some differences are of such a nature that I have been obliged to believe that the speeimen differs not only by characteristics of age. The most important differences are as follows:

1) The cirrals are short, not very much longer than broad, not at all or only slightly hour-glass-shaped (CF. Eu. pimatus and voriegatus). 2) $P_{1}$ and $P_{I}$ are on the proximal segments provided with prominences that are lacking in Eu. gracilis pulchellus. By these prominences it approaches Er. venustulus. 3) Further Eu. Loveni differs from Eu. gracilis mulchellus by the arms which, though of about the same length as in the last-mentioned species, are much coarser, 4) by the more spiny borders of the distal segments of $P_{2}$ and $P_{3}$, 5) by the relatively short distal pinnules.

The newly proposed species, which I have called after the late Prof. S. Lovex, is thus a peculiar type connected with many species within the genus Eudiocrims. 
Mariametridæ А. H. CLARK.

Liparometra A. II. C'LArk.

L. grandis A. H. CLark.

Fig. $85,86$.

Syn : Himerometre grendis 1908 A. II. Chark Wash. Proc. Biol. Soc. Vol. 21. 1. .2.".

Dichrometra grandis 1909 A. II. Clark Proc. Biol. Soc. Vol. 22, p. 13; 1912. Crin. Ind. Oe, p. 150.

Lipurometru grendis 1913 A. II. Clank Wash. Proc. Biol. Soc. Vol. 26, p. 143; 1915 Journ. Acal. Sci. Vol. 5, p. 214; 1918 Siboga Exp. Vol. 42 B, p. 103.

From St. $39(1),+7(1)=2$ specimens.

Sp. 1 (St. 39) Cd discoidal, free dorsal pole $2,5 \mathrm{~mm}$. C. XXIX $27-30$ (D) $3 \mathrm{I}-38$ (V), $16-2+\mathrm{mm}$. in two close whorls. $\mathrm{I}^{\mathrm{st}}-3^{\mathrm{d}} \mathrm{seg}-$ ment with a little conver proximal and concave distal margins in lateral view. $4^{\text {th }}$ and the following segments slowly inereasing to $\mathrm{L}=\mathrm{br}$ (at the $15^{\text {th }}$ or $20^{\text {th }}$ segment). No dorsal spine. Opposing spine small, coarse, blunt-ended, $h={ }^{1 / 3}$ of the br of the segment. Terminal claw short, coarse, $\mathrm{L}=$ the preceding segment.

$\mathrm{R}-\mathrm{S}$ narrow bands. I $\mathrm{Br}$ i $\mathrm{h}=1 / 5 \mathrm{br}$, in lateral apposition. I Brax low pentagonal, $h=1 / 3$ br, with coneave distal margins. I Br 1 and 2 form a low synarthrial tubercle. II and III Br-s: 2, (III Br-s in 6 cases on the outer sides). Primipostaxillaries united inside. Arms XXVI, $120 \mathrm{~mm}$. The br of $\mathrm{Br}^{\circ} \mathrm{L}=1,6-1,8 \mathrm{~mm}$. Br' 2 twice as long' on the outside. The first $10 \mathrm{Br}$-segments rectangular, $\mathrm{h}=1 / 2 \mathrm{br}$, then slightly oblique joints.

$1^{\text {st }}$ syzygy usually between $\mathrm{Br}^{\mathrm{r}} 3$ and 4 but often exceptions (see the example). Distally with an interval of 7-12 oblique articulations. Example of arm-division:

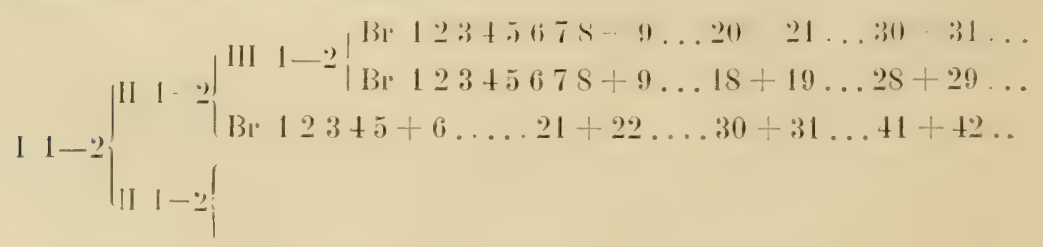


Example of the distribution of the distal syzygies from arm 3.

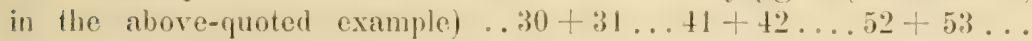
$65+66 \ldots 78+79 \ldots 90+91 \ldots 101+102 \ldots 109+110 \ldots$ Distal segments discoidal, short, $L=1 / 2-1 / 3$ br. Lateral profile rather smooth. 17-18 segments per em. (16, if the syzygial pairs are counted as units). 'The arms are very close to one another (interspaces chiefly between $\mathrm{I} \mathrm{Br} 2-\mathrm{Br}+$ on the outer side of the divisions).

$P_{1}(9-) 18-21:(4-) 11 \mathrm{~mm}$. (the $4^{\text {th }}$ and the following segments slender, $L=1^{1}: 2-2$ br. like the segments of following pinnules smoothi). $\mathrm{P}_{2} 19-25 ; 11-18 \mathrm{~mm} . \mathrm{P}_{3} 17-20 ; 14-16 \mathrm{~mm}$. (in a single case only $s ;+\mathrm{mm}$., is a young regenerate), $P_{4} 14-16 ; 10-13 \mathrm{~mm} ., P_{8} 14 ; 6,5$ mm. Distal p. $\pm 20 ; 8,5-10,5 \mathrm{~mm}$. (The $\mathrm{L}$ of the segments $=2 \times \mathrm{br}$ ).

Disk strongly incised, smallest diameter 5 , largest $7 \mathrm{~mm}$. 'The soft parts do not cover the whole ventral surface of the division-series. Colour: violet with lighter and darker transverse bands on the arms. Sp. 2 (St. 47$)$ C. XXIII $(11-) 1+-17 ;(3,5-) 5,5-7 \mathrm{~mm} .5^{\text {th }}-7^{\text {th }}$ segments longest, $\mathrm{L}=1^{1} / 2 \mathrm{br}$. No dorsal spines; the segments are, however, laterally compressed, forming a very weak carina. Opposing spine: $\mathrm{h}={ }^{1} 3{ }_{3}-{ }^{1 / 4}$ of the br of the segment.

$\mathrm{R}-\mathrm{S}$ as before. I $\mathrm{Br} \cdot \mathrm{h}=1 / 3 \mathrm{br}$, with slight, lateral prominences. I Brax $\mathrm{h}=3 / 4 \mathrm{br}$, almost 6 -angular by the backward directed median synarthrial tuberele. Arms X, $27 \mathrm{~mm}$. Br 1 united inside, ${ }^{1 / 2}$ as wide outside with a. convex outer margin ( $=$ an indistinct lateral prominence). $1^{\text {st }}$ syzygy between $\mathrm{Br} 3$ and 4 distally with an interval of 5-7 oblique articulations. The Br-segments smooth.

$P_{1} 13-15: 4,5-5,5 \mathrm{~mm}$. (Longest segments: $\mathrm{L}_{2}=2^{1 / 2}$ br), $\mathrm{P}_{2} 13 ;$ $5 \mathrm{~mm}$. (Segments to $3 \times$ br), $\mathrm{P}_{3} \mathbf{1 0} ; 3 \mathrm{~mm} . \mathrm{P}_{4} 9 ; 2$ to $: 3 \mathrm{~mm}$. Then longer p-s again. Jistal p. 15; 4,5 mm.

Disk incised 2,5-4 mm., whitish. Otherwise the animal is redbัตพก.

The specimen described last might perhaps, because of the short : pinnula, be a young of Lamprometra prolectus. It is, however, to be noticed that it is not until a rather advanced stage that the young forms obtain the relation between the lengths of the proximal pinnules which is peculiar to the full-grown species. For $P_{1}$ is first formed, then $\mathrm{P}_{2}$, and finally $\mathrm{P}_{3}$. The above-mentioned shortness of $P_{3}$ might therefore be ascribed to the youth of the animal. 
The length of the proximal $\mathrm{p}-\mathrm{S}$ in sp. 1 is, as shown above, very variable. It seems to me to be rather unfortunate within this family to base the characteristics of genus on the relation between the length of $\mathrm{P}_{1}, \mathrm{P}_{2}$ and $\mathrm{P}_{3}$, as has been done in the genera Liparometra, Lamprometra and Dichrometra. which surely are very closely related to each other.

\section{Colobometridae A. II. Crark.}

Cenometra 1. H. CLARK.

C. bella (H.ARTLick).

Fig. $57-59,74$.

Syn.: Antedon bella 1890 Hartuack Nichr. Ges. Güuingen 1890, p. 174; 1891 Leop. Carol. Cur. Vol. 58: 1; p. 43.

Cenometra bellu 1909 A. II. CL.ark Wash. Proe. Biol. Soc. Vol, 22, p. 8; 1912 Crin Ind. Oc., p. 153; 1915 Journ. Acad. Sei., Vol. 5, p. 214; Monograph 1p. 48,67 .

From St. 49: 1 specimen.

Sp. 1. Cd thickly discoidal $(\mathrm{h}=1,5 \mathrm{~mm}$.) with raised margins round the free dorsal surface, the diameter of which is $2 \mathrm{~mm}$. - C. XXVI $34-38 ; 16-18 \mathrm{~mm}$. in two whorls. The 12 first segments: L about ${ }^{1 / 2}-{ }^{2 / 3}$ br, the following ones similar or a little shorter. The distal half of the eirrus with a low transverse ribbon. which is indistinctly (or not at all) divided into two tubercles (slightly projecting in lateral view). Opposing spine: $\mathrm{h}={ }^{1 / 2}$ of the br of the segment. 'Terminal claw coarse, blunt-ended, L about the same as the preceding segment.

$\mathrm{R}-\mathrm{s} h=1 / 4 \mathrm{br}$, most apparent in the corners, baso-laterally united. I $\mathrm{Br} / \mathrm{h}=1 / 3$ br, laterally free, forming with I Brax a distinct. synarthrial tubercle. I Brax $h=2 / 3$ br, pentagonal. A ventro-lateral prominence on each ossicle from $\mathrm{I} \mathrm{Br} 1$ - $\mathrm{Br}$, largest on II $\mathrm{Br} \cdot$. where it occupies the whole side of the ossicle and reaches $1 / 5$ of the lateral hof the segment. II and III Br--s: 2 (the latter ones on the outer sides). Primipostaxillaries basally united inside. Arms XXVI, $90 \mathrm{~mm}$. Syzygies: $3+4,12+13$, distally with an interval of $7(-10)$ 
oblique articulations. The Br-segments rather smooth, 2I segments per cm. (18, if the syzygial pairs are counted as units). The longer side of the distal brachials, $L={ }^{2 / 3}$ br. the shorter one $L=1 / 2 \mathrm{br}$.

$\mathrm{P}_{1} 18 ; \pm 5 \mathrm{~mm}, \mathrm{P}_{2} 15-16 ; 9 \mathrm{~mm}$. (very much stiffer and twice as coarse or more than the other $p-s$. The distal ends of the pinnular's from the $6^{\text {th }}$ segment thickened and with a spiny garlandi). P $12 ; 4 \mathrm{~mm} . \mathrm{P}_{4}$ similar, $\mathrm{P}_{\mathrm{a}}$ always present though often only "2-3 $\mathrm{mm}$. Distal p. $17-18 ; 7,5 \mathrm{~mm}$. (distal pinnular's $\mathrm{L}_{4}=2-3 \times \mathrm{br}^{2}$ ).

Disk ineised $8-11 \mathrm{~mm}$. in diameter. Colour white with small brown spots. Anal cone short, pointed, 2, $5 \mathrm{~mm}$. The distal half of the p. quite violet-brown, the arms lighter with brown spots.

Differing from $C$. bella only by somewhat more cirri, which usually have transverse crista instead of a pair of tubercles, and by the primipostaxillaries, which are only united basally.

\section{Cyllometra A. II. CL.IRK. \\ C. disciformis (P. H. Cane.).}

Fig. 68-69.

Antedon disciformis 1589 P. II. Carpexter Chall, Rep. Vol. 26, p. 228S.

Cyllometra disciformis 1912 A. II. CLALK Crin. Ind. Oc, p. 15S; 1913 Smiths. Misc. Coll. Vol. 61: 15, p. 31; 1915 Nonograph; 1918 Siboga Exp. Vol. 42 B, p. 116 .

From St. 12 (1), 33: (1), $35(1)=3$ specimens.

Sp. I (St. 35) Cd discoidal, free dorsal part 2 mm. C. XV 25 -27: $13-15 \mathrm{~mm}$. in an almost single whorl. $3^{\text {th }}$ and $\mathrm{f}^{\text {th }}$ segments eubical, $5^{\text {th }}-7^{\text {th }}$ one slightly longer than broad, then shorter again, the distal ones $L=2 / 3 \mathrm{br}$. The $5^{\text {th }}\left(0 \mathrm{r}^{\text {th }}\right)$ to the $12^{\text {th }}$ segment with a small dorsal transverse ribbon with an excavation in the middle forming an indistinct double tubercle, from about the $13^{\text {th }}$ segment a simple dorsal spine, $h=1 / 4$ of the $b r$ of the cirral. Opposing spine $h=1 / 2$ of the br of the segment. Terminal elaw about as long as the preceding segment.

The distal border's of the $\mathrm{R}-\mathrm{s}$ visible under the $\mathrm{Cd}$. I Br I $h=1 / 5 \mathrm{br}$, laterally free. I Brax $h=1 / 3 \mathrm{br}$. Primipostaxillaries united 
inside. II Br-s: 2. Arms XVI, $90 \mathrm{~mm}$. slender, smooth, well separated basally. Inconspicuous synarthrial tubercles. The br of $\mathrm{Br} 1$ : 1.1-1,2 mm. Example of syzygies: $3+4,11+12,17+18$ ete., distally with an interval of $3-4(-5)$ oblique articulations. $\mathrm{Br} 1-7$ discoidal, then oblique joints. The longer side of the distal $B r-s: L=b r$. 19-20 segment per $\mathrm{cm}$. (15, if the syzygial pairs are counted as units).

$\mathrm{P}_{1} 15 ; 5,5 \mathrm{~mm}$. smooth, $\mathrm{P}_{2} 19 ; 9-9,5 \mathrm{~mm}$. $\left(5^{\text {th }}-12^{\text {th }}\right.$ segment: $\mathrm{L}=2-2{ }^{1} / 2 \mathrm{br}$, with spiny prominences on the distal ends of the segments. The tip of the pinnule usually smooth), $\mathrm{P}_{3} 14-15 ; 7-7,5 \mathrm{~mm}$. similar to the preceding. $\mathrm{P}_{4}(12 ; 4 \mathrm{~mm}$. $)$ and the following ones smooth. Distal p. 20-22; $8 \mathrm{~mm}$. (1 ${ }^{\text {st }}$ and $2^{\text {a }}$ segment short, coarser than the following ones, the distal end of the $2^{\mathrm{d}}$ segment therefore forms a weak notch against the outer segments which are longer, $L=2-3$ $x$ br; the last segment provided with microscopic dorsal hooks). Disk thrown off.

Cirri and division-series white. The distal parts of the arms spotted with red-brown. Proximal pinnules white, the other p-s with strongly coloured sacculi (which are about 4 pairs per segment) and otherwise light brown-violet.

The scheme given below is an example of the pimnulation of the proximal arm parts. $P_{1}$ is always lacking on the inner side, when there are 4 arms on a I Brax.

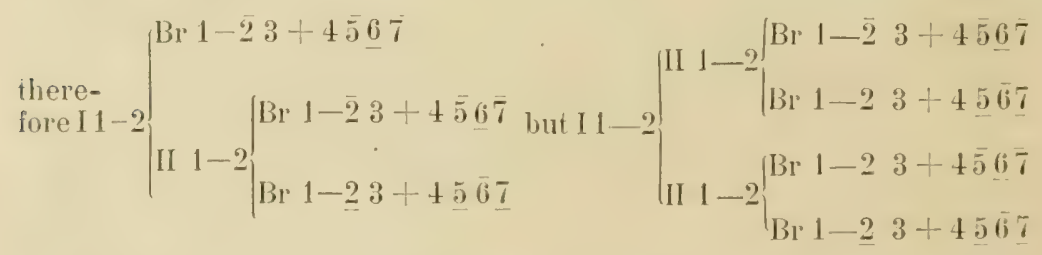

S Sp. 2 (St. 33) Probably also belonging to this species (possibly a young $C$. albopurpurea).

Cd $0,8 \mathrm{~mm}$. C. XX 15-18; $5-6 \mathrm{~mm}$. (the dorsal C. 12: 2,5 mm.). The $\mathrm{L}$ of the segments at most $1^{1 / 3} \mathrm{br}$. $4^{\text {th }}-\mathrm{S}^{\text {th }}$ segment with a double dorsal spine, then a single prominence in the middle of the segment. Antepenultimate segment usually smooth. Opposing spine $h=1 / 2$ of the br of the cirral. 'Terminal claw as long as the pre- 
ceding segment. The first segments proximally somewhat narrower, and therefore a rather serrate proximal profile.

$\mathrm{R}-\mathrm{S}$ narrow bands. I $\mathrm{Br} / \mathrm{L}={ }^{3} / 4$ br, laterally free. Axillary $\mathrm{h}={ }^{1 / 4} \mathrm{br}$. $\mathrm{Br} \cdot 1 \mathrm{~h}=1 / 2 \mathrm{br}$, basally united inside. Arms $\mathrm{X}, 25 \mathrm{~mm}$. Syzygies with an interval of $3-4$ oblique articulations. Distal Br-segments $L_{1}=1^{1 / 2}$ br, smooth.

$\mathrm{P}_{1} 6-7 ; 2 \mathrm{~mm} . \mathrm{P}_{2} \pm 10 ; 4 \mathrm{~mm} . \mathrm{P}_{3} 7-\mathrm{s} ; 2,5 \mathrm{~mm}$. $\mathrm{P}_{\mathrm{a}}$ lacking, $\mathrm{P}_{\mathrm{b}}, 9 ; 2,5 \mathrm{~mm}$. (3 and the following segments $\mathrm{L}=22-3 \times$ br', smooth). Distal p. $\pm 3,5 \mathrm{~mm}$.

Disk thrown off. Colour: violet spots on a white ground.

A young specimen of Colobometride, probably referable to this species, is also:

- Sp. 3 (St. 12) Cd discoidal, br 1,5 mm. - C. X 16-18; 5,5-6 mm. The cirrals are rather short, the longest ones $\mathrm{L}=$ the distal br. From the $t^{\text {th }}-7^{\text {th }}$ segments a transverse crista. A single dorsal spine from the $7^{\text {th }}$ eirral.

I $\mathrm{Br}^{\circ} 1$ and 2 with a weak longitudinal carination. Arms $\mathrm{X}$, broken. Syzygies: $3+4,9+10,1++15$ ete. with an interval of 3 oblique articulations.

$P_{1} 10$, shorter than $P_{2}$, which is $11 ; \pm m m . P_{3} 9 ; 3 \mathrm{~mm} . P_{5} 11$. $P_{a}$ absent. Disk thrown off.

Fixed on an Acanthogorgia Dofleini KükTr. \& Gorz. ${ }^{1}$

Though $C$. disciformis is evidently very closely related to $C$. manca I have, however, kept them as separate speeies. A. H. CLARK distinguishes the first-mentioned one from $C$. mancu by the long proximal cirrals. Nevertheless at the same time he states (Siboga Exp. Vol. 42 B, p. 116) that the length of the cirrals rapidly decreases in speeimens of $C$. disciformis from deeper water. The deepest localities from which this species has previously been dredged are 180 fathoms. The above-described specimens are found at depths of 400 and 90 to 200 fathoms respectively and have therefore very short cirrals approaching those of $C$. munca. I have deseribed below a specimen from Kiu Shin Islands belonging to this species. In this one the cirrals are never longer than broad. It is moreover a smaller form than the abovedescribed species from shallower water but in spite of that with shorter cirrals. 'The larger $C$. disciformis seems also to have fewer arms in

\footnotetext{
${ }^{1}$ For this information I am indebted to my friend Mr. Magnes Aunwluus.
} 
proportion to the length of the arms. A distinguishing characteristic of value might also be the distribution of the syzygies. In $C$. disciformis the syzygies are separated by 3 to $t$, in $C$. manca by 9 to 10 oblique articulations. This difference is also to be found in the original descriptions, where the first-mentioned species is said to have syzygies with a syzygial interval of $2-6$, the latter with an interval of $4-10$ (usually $7-8$ ) joints. The preceding species also seems to be more slender and to have longer and narrower distal pinnules than the one described below.

It might be worth while to eall attention to the fact that the genus Cyllometra, as also many other Colobometrids, approaches in many respects the Antedonid subfam. Perometrine. Both groups have an inconstant $V_{a}$. The Colobometrids, being an Oligophreat family, have umusually long pinnulars and cirrals, where the first-mentioned ones especially are very similar to those of the Antedonida. Perometrince, on the other hand, being a Macroplreat family, has short cirrals and pinnulars. The basal rays are often absent in the Colobometride and the rosette very similar to that of the Macroplueats. Also the centrodorsal cavity is unusually large. A feature distinguishing Colobometride from Perometrine is the occurrence of a double spine-row or a transverse crista on the proximal cirrals. On the distal segments, however, the dorsal spine is single. If a reduction of the spines of the proximals cirrals took place, we might probably refer a Colobometrid to Perometrince. It seems therefore as if we should find connections between Colobometricte and Perometrinc; the latter is possibly in this case to be deduced from the former and has developed convergently with the Antedonid typus (cf. p. $89 \mathrm{ff}$.).

\section{Cyllometra manca (P. II. Cirr.).}

Fig. 66,67 .

Syn: Antedon manca 18s5 P. H. CArpexter Chall. Exp. Vol. 26, p. 226.

Cyllometra manca 1907 A. 11. CLark Smiths Mise. Coll. Vol. 50, p. 357: 1912 Crin. Ind. Oc., p. 156; 1913 Smiths. Mise. Coll. Vol. 61: 15, p. 34; 1915 Monograph p. 89,$374 ; 1918$ Siboga Exp. Vol. 42 B, p. 116.

From St. 19: 1 specimen.

1) Sp. $1 \mathrm{Cd}$ large, discoidal, free dorsal pole $2.8 \mathrm{~mm}$. C. XXIII 23 -25; 10-11 $\mathrm{mm}$. in two whorls. All segments are shorter than long. 
the proximal ones are longest, $L=3 / 4$ br. From the $6^{\text {th }}$ segment a double dorsal spine, which at the $15^{\text {th }}\left(-17^{\text {th }}\right)$ segment becomes a single one, $h=1 / 4$ of the br of the segment. The paired prominences distinct, close to one another, only on the $6^{\text {th }}-9^{\text {th }}$ segment-indistinct, almost forming a transverse ridge. The antepenultimate and the nearest preceding segments with weaker spines. Opposing spine $h=1 / 2$ of the br of the segment. Terminal claw coarse, somewhat curved. about as long as the preceding segment.

$\mathrm{R}-\mathrm{s}$ narrow bands. I $\mathrm{Br} 1$ free laterally, $\mathrm{h}={ }^{1 / 4} \mathrm{br}(\mathrm{br}=0,8 \mathrm{~mm})$. I Brax $h=2 / 3$ br, as II Br 2 with a slight synarthrial tubercle. Primipostaxillaries united inside. Il $\mathrm{Br}-\mathrm{S}: 2$. No III $\mathrm{Br}-\mathrm{s}$. II $\mathrm{Br} \quad \mathrm{L} \mathrm{h}=$ $1 / 3-1 / 2 \times$ br (narrower on the inner side, broader on the outer side). Arms XIX, $50 \mathrm{~mm}$. smooth. After Br 7 oblique segments. Distal segments triangular with slightly swollen articulations. Syzygies: $3+4$. $15+16$ or $18+19$, distally with an interval of $7-10$ (usually $9-10$ ) oblique articulations. 18 segments per $\mathrm{cm}$. (16, if the syzygial pairs are counted as units).

$P_{1} 12 ; 4 \mathrm{~mm}$. Is occasionally missing on the inner side of a II Brax. $P_{2} 14 ; 7$ mm., outer segments with spiny collars, $P_{3} 12 ; 4,5 \mathrm{~mm}$.. $\mathrm{P}_{4} 11 ; 4$ mm., $\mathrm{P}_{\mathrm{a}}$ is most often absent, $\mathrm{P}_{\mathrm{b}} 12 ; 5,5 \mathrm{~mm}, \mathrm{P}_{\mathrm{c}}$ shorter. $\mathrm{P}_{2}$ and $P_{b}$ very much coarser than the other pinnules, longest segments $\mathrm{L}=2 \mathrm{br}$, somewhat angular and spiny. The other pinnules with smooth segments. Distal p. 14-17; 4,5-6 $\mathrm{mm}$. Disk thrown off. Colour yellow with black-red spots.

Example of the distribution of pinnules and division of arms.

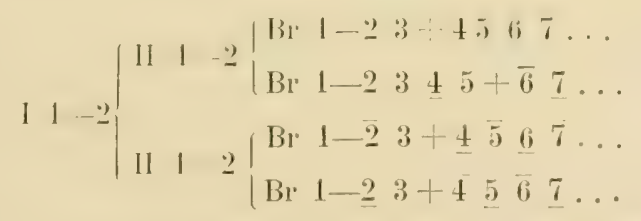

In this as in the following species the specimens that are found in the collection have the double prominences of the cirrals not rery distinctly marked. 


\section{Cyllometra albopurpurea A. H. CLARK.}

Fig. $64,65$.

Syna: Cyllometre albopurpurea 1908 A. H. Chak Proc. U. S. Nat. Mus. Vol. 34, p. 239; 1912 Crin. Ind. Oc, p. 158; 1913 Smiths. Misc. Coll. Vol. 61: 15, p. it; Wash. Proc. U. S. Nat. Mus. Vol. 43, p. $400 ; 1915$ Monograph pp. 54, 289 ; Journ. Aead. Sei. Vol. 5, p. 214; 1918 Siboga Exp. Vol. 42 B, p. 115.

Cyllometra manea 1907 II. L. CLark Bull. Mus. Comp. Zool. Vol. 51, p. 289 (according to A. II. CL.trk 1915 Monograph p. $54=$ albopurpurea).

From St. $53(2), 59(2)=4$ specimens.

Sp. 1 (St. 5!) Cd discoidal, 4,5 mm., free dorsal surface $3 \mathrm{~mm}$, $\mathrm{h}=1.8 \mathrm{~mm}$. C. XXIX $31-35 ; 19-21 \mathrm{~mm} .3^{\text {d }}$ and $4^{\text {th }}$ segments cubical. $5^{\text {th }}-9^{\text {th }}$ slightly longer, then shorter segments again, $10^{\text {th }}-12^{\text {th }}$ segments with a dorsal transverse ridge, $13^{\text {th }}-16^{\text {th }}$ with a 3 -pointed prominence. $16^{\text {th }}-24^{\text {th }}$ with a double spine then a single dorsal spine. The double prominences sometimes not distinctly separated. Dorsal spine very small, but in side view well bounded, fixed at the middle of the cirral. $\mathrm{h}=1 / 5$ of the br of the segment. Opposing spine considerably larger $h=1 / 2-{ }^{2} / 3$ of the br of the segment. Terminal claw pointed, curved, about as long as the preceding segment.

$\mathrm{R}$-S projecting under the margin of $\mathrm{Cd}$. I $\mathrm{Br} / \mathrm{h}={ }^{1} / 6 \mathrm{br}$, laterally free. I Brax $\mathrm{h}=1 / 2 \mathrm{br}$, the lateral sides bent at a slight angle to the preveding ossicle. A well-developed synarthrial tubercle between I Br 1 and 2. II and III Br-S:2, the later ones on the outer sides. Arms XXVI, broken (probably XXVIII in a complete specimen). Ex. of syzygies: : $)+4,18+19$, distally with an interval of $(6-) 9$ oblique articulations. Arms smooth, after Br 9 oblique joints.

$\mathrm{P}_{1}$ 17; $6 \mathrm{~mm}$.. $\left(\mathrm{P}_{1}\right.$ on $\mathrm{Br}^{2}$ 2 from the inuer side of a II Brax: 14: (f) $\mathrm{mm}$.), $\mathrm{P}_{2} 17-1 \mathrm{~s} ; 9, \mathrm{~mm} . \mathrm{P}_{3} 16-18 ; 7-8 \mathrm{~mm}$. The distal segments of $\mathrm{P}_{2}$ and $\mathrm{P}_{3}$ very long, $\left.\mathrm{L}=3 \mathrm{br}\right)$, in the distal margin serrate. $\mathrm{P}_{\mathrm{a}}$ lacking, $P_{h}=P_{2} . \quad P_{1}$ usually absent on the inner side after a III Brax. Distal p. $+20 ; 7 \mathrm{~mm}$.

Disk very much incised, smallest diameter 4, largest one 10 mm. Colour: red-violet with yellow longitudinal bands. Distally with yellow and red spots mingled.

Example of division of arms and distribution of pinnules: 
The Crtyoms from Dr. S. Bock's Expedition to Japax 1914. S:3

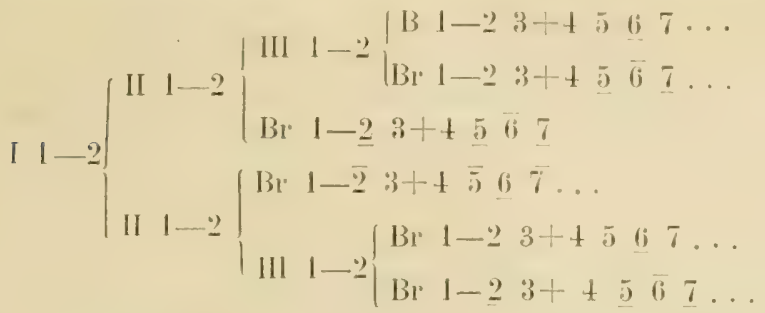

Sp. 2 (St. 59) Free dorsal pole of $\mathrm{Cd} \rightleftharpoons \mathrm{mm}$. C. XXV 25-31; $15-20 \mathrm{~mm}$. Usually a single dorsal spine from the $16^{\text {th }}$ segment. The middle prominence larger on the proximal segments.

$\mathrm{R}-\mathrm{s}$ projecting in the corners. I $\mathrm{Br} / \mathrm{h}=1 / 4 \mathrm{br}$. The divisionseries of rather uniform thickness. Arms XVI (possibly two more), broken. II and III Br-S: 2.

$P_{1} \quad 1 t-16: 5,5-6 \mathrm{~mm}$. (missing in eases comparable with those in the above-quoted scheme). All the ossicles after Br :3 broken. Disk thrown off. 'Colour': light hrown.

Sp. 3 (St.53) A young specimen, like the following one. C. XIT 9; $2 \mathrm{~mm}$. No dorsal spine, the ends of the eirrals somewhat swollen. Opposing spine $h=1 / 2$ of the br of the segment. Teminal claw a little longer than the preceding segment. Cirral 3 and $+\mathrm{L}-\underline{2}$ br.

$\mathrm{R}-\mathrm{s} \mathrm{h} 1 / 2 \mathrm{br}$. I $\mathrm{Br}, \mathrm{h}=-\mathrm{br}$. Axillary $\mathrm{h}=\mathrm{I}^{1 / 2} \mathrm{br}$, forming a slight synarthrial tubercle with the preceding ossicle. Arms $\mathrm{X}, 13 \mathrm{~mm}$.

$P_{1} 10+: 1$. mm. $P_{2}-P_{5}$ wanting. Disk not incised, $1,3 \mathrm{~mm}$.

$\checkmark$ Sp. 4 (St. 53) C. XVI 9-11, in a single or partly double whorl.

Arms XIII, $15 \mathrm{~mm},+$. II $\mathrm{Br}-\mathrm{s}: 2$. Syzygies with an interval of $4-5$ obligue articulations. 'The segment very much hour-glassshaped.

$\mathrm{P}_{1} \quad 14 ; 3,5 \mathrm{~mm} . \mathrm{P}_{2}, 13 ; 2,5 \mathrm{~mm}$. Disk incised, dark-red.

The young of this genus seem to have longer proximal brachials (I Br 1 and 2 especially longer) than other young forms I have examined.

The cirri in sp. 1 somewhat resemble $C$. manca and so there might be some doubt whether the two species are distinguishable (Sp. 1 corresponds in all the other characteristies with sp, 2, which is a younger individual of the same type, but with pronounced albopur- 
purea-cirri). Nevertheless certain differences might be given which speak in favour of the preservation of the species alboprrpurea. C. manca in the above-described specimen has 25 cirrals at a cirruslength of $11 \mathrm{~mm}$; the cirrals are shorter than long; C. albopurpurea does not have the same number of cirrals until a eirrus-length of 15 mm.; the proximal cirrals are longer than broad. Both the species during their evolution show a tendency towards short cirrals, but reach this stage at different cirrus-lengths. The characteristic dorsal spine of C-albopurpurea (and gracilis) is, in a somewhat similar form, to be found in the above-described young stage, referred with some doubt to C. disciformis.

As to the young stages it may be noted that young forms of C. albopupurea have more than $\mathrm{X}$ arms already at an arm-length of about $15 \mathrm{~mm}$., when the brachials are still very juvenile, long, and strongly hour-glass-shaped. The young of $C$. disciformis even at an arm-length of $25 \mathrm{~mm}$. has $\mathrm{X}$ arms and rather smooth brachials.

\section{Cyllometra pulchella $\mathrm{n}$. sp.}

Fig. 133-140. Photo 9.

From St. $6(7), 12(1), 13(33), 16(2), 17(3)=46$ specimens.

Sp. 1 (St. 13) Cd thickly discoidal, the free, flat, dorsal surface $1.5 \mathrm{~mm}$. C. XXIV $25-29 ; 10-12 \mathrm{~mm}$. in two whorls. $1^{\text {st }}-3^{\mathrm{d}}$ segment shorter than broad, $4^{\text {th }}$ about eubical, $5^{\text {th }}$ somewhat longer, the following ones $\mathrm{L}$ about $1^{1 / 3} \mathrm{br}$. Antepenultimate segment a little longer than broad. From about the $7^{\text {th }}$ segment a slight dorsal transverse carination, at the $12^{\text {th }}$ or $14^{\text {th }}$ segment a little thickened on both sides of the median line, appearing there as two inconspicuous tubereles (visible only by high magnification); from the $15^{\text {th }}$ or $20^{\text {th }}$ segment a single swelling which disappears again on the outermost cirrals. Penultimate segment about as long as broad, with an opposing spine, $\mathrm{h}=$ $1 / 3-1 / 2$ of the br of the segment. Terminal claw pointed, curved, $1^{1 / 2}$ times as long as the preceding segment.

$\mathrm{R}-\mathrm{S}$ very narrow bands, laterally united in the proximal half. I Br-s I laterally free, $h=1 / 3-1 / 4 \times$ br. I Brax pentagonal, $h=2 / 3$ br, forms vid I $\mathrm{Br} \quad \mathrm{I}$ a small synarthrial prominence with an indis- 
tinetly limited tuberele, not at all or only slightly prominent in lateral view. $\mathrm{Br} 1$ and 2 with a similar though still smaller prominence. $\mathrm{Br}-\mathrm{s}$ inwardly united basally: Ex. of syzygies: $3+4,9+10,14+15$ etc. with an interval of :3 (exceptionally only 2 ) oblique articulations. Arms $\mathrm{X}, 40-45 \mathrm{~mm}$. First $10 \mathrm{Br}-\mathrm{s}$ discoidal, not » wall-sided», then oblique joints. Arms smooth.

$\mathrm{P}_{1} \quad 13-15 ; 3-5 \mathrm{~mm}$. (T'he pinnular's smooth, eubical to $\mathrm{L}=$ $1^{1}{ }_{2} \times$ br $), P_{2} \quad 16 ; 5-6,5 \mathrm{~mm}$., longer and stouter than the preceding pinnule, the middle segments often with small, distal tubercles, $P_{3} 12$; $3-4 \mathrm{~mm}$. as the following ones smooth; $P_{4} 13$; of the same length or shorter. $P_{5}$ and the following pinnules again longer. $P_{a}$ absent, $P_{b} 14$; $4,5 \mathrm{~mm}$. Distal $\mathrm{p}-\mathrm{s} \pm 20: 5 \mathrm{~mm}$. ( $1^{\mathrm{st}}$ and $2^{\mathrm{a}}$ segments short, $3^{\mathrm{d}}$ cubical, the following pinnulars long and slender, $\mathrm{L}$ about $=2 \mathrm{br}$ ).

Disk incised, smooth, without calcareous granules, $3 \mathrm{~mm}$. Colour light-brown (in the preserved animal).

Sp. 2 (St. 13) Cd knob-formed, free dorsal surface 1,3 mm. 'Terminal claw about as long as the penultimate segment. - Axillary a low hexagon, $\mathrm{h}=2 / 3$ br. II $\mathrm{Br}-\mathrm{S}: 2.2$. Syzygies with an interval of $2-3$ oblique articulations. $\mathrm{Br} \quad 1-8$ discoidal. - Distal $\mathrm{p}-\mathrm{s}$ with a notch between the $2^{d}$ and $3^{\prime \prime}$ segment (a similar condition though not so decided in Sp. 1 too) by which the $2^{d}$ segment seems to form a small prominence. For further details as in the following specimens ef. the table.

Sp. 3 (St. 13) The distal pinnules as above. Sp. 4 and Sp. 5 (St. 13) -.

Sp. 6 (St. 13) All the cirri with the exception of a young one, broken. Some arms with widely separated syzygies. Example:

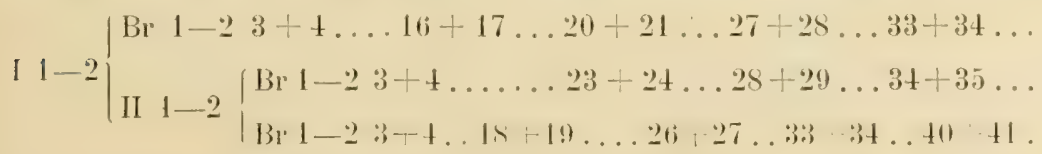

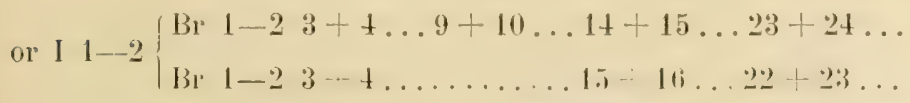

All the other specimens with normal distribution of syzygies. Colour of the specimen: whitish with red spots. 
Sp. 7, Sp. 8 and Sp. 9 (St. 13) -.

Sp. 10 (St. 13) $\mathrm{P}_{\mathrm{a}}$ in one case present (10 segments); $\mathrm{L}=2,2 \mathrm{~mm}$.

Sp. 11 (St. 13) $\mathrm{P}_{\text {a }}$ in one case present = the preceding specimen.

Sp. 12 (St. 13) -.

Sp. 13-28 (St. 1:3) $P_{n}$ exceptionally present. $P_{1}$ in rare cases lacking on a $\mathrm{Br}^{\circ}$ 2, when this ossicle stands on the inner side of a II Brax. Arms $\mathrm{I}: T$ cases, XI : 3 cases, XII : 3 cases. XIII : 1 case, XIV : 1 case, $\mathrm{XV}: 1$ case.

Sp. 29-33 (St. 13) not examined.

Sp. 31 (St. 6) The free dorsal surface of Cd $2 \mathrm{~mm}$. Syzygies with an interval of $3-4$ oblique articulations distally. $P_{1}$ about $=\mathbf{P}_{2}$.

Sp. 35 (St. 6) $\mathrm{P}_{c}$ 12; $4 \mathrm{~mm}$. Colour, as in most of the preceding specimens, yellowish, with small. sparse, crimson spots here and there. Disk thrown off.

Sp. 36 and 37 (St. 6) Syzygies with an interval of 3 oblique articulations. Colour as in Sp. 35.

Sp 38 (St. 6) In arms situated on II Brax ex. of syzygies: $3+4$. $13+14,18+19$. ete. with an interval of only two oblique articulations. The proximal pinnules on the distal side slightly carinated. Disk thrown off. Colow (as in Sp. 39-43) more uniformly yellowish. (in formol-spirit).

Sp. 39 (St. (i) Syzygies with an interval of $3-4$ oblique articulations.

Sp. 10 (St. 6) Syzygies with an interval of 2-3) oblique articulations. The segments are rather long, juvenile. $\mathrm{I}_{2}$ relatively small.

Sp. 41 (St. 12) Cirri in a single or double whorl. $R-s$ broad bands. I Br I h=1/2 br. No symarthrial tubercle.

Sp. 42 and sp. 43 (St. 16) R-s appearing as narrow bands.

Sp. 44 (St. 17) Disk $+\mathrm{mm}$. Colour as in the preceding specimens tigered (white, with small, rather sparse violet spots).

Sp. 45 and Sp. 46 (St. 17) Arms X, 28 and $32 \mathrm{~mm}$. respectirely.

A comparison of the number of arms shows the following distribution: $\mathrm{X}$ arms: 15 cases, XI: 8 cases. XII: 10 cases. XIll: 5 cases. XIV: 1 case, XV: 2 cases. Here, as in Astererometra anthus, one can observe the condition that it is not always the largest specimens that 


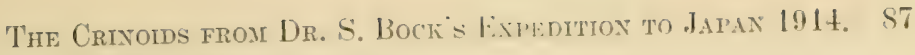

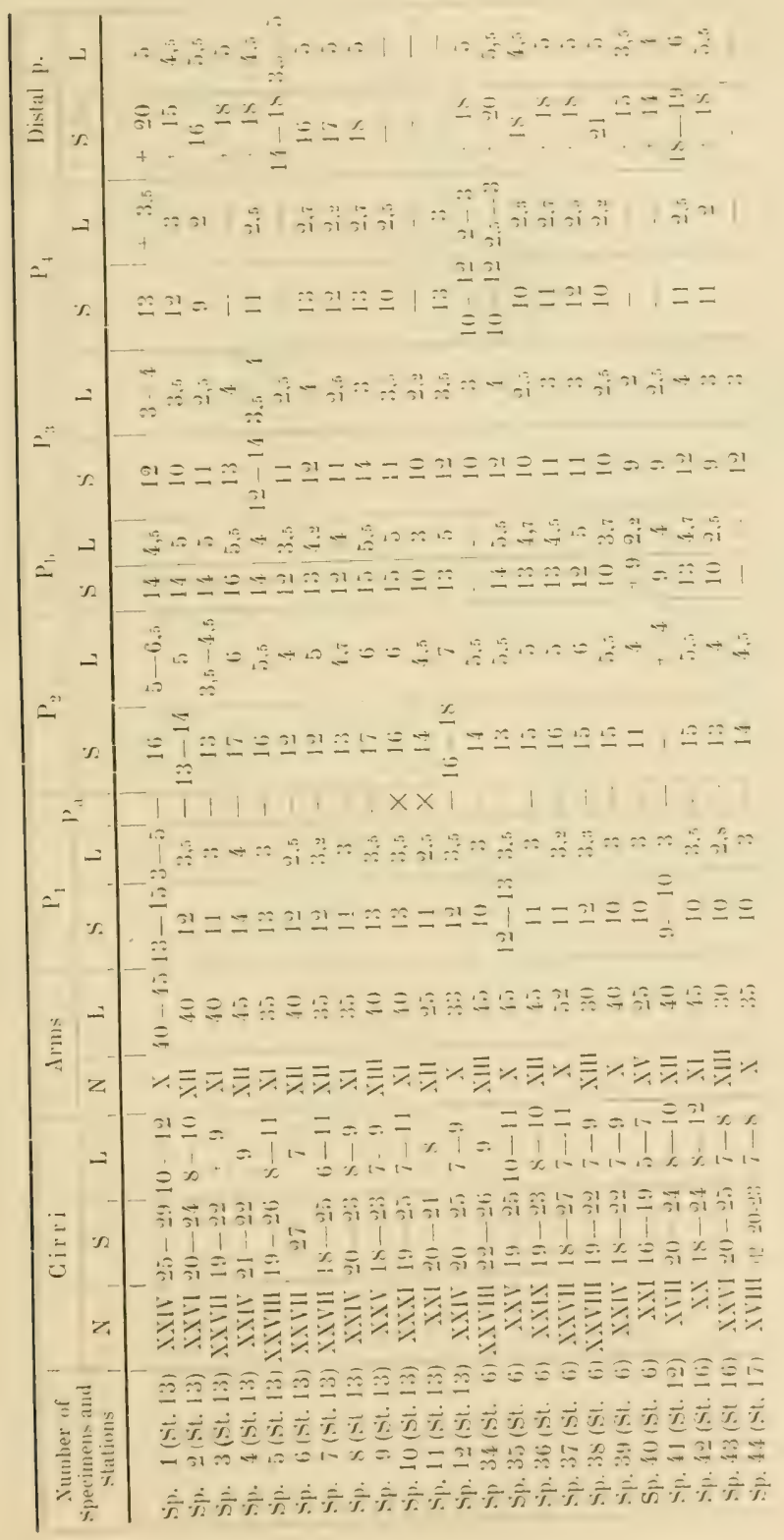




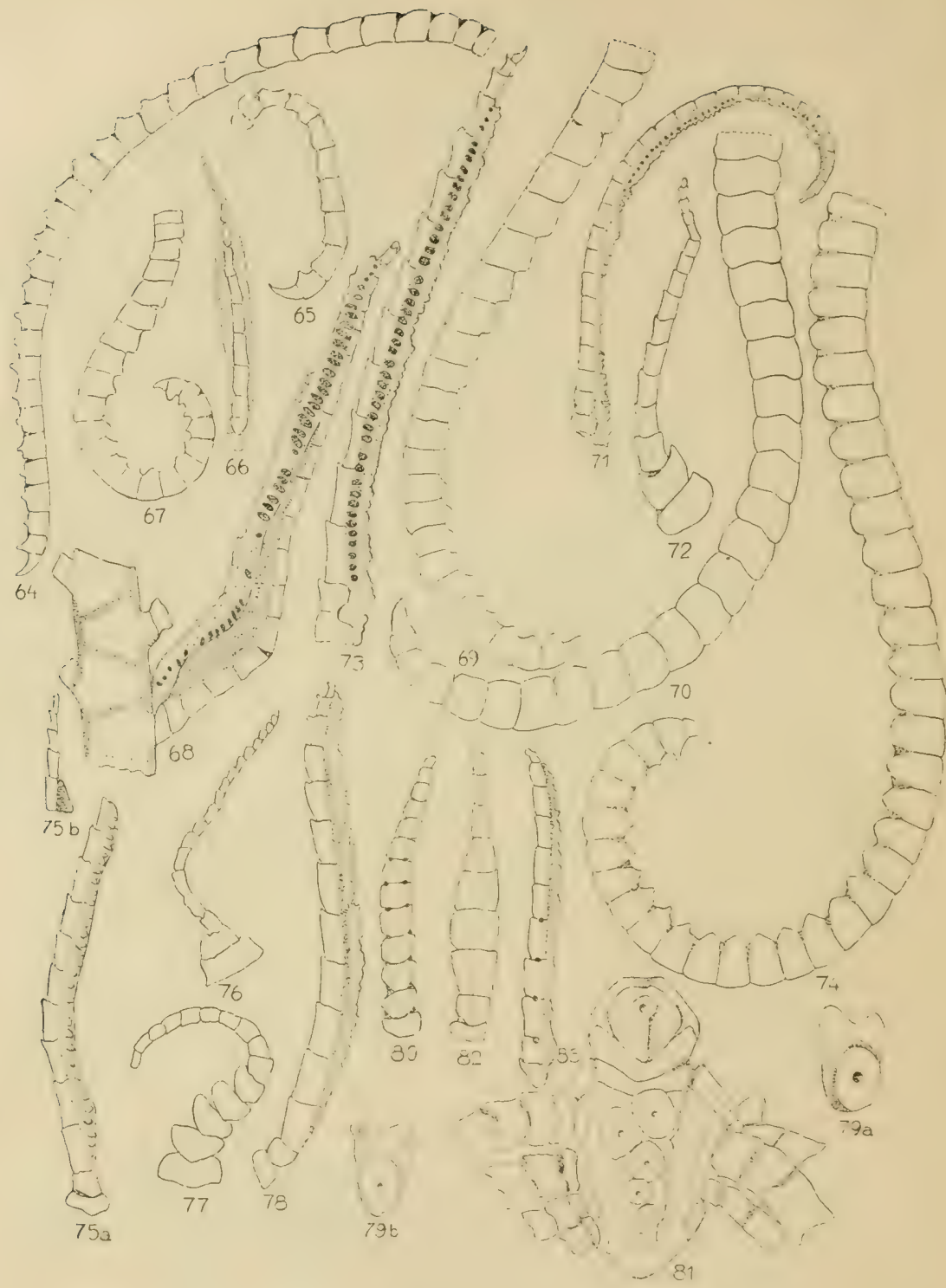

Fig. 64. 65. ('yllometra allopurpuren (14) Large cirrus (St. 59) $7 / 1$, 65) Cirrus from a young

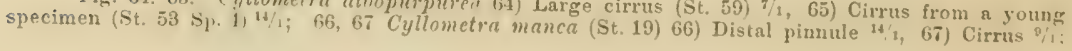


have the most arms, but rather the reverse. It is probable, as I have suggested when treating the above-mentioned species, that the question of eatching the food plays a certain rôle, but possibly (though not very likely, cosidering that I have often seen yduplicative» regenerates situated on $\mathrm{Br} 1$, but never a single arm regenerated from the same ossicle) one might also connect the phenomenon with the fact that the family Colobometride strongly tends to a X-armed type and that this is reached only after a transition stage with more than $\mathrm{X}$ arms.

By the small transverse carination (on some segments replaced by a pair of mieroscopic tubereles) on the proximal cirrals the new species proves itself to be a form of an Oligoplueat type, though otherwise it presents much that reminds us of certain Perometrins (the relatively large size of the centrodorsal cavity and the position of the rosette, which only radially forms »spout-like» processes).

The new species approaches most to $C$. manca, from which it differs by a smaller and less discoidal Cd, by longer cirrals, which have only inconspicuous carinations, by the absence of III Br-s. by the short interval between the syzygies, and by $P_{2}$ being almost smooth.

The species is an interesting form, showing a strong tendency of convergence towards the Macrophreat type.

\footnotetext{
68, 69 Cyllometra disciformis (St. 35) 68) Arm-stump with a genital pinnule 14/1, 69) Cirrus $9 \%$; 70, 71 Trnpiometra encrinus (St. 45), 70) Cirrus ${ }^{9 / 1}$, 71) Distal pinnule 0/1; 72, 73 Pectinometra flavpurpurea 72) $\mathrm{P}_{1} 11 / 1$, 73) Distal piunule ( $1-5$ pairs of Sacculi per segment) 14/1; 7t) Cenometra bella Cirrus \%: 75. 76 Tenmetra multicnlor (St. 12). 75 a) Distal pimule (the tip broken) 14/1, b) 'l'he tip of the pinmule from another specimen (in Dr Montrisex's collection) $14 / 1,7 t$ ) $P_{1}{ }_{14 / 1 ;} 76$. 78 Crossometra septentrionalis (st, 36), 77) PII (the 7 last segments broken) ${ }^{14}, 1,78$ ) Distal pimule $14 ;$; $79-8: 3$ Dindontometra Bncki (St. 56) 79 a) The pennitimate segment viewed from the proximal end, b) The same segment viewed from the distal end, $\left.\times 171 / 2,50) P_{3} 14 / 1,81\right)$ Cd with the cirri arranged in radial groups (observe the distal face of $\left[13 \cdot 1\right.$ ) $\% / 1,82$ ) Genital pimmle ${ }^{14} 1,83$ ) Distal pimule ${ }^{14} / 1$.
} 


\section{Tropiometridæ A. H. CLARK.}

Tropiometra A. H. CL.Lא.

Tr. afra var. macrodiscus (H.1R.1).

Syn.: Antedon mucrorliscus 1895 H.ara Zool, Mag. 'Jokyo Vol. 7, p. 115.

Tropiometra merodiscus 1907 A. H. Chamk Siniths. Misc. Coll. Vol. 50, p. 349; 1908 II. L. Codrk Bull. Mus. Comp). Zool. Vol. 5 l (N:o 11), p. 279; 1912 ג. H. Clirk Smiths. Misc. Coll. Vol. 60, N:o 10, p. 28; 1915 Journ. Aead. Soi. Vol. 5, p. 214; Monograph pp. 52, 54, 275; 1918 Siboga Exp. Vol, 42 B, p. 131.

Tropiometra "fre (part) 1908 A. H. CL.IRK Proc. U. S. Nat. Mus. Vol. 3H, p. 315; 1912 Crin. Ind. Oc., 1). 176.

From St. $27=9$ specimens.

Sp. 1 (St. 27) Cd discoidal, flat dorsal surface with slight radiating swellings, $10 \mathrm{~mm}$.

C. XLHI $36-39, \pm 40 \mathrm{~mm}$, in two whorls. The segments are uniform, cubical or somewhat $\left(\mathrm{L}=1 / 2-{ }^{2 / 3}\right.$ br) shorter. No dorsal spine. Terminal claw a little longer than the penultimate segment. Cirri coarse. Ventral cirri shortest and with a less number of segments.

$\mathrm{R}-\mathrm{s}$ somewhat projecting in the corners. I $\mathrm{Br} \perp \mathrm{h}=1 / 0 \mathrm{br}$, laterally grown together as are also the bases of the axillaries. The articulations between the proximal ossicles indistinct. $\mathrm{I} \mathrm{Br}^{\circ} 2 \mathrm{~h}=1 / 3 \mathrm{br}$, pentagonal or almost triangular with a small median tubercle well marked off from I $\mathrm{Br}$ 1. The proximal segments flattened, granular, as is often the case in Oligometrides. Arms X, $190-210 \mathrm{~mm}$. Br I united inside in pairs, their br $5,5 \mathrm{~mm}$. $\mathrm{Br}^{\circ} 1$ and 2 on the outer side twice as long: All the distal segments short, discoidal. Ex. of syzygies: $3+4,8+9,13+14,30+31,39+40,50+51$ or $3+4,9+10$, $15+16,29+29,41+42,51+52 \ldots$ Distally with an interval of about $S$ oblique articulations. The $\mathrm{L}$ of the segments $=1 / 4 \mathrm{br}$. 14 segments per cm. (12, if the syzygial pairs are counted as units).

$P_{1} 25--27 ; 20 \mathrm{~mm} . \mathrm{P}_{2} 3 t ; 26 \mathrm{~mm}$. (L. of the segments $=1^{1 / 2} \mathrm{br}$ ). $P_{2}-P_{10}$ slowly decreasing, larger and coarser than the following pinnules. Ambulacral furrow does not appear until $P_{9}\left(-P_{11}\right)$ (with the exception of on an arm shorter than the other ones). Distal p. $\pm 35 ; 15$ 
'The Crixoidos from DR. S. Bock's KxpentTiox to JAPAN 1914. 91

mm. (3-5 last segments with weak dorsal hooks, the other segments $\left.\mathrm{L}=1^{1 / 2}-2 \mathrm{br}\right)$.

Disk $22 \mathrm{~mm}$. Mouth subcentral, Anal cone $5 \mathrm{~mm}$. Colour: dark chocolate violet.

Sj). 2 (St. 27) $P_{1}-P_{11}$ without ambulacral furow. For further details see the table.

Sp. 3 (St. 27) $P_{1}-P_{10}$ without ambulacral furrow.

Sp. 4 (St. 27) $\mathrm{P}_{3}{ }_{3}^{2}$; $; 22 \mathrm{~mm}$. $\mathrm{P}_{1}-\mathrm{P}_{4}$ or $\mathrm{P}_{7}$ without ambulacral furrow. Example of distribution of syzygies: $3+4,9+10,18+19$. $28+29,30+37,42+43.48+49.5+55.59+60.69+70.77+78$. S2 $2+83,99+100 \ldots$

Sp. 5 (St. 27) $\mathrm{P}_{1}-\mathrm{P}_{5}$ or $\mathrm{P}_{8}$ without ambulacral furrow. Disk $26 \mathrm{~mm}$.

Sp. 6 (St. 27) $P_{3} 33,23 \mathrm{~mm} . \mathrm{P}_{1}-\mathrm{P}_{11}$ or $\mathrm{P}_{16}$ without ambulacral furrow: Disk $25 \mathrm{~mm}$.

\begin{tabular}{|c|c|c|c|c|c|c|c|c|c|c|c|}
\hline \multirow{2}{*}{$\begin{array}{l}\text { Number of } \\
\text { specimen }\end{array}$} & \multicolumn{3}{|c|}{ Girri } & \multirow{2}{*}{$\begin{array}{l}\text { Length } \\
\text { of arms }\end{array}$} & \multicolumn{2}{|c|}{$P_{1}$} & \multicolumn{2}{|c|}{$P_{2}$} & \multicolumn{2}{|c|}{ Dist. p. } & \multirow{2}{*}{$\begin{array}{l}\text { Diam. of } \\
\text { dorsal } \\
\text { pole of } \\
\text { Cil }\end{array}$} \\
\hline & $N$ & $\mathrm{~S}$ & L & & S & $\mathrm{L}$ & $\mathrm{S}$ & $\mathrm{L}$ & $\mathrm{s}$ & L & \\
\hline & & $36-39$ & & & 25 & 2 & $\mid 34$ & 26 & & 15 & \\
\hline Sp. 2 & & $34-40$ & & & \pm 30 & 22 & \pm 30 & - & \pm 30 & 14 & \\
\hline Sp. 3 & XLV & $34-38$ & & $130-250$ & 34 & 26 & 42 & 30 & 10-45 & $16-18$ & 7 \\
\hline Sp. 4 & XXXVI & $37-40$ & $35-42$ & & $24-28$ & 24 & 33 & 27 & \pm 35 & 15 & 7 \\
\hline Sp. 5 & XXX! & $36-41 \mid$ & $30-40$ & $120-180$ & 34 & 21 & 39 & 2 & 35 & 1 & 9 \\
\hline Sp. 6 & $\mathrm{x}$ & $38-40$ & \pm 40 & 150 & 26 & 18 & 30 & 29 & 3 & 1 & 6 \\
\hline Sp. 7 & L & $33-38$ & $35-45$ & & 35 & 23 & $25+$ & - & $37-40$ & 8 & 7 \\
\hline Sp. 8 & XLIII & $28-40$ & $30-50$ & $245-265$ & $33-42$ & $25-30$ & \pm 35 & $25-30$ & 36 & 18 & 9 \\
\hline Sp. 9 & XXXVI & $28-39$ & $38-45$ & $190-215$ & 27 & 18 & \pm 30 & 21 & 32 & 18 & 7,5 \\
\hline
\end{tabular}

Sp. 7 (St. 구) $\mathrm{P}_{3}, 38 ; 30 \mathrm{~mm}, \mathrm{P}_{1}-\mathrm{P}_{9}, 0 \mathrm{P}^{\circ} \mathrm{P}_{11}$ without ambulacral fแ1\%оw.

Sp. 8 (St. 27) Diameter of Cd $12 \mathrm{~mm}$. Some cirri with a slight opposing spine. In the pharyna a couple of very large Myzostomas. $P_{1}-P_{8}$ without ambulacral furrow. Disk $209 \mathrm{~mm}$.

Sp. 9 (St. 27) $\mathrm{P}_{1}-\mathrm{P}_{9}\left(-\mathrm{P}_{11}\right)$ without ambulacral furow. Disk $2+\mathrm{mm}$.

'The relative size of the proximal pinnules is very variable. P' is. however, always more slender beeause of the lack of a gonad.

Tropimetra afra macrodiscus differs according to A. H. CLARK from tr: afra by the presence of longer and coarser cirri which have more cirrals. 'This difference is also to be found in those that 
were brought home by the Bockian expedition. Nevertheless I cannot consider that a form that only differs in a characteristic of such a low systematie value as this is to be counted as more than a variety. Besides one must bear in mind that Tr. macrodiscus is only known from Sagami Bay, while Tr. afra is known from the coasts of Afriea, Australia and New Guinea. Therefore it is very probable that transition forms may be brought home from the intervening territory. Compare also A. If. Clark's own descriptions of specimens from Sagami (Proc. U. S. Nat. Mus. Vol. 34, p. 315), which are not very different from Ir. afra. Accordingly I am of the opinion that the differences of I'r. macrocliscus certainly cannot be given more than the value of those of a variety.

\section{Tropiometra encrinus (LÜTKEN).}

Fig. 70,71 .

For the older synonymy see 1912 A. H. CLARK Crin. Ind. Oc. p. 177 pro parte (only specimens east of India belonging to this species).

Tropiometra encrinus 1911 A. H. CLARK Austral. Mus. Mem. Vol. 4, part 15, 1. 780; (?) Fauna Sïd-West Austr. Bd 3, Lief. 13, p. 4t0; 1912 Ree. Ind. Mus. Vol. 7, p. 270, (?) Smiths. Mise. Coll. Vol. 60: 10, p. 29; 1913 Proc. U. S. Nat. Ifus. Tol. 43, p. 402; 1914 A. Reichensperger Crin. Aru u. Kei-Inseln, Senckenbg. Vol. 35, p. 106; 1915 A. II. CLak Monograph pp; 1918 Sibogit Exp. Vol. 42 B, p. 131 .

From St. 45: 1 specimen.

Sp. 1 Cd flattened, free dorsal pole $2 \mathrm{~mm}$, with indistinct scars after fallen cirri. - C. XX 25-29 (one cirrus regenerated from the $11^{\text {th }}$ segment), $18-24 \mathrm{~mm}$. in two whorls. Cirrals uniform $\mathrm{L}=1 / 2-$ (distally) ${ }^{2 / 3} \mathrm{br}$, antepenultimate segment $\mathrm{L}=\mathrm{br}$. Opposing spine an indistinct prominence. T'erminal claw $\mathrm{L}=\mathrm{L}^{1 / 2} \times$ the preceding segment, curved, pointed.

$\mathrm{R}-\mathrm{S} \mathrm{h}=1 / 4 \mathrm{br}$, broadest in the corners. I $\mathrm{Br}^{\prime} \mathrm{l} \mathrm{h}={ }^{1 / 3} \mathrm{br}$, laterally free. Axillary triangular $h={ }^{1} / 3$ br. Arms $X, 105 \mathrm{~mm}$. Br 1: br $2,7 \mathrm{~mm}$. united inside in pair's to ${ }^{1 / 3}$ of their height, on the outside twice as lonğ like Br 2. Example of syzygies: $3+4,8+9$ (or $9+10), 16+17$, distally with an interval of 5 to 9 oblique articulations. 'The brachials distally somewhat overlapping, giving the distal parts of the arms at somewhat serrate profile. 'The proximal arm-parts smooth, a little 
'The Crinoids from Dr. S. Boch's Expedition to Japax 1914. 93

flattened. I Brachials laterally with a sharp edge, never a mediodorsal carination. 15 segments per $\mathrm{em} .(12-13$, if the syzygial pairs are counted as units).

$P_{1} 24-25 ; 12,5 \mathrm{~mm}$. smooth, 2- th $^{\text {th }}$ segment with a slight keel on the side which faces the distal parts of the arms, $P_{2}$ similar, $P_{3} 25$, $12 \mathrm{~mm} . \mathrm{P}_{5} 21 ; 11 \mathrm{~mm} . \mathrm{P}_{8} 23 ; 8 \mathrm{~mm}, \mathrm{P}_{1}-\mathrm{P}_{5}$ without ambulacral furrows, larger and coarser than the other pinnules, with gonads. Nevertheless not so marked as in Ir. afra macrodiscus. Distal p. $+30 ; 14$ mm. ( $1^{\text {st }}$ to $2^{\text {d }}$ or $3^{d}$ segment short, then $L=1^{1} / 2-2 \times$ br). Disk 13 mm. Colour: red-violet.

I have kept this 'Tr. encrinus as a species, though it is obvious that intermediate forms are to be found in territories between the region of distribution of $T \%$. carinate and that of $T \%$. encrinus. According to A. H. Cuark (Siboga Exp. Vol. 42 B) Tr.encrinus is said to be restricted to the territories east of India, $T r$. carinata to occur west of this peninsula. In Crinoids of the Indian Ocean (1912) he is not of the same opinion. In this work he certainly separates Tr. carinata from encrimus, but of Tr. encrims he says that it appears to the westward to Aden, the Red Sea etc. About the cirrals he states that: »the outer segments are about twice as broad as long as in Tr. carinato». In the Siboga work he distinguishes the species by the distal cirrals, which in the former species are »much less than twice as broad as long» in Tr. carinate: »more than twice as broad as long». It may be questioned which distinguishing feature he used in 1912 to keep the two species separate.

Reichensperger (1914 p. 107) states that specimens from Ceylon that he has examined present some variations in the relation between $\mathrm{L}$ and $\mathrm{br}$ of the cirrals. In a table he has given the cirrus-length and the number of cirrals of the different specimens, but his assertion that one »aus einem Vergleich der Gliederzahlreihe mit der Cirrenlänge ohne weiteres einsieht» that the relation between $\mathrm{L}$ and br of the cirrals varies is not, however, quite correct. The proportions between $\mathrm{L}$ and br might have been the same even if the number of circals and length of cirri has varied, for the coaseness of the cirrus is also subject to variability.

Retchensperger's second criterion of the identity ot the two species (that P. II. CARPENTER has described a young specimen from Bahia 
with longer cirrals) shows nothing, for, as is well known, all young Crinoids have longer cirrals. As a general opinion one may say that the difference given by CLARK 1918 seems to be the only distinguishing feature, but that it is probable that the difference is only a function of different geographical and ecologieal factors. Here, as always, one has, however, also to keep in mind the probability of hybridisation between two separate forms, which would give intermediate forms in the transition territory. Such intermediate forms are, according to Retonensperger, found at Ceylon, but whether they are caused by geographical factors or by hybridisation cannot yet be determined.

\section{Calometridæ A. H. CLARK.}

\section{Neometra A. H. CL.Mri.}

N. multicolor $\Lambda$. II. Ci..RRK.

Fig. $75,76$.

Syn.: Antedon discoidea (part) 1906 Af Crexdox Bull. Amer. Mus. Vol. 22, Pl. $120,125,126$ according to $A$. II. CLaRK.

Antcion multicolor 1907 A. II. CLani Proc. L. S. Nat. Mlus. Vol. 33, p. 130. Antedon thetis 1907 A. H. Chark Proc, U. S. Nat. Mlus. Yol. 33, p. 151.

Calometra multicolor 1907 A. II. Cц.ан Smiths. Mise. Coll. Vol. 50, p. 363.

Neometra multicolor 1912 A. II. Clark Crin. Ind. Oc. p. 183; Smiths. Misc. Coll. Vol. 60: 10, p. 29; 1915 Monograph pp. 67, 329, 363; Wash. Journ. Aead. Sei. Vol. 5, p. 214; 1918 Siboga Exp. Vol. 42 13, p. 133.

From St. $12=2$ young specimens.

Sp. 1 (St. 12) Cd slightly arched, dorsally flattened, 1,5 mm., C. XII $27-30 ; 11 \mathrm{~mm}$. in a thin whorl. $1^{\text {st }}$ segment short, $2^{\text {cubical, }} 3^{\mathrm{a}}$ a little longer, $4^{\text {th }}$ and the following ones $L=1^{1 / 2}$ br, distally shorter. The distal parts of the cirrals from the $5^{\text {th }}$ segment somewhat collarshaped and bent outwards. Dorsal spine single, from about the $1^{\text {th }}$ segment. Opposing spine $\mathrm{h}=1 / 2$ of the br of the segment. Terminal claw curved, shorter than the penultimate segment.

$\mathrm{R}-\mathrm{S} \mathrm{h}={ }^{1} / 4 \mathrm{br}$, IR prolonged to tips which separate I Br 1 laterally. I $\mathrm{Br} \perp \mathrm{h}=1 / 3 \mathrm{br}$, widely spread out from each other, provided with slight lateral prominences and an inconspicuous medio-dorsal list 
The Crinoids from Dr, S: Bocri's Expedition to Japan 1914. 95

(as is also the case in the preceding and following ossicle). Between $\mathrm{I} \mathrm{Br} 1$ and 2 a close articulation. Axillary $\mathrm{h}={ }^{3} / 4 \mathrm{br}$, without a lateral flange. II Br-s: 2. Arms XII, $30 \mathrm{~mm}$. Primipostaxillaries basally united inside. $\mathrm{Br}^{2} 2$ on the outside twice as broad than on the inside.

Ex, of syzygies: $3+4,12+13,17+18,21+22 \ldots$ ete, with an interval of 3 to $t$ oblique articulations.

$P_{1} 19 ; 4,5 \mathrm{~mm}$. (the 2 first segments strongly enlarged, $1^{\text {st }}$ segment $h=1 / 3$ br with a wing which is broader than the br of the segment, $2^{d}$ segment $h={ }^{1 / 2} b r^{2}$ with a smaller wing, the following segments slender $h=1^{1} / 2$ br, rather smooth, though angular). $P_{2} 17 ; 7 \mathrm{~mm}$. coarser than $P_{1}\left(l^{\text {st }}\right.$ and $2^{2}$ segments as in $P_{1}$, but more slightly alated. $3^{\mathrm{d}}$ and the following segments $\mathrm{L}=3-\mathrm{t} \times \mathrm{br}$, distal segments shorter. with small distal, spiny whorls). $\mathrm{P}_{3} \quad 10 ; 5 \mathrm{~mm}$. (only the $1^{\text {st }}$ segment with a wing). A wing on the $1^{\text {st }}$ segment more and more inconspicuous out to $\mathrm{P}_{10}$ or $\mathrm{P}_{15}$. Distal p. $15 ; 7 \mathrm{~mm}$. $\left(\mathrm{I}^{\text {st }}\right.$ and $2^{\mathrm{a}}$ segment a little enlarged $L={ }^{1 / 2}-{ }^{1 / 1} \mathrm{br}, 3^{\mathrm{d}}$ and following segments $L=2-2^{1 / 2}$ br. Last + segments shorter and more delicate, with distal, spiny whorls). Disk thrown off. Eetoparasitical Eulima.

Sp. 2 (St. 12) C. X $28-31, \pm 11 \mathrm{~mm}$. A dorsal spine from the $12^{\text {th }}$ segment.

The $R-S$ IR projecting. The carination on $\mathrm{I} \mathrm{Br} 1$ and 2 very slight and indistinct. Arms $\mathrm{X}, 32 \mathrm{~mm}$. Syzygies: $3+4,9+10,13+14$ etc. with an interval of 3 oblique articulations.

$\mathrm{P}_{1} 21 ; 5 \mathrm{~mm} . \mathrm{P}_{2} 1 t+; 6 \mathrm{~mm} ., \mathrm{P}_{3} 13 ; 4,7 \mathrm{~mm}$. Distal p. 13+; $6 \mathrm{~mm}$.

Disk thrown off. - The specimen sticking to an Acanthogorgia Dofleni KÜктн. \& GoRz.

The description evidently corresponds on the whole to A. $\mathrm{H}$. CLark's description of Antedon thetis which is a young form of $N$. multicolor. A characteristic in which specimen 1 differs from both the Clarkian descriptions, is a slight medio-dorsal carination of the radials and the I Br series.

Possibly the original Clarkian opinion that Calometre and Neometra ought to be united in one genus is the right one. The difference between the two genera, namely that $P_{1}$ and $P_{2}$ in Calometra are about as long as the following pinnules, in Veometra considerably longer, scarcely holds good (see the comparison given below). 
T. GisLÉx,

C. callista

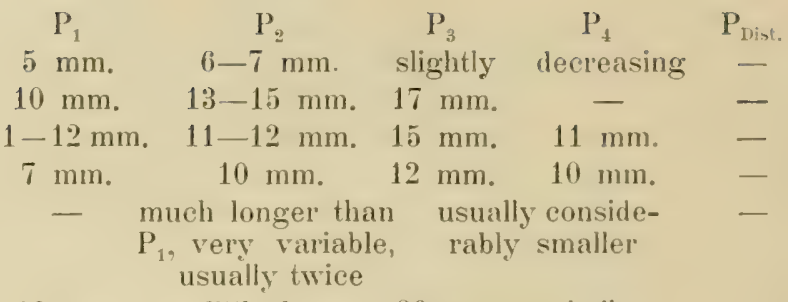

N. spinosissima $10 \mathrm{~mm}$. a little longer $20 \mathrm{~mm}$. similar

My specimen 1

of $N$. mull. $4,5 \mathrm{~mm}$. $\quad 7 \mathrm{~mm}$. $5 \mathrm{~mm}$. $\quad-7 \mathrm{~mm}$.

When one takes into consideration that the length of $\mathrm{P}_{2}$ in $N$. multicolor, as stated by CLARK, is very variable, I cannot think that the above quoted characteristic can be a genus-separating one. It may be true and applicable to full-grown individuals that the arms are $\mathrm{X}-\mathrm{XI}$ in Calometra but XVI-XL in Neometra but this characteristic alone is hardly of genus-separating value. The other distinguishing marks which are given in the diagnosis of the two genera are (with the exception of the one cited below) common to both of them. Calometra diana seems to be an interesting intermediate link between Calometra and Neometre.

In one characteristic, however, both the genera seem to be separated and for the present I have not brought them together. The $\mathrm{R}-\mathrm{s}$ are of different formation. In $C$. callista the interradial processes from $R$ characteristic of Neometra are lacking and I Br-s 1 are therefore in lateral opposition. Judging from the figure given by CARPENTER (Chall. Exp.) the R-S in $C$. discoided also seem to have a similar formation, though an evident approach to the Neometra type may be traeed (ef. A. H. Clark Smiths. Misc. Coll. Vol. 61: 15, p. 42). It is, however, also to be noted that other Calometrid genera (e. g. Pectinometra) often have an interradial prominence on the $R-s$. 
The (rixotas from Dr. S. Bock's Expentriox to Japax $1914 . \quad 97$

Pectinometra 1. II. Crisk.

P. flavopurpurea 1 . H. CLirk.

lig. 72. 73 .

Syn.: Antedon discoiden (part) 1906 Mc Crespos Bull. Aner. Mus. Yol. 22. p). 120, 125, 126 aceording to A. H. CLARK.

Antedon flaenpurpuren 1907 A. H. Clark Proc. U. S. Nat. Mus. Vol, 33, p. [33. Calometra flacopupurea 1907 A. H. CLak smiths. Misc. Coll. Vol. 50, p. 3363. Pectinometra flaropurpurea 1912 1. II. Crark Crin. Ind. Oc., p. 188; 1915 IV ash. Joum. Acau. Sci. Vol. 5, p. 215; 1918 Siboga Exp. Vol. 42 B, p. 138.

From St. 34 (5 spo), 35 (1), 36 (1) $=7$ specimens.

Sp. 1 (St. 36) Cd flattened, $2,2 \mathrm{~mm}$., free dorsal pole $1,5 \mathrm{~mm}$. C. XIX $21-24$ (D) 25-27 (V), 9-12 mm. in two whorls, arranged in 10 rows. $4^{\text {th }}$ segment a little longer than broad, $5^{\text {th }}$ and $6^{\text {th }}$ longest, $L=1^{1}{ }^{1} / 4$ br, then shorter again, distally $L=1 / 2$ br. From the $7^{\text {tir }}$ segment a dorsal spine, compressed from the sides and therefore crista-shaped. distally shortened to a spine. Opposing spine similar to the preceding ones, $h=1 / 3$ of the br of the segment. 'T'erminal claw shorter than the penultimate segment.

$\mathrm{R}-\mathrm{s}$ with a pointed interradial prominence which separates I Br-s 1 . These ossicles with a medio-dorsal, slightly two-topped crista and small lateral prominences which meet above the radial processes. I Br I $\mathrm{h}={ }^{1} / 3 \mathrm{br}$. I $\mathrm{Br} \geq \mathrm{h}=1 / 2 \mathrm{br}$, in the proximal half a crista continuing this one on I Br I. II Br-s: ‥ Arms XVIII, $50 \mathrm{~mm}$. Il Br I basally contiguous inside, with a lateral process on the proximal outer margin. A similar though indistinct one on $\mathrm{Br}$ 1. II $\mathrm{Br}^{\circ} 1$-22 with an indistinet synatrial prominence. Br 2 wice as narrow on the inside, thickened on the outside to receive $\mathrm{P}_{1}$. Example of division of arms and distribution of syzygies:

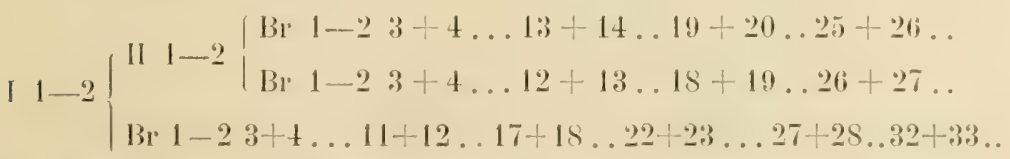

'The segments not overlapping, distally somewhat longer' than broad. 
I', $13 ;-+4$ mm. (much more slender than the following p. T'wo first segments with wing-like processes, $1^{\text {st }}$ segment br $=3 \mathrm{~h}, 2^{\text {d }}$ one bi $\mathrm{r}^{2}=2^{1}{ }_{2} \mathrm{~h}, 3^{\mathrm{l}}$ segment about cubical. Distal segments slender, longer than broad), $\mathrm{P}_{2}, 10 ; 4,2 \mathrm{~mm} . \mathrm{P}_{3}, 9 ; 3,7 \mathrm{~mm} . \mathrm{P}_{4} 9 ; 3,8 \mathrm{~mm}$. with still more insignificant wings. Distal p. 15- $16 ; 6,5 \mathrm{~mm}$. ( $1^{\text {st }}$ and $2^{\mathrm{d}}$ segments short and somewhat swollen, last 3 slender with distal spiny whorls. The other segments smooth, $L=3-+\times$ br). Disk thrown off. Colour (in spirit) yellow-brown, cirri with white and red-grey bands alternating.

Two Myzostomas on the pinnules.

Si). 2 (St. 35) Cd 3 mm, free dorsal pole 2. $5 \mathrm{~mm}$. (. XX $25-30$; 14- $18 \mathrm{~mm}$. arranged in 5 interradial groups, separated by radial interspaces.

R-s not very much IR prolonged. Arms XVII, 65 mm. II Br-s: 2. Br. segments about 100 . 'The bases of the arms bent outwards from Cid at almost a right angle. Syzygies with an interval of $4-6(-11)$ oblique articulations. The segments slightly overlapping and serrate.

$\mathrm{P}_{1} 14-15 ; 4-5,2 \mathrm{~mm}$. (3 $3^{\mathrm{l}}$ segment $\mathrm{h}=1^{1 / 2}$ br), $\mathrm{P}_{2} 14 ; 6,8-7 \mathrm{~mm}$. $\left(t^{\text {th }}-10^{\text {th }}\right.$ segment $\left.\mathrm{L}=2-2^{1 / 2} \mathrm{br}^{\prime}\right), \mathrm{P}_{3} \quad 13 ; \quad \mathbf{i}_{9} \mathrm{~mm}$. coarser than the two preceding ones, $\mathrm{P}_{4} 9+; 4,7 \mathrm{~mm}$. A wing on the first two segments out to $P_{7}$. Distal p. $15-17 ; 7,5-8$ mm. The pinnules are stiff.

Disk $5 \mathrm{~mm}$. with close calcareous granules. Anal cone $2 \mathrm{~mm}$. narrow, with coarse calcareous granules. Colour: arms with yellow and violet bands alternating (= all the following specimens), cirri as in Sp.. 1.

Sp. 3 (St. 3t) Cd 2,3 mm., free dorsal part 1,8 mm. C. XX 22-31; 9-17 mm., indistinctly separated in groups. R-s with small interradial prominences. Alms XVIII $(+1 \%), 75 \mathrm{~mm}, \mathrm{P}_{1} 18 ; 5.5 \mathrm{~mm} . \mathrm{P}_{2}$ 19; 8 mm., $P_{3} 17 ; 8.5 \mathrm{~mm} . \mathrm{P}_{4} 15 ; \mathrm{smm}$. Distal p. 15--16;9-9,5 $\mathrm{mm}$.

5\%. 4 (St. 3t) Cd 3,2 mm., free dorsal pole 2,5 mm. C. XIIII 29-33; 14- $18 \mathrm{~mm}$. Arms + XX, $85 \mathrm{~mm}$. R-s not very much IR prolonged. I Br-s 1 contiguous basally. Syzygies with an interval of $(6-) 11-1+$ oblique articulations. - $\mathrm{P}_{1}$ 19) segments, $\mathrm{P}_{2} 21$; 9, mm. $P_{10} 13 ; 6,2 \mathrm{~mm}$. Distal p. $15 ; 9-9,5 \mathrm{~mm}$.

Sp. 5 (St. 3t) Cd $t$ mm., bare pole 3 mm. C. XXIl 27-37; 17-2t mm. The cirrus-groups IR well separated. I Brax almost. without mediun tubercle, $\mathrm{h}={ }^{1 / 2}$ br. Arms $\pm \mathrm{XX} . \mathrm{P}_{1}$ 22; $7 \mathrm{~mm}$. Disk coarsely granulated, strongly incised, largest diameter $S$ mm., smallest $+\mathrm{mm}$. 


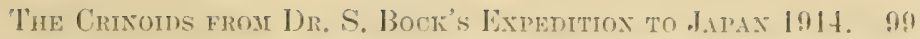

Sp. 6 (St. 34) C. XXII 25-31: 1+-20 mm. Arms + XX. $90 \mathrm{~mm}$. Br-segments about 130, from about Br 100 a slight median carination. Syzygies with an interval of $t-10$ oblique articulations. $-P_{1} 18$; 5 . mm. $P_{2} 17 ; 9,5 \mathrm{~mm}, \mathrm{P}_{3} \quad 16-17 ; 8,5-9$ mm., $P_{4} \quad 16 ; 9,5$ mm.. $P_{3} \quad 13 ;$ $6 \mathrm{~mm}$. Distal p. 17; $-10 \mathrm{~mm}$. - Disk regenerating, 3,5 to $7 \mathrm{~mm}$. in diameter.

Sp. 7 (St. 3t) the dorsal, free surface of (d 2 mm. C. XIX

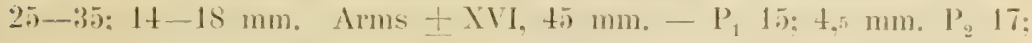
$7 \mathrm{~mm}$. Distal $\mathrm{P}$. 14 ; $8,5 \mathrm{~mm}$. $\mathrm{P}_{\mathrm{a}}$ small $3,5-4 \mathrm{~mm}, \mathrm{P}_{\mathrm{l}}$ and $\mathrm{P}_{\mathrm{c}} 17,+9$ mm. Disk regenerating.

The interradial prominences of the $R-s$ most distinct on the youngest specimens, then the I Br-s I inerease more rapidly and come in lateral apposition. In the largest specimens I Brax is almost rhombic with rariable carination. The wing-like prominences on the $1^{\text {st }}$ and $2^{\text {s }}$ segments of the promimal pinnules are in Sp. 6 distinet out to about $P_{10}$ but still noticeable on the distal pinnules.

Thalassometridæ A. II. CLARK.

Pterometra A. II. Cramk.

Pt. trichopoda A. HI. CL.ARK.

lig. 101, 102.

Syn.: Ptitometra trichoporte 1905 A. II. Chark With. Smiths. Mise. Coll. Vol. 52, p. 224.

Pterometra trichopoda 1911 A. II. Cham Wash. Proc. L. S. Nat. Mus. Yol 39, p. 545; 1912 Crin. Ind. Oc., p. 190; 1915 Monograph, p. S1; 1918 Sibnga Exp. Vol. $42 \mathrm{~B}, \mathrm{p}, 143$.

From St. t5 (1 sp.), ts (1), $59(3)=5$ specimens.

Sp. 1 (St. 45) $\mathrm{Cd} \mathrm{h}=2 \mathrm{~mm}$, br $=2 \mathrm{~mm}$. with 5 radially arranged warts on the dorsal cone.

C. XXIV 67 (D) - 75 ( $\mathrm{V}), 38-44 \mathrm{~mm}$. arranged in 10 rows, 2 rows in every radius, and 22 or 3 cirri in every row. $4^{\text {th }}$ segment cubical, $5^{\text {th }}$ to about $20^{\text {th }} \mathrm{L}=1^{1} / 2 \mathrm{br}$, then shorter segments again. Distal 
segments $L=1 / 2$ br with a strong dorsal spine $(h=1 / 4-1 / 3$ of the br of the segment) from the $30^{\text {th }}$ or the $40^{\text {th }}$ segment. $5^{\text {th }}-12^{\text {th }}$ with a large ventral spine in the distal margins of the segments. The ventral spine curved and projecting over' a part of the following segment, $L=1 / 3$ of the br of the cirral. T'erminal elaw about as long as the preceding segment.

B-S projecting in the corners. $R--S h=1 / 8$ br with a mediodorsal tubercle, sharply set off on the ossicle. I $\mathrm{Br} \cdot 1 \mathrm{~h}=1 / 4 \mathrm{br}$, laterally contiguous in the basal parts, with a longitudinal crista. $1 \mathrm{Br}^{2}-$ $h=1 / 3$ br with a similar crista on the proximal ${ }^{2} / 3$ of the ossicle. A similar prominence also on the $\mathrm{II} \mathrm{Br}-\mathrm{S}$ and on $\mathrm{Br} 1-2$. II $\mathrm{Br}-\mathrm{S}: 2$. Arms XX, $60 \mathrm{~mm}$. Br $1-9$ discoidal, then oblique joints. Distal segments (from about the $40^{\text {th }}$ segment) provided with a slight dorsal spine as in an Asterometra-species. Ex, of syzygies: $3+4,16+17$, $23+24,30+31 \ldots$ ete.

$\mathrm{P}_{1} 11 ; 4,5 \mathrm{~mm} . \mathrm{P}_{2} 10 ; 8 \mathrm{~mm} . \mathrm{P}_{3} 11 ; 8 \mathrm{~mm} . \mathrm{P}_{6} 12 ; 9 \mathrm{~mm} .\left(1^{\text {st }} \mathrm{seg}-\right.$ ment $\mathrm{L}=1 / 2$ br, $2^{d}$ about cubical, $3^{\mathrm{d}}$ and the following ones $\mathrm{L}=1^{1}{ }^{1 / 2}$ $-2 \times$ br, prismatic, smooth). Distal p. $18 ; 10 \mathrm{~mm}$. (the last 6 segments more delicate, slightly collar-shaped). -- Disk thrown off. Colour (in spirit): arms and $\mathrm{p}-\mathrm{S}$ white-grey. Cirri violet.

Sp. 2 (St. 48). C. XV $64-70 ; 35--14 \mathrm{~mm}$. Arms XIV, $50 \mathrm{~mm}$. II Br-s: 2.

$\mathrm{P}_{1} 8 ; 4,2 \mathrm{~mm} . \mathrm{P}_{2} 10 ; 5,2 \mathrm{~mm}, \mathrm{P}_{3} 10 ; 5,8 \mathrm{~mm}$.

S'). 3 (St. 59) C. XVI $61-68 ; 30-35 \mathrm{~mm}$. A dorsal spine from the $22^{\text {th }}\left(-26^{\text {th }}\right)$ segment; the ventral spine from the $4^{\text {th }}$-the $10^{\text {th }}$ (or $\left.12^{\text {th }}\right)$ one.

$\mathrm{R}-\mathrm{S} \mathrm{h}=1 / 6 \mathrm{br}$. I Brax $\mathrm{h}=1 / 2 \mathrm{br}$. Arms XIV t, brolien. $\mathrm{P}_{1} 7+, 3,5 \mathrm{~mm}$. Disk $6,5 \mathrm{~mm}$. with caleareous grauules, - Differing from Sp. 1 by the lower and dorsally smooth Cd. A younger sperimen.

Sp. 4 (St. 59) Cd h $=3 \mathrm{~mm}$., dorsally as in Sp. 1. C. XXII $66-8+; 30-48 \mathrm{~mm}$. The ventral spine from the $t^{\text {th }}$ to the $13^{\text {th }}$ segment. - Primipostaxillaries basally contiguous inside. $\mathrm{I} \mathrm{Br} /$ and II Br 1 with the proximal borders somewhat bent outwards on both sides of the median line. In the latter ease ( $\mathrm{II} \mathrm{Br}$ 1) this condition only on the outside. Arms XX, broken. Il Br-S:2. Syzygies with an interval of $6-7$ oblique articulations. The $\mathrm{Br}-\mathrm{s}$ with a blunt dorsal 
The Crinoids from Dr. S. Bocr's Expedition to Japax 1914. 101

spine from about the $15^{\text {th }}$ segment. $\mathrm{l}_{1} 10+$, $5 \mathrm{~mm}$. Disk $10 \mathrm{~mm}$., thrown off.

5p. 5 (St. 59) Cd h=1.5 mm., with a indistinet, radial tubercles, and a slight central prominence. - C. XY 68-75; 32-37 mm. The ventral spine from the $t^{\text {th }}-10^{\text {th }}$ segment. Dorsal spine from the $20^{\text {th }}-25^{\text {th }}$.

Arms XVII, brokien. II Br--s:2. $P_{1} 9 ; 4$ mm. Disk very much incised and granulated. Longest diameter 6 , shortest $3 \mathrm{~mm}$.

The proximal parts of the animals narrow; the arms after about Br 8 strongly bent outwards. Differ from the original specimen chiefly by having fewer arms and a somewhat smaller size.

Asterometra 1. 11. Cr.irk.

A. macropoda A. H. Ci.ski.

Fig. 99. 100.

Syn: Antedon macropade 1907 A. H. CLark P'oc. L. S. Nat. Mus. Yol. 333, p. 1366 .

Ptilometre maeropode 1908 A. II. CLark Wash. Smiths. Mise. Coll. Vol. 50, p. 359 .

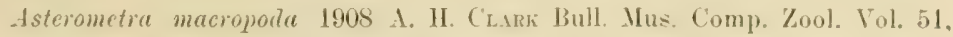
p. 245; 1912 C'rin. Ind. Oe. p. 193; 1915 Monograph pp. 155, 235 etc.; Wash. Journ. Acal. Sci. Vol. 5. p. 215; 1918 Siboga Exp. Vol. 4'2 B, p. 141.

From St. 12 $=2$ specimens.

bjo. 1 (St. 12) Cd: br $=3 \mathrm{~mm}$., visible $\mathrm{h}=2 \mathrm{~mm}$. 5 dorsal, close, radial tubercles arranged round a small, central cavity. - C. XVI 55-75; $45-55 \mathrm{~mm}$. in 5 groups separated by inconspicuous radial interspaces. The $10^{\text {th }}$ to the $25^{\text {th }}$ segments: $L=1^{1 / 3}-1^{1 / 2}$ br. From about the $30^{\text {th }}$ segment $\mathrm{L}=\mathrm{br}$, from the $40^{\mathrm{th}} \mathrm{L}=2 / 3 \mathrm{br}$, the distal segments $L=1 / 2$ br. About the $25^{\text {th }}$ segment the cirrus becomes serrate on the dorsal side in lateral profile. The dorsal spine $h=1 / 4$ of the br of the segment, on the distal segments smaller. Opposing spine $h={ }^{1 / 3}$ of the $b^{\prime}$ of the segment. Terminal claw a little shorter than the penultimate segment. Cirri laterally pressed together.

$\mathrm{R}-\mathrm{S} \mathrm{h}={ }^{1 / 3}$ br. with a small tubercle well limited. I Br $-\mathrm{S}$ I baso-laterally fused, somewhat broader than the $R-s$, in close synarthrial articulation with the axillary. No synarthrial prominenee. Axil- 
lary $\mathrm{h}={ }^{1 / 2} \mathrm{br}$. Arms $\mathrm{X}, 65 \mathrm{~mm} . \quad \mathrm{Br}-\mathrm{S} 1$ inside united in pair's to ${ }^{1 / 3}$ of the $\mathrm{h}$, like $\mathrm{Br} 2$ broader on the outside. The ossicles laterally flattened out to $\mathrm{Br} 4$. After $\mathrm{Br} 10$ oblique joints. Syzygies usually $3 \pm 4,21+22,32+33 .+42+43$ etc. with an interval of $8-10$ oblique articulations. In one abnormal case. howerer:

$$
\text { I } 1-2\left\{\begin{array}{l}
\text { Br } 1-23+4(5+6) \ldots 22+23 \ldots 38+39 \ldots \\
\operatorname{Br} 1-2 \ldots \ldots \ldots \ldots .27+28 \ldots
\end{array}\right.
$$

After $\mathrm{Br} 50(-60)$ a prominent, distally directed, median, dorsal claw which on the outermost segments becomes a strong spine, $h=1 / 3-1 / 2$ of the br of the $\mathrm{Br}$, when riewed in lateral profile. $7-8$ of the most distal $\mathrm{Br}-\mathrm{S}$ with rudimentary pinnules.

$P_{1} 9-10 ; \pm 5 \mathrm{~mm}$. ( $\mathrm{P}_{\mathrm{a}} 10 ; 5 \mathrm{~mm}$, a little more slender $)$ coarse and thick with prismatic pinnulars. $1^{\text {st }}$ and $2^{\text {d }}$ segments short, the other ones somewhat longer than broad. $\mathrm{P}_{2} \mathrm{~S}-10 ; 5 \mathrm{~mm}, \mathrm{P}_{3}$ similar, Distal p. 16; 6,5 mm. Disk thrown off. Colour (in spirit) white.

Sp. 2 (St. 12) C. XV S5-90: $75-80 \mathrm{~mm}$. A dorsal spine from about the $40^{\text {th }}$ segment.

I $\mathrm{Br}$ 1-2 with a slight synarthrial prominence. Each of the two ossicles with a central, inconspicuous, small wart. I Br 2 moreover with 2 low ridges starting from the wart and running proximolaterally. Arms $\mathrm{X}, 70 \mathrm{~mm}$. Ex, of syzygies: $3+4,9+10,13+14$. $19+20 \ldots$ or $3+4,(7+8), 1++15,19+20,26+27,32+33,44$ $+45, \ldots$ A dorsal $\mathrm{Br}$ spine from about the $50^{\text {th }}$ segment. The rudimentary $\mathrm{Br}-\mathrm{S}$ are $\mathrm{S}$.

$\mathrm{P}_{1} 13 ; 5,5 \mathrm{~mm} ., \mathrm{P}_{2} 10 ; 5,7 \mathrm{~mm}, \mathrm{P}_{3} 11 ; \mathrm{P}_{4} 12 ; 6 \mathrm{~mm}, \mathrm{P}_{\mathrm{a}} 14 ; \mathrm{P}_{1}, 11$ of about the same length. Distal p. $16-20 ; 7 \mathrm{~mm}$. (1 $1^{\text {st }}$ and $2^{\mathrm{d}} \mathrm{seg}-$ ment shorter and a little thicker than the following ones, the $\mathrm{L}$ of which is $\left.1^{1 / 2} \times \mathrm{br}\right)$. The pinnules laterally compressed and therefore with a dorsal rim. - Disk thrown off.

The specimens are closely related to $A$. macropoda, from which they differ by having almost smooth proximal brachials. Sp. 1 is a rather young individual with cirri shorter than the arms. The radial, dorsal tubercles of $\mathrm{Cd}$ are, however, well developed and by this it can easily be distinguished from $A$. anthus. The dorsal spines of the cirri are not so prominent and pointed as in $A$. chthus (cf, the figures). 
The Crixoids from Dr. S. Bock's Expedrtrox to Japax 1914. 103

Asterometra anthis A. H. Cimik.

Fig. 92-98, Photo 16.

Syn.: Antedon longicirre (part) 1S!:3 BeLs Journ. Linn. Soc. Vol. 2t, p. 339.

Antedon anthus 1907 1. II. Chank Proc. L. S. Nat. Ifus. Vol 333, 1). 136.

Ptilometra unthus 190S A. II. Crume Smiths Mise. Coll. Yol. 50, p. 359.

Asterometra anthus 1912 1. H. CLam Crin. Ind. Oe., p. 193; 1915 Wash. Journ. Acard. Sci. Vol. 5, p. 215; 1918 Siboga Exp. Vol. 42 B. p. 141.

Asterometra acerbe 1909 1. H. Cism Proc. Biol. Soc. Vol. 22, p. 147; 1912 Crin. Ind. Oc., p. 193; 1915 IIonograph p. 181; 1918 Siboga Exp. Vol. 42 B. p. 141.

Asterometre lepidu l90S A. H. CLam Wash. Proc. Biol. Soc. Vol. 21, p. 229; 1909 Videnskabl. Meddelser, Kobenhaxn, p. 181; 1912 Crin. Ind. Oc, p. 195; 1915 Wash. Journ. Aead. Sei. Vol. 5, p. 215; 1918 Siboga Exp. Vol. 42 B, p. 141.

From St. $45(5), \pm 6(2), 47(5), 53(11), 5+(2), 55(1), 56(7)$, $57(1), 59(20)=5 t$ specimens.

Sip. 1 (St. 51) Cd pointedly conical, br $3 \mathrm{~mm}$., visible $\mathrm{h}=3 \mathrm{~mm}$. Dorsal pole smooth, arched, somewhat hollowed at the top.

C. XVII 80-81; $50-55 \mathrm{~mm}$. arranged in rows which are separated by radial interspaces. $1^{\text {st }}$ and $2^{\text {a }}$ segments short, then increasing to cubical or a little longer $\left(5^{\text {th }}-20^{\text {th }}\right.$ segment $)$, distally decreasing again, from about the $40^{\text {th }}$ segment $\mathrm{L}=1,2 \mathrm{br}$. Usually the $: 3^{\mathrm{d}}\left(\mathrm{or} 5^{\text {th }}\right)-$ about the $15^{\text {th }}$ segments have a dorsal erista, which is most marked on the proximal segments. The $15^{\text {th }}-25^{\text {th }}$ segments are most often more or less smooth, then a dor'sal crest appears, which distally becomes pronounced to dorsal spines. Opposing spine larger than the preceding ones, $h=1 / 2$ of the br of the segments $(3-5$ last segments before the penultimate one have very slight dorsal spines or lack them entirely. Terminal claw short, as fong as the preceding segment).

$\mathrm{R}-\mathrm{s} \mathrm{h}=1 / 4$ br with a tubercle on the medio-dorsal part. I Br I baso-laterally united, br $=2^{1 / 2} \times L$. I Brax low pentagonal, like the preceding ossicle with an indistinct, median, longitudinal crista. II Br-s : ". . similar to the I $\mathrm{Br}_{\mathrm{r}} \mathrm{s}$. Arms XVI, $65 \mathrm{~mm}$. Primipostaxillaries connected basally in pairs. Arms laterally sharply flattened out to about Br 10. Ex. of syzygies: $3+4,12+13,22+23,30+31,37+38 \ldots$ or $3+4,13+14,21+22,28+29,35+36, \quad+1+42,48+49,55$ $+56 \ldots$ in a single case $t+5,13+1+\ldots$ After $\mathrm{Br}^{\circ} 10$ decided 
triangular segments. 'The $\mathrm{Br}-\mathrm{S}$ with a median, dorsal, distally directed spine after the $40^{\text {th }}\left(-50^{\text {th }}\right)$ segment. The last $10 \mathrm{Br}-\mathrm{s}$ with rudimentary pinnules.

$P_{1} 12 ; 5 \mathrm{~mm}$. (1 $1^{\text {st }}$ segment shorter than long, the following ones $\mathrm{L}=1^{1 / 2}-2 \mathrm{br}$, smooth, prismatic), $\mathrm{P}_{2} 12 ; 5,5 \mathrm{~mm}, \mathrm{P}_{3}{ }_{3} 12 ;$ ij $\mathrm{mm}$. $P_{10} 15 ; 8 \mathrm{~mm}$. Distal p. $18 ; 10 \mathrm{~mm}$. (The $\mathrm{L}$ of the segments $=2 \mathrm{br}$ ).

Disk $8,5 \mathrm{~mm}$. Colour (in spirit) yellow-brown. In life probably flame-coloured (the spirit and still more the formalin in which the following specimens are preserved brightly red-coloured). - One arm with an entoparastical gastropode (Stylina?).

Sp. 2 (St. 56 ) Cd br 4 mm., h $4 \mathrm{~mm}$. The dorsal cavity slightly developed. No distinet dorsal spine on the cirri before the $20^{\text {th }}$ (or $25^{\text {th }}$ ) segment (the $6^{\text {th }}-12^{\text {th }}$ segment with a slightly indicated dorsal crista). Syzygies in some cases $1+23+4$. or $3+45+6$. Example:

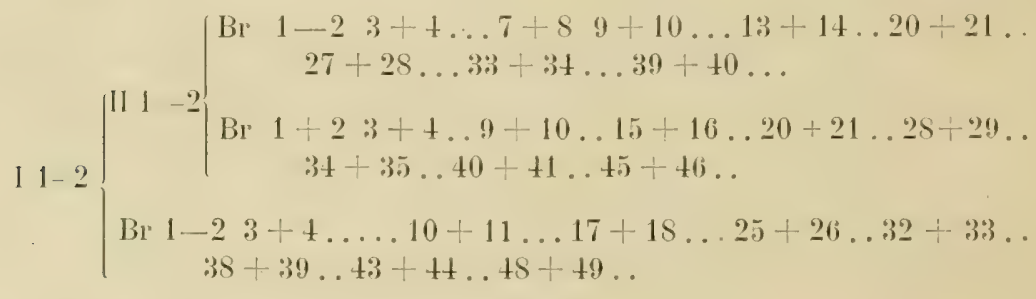

Parasitic Stylinas. For further details, as in the following specimens, see the table.

Sp. 3 (St. 56) Cd without dorsal eavity. Cirrals with a dorsal crista on most of the C. from the $4^{\text {th }}-5^{\text {th }}$ segment. No gap between this and the dorsal spines, which occur from about the $15^{\text {th }}$ segment. The arms laterally flattened to $\mathrm{Br}$ t. A dorsal spine on the $\mathrm{Br}-\mathrm{s}$ from about the $60^{\text {th }}$ segment. Last 8 segments with rudimentary p-S. - Parasitic Stylinas.

Sp. 4 (St. 56) Cd lower than in the preceding specimen, not conical at the top. H: $1,5 \mathrm{~mm}$, br $2,5 \mathrm{~mm}$. No dorsal cavity. Cirrals $3-5$ with a dorsal spine, then a erista. About the $15^{\text {th }} \mathrm{seg}$ ment smooth cirrals which gradually become dorsal spines distally. $\mathrm{R}-\mathrm{S}$ with a slight tubercle. Dorsal spine from the $40^{\text {th }} \mathrm{Br}$. 
'The Crtaids from Dr. S. Bock's Expenttion to Japax 1914. 105

Sp. 5 (St. 50) Cd and C. as in Sp. 4. R-s with a very high and well marked tubercle. I Br 1 with a trace of a crista. 13r--s with a dorsal spine from about the $20^{\text {th }}$ segment. Last 7 segments with rudimentary pinnules.

Sp. 6 (St. 56) $3^{\text {d }}-5^{\text {th }}$ cirral with a small dorsal spine; $6^{\text {th }}-10^{\text {th }}$ (or $15^{\text {th }}$ ) segments smooth. R-s with a very small tubercle. Dorsal spine from the $40^{\text {th }} \mathrm{Br}$.

Sp. 7 (St. 56) A rather small specimen. The cirrus-segments longer than in the preceding specimens. $2^{\text {d }}-6^{\text {th }}$ eirral with both a ventral and a dorsal crista, $7^{\text {th }}-10^{\text {th }}\left(\right.$ or $\left.12^{\text {th }}\right)$ segments smooth. $\mathrm{R}-\mathrm{S}$ with a high prominence. I $\mathrm{Br}-\mathrm{S}$ almost smooth. lixample of syzygies: $3+4,14+15,22+23,31+32 \ldots$ Dorsal spine from the $35^{\text {th }}$ Br. 2-4 segment with rudimentary p-s. - Parasitic Styline.

Sp. 8 (St. 59) Cal pointedly conical, $\mathrm{h}=3 \mathrm{~mm}$. Cirri with a

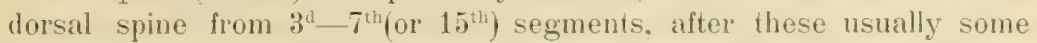
smooth cirrals. $9^{\text {th }}-25^{\text {th }}$ segments longer than broad. All the distal segments with spines. Opposing spine usually not longer than the preceding ones. - $\mathrm{R}-\mathrm{S} \mathrm{h}={ }^{1 / 3}$ br. Arms laterally flattened out to $\mathrm{Br} 8$. Dorsal elaw from the $60^{\text {th }} \mathrm{Br}$. Colour red-brown.

Sp. 9 (St. 59) More often than in Sp. 8 weak spines before the opposing spine. $\mathrm{R}-\mathrm{S}: \mathrm{h}=1 / 3 \mathrm{br}$ with a dorsal crista. Dorsal claw from the $50^{\text {th }}$ or $60^{\text {th }} \mathrm{Br}, h={ }^{1 / 3}$ of the br of the segment. The $\mathrm{L}$ of the distal pinnulars $=2^{1 / 2} \mathrm{br}$.

Sp. 10 (St. 59) $\mathrm{H}$ of $\mathrm{Cd} 2,5 \mathrm{~mm}$. No dorsal spine before the $20^{\text {th }}\left(-25^{\text {th }}\right)$ cirral. From about Br 65 a dorsal claw, $h=1 / 5$ of the segment.

Sp. 11 (St. 59) R-S: br $=2{ }^{1 / 2} \times \mathrm{L}$. Dorsal elaw from about $\mathrm{Br} 50$, the $h$ as in sp. 10.

Sp. 12 (St. 59) Cd rather bluntly conical, $h=2 \mathrm{~mm}$. $\mathrm{R}-\mathrm{s}$ with a very slight dorsal tubercle. The proximal $\mathrm{Br}-\mathrm{s}$ a little knobby. Dorsal spine from the $50^{\text {th }}\left(-60^{\text {th }}\right) \mathrm{Br}$. The $\mathrm{L}$ of distal pinnulars $2 \frac{1}{2}$ $-3 \times$ br.

Differs by having a somewhat lower and more rounded Cd and a weaker radial tubercle.

Sp. 13 (St. 59) Il of Cd $3 \mathrm{~mm}$. R-S: $\mathrm{h}=1 / 4 \mathrm{br}$ with a slight dorsal tubercle. Arms broken. $1^{\text {st }}$ syzygy in one ease between Bi. I and 2. Fewer pinnulars on $P_{1}$ (8) after II Brax. Disk 7 mm. 
Sp. 14 (St. 59) Cd pointedly conical, $\mathrm{h}=2,8 \mathrm{~mm}$. The proximal row of prominences on the cirri indistinctly separated from the distal one. $\mathrm{R}-\mathrm{S} \mathrm{h}=1 / 3 \mathrm{br}$ with a dorsal tubercle, indistinctly limited distally. Dorsal spine from the $50^{\text {th }} \mathrm{Br}$.

$P_{4} 10 ; 6 \mathrm{~mm} ., P_{5} 14 ; 7,5 \mathrm{~mm}$. The longest segments on the distal $\mathrm{p}-\mathrm{S}$ at least $\mathrm{L}=3 \mathrm{br}$. Disk $6 \mathrm{~mm}$.

Sp. 15 (St. 59) $\mathrm{R}-\mathrm{S} \mathrm{h}={ }^{1} / 4$ br with a dorsal erista. Dorsal spine from about the $40^{\text {th }} \mathrm{Br}, \mathrm{P}_{4} 11 ; 0 \mathrm{~mm}$. The $\mathrm{L}$ of the distal pinnulars $=2^{1 / 2-3} 3^{1 / 2} \mathrm{br}$.

Sp. 16 (St. 59) II of Cd $3 \mathrm{~mm}$, blunily conical. $\mathrm{R}-\mathrm{s}: \mathrm{h}=1 / 5 \mathrm{br}$ with a dorsal tubercle. A dorsal elaw from the $60^{\text {th }} \mathrm{Br}(\mathrm{h}=1 / 3$ of the br of the segment). $\mathrm{P}_{4} 13 ; 8,5 \mathrm{~mm}$. The $\mathrm{L}$ of the distal pinnulars 2-2 ${ }^{1} / 2$ br. - Parasitic Stylina.

Sp. 17 (St. 59) $\mathrm{R}-\mathrm{S} \mathrm{h}=1 / 4$ br with a dorsal tubercle. Dorsal claw from $\mathrm{Br} 50$. The $\mathrm{L}$ of distal pinnulars $2{ }^{1 / 2}-3 \mathrm{br}$.

Sp). 18 (St. 59). Cd bluntly dome-shaped, h=4,5 mm. Cirrusmarks arranged in 5 groups; in each group $3-5 \mathrm{C}$. All the cirri thrown off. $\mathrm{R}-\mathrm{S} h=1 / 5 \mathrm{br}$. Arms sharply tlattened laterally out to $\mathrm{Br}$ 4. Dorsal spine from about $\mathrm{Br} 55$. An example of multiplicative regeneration of arms:

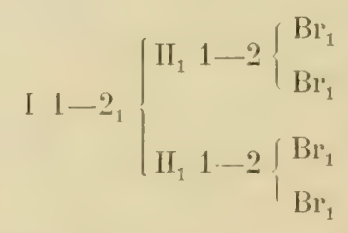

Sp. 19 (St. 59) $\mathrm{Cd}$ a pointed cone. $\mathrm{R}-\mathrm{s}: \mathrm{h}=1 / 3$ br with a dorsal crista. A dor'sal claw from about $\mathrm{Br} 55$. The $\mathrm{L}$ of distal pinnulars $2{ }^{1 / 2} \mathrm{br}$.

Sp. 20 (St. 59) H of $\mathrm{Cd} 3,5 \mathrm{~mm}$. R-S $\mathrm{h}=1 / 4-1 / 3$ br with a dorsal crista. A dorsal spine from $\mathrm{Br}$ 55. The $\mathrm{L}$ of distal pinnulars $2{ }^{1 / 2}-3$ br.

Sp. 21 (St. 59). Dorsal Br spine from about the $40^{\text {th }}$ segment, slowly increasing. The $\mathrm{L}$ of distal pinnulars $2^{1 / 2}$ br.

Sp. 22 (St. 59) H of Cil $2,5 \mathrm{~mm}$. pointedly conical. $\mathrm{R}-\mathrm{S} \mathrm{h}=$ ${ }^{1 / 4} \mathrm{br}$ with a dorsal tubercle. Dorsal Br-spine appearing first about the 
The Crixolds from Dr. S. Bock's bixpedition to Jaldx 1914. 107

$75^{\text {th }}$ segment, rather low. $P_{4} 12 ; 6,5 \mathrm{~mm}$. The $\mathrm{L}$ of distal pinnulars $2-21 / 2 \mathrm{br}$.

Sp. 23 (St. 59) $\mathrm{R}-\mathrm{S} \mathrm{h}={ }_{1}^{1 / 3}$ br with a slight tuberele. Dorsal Br-spine from the $50^{\text {th }}$ segment. The L of distal pinnulars 2 br.

Sp. 21 (St. 59) II of Cd 3 mm., eylindrical, dorsally rounded with a small cavity. $\mathrm{R}-\mathrm{s} \mathrm{h}=1 / 6$ br with a dorsal crista; a slight carination on $\mathrm{I} \mathrm{Br} \cdot 1$ and 2. Dorsal Br-spine rather weak, from about the $50^{\text {th }}$ segment. The $\mathrm{L}$ of distal pinnulars 2 br. - Parasitic Stylines.

Sp. 25 (St. 59) $\mathrm{R}-\mathrm{S} \mathrm{h}-{ }^{1}+\mathrm{br}$ with a torsal tubercle. I Br 1 smooth. Arms broken.

Sp. 26 (St. 59) Cd a rather low $(\mathrm{h}=2 \mathrm{~mm}$. $)$, pointed cone. The short dorsal cirri with the $7^{\text {th }}-14^{\text {th }}$ segments slender, $L=2$ br. $\mathrm{R}-\mathrm{s} \mathrm{h}={ }^{1 / 3}$ br with a dorsal crista. Dorsal Br-spine from the $50^{\mathrm{th}}$ segment. 'The $\mathrm{L}$ of the distal pinnulars $2-2^{1 / 3}$ br. Disk $7 \mathrm{~mm}$.

Sp. 27 (St. 59) H of $\mathrm{Cl} 3,5 \mathrm{~mm} . \mathrm{R}-\mathrm{s} \mathrm{h}=1 / 3$ br with a dorsal crista. Dorsal Br-spine from the $50^{\text {th }}$ segment. The $L$ of the distal pinnulars $2-2{ }^{1 / 2}$ br.

Sp. 28 (St 46) Cd: h: 3, br: $3 \mathrm{~mm}$. Most cirri broken or very small. From the $7^{\text {th }}$ cirral a dorsal crista which is gradually transformed into a dorsal spine. $\mathrm{R}-\mathrm{S} \mathrm{h}={ }^{1 / 2}-{ }^{1 / 3}$ br with a small dorsal tubercle. B-S IR visible. Dorsal Br-spine from about the $55^{\text {th }} \mathrm{seg}$ ment, strongly curved, slowly increasing. The L of the distal pinnular's $2{ }^{1} / 2-3$ br.

Sp. 29 (St. 46) A young individual. Cd smaller, $\mathrm{h}=1 \mathrm{~mm}$. Cirri slender, as in the dorsal whorl in older specimens. $R-s: h=1 / 1$ or $2 / 3$ br with a dorsal longitudinal crista. The arm-bases laterally flattened out to $\mathrm{Br}$. Dorsal Br-spine from the $50^{\text {tht }}$ segment; because of the shortness of the arms only a small part of the arms spiny. The $\mathrm{L}$ of the distal pinnulars $2^{1 / 2}$ br:

Sp. 30 (St. 53) $\mathrm{R}-\mathrm{S} \mathrm{h}={ }^{1} / 5$ br with a dorsal tuberele. Dorsal Br-claw from the $45^{\text {th }}$ segment. The $\mathrm{L}$ of distal pinnulars on the distal pinnules 2 br.

Sp. 31 (St. 53) Cd with an arehed and rounded dorsal pole. 'The proximal and distal series of prominences on the cirri not distinetly separated. $\mathrm{R}-\mathrm{s} \mathrm{h}={ }^{1 / 4} \mathrm{br}$ with a dorsal spine or erista. $11 \mathrm{Br}-\mathrm{s}$ as always : 2. A pair of new regenerated arms of somewhat unequal size. 
Dorsal Br-claw from about the $50^{\text {th }}$ segment $P_{5} 10 ; 7 \mathrm{~mm}, \mathrm{P}_{8} 13 ; 7,5$ $\mathrm{mm}$. The $\mathrm{L}$ of distal pinnulars $=2-2^{1} / 2 \mathrm{br}$.

Sp. 32 (St. 53) R-S h=1/3 br with a dorsal erista. Dorsal Br-claw from the $50^{\text {th }}$ segment. The $\mathrm{L}$ of distal pinnulars $2 \mathrm{br}$.

$\mathrm{Sp} .33$ (St. 53) $\mathrm{R}-\mathrm{S}$ as in the preceding specimen. Dorsal Brspine from the $50^{\text {th }}$ segment. $P_{5} 14 ; 7 \mathrm{~mm}$. - The $L$ of distal pinutlars $2-2{ }^{1 / 2}$ br: $P_{3}$ of an arm grown out to a complete new arm.

SP. 34 (St. 53) Cd rather low. Cirri typical. $\mathrm{R}-\mathrm{S} \mathrm{h}=1 / 2 \mathrm{br}$ with a dorsal crista. A very indistinet carination of $\mathrm{I} \mathrm{Br} 1$ and 2 and $\mathrm{Br} 1$ and 2. Dorsal Br-spine from the 50 $0^{\text {th }}$ segment, rather low but rapidly increasing the last $\mathrm{cm}$. The $\mathrm{L}$ of the distal pinnulars $2{ }^{1} / 2 \mathrm{br}$.

Sp. 35 (St. 53) II of $\mathrm{Cd} 2,5 \mathrm{~mm}^{2}$, pointedly conical. $\mathrm{R}-\mathrm{s} \mathrm{h}=$ $1 / 3$ br with a dorsal crista. Dorsal Br-spine from the $50^{\text {th }}$ segment. The arms with $80-90 \mathrm{Br}-\mathrm{S}$. The $\mathrm{L}$ of distal pinnulars $2 \mathrm{br}$. - Parasitic Stylinas.

Sp. 36 (St. 53) Cd as before. Dorsal Br-spine from about the $40^{\text {th }}$ segment. The Br-segments $70-75$.

\section{Adolescent or juvenile specimens.}

S1). 37 (St. 53) Cirri: $1^{\text {st }}$ segment short, $2^{\text {d }}$ somerwhat longer than broad, $3^{\mathrm{d}} \mathrm{L}=2^{1} / 2 \mathrm{br}, 4^{\text {th }}$ and $5^{\text {th }}$ cirral $\mathrm{L}=2 \mathrm{br}, 6^{\text {th }}$ segment $\mathrm{L}=1^{1} / 2 \mathrm{br}$, distally widened, $7^{\text {th }}$ and the following ones $\mathrm{L}=\mathrm{br}$, with an inconspicuous dorsal carination, which is transformed distally into a dorsal spine. Opposing spine $h={ }^{1 / 2}$ of the br of the segment. Terminal claw about as long as the penultimate segment.

B-s especially projecting in the corners, form basally a narrow, continuous ring. $\mathrm{R}-\mathrm{Sh}=1^{1 / 2} \mathrm{br}$, with a strong, longitudinal crista in the proximal $2 / 3$. R-S laterally contiguous, enclose practically the whole intestinal sac. I $\mathrm{Br}-\mathrm{S} I$ with a medio-dorsal crista, like the axillaries well separated from each other laterally. The entire arm only 13 - 18 segments.

$P_{1}-P_{3}$ usually absent. Sometimes, however, $P_{1}$ and $P_{3}$ developed. Observe the considerable length of the distal pinnules, when compared with the arm. The $\mathrm{Br}-\mathrm{S}$, especially $\mathrm{Br} \mathrm{S}$ and 11 , appear almost as axillaries because of the relatively great size of the pinnules. Example of pinnulation: 


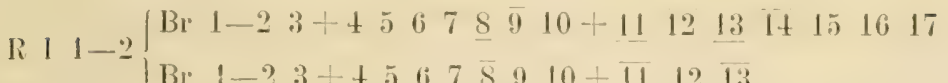

Disk concealed, probably with orals; compare for instance sp. $3 S, 44,45,50,51$.

Sp. 35 (St. 53) The $\mathrm{L}$ of the distal pinnulars $=3$ br. Rudimentary orcls.

S1). 39 (St. 53) and Sp. 40 (St. 53) The L of the distal pinnulars on the distal $\mathrm{p}-\mathrm{S} 2^{1 / 2}$ br.

Sp. 41 (St. 45$) \mathrm{L}$ of cirral $5-7=\mathrm{L}^{1 / 2} \mathrm{br}$. The $\mathrm{L}$ of the distal segments - br. A dorsal spine from cirral 10. - B-s projecting IR as small prominenees, $\mathrm{R}-\mathrm{S} \mathrm{h}=\mathrm{L}^{1 / 2} \mathrm{br}$, in lateral apposition, with a strong longitudinal crista, proximally ending in a blunt spine. I Bl-s 1 : $\mathrm{h}=1 / 2$ br. I Brax h $\ldots 2 / 3$ br. A slight synarthrial carination. Aims »wall-sided» with small lateral crests out to $\mathrm{Br}$ 2. 'The entire arm with $40 \mathrm{Br}-\mathrm{s}$. A dorsal Br-spine from the $25^{\text {th }}$ segment. The distal pinnulars with small spiny whorls in the distal ends. $3^{4}$ and $4^{\text {th }}$ pinnular $L_{L}=3$ br.

Sp. 42 (St. 45$)-S p .43$ (St. 45$)$-.

Sp. 44 (St. 45). The $\mathrm{L}$ of the segments of the dorsal cirri $1^{1 / 2}-$ 2 br. Complete pinnulation. Small orals.

Sp. 45 (St. 45) $\mathrm{P}_{2}$ wanting. Orals large and well developed, covering ${ }^{1} / 3$ of the radius of the disk.

Sp. 46 (St. 47) $\mathrm{R}-\mathrm{S}: \mathrm{h}=2 / 3$ br with a dorsal crista. The $\mathrm{L}$ of the distal pinnulars of the distal pinnules $2 \mathrm{br}$.

Sp. 47 (St. 47) R-S h $=1^{1 / 2}$ br. An indistinet median erista on $\mathrm{I} \mathrm{Br} 1$ and 2 . The $\mathrm{L}$ of the distal pinnulars $=21 / 2 \mathrm{br}$.

Sp. 48 (St. 47 ) $\mathrm{R}-\mathrm{S} \mathrm{h}=1^{1 / 2}$ bl'. The $\mathrm{L}$ of the distal pinnulars $21 / 2-3$ br. Orals resorbed.

Sp. 49 (St. 47) R-S: h-br. I Br-S 1 and 2 rather smooth.

Sp. 50 (St. 47) R-s: h > br. A crista on I Br 1 and 2 with slight medio-dorsal tubereles. $\mathrm{P}_{2}$ sometimes lacking. The $\mathrm{L}$ of the distal pinnulars $2^{1 / 2}$ br. Orals thin, but well preserved.

Sp). 51 (St. 5t) $t^{\text {th }}$ cirral the longest $L=3$ br. Dorsal spine from the $6^{\text {th }}\left(-10^{\text {th }}\right)$ segment. - $\mathrm{R}-\mathrm{S} \mathrm{h}=-1^{1 / 2} \mathrm{br}$, with a well boldered median tuberele. I BI-S 1 and 2 similar, but with a median keel, $h={ }^{2 / 3}$ and $1 / 1 \times b_{1}$ respectively. A slighter keel on $\mathrm{Br} 1$ and 2 . 
I $\mathrm{Br} 1$ and $\mathrm{Br} 1$ with a slight lateral carination. $\mathrm{P}_{2}$ lacking. Small orals.

Sp. 52 (St. 54) R-S h-br. $1 \mathrm{Br} 1$ and 2 with a rather dislinet median crista. The $\mathrm{L}$ of the distal $\mathrm{p}-\mathrm{s}=2 \mathrm{br}$.

Sp. 53 (St. 55 ) $3^{\text {d }}-6^{\text {th }}$ cirral the longest, $L=2^{1 / 2}$ br. $L$ of the distal segments $1^{1 / 2}$ br. $\Lambda$ dorsal carination from cirral 9. Opposing spine: $h=1 / 2$ of the $b r$ of the segment.

$\mathrm{B}-\mathrm{S}$ as in Sp. 37. R-S $\mathrm{h}={ }^{1 / 2}$ br, with a high carina, IR somewhat extended and projecting as flaps between $\mathrm{I} \mathrm{Br}-\mathrm{s} 1$. The very last $B r$-segments with a small dorsal spine. The pinnule-supporting Br-s usually shaped like axillaries. - 'The first pinnule most often on $\mathrm{Br} 7$ (sometimes also a small $\mathrm{P}_{1}$ ). An axillary partly supports a long arm on the left, which is $5 \mathrm{~mm}$. long, and provided with a small $\mathrm{P}_{1}$ and distal pinnules, and partly a smaller arm on the right, $2 \mathrm{~mm}$. without pinnules. Of the remaining arms too the right ones are usually a little shorter than the left ones. $\mathrm{P}_{3} 12 ; 2 \mathrm{~mm}$. Example of pinnulation:

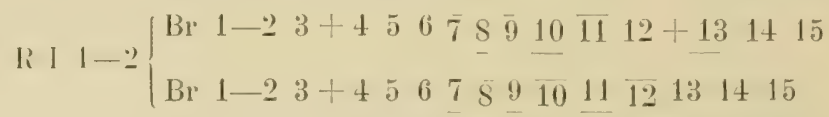

Sp. 54 (St. 57) $\mathrm{R}-\mathrm{S} \mathrm{h}=\mathrm{br} . \mathrm{I} \mathrm{Br} 1$ and 2 rather smooth. $\mathrm{P}_{2}$ missing. The $\mathrm{L}$ of the distal piunulars $=2 \mathrm{br}$. Disk $1,8 \mathrm{~mm}$. Orals resorbed. A small intumescense for a parasitic stylina.

Generally the radial erista is more distinct on the $\mathrm{R}-\mathrm{S}$ in younger specimens since the $R-S$ tre longer then. With increasing age the $\mathrm{R}-\mathrm{S}$ are more and more concealed by $\mathrm{Cd}$, and shortened by the rapid increase in the breadth. By this the crista also grows smaller and finally only remains as a rounded tubercle.

An investigation of the number of arms in the (nearly) full-grown specimens $1-36$ shows the following distributions. $X$ arms: 18 specimens, XI: 9 sp., XII: 5 sp., XIII: 2 sp., and XVI: 2 sp. It is rather peculiar that the largest specimens often have only $\mathrm{X}$ arms, while the multibrachiate specimens have shorter arms. $\Lambda$ similar condition is also noticed in Cyllometra pulchelle and has perhaps something to do with the catching of the food. 
The Crinotds froyr Dr. S. Bock's Expedition to Japan 1914. 111

\begin{tabular}{|c|c|c|c|c|c|c|c|c|c|c|c|c|c|c|}
\hline \multirow{2}{*}{$\begin{array}{l}\text { iumber of spe. } \\
\text { cimens and } \\
\text { - iations }\end{array}$} & \multicolumn{3}{|c|}{ Cirri } & \multicolumn{2}{|r|}{ Arms } & \multirow{2}{*}{$\begin{array}{c}\text { Interspace of } \\
\text { oblig. artic. } \\
\text { belween the } \\
\text { syzygres }\end{array}$} & \multicolumn{2}{|c|}{$P_{1}$} & \multicolumn{2}{|c|}{$P_{2}$} & \multicolumn{2}{|c|}{$P_{3}$} & \multicolumn{2}{|c|}{ Dist. $\mathrm{p}$. } \\
\hline & $\mathrm{N}$ & $\mathrm{S}$ & $\mathrm{L}$ & $\mathrm{N}$ & L & & S & L & S & L & $\mathrm{S}$ & L & $\mathrm{S}$ & $\mathrm{L}$ \\
\hline 121.56 & XVIi & $\mathrm{SO}-\mathrm{Si}$ & $50-55$ & $\mathrm{XVI}$ & 65 & $6-9$ & 12 & $\dot{\xi}$ & 12 & 5,5 & 12 & 6 & 18 & 10 \\
\hline 1. $\cong(s t .5 t$ ) & XX & $85-90$ & $60-70$ & XII & $190-100$ & $4-7$ & 13 & 6 & 13 & 7 & 13 & 6,5 & $17-9$ & 11 \\
\hline 1: 31.56 & $\mathrm{XX}$ & $71-86$ & $40-56$ & $\mathrm{XI}$ & 80 & $4-6$ & 12 & 5,5 & 9 & 5,5 & 9 & 6 & $18-19$ & 11,5 \\
\hline 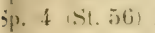 & XVI & $69-76$ & $40-55$ & & 70 & $6-11$ & 8 & 4 & 10 & 5 & 10 & 5 & 16 & 10 \\
\hline ist. Jti, & XVI & $59-82$ & $20-54$ & $\mathrm{X}$ & 80 & $6-8$ & - & 5 & - & 5,5 & - & 5 & 19 & 10 \\
\hline 1) $(\$ 1.56)$ & XII & $57-6 s$ & $35-48$ & XII & 55 & $6-9$ & 9 & 4,5 & 9 & $5, \overline{1}$ & 7 & 6 & $1 \tilde{5}$ & S \\
\hline 7 (5t.56) & XIII & $39-62$ & $14-99$ & $\mathrm{X}$ & 35 & - & 9 & 3,5 & 9 & 4 & 10 & 4 & 16 & 7 \\
\hline 1. 8 (St. 59) & XVII & $77-90$ & $15-65$ & $\mathrm{X}$ & 95 & $4-6$ & 12 & 7 & 12 & 8 & 9 & 7,5 & 16 & 11 \\
\hline อ. 9 (St. 59) & IIX & $56-75$ & $40-50$ & $\mathrm{XI}$ & 75 & $6-7$ & 12 & 5,3 & 11 & 6,5 & $7 \cdot 9$ & 5 & 18 & 11 \\
\hline $.10(\mathrm{St} .59)$ & XVII & $65-85$ & $45-60$ & $\mathrm{XI}$ & 85 & $4-6$ & 1.1 & 6,5 & 14 & 8,6 & 13 & 8 & 22 & 12,5 \\
\hline $11(\mathrm{St} .5:)$ & XVIII & $65-85$ & $40-65$ & $\mathrm{X}$ & 83 & $5-10$ & 11 & 5,5 & 11 & 6 & 11 & 6 & 20 & 13 \\
\hline $.12(\mathrm{St} .59)$ & $\mathrm{XX}$ & $65-80$ & $40-55$ & $\mathrm{X}$ & 95 & $6--11$ & 12 & 6,5 & 12 & 7,5 & 11 & 7 & 22 & 13,5 \\
\hline 13 (St. 59) & XXI & $5 \overline{5}-+$ & $35-+$ & XIII & - & - & $8-10$ & 5 & $9-10$ & 6 & 8 & 5,5 & - & - \\
\hline $14(\mathrm{St} .5 \overline{9})$ & XX & $60--70$ & $30-55$ & $\mathrm{X}$ & 85 & $4-5$ & 11 & 6,5 & 13 & 9 & 11 & 8 & 21 & 12,5 \\
\hline 15 (St. 59$)$ & XVIII & $50-65$ & $30-50$ & XI & 70 & $6-9$ & 11 & 6 & 11 & 6,5 & $9-10$ & 6,5 & 18 & 11 \\
\hline $16($ St. 59$)$ & XXII & - & - & XI & 95 & $4-7$ & 12 & 7 & 13 & 9 & 11 & 7 & - & $10+$ \\
\hline $17(\mathrm{St} .59)$ & XX & $61-82$ & $40-65$ & $X$ & 83 & $4-6$ & - & - & 12 & 7 & $10 \div$ & 7 & $17-20$ & $11,5-13,5$ \\
\hline $18(\mathrm{St} .59)$ & XX & - & - & XII & 100 & $6-7$ & 13 & 7 & 14 & $9, \hat{\mathrm{s}}$ & 12 & 8 & - & $12+$ \\
\hline $19($ St. 59) & XVII & $65-83$ & $\mid 38-68$ & $\mathrm{X}$ & 85 & $(3-) 5-6$ & - & - & - & - & - & - & 19 & 11,5 \\
\hline $20(\mathrm{St} .59)$ & XXII & $72-82$ & $55-73$ & $\mathrm{X}$ & 105 & 6 & 一 & - & - & 一 & $\cdots$ & - & 22 & 15 \\
\hline .21 (St. 53 ) & $\mathrm{XIX}$ & $75-86$ & $38-63$ & $\mathrm{X}$ & 85 & $5-6$ & - & - & - & - & - & - & 17 & 11 \\
\hline 22 (St. 59) & XXI & $55-75$ & $30-57$ & $\mathrm{X}$ & 75 & $6-7(-17)$ & 10 & 5 & 12 & 5,5 & 10 & 6 & 20 & 11 \\
\hline .23 (St. 59$)$ & XVIII & $56-76$ & $32-57$ & $\mathrm{XI}$ & 65 & $4-6$ & - & 5 & 11 & 5,7 & 10 & 6 & 19 & 10,5 \\
\hline $.24(\mathrm{SL} .59)$ & XXII & $68-77$ & $45-60$ & $\mathrm{X}$ & 70 & $5-7$ & - & - & - & - & - & - & - & \pm 10 \\
\hline .25 (St. 59 ) & XVIII & $70-100$ & $55-70$ & $X$ & - & - & 9 & 6 & 11 & 7,5 & 9 & 7 & - & - \\
\hline $26(\mathrm{St} .59)$ & XV & $56-70$ & $25-47$ & $\mathrm{X}$ & \pm 60 & $5-6$ & 10 & 5,5 & - & - & - & - & 18 & 9,5 \\
\hline $27(\mathrm{St} .59)$ & XVII & $67-82$ & $48-62$ & XI & 85 & $6-9$ & 11 & 5,5 & 12 & 7 & 9 & 6,2 & 18 & 10 \\
\hline .28 (St. 46$)$ & XXII & -80 & 45 & XVI & 70 & $4-8$ & 12 & - & 13 & $>P_{1}$ & 12 & - & 16 & $10-11$ \\
\hline 29 (St. 46 ) & XV & $41-46$ & $14-18$ & $\mathrm{X}$ & 25 & $3-6(-9)$ & $S-9$ & 2,5 & 9 & 3 & S & 2,5 & $15-16$ & $5,5--6$ \\
\hline .30 (St. 53 ) & $\mathrm{XXI}$ & $69-85$ & $45-70$ & XII & 90 & $4--7$ & - & - & - & 一 & - & - & $19-22$ & $11,5-12,5$ \\
\hline 31 (St. 53) & XVI & $62-81$ & $10-65$ & XIII & 80 & $6(-17)$ & 11 & 5,5 & 11 & 6 & 12 & 5,5 & 19 & $11,5-12$ \\
\hline 32 (St. 53 ) & XYII & $65-72$ & $25-40$ & XII & 55 & $4-6$ & $|11-12|$ & 5,5 & 11 & 6 & 9 & - & 17 & $8,5-9,5$ \\
\hline 33 (St. 53) & XVIII & $65-85$ & $\mid 36-53$ & $X$ & 75 & $5-7$ & 13 & 5,5 & 12 & 6 & 11 & 5,8 & $18-20$ & $11-11,5$ \\
\hline 31 (St.53) & XIV & $55-64$ & $30-35$ & XI & 70 & $5-6$ & 13 & 5 & 11 & 5,8 & 9 & $\overline{5}, 8$ & 18 & 11,5 \\
\hline . 35 (St. 53) & XI & $60-65$ & $25-35$ & $X I$ & 50 & $7-8$ & 一 & - & - & - & - & - & 18 & 10 \\
\hline 36 (St. 53) & XVI & $50-60$ & $20-30$ & $X$ & 45 & $5-7$ & 9 & 3,5 & 10 & 3,8 & 9 & 3,5 & 18 & 9 \\
\hline $.37(\mathrm{Sl} .53)$ & XI & $20-21$ & $2,5-3,0$ & $X$ & 7 & - & - & $1-$ & - & - & - & - & 14 & 3 \\
\hline $.38(\mathrm{St} .53)$ & XIV & $20-35$ & $7-10$ & $X$ & 15 & - & - & $1-$ & - & 一 & - & - & 15 & 5,6 \\
\hline .39 (St. 53 ) & XI & $25-35$ & $8-13$ & $\mathrm{X}$ & 15 & - & - & - & $\cdots$ & 一 & - & - & 15 & 5,5 \\
\hline $.40(\mathrm{St} .53)$ & XIII & $.17-31$ & $3-11$ & $X$ & 15 & - & - & - & - & - & - & - & 15 & 5,0 \\
\hline .41 (St. 45$)$ & XI & $27-34$ & $7-10$ & $\mathrm{X}$ & 15 & 5 & 7 & 2,3 & 7 & 2 & 9 & - & 13 & 5 \\
\hline .42 (St. 45$)$ & XII & $26-36$ & $7-11$ & $\mathrm{X}$ & 18 & 4 & 8 & 2,3 & 8 & 2 & - & - & 13 & 5 \\
\hline P. 43 (St. 45$)$ & XVI & $23-32$ & $5-10$ & $X$ & 15 & - & 9 & 2,5 & 8 & 2,1 & 10 & 3,2 & - & - \\
\hline 1. 41 (St. 15) & - & $13-30$ & $2-8$ & $X$ & 12 & $\longrightarrow$ & - & - & $\cdots$ & & $\ldots$ & & & 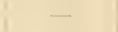 \\
\hline .45 (St. 45) & XIV & $12-26$ & $2-5$ & $\mathrm{X}$ & 8 & - & 7 & 1,7 & - & - & - & - & - & 一 \\
\hline p. $16(\mathrm{St} .47)$ & XIII & $42-46$ & $15-23$ & XII & 35 & $5-6$ & - & - & - & $\cdots$ & - & - & 17 & 7 \\
\hline p. 47 (St. 47) & XIV & $27-34$ & $5-9$ & $\mathrm{X}$ & 20 & $\div$ & 8 & 3 & 8 & 2,3 & 一 & - & 15 & 5,5 \\
\hline p. 48 (St. 47) & XII & $25-36$ & 7 & I & 12 & 5 & 7 & - & 8 & 9 & - & - & 11 & 5 \\
\hline p. 49 (St. 47) & XIV & - & 12 & $\mathrm{X}$ & 25 & - & 10 & 3 & 10 & 3,5 & 9 & $\pm 3,5$ & $\rightarrow$ & 一 \\
\hline p. 50 (St. 47) & $\mathrm{X}$ & $20-32$ & $4-10$ & $\mathrm{X}$ & 15) & - & 9 & 2 & 9 & 1,8 & $8-9$ & 9,5 & 12 & 4 \\
\hline p.51 (St. 54) & XVI & $(14)-27$ & $(3)-\bar{t}$ & $\mathrm{X}$ & 8 & - & 9 & 2,2 & - & $\longrightarrow$ & - & - & 一 & 一 \\
\hline p. $52(\mathrm{St} .54)$ & XV & - & $10-16$ & $\mathrm{X}$ & 25 & - & - & $\div$ & - & - & -1 & - & 一 & 6,5 \\
\hline p. 53 (St. 55$)$ & XI & $16-22$ & $4-4$ & $X$ & 7 & 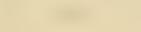 & $=$ & & & & & & & \\
\hline Sp. 54 (St 57) & $\mathrm{XY}$ & $17-32$ & $1-10$ & & 12 & - & 8 & 4,5 & - & $\ldots$ & 10 & 2,8 & 14 & 4 \\
\hline
\end{tabular}




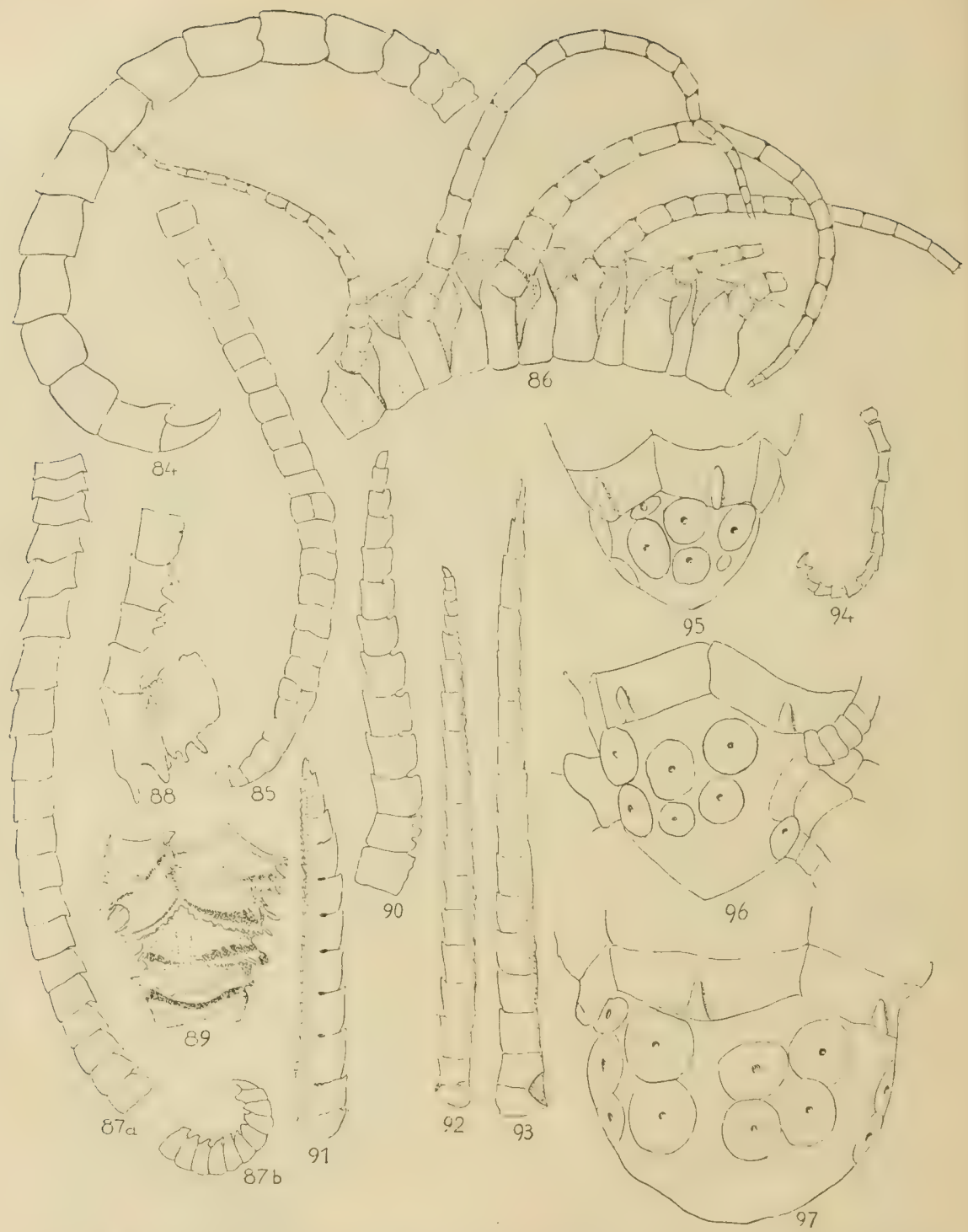

Fig. 84 Dindontometra Bocki Cirrus \% $/ 4$; 85,86 Liparometra grandis (St. 39) 85) The distal part of a cirrus with two abnormally longitudinally split cirrals $\% / 1$. 86) The proximal part of an arm with $\mathrm{P}_{1}-\mathrm{P}_{6}\left(\mathrm{P}_{4}-\mathrm{P}_{8}\right.$ with broken tips); observe $13 \mathrm{r} 1+23+4,7 / 1 ; 87-91$ Stenometra dentata (St. 56) 87 a) The most proximal 20 cirrals, b) The distal part of the cirrus $9 / 1,88) \mathrm{Br}_{2}-4$ with the base of

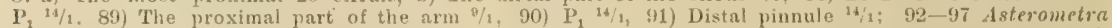
anthus 92) Distal pinumle of the tyre of $A$. anthus (St. 56) $8 / 1,93$ ) Distal pinmule of the type of $A$. acerba (St. 59) $\% 1,9.1$ ) Cirrus of a very young animal (Sp, 51), $\left.\times 17 \frac{1}{2}, 95\right)$ Cd of sp. 31 (lepida type) $9 / 1$, в6) $\mathrm{Cd}$ of $\mathrm{Sp} .27 \%$, 97$) \mathrm{Cd}$ of $\mathrm{Sp}, 18 \%$, 
The Crivoins from Dr. S. Bock's Expeditiox to dapax 1914. 113

The $\mathrm{L}$ of the distal $p$-s with some irregularities follows the $\mathrm{L}$ of the arms; nevertheless it shows great variability in specimens with an arm-length of $70-90 \mathrm{~mm}$.

A. II. CLark has distinguished the two species $A$. unthes and $A$. acerbu by the following characteristies:

\section{A. anthus}

A) Distal pinuules $9 \mathrm{~mm}$.

B) The outer segments of distal $\mathrm{p}-\mathrm{S}: \mathrm{L}_{1}=2 \times \mathrm{br}$.

C) 'The Br dorsal spines long' and strongly curved

D) $R-s$ with a rounded tubercle

E) I Br-s without median carination

(i) Arms more than $X$.
A. acerbu

a) distal pinnules $13 \mathrm{~mm}$.

b) the outer segments of dist. p-s $\mathrm{L}>3 \times \mathrm{br}$.

c) the Br dorsal spines blunt, short, not much curved.

d) $\mathrm{R}-\mathrm{S}$ with a dorso-ventrally elongated tuberele.

e) I Br-s with a faint, low median carination.

f) Arms X).

Some examples from the above-described specimens may be quoted and may be denoted as follows:

\begin{tabular}{|c|c|c|}
\hline Sp. 1 & $A(a) B C D E F$ & Sp. 1f a bCDEf \\
\hline Sp. 9 & $\triangle a \mathrm{BbCdEF}$ & Aa b C d E F \\
\hline & $\triangle(\mathrm{a}) \mathrm{Bcde}(\mathrm{F}) \mathrm{f}$ & (A)a Bb Ce deF \\
\hline 1). 12 & a (B)b C D E f & a b C d E f \\
\hline
\end{tabular}

From the above cited examples it seems evident to me that the characteristies of $A$. anthus and acerbe are irregularly mixed in the different specimens. Cuark lays special stress upon the fact that the $\mathrm{L}$ of the distal pinnules and pinnulars and the blunt spines on the distal Br-s are characteristic of acerba. 'This combination searecly ever occur's in the above-described specimens, but often long p-s together with strongly developed Br-spines.

From what is stated above - the examples could be multiplied it seems to me to be clear that $A$. anthus and acerba ought to be referred to the same species.

A. lepide is a thind species of the genus Asterometra that A. II. Crark has described. It is a form differing from the two previously mentioned species (which have a large cylindrieal Cd with a conical end) by a small and conical Cd. It is further mentioned that the cirus-sockets 
are smaller and therefore the cirri too, which are lacking on the only known specimen, are probably more slender than in the other species. With regard to the last characteristic I may emphasize the following facts. It is a general rule that cirri formed in the dorsal cirrus-whorl (also dating from a younger stage) are more slender than the ventral ones, which are formed at an older stage. The more robust the specimen is, the more coarse are also the cirri. Thus for instance the cirri in sp. 24 are thin and slender, in sp. 11 and 12 very much coarser and thicker. 'This character' is therefore not necessarily so very important, when other distinguishing features which support the suggestion of a real difference between the species are not added. With regard to $A$. lepida it is also stated that $C d$ should have a specific formation. A glance at the collected facts given above in the descriptions of the specimens shows that the appearance of $\mathrm{Cd}$ is also subject to great variation. I have selected sp. 18, 27 and 34 to be reproduced. The last-mentioned specimen, which has an arm-length of $70 \mathrm{~mm}$. and is therefore of the same size as the single specimen of A. lepide found, has a small, conical Cd with relatively small cirrussockets. Cd of sp. 27 (arm-length $85 \mathrm{~mm}$.) is a transition-form to Cd of Sp. 18 (arm-length $100 \mathrm{~mm}$.) which is of typical A. anthus-acerba formation.

As all transitions between these two types are found among the above-described specimens, I cannot consider A. lepida to be a separate species but regard it only as a younger individual of Asterometra conthus.

Finally some words about the above-described very young specimens. One can plainly follow the growth-abbreviation of all ossicles, already observed by P. II. Carpenter. Perhaps one finds this fact demonstrated best in the proportion between $L$ and br of the cirrals (cf. e. g. sp. 1; 37 and 53), but one can also get good subjects for demonstration in the $\mathrm{R}-\mathrm{S}$ and proximal $\mathrm{Br}-\mathrm{s}$. In the latter one can also follow the disappearance of the juvenile carina on $\mathrm{I} \mathrm{Br} 1$ and 2 and the appearance of certain marks of old age (the indistinct crista on the same ossicles in certain old specimens). The pinnular's seem to be but slightly affected by this abbreviation (ef. e.g. sp. 1 and 54).

The occurrence of orals is also very interesting. In specimens of an arm-length of less than $10 \mathrm{~mm}$. they are well preserved, but 
usually begin to be resorbed at an arm-length of 10-12 mm. and are completely lost when the arms measure $15 \mathrm{~mm}$, that is at about the same time as the arms get a complete pinnulation. - The smallest specimens have also large $B-s$ which form a continuous ring visible under the radial whorl. In the smallest specimens the latter: practically encloses the whole intestine sac. All these primitive characteristies thus persist rather late.

Stenometra A. H. Cr.uri

St. dentata 11. sp.

Fing. S7-91. Photo 7.

From St. 5 - (1), $56(5), 59(3)=9$ specimens.

Sp. 1 (St. 56) Cd eylindrieal, the flattened, dorsal pole with small spines; diameter of the dorsal surface $2 \mathrm{~mm}$. $H$ of the free part of $\mathrm{Cd} 1,5 \mathrm{~mm}$.

C. XXIV 74-76; 25-34 mm, in two close whorls, which are ventrally divided in groups, separated IR. by ribbons of Cd. $I^{\text {st }}$ segment short with a distal collar which, especially ventrally, has a somewhat serrate border. $2^{d}$ and $3^{d}$ segments $L=1 / 2 \mathrm{br}$. similar to the preceding segment but with a slighter distal collar. $4^{\text {th }}$ and $5^{\text {th }}$ segments cubical or a little longer. $6^{\text {th }}-10^{\text {th }}$ slightly hour-glass-shaped, $\mathrm{L}=1^{1 / 2}$ br: $\quad 1^{\text {st }}-7^{\text {th }}$ segments with a small ventral spine, slightly projecting in lateral profile, because of the above-mentioned collar. $8^{\text {th }}-$ $13^{\text {th }}\left(-16^{\text {th }}\right)$ segments smooth, then a dorsal spine. Distal segments $\mathrm{L}=$ $1 / 2-1 / 3 \times$ br. Dorsal spine small, distinct, distally eurved, $h={ }^{1 / 3}-{ }^{1 / 4}$ of the br of the segments. Opposing spine somewhat coarser, $h=1 / 2$ of the br of the segment. Terminal claw about as long as the penultimate segment.

$R$-s narrow bands, IR somewhat bent outwards by the interradial ribbons on $\mathrm{Cr}, \mathrm{L}=+^{1 / 6}$ br. $1 \mathrm{Br} \quad 1 \mathrm{~h}=1 / 4$ br, laterally free, with a median carination and moreover both proximally and distally a vertical 4-5-lobated calcareous plate, constituting the enlarged and overlapping ends of the segment. I Brax $h=1 / 2 \mathrm{br}$, rhomboidal, in the 
proximal part with a well-bordered, strong, median tooth visible in side view as a ligh bidentate wing, which, logether with the distomedian tubercle of I $\mathrm{Br}^{\circ} \mathrm{l}$, forms a strong synathrial prominence. The distal borker of I Brax obtuse-angled, with $6-T$ pointed prominences. II Br-s: 2, similar to the I Br-s, but with smaller and weaker synarthrial tubercles. Arms probably XX (II branches broken), 65 mm., indistinctly flattened laterally. The first $6 \mathrm{Br}$-s smooth, but with prominent, lamelli-shaped lobated prominences both proximally and distally (ef. above). In addition the most proximal Br-s partly with a median, dorsal prominence, which develops more distally to a dorsal spine, partly with a pair of similar medio-lateral prominences, alternately most developed on the left and on the right. These lateral tubercles, situated on both sides of the median dorsal spine, disappear at the $15^{\text {th }}$ to $20^{\text {th }}$ Br-segments and from these only the median dorsal spine remains. The distal segments rather strongly pressed together from the sides. Ex of syzygies: $3+4,22+23$ or $3+4,35+36$ ete. with an interval of $6-11$ oblique articulations. About 5 distal segments with rudimentary pinnules.

$P_{1} 12-13 ; 8 \mathrm{~mm}$. (5-7 first pinnulars concave on the outside, the concavity bordered by a more or less lobate wing-like prominence: $6^{\text {th }}$ and the following segments a little longer than broad, smoother with a smaller wing and somewhat spiuy distal collars); $\mathrm{P}_{2} \quad 11 ; 5,5 \mathrm{~mm}$. $\mathrm{P}_{3} 6 ; 4,5 \mathrm{~mm}$. $\mathrm{P}_{4}, 7$, a little longer. Distal P. $\mathrm{l}_{2}^{\circ} ; 5 \mathrm{~mm}$. ( $\mathrm{l}^{\text {st }}$ and $\mathbf{2}^{2}$ segments short, the following ones $\mathrm{L}=1^{1 / 2}-2 \mathrm{~b}$ ', the two last segments short again. The pinnulars smooth, in the proximal part triangular, in the distal part rounded).

Disk encrusted with coarse granules, like the other weak parts dark-brown. 'The ossicles are a lighter brown.

Sip. 2 (St. 5(i) C. XX 57-61: 20-25 mm. A dorsal spine already on the $12^{\text {th }}$ cirral. Arms $\pm \mathbf{X X}$, $65 \mathrm{~mm}$. I Brax rhombieal. Aready about. Br 10 the dorsal claw is the only remaining prominence. Ex. of syzygies: $3+t, 31+32$ or $3+4,6+7,32+33$ ete. distally with an interval of $8-11$ oblique articulations. $P_{1} 13 ; 7,5 \mathrm{~mm} . \mathrm{P}_{2} 10$; $5 \mathrm{~mm}, \mathrm{P}_{3} \mathrm{~s} ; \mathrm{tmm}, \mathrm{P}_{4} 7 ; 3 \mathrm{~mm}, \mathrm{P}_{5} \mathrm{~s} ; 3,5 \mathrm{~mm}$. Distal $\mathrm{p}-\mathrm{s} 11 ; 6 \mathrm{~mm}$. Sp. 3 (St. 56) C. XXVII 37-56; 1+-24 mm. Dorsal surface of Cd 1,5 mm. Irms XX, $50 \mathrm{~mm}$. Br-s with shorter processes than in the preceding specimens. A single dorsal spine from Br 10. Arms 
The Crinoids from Dr. S. Boct's lixpenteton to Japan 1914. 117

distinetly flattened laterally out to $\mathrm{Br}^{\circ} 5$. Syzygies with an interval of 13-16 oblique articulations, $P_{1} 13-15 ; 5,5-7,5 \mathrm{~mm}, \mathrm{P}_{2} 9-11 ; 4,5-5$ mm. $P_{3} 8-9,4-5$ mm. Distal $\mathrm{p}-\mathrm{s}$ 11:

Sp. 4 (St. 56) C. XXI 43-57: $18-+22$ mm. The 6 first cirrals with a real rentral spine. Dorsal spine from about the $10^{\text {th }}$ - $20^{\text {th }}$ segment. Arms $\mathrm{XV}$. $45 \mathrm{~mm}$. The median keel on I Br'2 somewhat lower than in Sp. 1. Arms after Br 6 without lateral prominenees. The dorsal Br-spine low. Syzygies with an interval of 5-18 oblique articulations. Sbout $90 \mathrm{Br}$ segments. The distal segments with rudimentary p-s are about 5. Example of arm-branching:

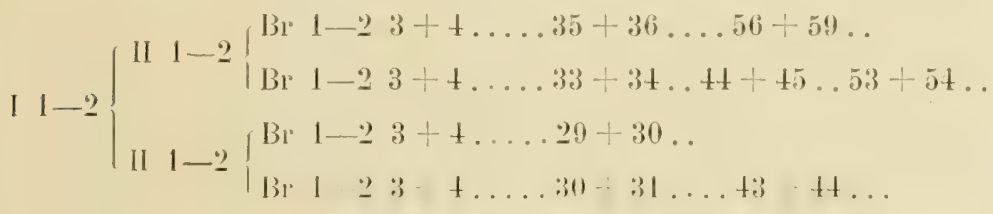

$\mathrm{P}_{1}$ I2; $4 \mathrm{~mm}$. (last $\mathrm{S}$ segments collar-shaped, their distal parts overlapping; a similar condition, though not so marked on $\mathrm{P}_{2}-\mathrm{P}_{4}$ ). $\mathrm{P}_{2}$ 9: $3,5 \mathrm{~mm} . \mathrm{P}_{3} 9 ; 3 \mathrm{~mm} . \mathrm{P}_{4} 8 ; 3 \mathrm{~mm}$. Distal p. 12; 5,5.mm.

Sp. o (St. 56) C. XVIII 5t-65; 25-30 mm. Arms XV, 60-65 mm. A regenerate from a $I 1$ Br 1 with 2 small, still smooth arms. $\mathrm{P}_{1} \mathrm{~S}-13 ; 4-6 \mathrm{~mm} . \mathrm{P}_{2} \mathrm{~s} ; 4 \mathrm{~mm} . \mathrm{P}_{3} 7 ; 3 \mathrm{~mm}$. Distal p. 9-10; $5,5 \mathrm{~mm}$. Sp. 6 (St. 59) C. XVIII 62-65; 24-28 mm. Arms XVI, broken. II Br-s: 2. $\mathrm{P}_{1} 13 ; 5 \mathrm{~mm}$. Disk $6 \mathrm{~mm}$.

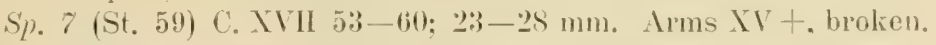
II Br-s: 2. P $\mathrm{P}_{1} 13 ; 6 \mathrm{~mm}$. Disk $7 \mathrm{~mm}$.

Sp. 8 (St. 59) C. XIV t0-43; 15- $18 \mathrm{~mm}$, in a partly double whorl, hardly divided in groups. The dorsal surface of Cd $1 \mathrm{~mm}$. Arms XII, $40 \mathrm{~mm}$. The calcareous lamels on the proximal ossicles only slightly serrate. A single dorsal spine from Br S. Syzzgies with an interval of $5-8$ oblique articulations. Example: 


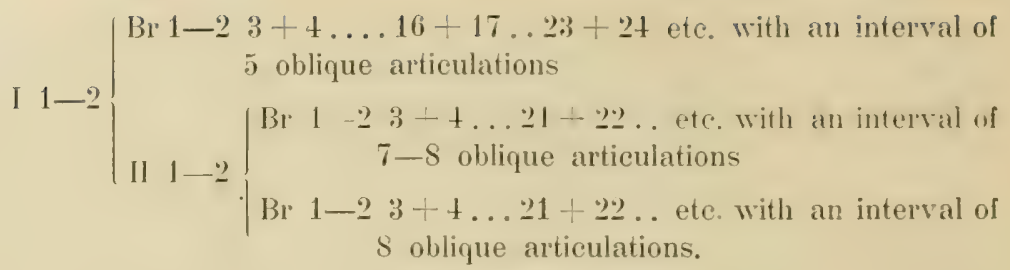

$\mathrm{P}_{1} 10 ; 4-4,3 \mathrm{~mm} . \mathrm{P}_{2} 9 ; 3,5 \mathrm{~mm} . \mathrm{P}_{3} 7 ; 2,5 \mathrm{~mm}$.

Sp. 9 (St. 55) C. XV 20-21; 3,5-5 mm. (2d segment with a small ventral spine, $3^{\mathrm{d}}-5^{\text {th }}$ segment $L=2 \mathrm{br}$, hour-glass-shaped, then shorter segments, from about the $10^{\text {th }} \mathrm{L}=$ br or shorter. A dorsal spine from the $6^{\text {th }}$ segment, $\mathrm{h}=1 / 4$ of the br of the segments. Opposing spine $h=1 / 2$ of the br of the segment.

$\mathrm{R}-\mathrm{S} h=1 / 2$ br with a median crista and small distal prominences, IR fused and elongated, separating I Br-s 1 . I Br $1 \mathrm{~h}={ }^{2 / 3}$ $\mathrm{bl}^{2}$ with a median tubercle and latero-distal prominences. Similar, still larger, lobate flanges on $\mathrm{I} B r a x, \mathrm{Br} 1$ and $\mathrm{Br} 2$. I $\mathrm{Br} \geq \mathrm{h}=\mathrm{br}$, triangular with a small eavity in the distal angle. Arms X, $13 \mathrm{~mm}$. Br (1-2) $\mathrm{h}=\mathrm{br}$, as the syzygial pairs $\mathrm{Br} 3+4$. From $\mathrm{Br} 15$ a medio-dorsal claw. The left arm often a little longer and better developed, in one case, however, the reverse. $P_{1} 5 ; 1 \mathrm{~mm}, P_{2}$ and $P_{3}$ as $P_{h}$ and $P_{c}$ usually lacking. Distal p. 10; $2 \mathrm{~mm}$. Example of pinnulation:

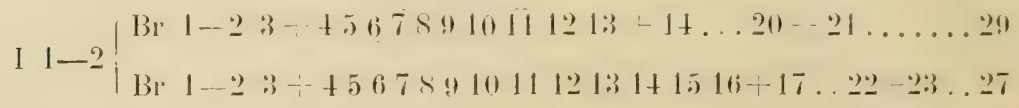

Orals $h=1 / 4$ of the radius of the disk, only the acute angle remaining: (the base and the inner parts resorbed).

With regard to the number of the cirrals this species is most closely related to Si. diadema, but well separated from this by the formation of $\mathrm{Cd}$, by the shortness of the cirri, when compared with the arms (the latter are at least twice as long as the cirri) and by the darge and many prominences on the ossicles of the arm-bases. By this the new species approaches Dudidumetru thuma), a genus properly distinguished from Stenometra only by a smaller number of arms. The above-described species is to a certain extent a transition-form between the above-mentioned genera. 
The Crinoids from Dr. S. Bock's Expenttion to Japan 1914. 119

Charitometridæ A. I. CLARK.

Crossometra A. II. Ci.ıkк.

Cr. septentrionalis A. H. CL L IRK.

lig. 77,78 .

Syn: Charitometre distinctu (preocenpied) 1908 1. II. CL.nk Proc. U. S. Nat. Mus. Vol. 34, p. 312.

Pacheylometra septentrionalis 1911 1. II. Cramk Proc. U. S. Nat. Mus. Vol. 39, p. 554; 1912 Crin. Ind. Oc., 1. 215; 1915 Wash. Journ. Acad. Sci. Vol. 5, p. 215. C'rossometre septentrionalis 1918 A. II. Cusk Siboga Exp. Tol. 42 B, p. 176.

From St. $36=1$ specimen.

Sp. 1 (St. 36) Cd br 3 mm., h 1,5 mm., rounded conical, free dorsal surface without tubercles, $1,5 \mathrm{~mm}$. C. XIX 14-16:14-17 mm. very coarse, in a single or double whorl and 10 rows. $5^{\text {th }}$ segment the longest $L=1^{1} / 2$ br. From the $S^{\text {th }}$ segment a dorsal, longitudinal crista. The ventral margin of the distal segments about as long as the br. Opposing spine $\mathrm{h}={ }^{1 / 3}$ of the br of the segment. 'Terminal claw curved, somewhat longer than the preceding segment.

$\mathrm{B}-\mathrm{s}$ projecting as large interradial prominences, $\mathrm{R}-\mathrm{S}: \mathrm{h}=1 / \mathrm{s}$ br with a median tubercle. I $\mathrm{Br} 1 \mathrm{~h}=1 / 5 \mathrm{br}$, laterally united, as on the proximal part of I Brax with a median tubercle. I $\mathrm{Br} 2 \mathrm{~h} h=1 / 3 \mathrm{br}$. II $\mathrm{Br}-\mathrm{s}:$ + with similar median prominences. Primipostaxillaries united inside. III Br-s: 2, developed on the inner sides. These ossicles and $\mathrm{Br} 1$ and 2 with still slighter median tubereles. Arms XVIII + . $70 \mathrm{~mm}$., strongly wall-sided out to $\mathrm{Br}_{\mathrm{r}} 2$. The bases of $\mathrm{P}_{\mathrm{II}}$ visible between the arm-bases. Br 1-12 discoidal, then oblique joints. $1^{\text {st }}$ syzygy on the inner side usually between $\mathrm{Br} 1$ and 2. Distally with an interval of 4 oblique articulations. Example: Br $1--23+t \ldots 11+12 \ldots$ $16+17 \ldots 21+22 \ldots$ The distal $\mathrm{Br}-\mathrm{s}$ with a low, not overlapping dorsal spine. Example of arm-branching and regeneration:

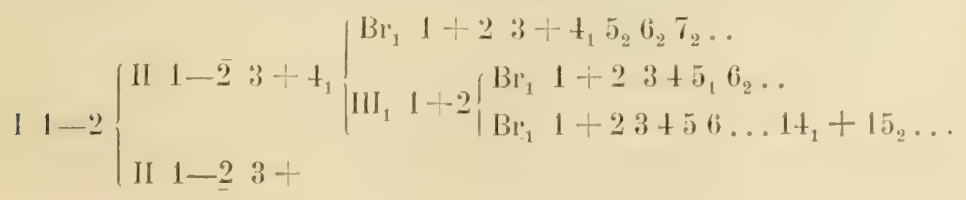


$\mathrm{P}_{\text {II }} 22 ;+5 \mathrm{~mm} \cdot 1^{\text {st }}-5^{\text {th }}$ segments thickened with dorsal prominences similar to those in the fam. Calometride (cf. the figure). $1^{\text {st }}$ segment $\mathrm{L}={ }^{1 / 2} \mathrm{br}$. The $7^{\text {th }}$ and following segments more slender, a little flattened. Distal segments: $L \geq$ br. $P_{1}+18 ;+$ mm., $P_{2} 14 ; 3,2$ mm. Distal p. 13-14; $4,5 \mathrm{~mm}$. (The first 2 and last 2 segments short, the other ones $\mathrm{L}=2-2^{1} / 2 \mathrm{br}$ ).

Disk very closely and coarsely granulated, »lean», somewhat incised, diam. $4 \mathrm{~mm}$., not completely regenerated, dark-brown. The animal otherwise white (in spirit).

The above-described specimen is as a young of $C r$. septentrionalis. Though the species-name Cr . distincto is older still, in conformity with A. H. Chark, I do not wish to use it, partly because it is a nomen nudum, partly because the name distincta was given by P. H. Carpenter to a species in the closely-related genus Pachylometra (CLARK did not separate this genus from Crossometra before 1918).

Perissometra A. II. Clamk.

P. aranea 11. sp.

Fig. 103, 104 .

From St. 7 a: 1 specimen.

Sp) 1 (St. 7 a) (d a low cone, br $2 \mathrm{~mm}$. Dorsally with a central eavity and small side-cavities. C. XIV 17-21;10-11 $\mathrm{mm}$. in a single or double whorl and in 10 rows. $1^{\text {st }}-3^{\mathrm{d}}$ segments $\mathrm{L}$ shorter than br, $4^{\text {th }}$ one somewhat longer, $5^{\text {th }} \mathrm{L}=1^{1} \cdot 2$ br, $6^{\text {th }}$ one $\mathrm{L}=2 \mathrm{br}$, distally a little widened, with an inconspicnous dorsal spine. Then shorter segments witlr a dorsal spine. The cirrals from about the grh about cubical, antepenultimate segment $L_{1}={ }^{3} / 4$ br. Opposing spine $h_{h}=1_{1,5}$ of the br of the segment. Terminal claw curved, somewhat longer than the preceding segment.

R-s narrow bands, almost concealed, I Br-s 1 contiguous, $h={ }^{1} / 4 \mathrm{br}$, with a low median carination. I Brax pentagonal, $h=1 / 3 \mathrm{br}$. with a similar, low longitudinal tubercle; a slight thickening of the distal border, the rest of the ossicle smooth; laterally flattened like 
$\mathrm{Br}$ 1. Arms $\mathrm{X}, 70 \mathrm{~mm}, \mathrm{Br} 1$ and 2 with a carination similar to the one on the 1 Brachials but very much slighter. Br-s 1 inside contiguous in pairs, outside broader, as also Br 2. Syzygies: $3+4,13+14$, $18+19 \ldots$ distally with an interval of about 5 oblique articulations. $\mathrm{Br} \quad 1-10$ discoidal, then irregularly oblique joints. 'The proximal ossicles rounded and smooth; from $\mathrm{Br}^{\prime} 15$ a low, median, longitudinal crista. slightly projecting in lateral profile.

$\mathrm{P}_{1} 13 ; 5 \mathrm{~mm} . \mathrm{P}_{\mathrm{a}} 13 ; 5 \mathrm{~mm} . \mathrm{P}_{2} 8-9,3,5 \mathrm{~mm} . \mathrm{P}_{3}$ similar. $\mathrm{P}_{1}$ coarser than $P_{2}$. The segments rather uniform, smooth, a little longer than broad, distally somewhat angular. $P_{4}-P_{12} \pm 10 ; 3-4 \mathrm{~mm}$. (Proximal segments very slightly dorso-ventrally flattened). Distal $p-s \pm 14$; $5-6 \mathrm{~mm}$. $\left(1^{\text {st }}\right.$ and $2^{\mathrm{d}}$ segments shorter and a little coarser than the following ones, which have the $\mathrm{L}=2 \mathrm{br}$ ).

Disk a little incised, with large calcareous granules, diameter $4 \mathrm{~mm}$, colour brown. Otherwise the animal is light yellow-brown.

This new species resembles most closely P. late from which, however, it differs sharply by the cirri, very short in comparison with the arm-length but in spite of this with relatively many segments, by the rather smooth proximal arm-parts, and, above all, by the proximal pinnules, which have a few, rather long pinnulars.

After a comparison with specimens of Dr Mortensen's collection I am convinced that this species often has XI or XII arms attaining: a length of $>70 \mathrm{~mm}$. II Br-s are 2. $\mathrm{P}_{1}$ might get 15 segments and attain a length of $\pm 6 \mathrm{~mm}$. $\mathrm{P}_{2}-\mathrm{P}_{10}$ are short, with the $5-6$ first segments somewhat thickened in dorsal view.

In the short genital pinnules has the species an unusual resemblance to a spider, whence the name.

\section{Diodontometra $n$, gen.}

This exeedingly peculiar type of the family Charitometride resembles the genus Charitometra by the strongly expanded proximal segments on the genital pinuules. l'rom this genus it differ's, however, in several characteristies. The arms are XX, the II Br-s: 2. Cd is high and pointedly conical and the eirri arranged in radial groups, separated by large interradial interspaces. And, finally, the opposing spine is divided into two prominences standing side by side and usu- 


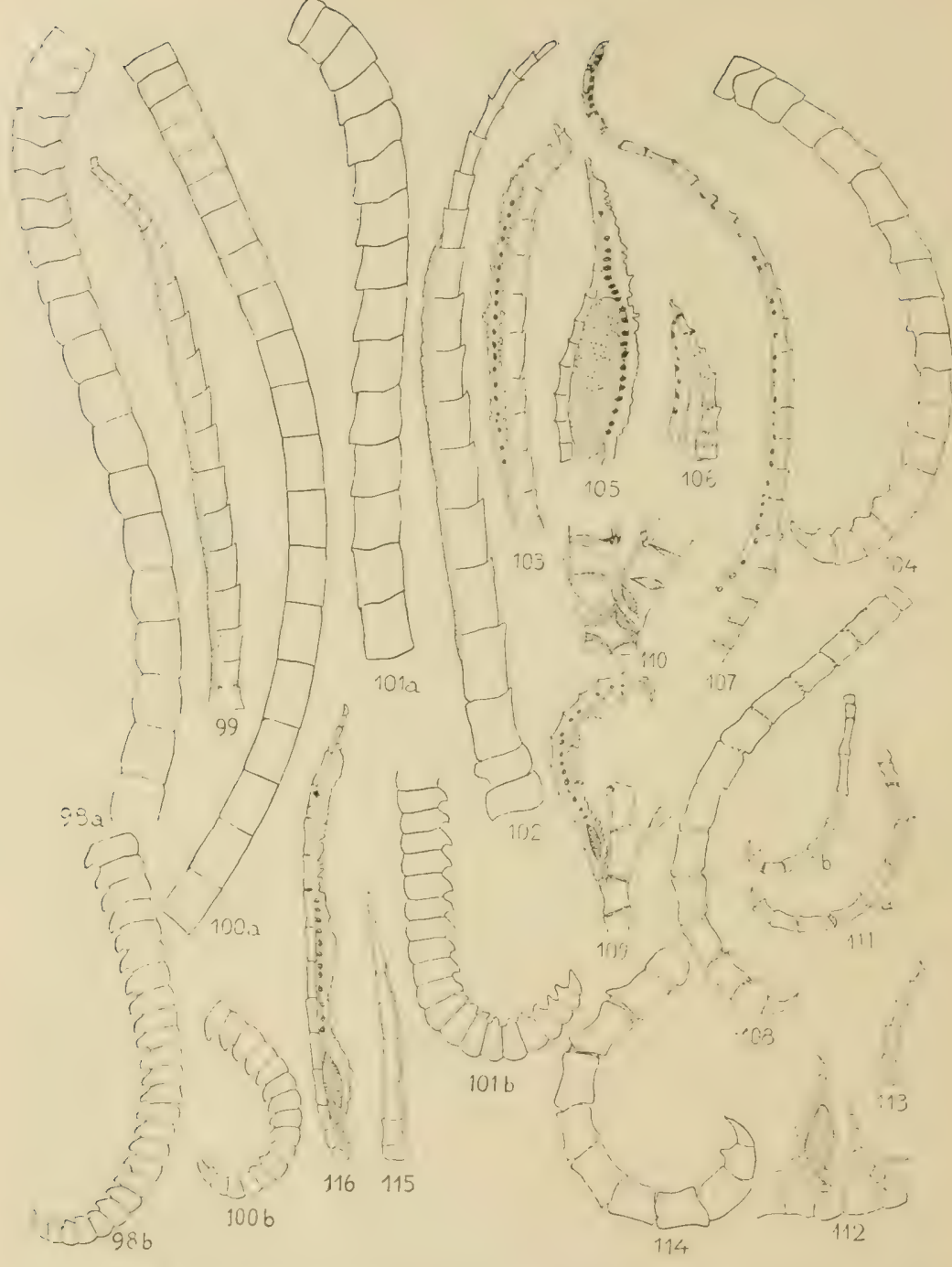

Fig. 98) Asterometra anthus a) The proximal, b) the distal part of a cirrus; some of the proximal segments with a slight dorsal spine $i_{1} ; 99,100$ dsterometra macroporla (St. 12). 99) Distal, pinmule $9 / 8$, 100 a) The most proximal 20 segments, b) the distal segments of a cir= 


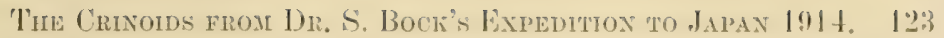

ally flanked by an additional side-spine on each outer side. (A bifueated opposing spine has been previously noticed only in the genus Epimetra fam. Colobometride).

\section{Bocki n. sp.}

Fig. 79-St, Photo 10 .

From St. $56: 1$ specimen.

Sp. I (St. 56) Cd pointedly conical, h $3.5 \mathrm{~mm}$., br. $3 \mathrm{~mm}$.

C. XXVI 10-12 (D) $15-17$ (V); 5-6 or $15-20 \mathrm{~mm}$. respectively, in $3-4$ whorls. The cirri are arranged in 5 radial groups separated by interradial interspaces which are almost as broad as the area occupied by the C. In each group 5-6 cirri, often forming an almost single row. $1^{\text {st }}$ and $2^{\text {at }}$ segments short, $3^{\text {a }}$ cubical, $4^{\text {th }}$ increasing, $5^{t_{1}}-7^{t^{1}} \mathrm{~L}=1^{2} / 3 \mathrm{br}, 8^{\text {th }}\left(-9^{t_{1}}\right)$ - the antepenultimate segment not much longer than broad. The dorsal surface of the distal cirrals slightly carinated and overlapping. No dorsal spine. Opposing spine in the distal part of the penultimate segment, large, in the middle deeply incised and therefore bifureated, on the lateral sides moreover often a small additional spine. 'T'erminal claw slender, curved, pointed, longer' than the preceding segment.

$\mathrm{R}-\mathrm{S}$ visible as narrow bands in the corners. I $\mathrm{Br} / \mathrm{h}=1 / 4 \mathrm{br}$, in the basal half laterally grown together, at the middle somewhat narrower because of the synarthrial tuberele from I Brax. I $\mathrm{Br} 2$, pentagonal, $\mathrm{h}=1 / 2 \mathrm{br}$ as the preceding ossicle with a slight median carination, the rest of the ossicle rounded dorsally. The II $\mathrm{Br}$-s are 2 , similar to the I Br-S. Primipostaxillaries in the basal half grown together in pairs. Arms XIX + (probably originally XX), $60 \mathrm{~mm}$, in 4 cases broken between 1 Br 1 and 2 (the synarthial articulation well

rus $\% / 1 ; 101,102$ Pterometra trichopoda (St, 45) 101 a) The 15 most proximal cirrals, with a ventral spine from the 1 th-the 12 th segments b) The 20 most distal cirrals $" 1 / 1,102$ ) 1)istal pin-

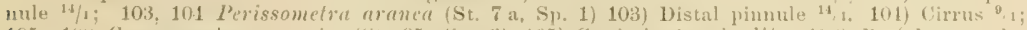

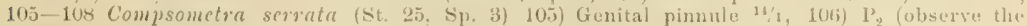
indistinct stripe under the saceuli; a rudmentary genilal cord?) ${ }^{11 / 1,107)} P_{1}{ }^{11}{ }_{1}, 10 \mathrm{~s}$ ) ('irmus ${ }^{14}$; 109-113 Compsonetra parviftora (St. 47) 109) I stump of the arm with a distal pinule $14 / 1$, 110) The base of an arm from I $13 \times 1-\mathrm{Br}^{\circ} 514 / 1,111$ ) (irri a) St. 17, b) from the dorsal whor) of a specimen from St. 45 ; long cirrals $14 / 1,112) \quad 3 x+1-8$ with $P_{2}$ and $\left.I_{3} 1_{14}, 113\right) P_{1} 14 / 1$; 114-116 Toxometra aquipina (St 4, Sp. 1) 114) Cirrus 14/1, 115) $\mathrm{P}_{3}$ 14/1, 116) Distal pinnule with a small genital gland 14,1 , 
developed). Br 1 and 2 with a slight synarthrial tubercle. Arms out to $\mathrm{Br} 4$ laterally flattened. $\mathrm{Br} 5-10$ with the distal ends a little overlapping. The 12 first $\mathrm{Br}$-s discoidal, then oblique joints. The distal segments smooth. $7-S$ of the distal $\mathrm{Br}-\mathrm{S}$ supporting rudimentary pinnules. Ex. of syzygies:

$$
\left\{\begin{array}{l}
\mathrm{Br} 1-23-4 \ldots 21+22 \ldots 31+32 \ldots 41+42 \ldots \\
\mathrm{Br}^{\mathrm{r}} 1-23-4 \ldots 17+18 \ldots 26+27 \ldots 35+36 \ldots+4+45 .
\end{array}\right.
$$

$\mathrm{P}_{1} 13 ; 3,5 \mathrm{~mm} . \mathrm{P}_{2} 12 ; 4,5 \mathrm{~mm}, \mathrm{P}_{3} 11 ; 4 \mathrm{~mm}, \mathrm{P}_{4} 10 ; 3,5 \mathrm{~mm}$. The segments on $\mathrm{P}_{1}-\mathrm{P}_{2}$ or $\mathrm{P}_{3}$ rather uniform, $\mathrm{L}=1 / 2-1 / 1 \times \mathrm{br}$. On the outer sides of the $3^{d}$ and following pinnulars small wings partly caused by small notches between each segment. From $P_{3}-$ about $P_{12}$ $\left(10-11\right.$ segments, L $3,5-4 \mathrm{~mm}$.) the $3^{\mathrm{d}}-5^{\text {th }}\left(\right.$ or $\left.6^{\text {th }}\right)$ segments are flattened dorso-ventrally, cupular, with winglike borders, the $7^{\text {th }}-11^{\text {th }}$ pinnulars are narrow and long again. The cupular segments are in dorsal view about cubical, the distal ones $\mathrm{L}=2$ br: Distal p. $11 ; 4 \mathrm{~mm}$. $\left(1^{\text {st }}\right.$ segment short, $2^{\mathrm{d}}$. cubical, $3^{\mathrm{d}}-10^{\text {th }} \mathrm{L}=1^{1} / 2 \mathrm{br}$, last segments short, all segments smooth).

Disk thrown off. 'The colour of the animal light brown; saceuli rather sparse.

\section{Antedonidæ A. H. Clark.}

Antedoninæ A. H. CLARK.

Compsometra A. II. ClakK.

C. parviflora A. II. Chalki.

Fig. 109-113.

Syn.: Compometra parviftora 1912 A. H. Cu.rk Notes from the Leyden Mus. Vol. 34, p. 133; 1918 Siboga Exp. Vol. 42 B, p. 207.

From St. $44(1), 45(2), 46(1), 47(2), 54(1)=7$ specimens.

Sp. 1 (St. 46) Cd: br about $1,4 \mathrm{~mm}$. C. $+\mathrm{XXXV} 9-10 ; 2-2,5$ $\mathrm{mm}$. in two elose whorls. $3^{\mathrm{d}}-5^{\text {th }}$ segments very much hour-glassshaped, $L=2^{1 / 2}-3 \times$ the distal diameter. The distal cirrals of more uniform thickness. The $7^{\text {th }}$ segment $\mathrm{L}=1^{1} / 2 \mathrm{br}$. 


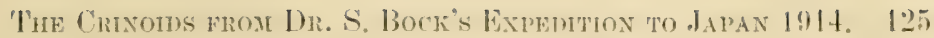

Axillary $h=1 / 2$ bl, rhombieal, the proximal angle covering a part of $\mathrm{I} \mathrm{Br} 1$. The axillary is broader than $\mathrm{I} \mathrm{Br} 1$. Br-s 1 inside well separated. Arms $\mathrm{X}, 20 \mathrm{~mm}$. + , but not very much longer.

$P_{1} 10 ; 4 \mathrm{~mm}$. (a distal, spiny whor from the $6^{\text {th }}$ pimnular), $P_{2} 7$ : $2 \mathrm{~mm}$, without genital gland, $\mathrm{P}_{3} 7 ; 2$ mm. with a genital gland from the $3^{\text {t }}$-the $5^{\text {th }}$ segment. $\mathrm{P}_{8} 13 ;+\mathrm{mm}$. ( $\mathrm{I}^{\text {st }}$ and $2^{2}$ segments short, the other ones long).

Disk $t \mathrm{~mm}$. Anal funnel long.

Sp. 2 (St. 47) C. XXXVII $8-11 ; 2-4,5 \mathrm{~mm}$. ( $t^{\text {th }}$ cirral the longest, $\mathrm{L}=3-4 \times \mathrm{br}) . \mathrm{R}-\mathrm{S}$ concealed. Axillary $\mathrm{h}=2 / 3 \mathrm{br}$ with strongly concave distal margins. Br'-s I basally contiguous inside, hof the outer border $1 / 2$, of the inner one $1 / 4 \times$ br. Arms $X, 25 \mathrm{~mm}$.

$P_{1} \quad 7-8 ; 2 \mathrm{~mm}$. (The $\mathrm{L}$ of the segments with the exception of the two first and the very last ones $2-3 \times \mathrm{hr}), \mathrm{P}_{2} 6 ; 1,2 \mathrm{~mm}, \mathrm{P}_{3} 8$; $2,2 \mathrm{~mm}$. with a genital gland, $\mathrm{P}_{4} 8 ; 2,2 \mathrm{~mm}$. Distal P. 14; $4 \mathrm{~mm}$.

Sp. 3 (St. 47) C. XXXI $9-10 ; 2,5-3,5 \mathrm{~mm}$.

Axillary as in the preceding specimens. Arms broken, probably between 20 and $25 \mathrm{~mm}$.

$P_{1} 8 ; 3 \mathrm{~mm}$. (3 $3^{11}$ segment $L=2^{1 / 2}, 4^{\text {th }}$ one $L=3^{1} / 2$ br) $P_{2} 5-6$; 1,2-1,5 mm. $P_{3} 7 ; 2 \mathrm{~mm}$. No pinnules genitally swollen.

Disk $1,8 \mathrm{~mm}$. Parasitical Myzostomids.

Sp. 4 (St. 45) C. about XXV on a hemispherical Gd; arranged in two whorls: $9-11 ; 2-4,5 \mathrm{~mm}$. The segments very pronouncedly hour-glass-shaped, those before the antepenultimate cirral $\mathrm{L}=2 \mathrm{br}$, antepenulimate segment $\mathrm{L}=1^{1 / 2}$ br. Cirri from the dorsal whorl with very much longer segments (cf. the figure 111), in this case the terminal claw and opposing spine are relatively large.

I $\mathrm{Br} \cdot \mathrm{l} h=1 / 6$ br. Axillary rhombical, $\mathrm{h}=1 / 2 \mathrm{br}$ (lower, and with smaller lateral angles than in the preceding specimens). Arms X, 15 mm. t. Br-s 1 inside basally contiguous. Syzygies with an interval of 3 oblique articulations. Br-s rather smooth.

$P_{1} S ; 1,5 \mathrm{~mm} . \mathrm{P}_{2} 6 ; 1 \mathrm{~mm} . \mathrm{P}_{3} 7-8 ; 1,8 \mathrm{~mm}$. with a genital gland. Disk $2,5 \mathrm{~mm}$. Anal cone $1,3 \mathrm{~mm}$.

Sp. 5 (St. 45) C. + XXV 10-11;2-3 mm. ( $t^{\text {th }}$ segment $\mathrm{L}=+4 \times$ br). Arms about $15 \mathrm{~mm}, \mathrm{P}_{1} 6 ; 1 \mathrm{~mm}, \mathrm{P}_{2} 4 ; 0,5 \mathrm{~mm}$. or lacking. Disk $1 \mathrm{~mm}$. No gonads developed. 


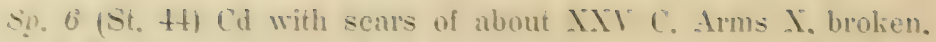
$3 \mathrm{~mm}+$. I Br $1 \mathrm{~h}=1 / 3$ br with a thicliened rim against the $\mathrm{R}$. Axillary $h=1$ s br, rhombical. $P_{t} 7: 1,2 \mathrm{~mm}$. $P_{2}+5: 0.8 \mathrm{~mm}, \mathrm{P}_{3} 6: 1.2 \mathrm{~mm}$.

Sp. i (St. 5t) Cd 0.5 mm. low. rounded, with sears of about AITT $C$ arranged in 3 whorls. The central, dorsal pole is oceupied by a small rounded star with a sear of the central canal of the stem. - $\mathrm{h}-\mathrm{s}$ at the rim of Cd. I Br $1 \mathrm{~h}=1 / 4 \mathrm{br}$. latero-distally squeezed together. Axillary $h=1 / 2 \mathrm{br}$. rhombieal with one proximally and one distally directed lappet. Arms X. about jo mm. Br-s 1 inside contiguous. $h=1 / \mathrm{br}$. on the outer side twice as broad. Br 2 with a backward directed synarthrial prominence. missing.

$P_{1} T_{:} P_{0}, 5$, shorter. $P_{3} T$. about as long as $P_{1}: P_{4}$ sometimes

The above-deseribed specimens agree well with A. H. Cuarh's deseriptions of $C$. parciflora. By my specimens the cirrals are a little shorter: one may. however. also tind eirri with longer segments, as my tigure of a cirrus from sp. $t$ shows.

Cone of these $\mathrm{i}$ specimens has a genital gland on P'. contrary to the trpe specimen from the Siboga st. 50 . From some other sibogatlocalities. however. there are speeimens with a gonad first on $P_{30}$ as in the bockian specimens. Might this difference perhaps have the value of variety: The disparity is probably not a difference of age. since for instance sp. 2 is completely mature and nevertheless has no trace of a genital gland on $P_{3}$.

Compsometra serrata -1. H. CLIEK.

Fin. 10.5-10s.

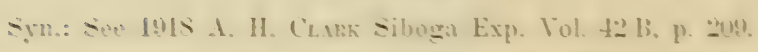

From si. $1(t) .2(3), 3(1), 21(1), 22(3), 23(1), 25(3) .2(2)=18$ sp.

S1\% 1 (st. 25) Ca hemispherical. C. XXll $12-15: 7 \mathrm{~mm}$. in a single or double whor!. $t^{\text {th }}$ and the following segments a little squeezed together in the middle. $\mathrm{L}=1^{1} / \mathrm{x} X$ the distal br. Antepenultimate segment $\mathrm{L}=1^{1}$ s br. Penultimate one with a very inconspieuous op- 
posing spine. 'Terminal claw narrow, curved, somewhat longer than the preceding segment.

$\mathrm{R}-\mathrm{s}$ concealed. I $\mathrm{Br} \quad \mathrm{I} \mathrm{h}=1 / \mathrm{B} \mathrm{br}$, laterally almosit free. The axillary $h=1 / 3-1 / 2$ br, triangular. Arms $\mathrm{X},+25 \mathrm{~mm}$, Bris 1 united inside in pairs, like the following ossicle on the onter side twice as broad. Br-s 2 on the inner side separated by a rather wide interspace. The first \& Br-s diseoidal, then oblique joints. Lix, of syzygies: $3+4,9+10,13+14,17+18 \ldots$ ete. Arms rather smooth.

$P_{1} 15 ;+5 \mathrm{~mm}, \mathrm{I}^{\text {st }}$ and $2^{\mathrm{t}}$ segment short, the other segments $\mathrm{L}=2-21 / 2 \mathrm{br}$, the distal parts widened, spiny. $\mathrm{P}_{2}, 9 ; 2,3 \mathrm{~mm}$. The proximal cirrals with strongly spiny borders. $P_{3}(11 ; 3,-m m)-.P_{5}$ with a similar dorsal earination on the 6 first segments. From $P_{3}$ there is a large genital gland. Genital p. $13-15 ; 4 \mathrm{~mm}$. The dorsal carination of the proximal pinnules continues at least out to $P_{10}$, then more indistinet.

Disk $3 \mathrm{~mm}$., white-coloured, without granules, a little swollen. The arms darker. Each eirral with a dark spot proximally.

Sp. 2 (St. 25) The cirrals somewhat more hour-glass-shaped. Syzygies with an interval of $3-4$ oblique articulations. $P_{3}$ and the following ones with a gonad. $P_{1}-P_{6}$ with strong spiny whorls on the distal parts of the $2^{4}-5^{\text {th }}$ segments. For further details see the table.

Sp. 3 (St. 25) I Br $111=1 / 6$ br. Syzygies, as in Sp. 2. I ${ }_{3}$ and the following pinnules with a genital gland. Colour: somewhat more red-brown than in the preceding specimens.

Sp. 4 (St. 1) The syzygies, as in sp. 5-8, with an interval of 3 oblique articulations. (Jiri more than in the preceding speeimens, in a double whorl. $P_{1}$ and the following ones with very large spiny prominences. $P_{a} 9 ; 3 \mathrm{~mm}$. Disk $5 \mathrm{~mm}$. Colour reddish.

Sp. 5 (St. 1) Cirri arranged in about :3 whorls. P' as in sp. 4.

Sp. 6 (St. 1) $\mathrm{P}_{\mathrm{a}} \mathrm{S} ; 2,5 \mathrm{~mm}$. Disk $4,5 \mathrm{~mm}$.

Sp. 7 (St. 1) Cirri in a double, incomplete whorl. P $7 ; 2 \mathrm{~mm}$.

Sp. 8 (St. 2) Cirri in a partly double whorl. P, 11;:3 $\mathrm{mm}$. with a genital gland. $P_{n}$ small. Anal cone large. Disk 5 mm. lighter than the red-grey arms, which dorsally have greyish segments and light articulations.

Sp. 9 (St. 2) $\mathrm{P}_{3}$ with a gonad. Disk $4,5 \mathrm{~mm}$. 


\begin{tabular}{|c|c|c|c|c|c|c|c|c|c|c|c|c|}
\hline \multirow{2}{*}{$\begin{array}{c}\text { Number of } \\
\text { Specimens and } \\
\text { Stations }\end{array}$} & \multicolumn{3}{|c|}{ Girri } & \multirow{2}{*}{$\left|\begin{array}{c}\text { Arm- } \\
\text { length }\end{array}\right|$} & \multicolumn{2}{|c|}{$\mathrm{P}_{1}$} & \multicolumn{2}{|c|}{$\mathrm{P}_{2}$} & \multicolumn{2}{|c|}{$\mathrm{P}_{3}$} & \multicolumn{2}{|c|}{ Dist. $p$. } \\
\hline & $\mathrm{N}$ & $\mathrm{S}$ & $\mathrm{L}$ & & $\mathrm{S}$ & L & $\mathrm{S}$ & L & $\mathrm{S}$ & L & $\mathrm{S}$ & L \\
\hline Sp. 1 (St. 25) & XXIII & $12-15$ & 7 & 25 & 15 & \pm 5 & 9 & 2,3 & 11 & 3,5 & 15 & 4 \\
\hline Sp. 2 (St. 25) & XXIII & $9-12$ & $3,5-4,5$ & 20 & 12 & 3,5 & 6 & 1,5 & & - & 9 & 2 \\
\hline Sp. 3 (St. 25) & XXVI & $\mid 2-15$ & $6,5-7,5$ & 35 & $23-28$ & $8-10$ & 9 & 2,5 & 12 & 3,5 & 18 & 5 \\
\hline Sp. 4 (St. 1) & XXXVIII & $12-14$ & $4-8$ & 35 & 23 & 10 & 8 & 3 & 10 & 4 & 16 & 5,5 \\
\hline Sp. 5 (St. 1) & XLV & $11-14$ & $6-7$ & 40 & 21 & 9 & 10 & 3 & 11 & 4 & - & 4,5 \\
\hline Sp. 6 (St. 1) & XLI & $11-14$ & $4-7$ & 35 & 28 & 11 & 9 & 3 & 12 & 4 & 16 & 4,5 \\
\hline Sp. 7 (St. 1) & XVIII & $11-12$ & $4-5$ & 15 & 16 & 5 & 8 & 2,2 & 10 & 3,5 & - & 3,5 \\
\hline Sp. 8 (St 2) & XXXI & $11-14$ & $4-7$ & 30 & \pm 20 & 6 & 7 & 2 & 9 & 2,5 & - & 4 \\
\hline Sp. 9 (St. 2) & XXVII & $11-13$ & 5 & 20 & \pm 18 & 5 & 6 & 1 & 8 & 2 & 16 & 3,5 \\
\hline Sp. 10 (St. 2) & XXXII & $\mid 1-13$ & \pm う & 25 & 17 & 4 & 9 & 2 & 9 & 2,2 & - & 3,5 \\
\hline Sp. 11 (St. 3) & XXV & $11-13$ & 7 & 30 & $13-15$ & 4,5 & 9 & 2,5 & 11 & \pm 4 & 17 & 4 \\
\hline Sp. 12 (St. 23) & XXII & $12-13$ & $5-6$ & 25 & 20 & 6,5 & 8 & 2,5 & 11 & 3,5 & - & 3 \\
\hline Sp. 13 (St. 26) & XXIV & $11-13$ & - & 27 & $15-20$ & $4-6,5$ & 7 & 2 & 9 & \pm 3 & \pm 15 & 4 \\
\hline Sp. 14 (St. 26) & XXXII & $11-13$ & $5-6,5$ & \pm 20 & 16 & 6 & 8 & 2,2 & - & - & \pm 18 & 4,5 \\
\hline Sp. 15 (St. 22) & - & 12 & 5 & 25 & $12-16$ & $3-4$ & 8 & 1,3 & - & - & - & 2,5 \\
\hline Sp. 16 (St. 22) & - & 12 & 5 & 25 & 17 & 4,5 & 8 & 2 & - & - & - & 3 \\
\hline Sp. 17 (St. 22) & XII & 9 & 1,2 & 3,8 & - & - & 一 & - & - & - & - & - \\
\hline Sp. 18 (St. 21) & $\mathrm{X} I \mathrm{X}$ & $9-10$ & 1,5 & 5 & 一 & - & - & -1 & - & - & - & - \\
\hline
\end{tabular}

Sp. 10 (St. 2) $\mathrm{P}_{4}$ 12; $4 \mathrm{~mm}$, like the following ones with a gonad. Disk $4,5 \mathrm{~mm}$, dark brown.

Sp. 11 (St. 3) $\mathrm{P}_{3}$ and the following ones with a genital gland. The specimen is a of with many eggs fixed outside the pinnules. Syzygies with an interval of $3-4$ oblique articulations. Disk $7 \mathrm{~mm}$. violet.

Sp. 12 (St. 23) $\mathrm{P}_{\mathrm{a}}$ 8; $2 \mathrm{~mm}$. Disk $6 \mathrm{~mm}$. Colour: greyish red-

Sp. 13 (St. 26) As is obvious from the table, the $L$ of $P_{1}$ is very variable. $P_{n} 7 ; 2$ mm。 A genital gland from $P_{4}$. The proximal parts of the Br-s darker than the distal parts and by this the arms get a spotted appearance. This condition also often in the preceding specimens. A light longitudinal stripe on the dorsal side of the arms.

Sp. 14 (St. 26) Disk $5 \mathrm{~mm}$. A light-coloured specimen.

Sp. 15 (St. 22) $\Lambda$ genital gland from $P_{3}$. Disk $3,5 \mathrm{~mm}$. Anal cone $2 \mathrm{~mm}$. swollen at the base.

Sp. 16 (St. 22) Disk $4 \mathrm{~mm}$., anal cone $3 \mathrm{~mm}$. Colour: spotted in light olive-brown and dark-violet (specimen in spirit).

Sp. 17 (St. 22) After $P_{1}$ a large pinnule-gap. B-s visible as small tongues IR. Small curved remains of the orals. 
Sp. 18 (St. 21) All the proximal pinmules present, though $P_{2}$ and $P_{3}$ especially are very small and incompletely calcified. Disk swollen. No orals.

The specimens from Shimonoseki (St. 1) obviously differ from the other ones by having more cirri; they are also a little larger and coarser than the rest of the specimens.

It is interesting to observe the great variability in the number of pinnulars and relative lengths of the proximal pinnules.

Toxometra A. H. Cr.ARK.

T. æquipinna n. sp.

Fig: 11t--116, Photo 11.

From St. 4: 2 specimens.

Sp) 1 (St. 4) Cd almost discoidal, free dorsal pole $\pm 1 \mathrm{~mm}$. -

C. XXVIII $10-11,5-6,5 \mathrm{~mm}$, in a double whorl. $1^{\text {st }}$ segment $\mathrm{L}={ }^{1 / 2} \mathrm{br}, 2^{\mathrm{d}}$ one $\mathrm{L}$ about $=\mathrm{bl}^{2}, 3^{\mathrm{d}}$ and the following ones $\mathrm{L}=1^{1 / 3}-$ $1 \frac{1}{2} \times$ the median br. No dorsal spine. Antepenultimate segment $\mathrm{L}=$ br. Opposing spine $h=1 / 3$ of the br of the segment. T'erminal claw curved, a little longer than the penultimate segment.

$R-S$ narrow bands (the distal borders concave), almost concealed by $\mathrm{Cd}$. I $\mathrm{Br}-\mathrm{s} 1$ laterally free, $h=1 / 5 \mathrm{br}$, with a small lateral tubercle and a strong, median, longitudinal erista which continues on the proximal $2 / 3$ of the axillary. This ossicle is hexangular, $h$ of the middle line $2 / 3$ of the br. The distal margin concave. 'The proximal and distal edges strongly bent outwards. Arms X, $65 \mathrm{~mm}$. Br-s 1 inside basally contiguous in pairs. $\mathrm{Br} 1$ and 2 with a median tuberele similar to the erista on the $1 \mathrm{Br}$ series, but more slightly developed than this. After Br. 9 oblique joints. All the distal edges of the segments strongly bent outvards, a little proximally directed and finely spinous. This condition most pronounced on the proximal segments. The distal $\mathrm{Br}-\mathrm{S}$ long $\left(\mathrm{L}=1^{1 / 2}-2 \mathrm{br}\right)$ somewhat hour-glassshaped. kx. of syzygies: $3+4,9+10,1++15,19+20$ ete. with an interval of usually 3 oblique articulations. 
$\mathrm{P}_{1} 8-9 ; 3 \mathrm{~mm}$. (3 ${ }^{\mathrm{d}}$ and $4^{\text {th }}$ segment the longest, $\mathrm{L}=2 \mathrm{br}$, all the segments smooth), $\mathrm{P}_{2} 11 ; 4 \mathrm{~mm}$. similar to $\mathrm{P}_{1}$, but coarser, $\mathrm{P}_{3} 10$; $3,3 \mathrm{~mm} . \mathrm{P}_{4} 9 ; 2,2 \mathrm{~mm}$. with a genital gland from the $4^{\text {th }}$ to the $6^{\text {th }}$ segment, much more slender than the preceding ones. Then the pinnules increasing again. $P_{a} 8 ; 2,3 \mathrm{~mm}, P_{b}, 8 ; P_{c} \&$ about as long as $P_{a}$. The distal P. $16-17 ; 6,5-7 \mathrm{~mm}$. (the 8 first pinnulars rather short, the other ones $\mathrm{L}=3-4 \times \mathrm{br}$, a little swollen at the joints).

Disk dark brown, otherwise the animal is light brown (in spirit). Sp. 2 (St. 4) C. XIV $10-11 ; 4-5 \mathrm{~mm}$.

$\mathrm{I} \mathrm{Br} / \mathrm{h}=1 / 4 \mathrm{br}$, with a dorsal tubercle (not a crista) together with the axillary. Arms $\mathrm{X}, 40 \mathrm{~mm} . \mathrm{P}_{1} 8 ; 2,2 \mathrm{~mm} . \mathrm{P}_{2} 9-10 ; 2,7 \mathrm{~mm}$. $\mathrm{P}_{3} 8 ; 2 \mathrm{~mm} . \mathrm{P}_{\mathrm{a}} 6 ; 2 \mathrm{~mm}$. Distal p. $5 \mathrm{~mm}$.

The specimen sticking to a caleareous sponge.

The placing of this species has caused some trouble.

A. H. CLARK, whom I have consulted about this question, writes: »Your new antedonid from Japan may very well be a new species of the genus Argyrometra, now known from Hawaii and from New Zealand. The oceurrence of this genus in southern Japan is highly probable. This genus belongs to that section of the Antedoninx in which $\mathrm{P}_{3}$ is similar to the succeeding pinnules. There are two species $A$. mortenseni from New Zealand and A. (»Compsometra») crispa from Hawaii. Smaller species of this genus may well have a more or less discoidal centrodorsal. The large size of $P_{3}$ seems to be an especially well marked character both of Toxometra and Dorometras.

I cannot believe that the species in question ought to be referred to Argyrometra. Cd in this genus is conical already at an armlength of $30 \mathrm{~mm}$. and my species, which has an almost discoidal $\mathrm{Cd}$, is not a smaller species of this genus but has an arm-length of $65 \mathrm{~mm}$. The number of cirri does not amount to XXX; it might have been larger if the species had been a large form of Argyrometra, where even small species with an armlength of $30 \mathrm{~mm}$. have a number of LX-LXXX. $P_{3}$ has not the same character as the following pinnules, which are genital pinnules and, finally, the Br-structures does not resemble that of Antedon petasus but much more that of Toxometra.

The above-described species differs from Toxometra by the 3 first pinnules, which are of about equal length, and in this it resembles Andrometra psyche (and Iridometra). The genus Andrometra, how- 
ever, has a conical Cd, while the above-described species, like Toxometra panpera, has a discoidal one. (Iridometra has smooth arms and at least 13 segments on $\mathrm{P}_{1}-\mathrm{P}_{3}$.) - T'o the relation between the relative length of the proximal pinnules is, generally, attached a rather great value in judging the genera within the Antedonid family. When characterizing the genus Toxometra $\Lambda$. II. CLaRK says that $P_{3}$ should be the longest p. The ease in question shows that one must be rather cautious in using such a character as a generic mark. If my species really belongs to toxometra then $P_{3}$ is the longest pinnule only in $T$. panpera and may not be used as a mark of genus. A comparison between the different species described as T. paupera shows, moreover, that within this species too there is rather great variability in the relative length of the proximal pinnules. The largest specimen has $\mathrm{P}_{1}$ $15 ; 5,5 \mathrm{~mm} ., \mathrm{P}_{2} 16 ; 7,5 \mathrm{~mm}$. and $\mathrm{P}_{3} 22 ; 12-13 \mathrm{~mm}$., the smallest one with an arm-length of $80 \mathrm{~mm}$. has $P_{1} 12 ; 4,5 \mathrm{~mm} . \mathrm{P}_{2} 14 ; 6 \mathrm{~mm} . \mathrm{P}_{3}$ $17 ; 7-7.5 \mathrm{~mm}$. With shorter arms we therefore get a proportionally greater abbreviation of $P_{3}$ than of $P_{1}$ and $P_{2}$ within this species. (CF. p. 76). I have also demonstrated the same general rule concerning $\mathrm{P}_{2}$ in Cyllometra pulchella.

Nevertheless, because of the following facts, 1 have not thought the specimens in the Bockian collection to be young forms of 'T'. partpera. 1) The cirrals are somewhat shorter than in the species mentioned (if we had been concerned with a young form, they ought to be longer). 2) The distal pinnules are longer than in ' $T$ '. poupera when compared with the arm-length. 3) The genital glands are rather well developed. 4) The photo in the Siboga work shows that T. paupera, though very much larger than $T$. cequipima, has smaller prominences on the Br-segments (if the last-mentioned speeies had been a young form, the condition ought to have been the reverse), and 5 ) the geographical distribution is rather different, as 'T'. paupera is only noted from the Sunda Islands and the Philippines. 
Iridometra A. H. Cislik.

I. melpomene A. H. ClahiK.

Fig. $117-119$.

Syns: Iridometra metpomene 1911 A. II. Chak Proe. U. S. Nat. Mus, Vol. 39 , p. 559; 1912 Crin. Ind. Oc. p. 230; 1918 Siboga Exp. Vol. 42 B, p. 2 \&2.

From St. $32(1), 37(1)=2$ specimens.

Sp. 1 (St. 32) Cd low, bluntly conical. C. XXXII 10-1S (usually $17-18), 9-11 \mathrm{~mm}$. (The dorsal C. with 10 segments, $2 \mathrm{~mm}$ ). $1^{\text {st }}$ and $2^{\mathrm{u}}$ segments short, then the $\mathrm{L}=2-2^{1 / 2} \mathrm{bl}$. 'The segments distally much broader, not hour-glass-shaped. No dorsal spine. Antepenultimate segment $\mathrm{L}=1^{3} / 4 \mathrm{br}$. Penultimate segment $\mathrm{L}=1^{1 / 3} \mathrm{br}$, with an opposing spine, $\mathrm{h}=1 / 3$ of the br of the segment. 'Terminal claw slightly curved, somewhat shorter than the preceding segment.

$\mathrm{R}-\mathrm{S}$ not very visible. I $\mathrm{Br}^{\circ} \mathrm{I} \mathrm{h}=1 / 4 \mathrm{br}$, a little narrower at the middle because of the slightly backwards directed synarthrial tubercle on I Brax. I $\mathrm{Br}^{\prime} 2 \mathrm{~L}=$ br, rhombic, with a long, low carination on the synarthrial tubercle, the distal angle prolonged. Arms X, $\pm 40 \mathrm{~mm}$. $\mathrm{Br}-\mathrm{s} 1$ basally united inside; $\mathrm{Br}^{2}$ considerably longer than the preceding ossicle, with a proximal border of the same form as in $1 \mathrm{Br} 2$, inside widely separated. Ex. of syzygies: $3+4,9+10,14+15$ ete. with an interval of about 3 oblique articulations. The distal parts of the arms smooth.

$P_{1} 14-15 ; 5,5-6 \mathrm{~mm} . \mathrm{P}_{2} 1+-15 ; 6-6,5 \mathrm{~mm}, \mathrm{P}_{3} 13 ; 0 \mathrm{~mm}$. All these p-s very slender, the two first segments short, the following ones $\mathrm{L}=3 \mathrm{br} . \quad \mathrm{P}_{4} 8-1 \mathrm{l} ; \mathrm{mm}$. with a genital gland. Distal $\mathrm{p}-\mathrm{s} 16$; $6,5 \mathrm{~mm}$.

Disk without calcareous granules, $4,8 \mathrm{~mm}$. Anal cone $2,7 \mathrm{~mm}$. Colour: arms white with red transverse bands.

Sp. 2 (St. 37) C. XXXVIII 10-16; 3-S mm. Arms X, $37 \mathrm{~mm}$.

$\mathrm{P}_{1} 12 ; 5,5 \mathrm{~mm} . \mathrm{P}_{2} 11 ; 5 \mathrm{~mm} . \mathrm{P}_{3} 10,5 \mathrm{~mm} . \mathrm{P}_{4} 10$, with a genital gland from the $3^{\mathrm{d}}-6^{\text {th }}$ segment. Distal $\mathrm{p}$. $\pm 1 \overline{5} ; \overline{5}, 5 \mathrm{~mm}$.

Un account of the few segments of $\mathrm{P}_{1}$ and $\mathrm{P}_{2}$ and the relatively short $P_{3}$ the above-described specimens appear to come next to $I$. metpomene, previously found at Ilongkong. I. adrestine is a not rery different species from south Japan. It is distinguished by some more 
The Criyoins from Dr. S. Bock's Expention to Japdx 1914. 1838

$(18-20)$ pinnulars on $\mathrm{P}_{1}-\mathrm{P}_{3},\left(\mathrm{P}_{3}>\mathrm{P}_{2}>\mathrm{P}_{1}\right)$, and usually has somewhat fewer cirrals. An examination of more ample material will probably show that the two forms belong to the same species.

A. II. CLark 1918 in the Siboga work gives Antedon mimule as a synonymous form of $I$. adtrestine. If this is correct there might be a mistake in the deseription of the first-mentioned species. I. udrestine is said to have $P_{1} 19 ; 10 \mathrm{~mm}$. and in this case $A$. minute can scarcely have $P_{1} 18 ; 3 \mathrm{~mm}$. because of a lule that one always finds verified in the examination of growth-series of Crinoids and that runs thus: Length and number of segments of a cirrus, an arm or a pimule stand in a certain relation to the ontogenetical derelopment and in a certain relative proportion, viz. that younger sprecimens have shorter cirri, arms, and pinnules and fewer cirrals and pinnulars, than the fullgrown ones. The figures obtained by these characteristics are rather constant in relation to one another at a given size and when compared with the same characteristic in older and younger individuats of the same species they can be fittel into an arithmetical series.

Dorometra A. II. C'Lark.

D. nana (H.artLaub).

Fig. 123, 124.

Syn.: See 1918 A. II. Clark Siboga Exp. Vol. 42 B, p. 216.

From St. 41: 3 specimens.

Sp. 1 (St. 41) The free, flat, dorsal pole of Cd about $0.5 \mathrm{~mm}$. C. LI $10-14 ; 4-8 \mathrm{~mm}$. $1^{\text {st }}$ segment short, $2^{\mathrm{d}}$ cubical, $3^{1} \mathrm{~L}=1^{1 / 2}-2 \times$ br, $4^{\text {th }}-7^{\text {th }}$ segment: $L=2-3 \times b r$, then shorter again. Antepenultimate cirral $L=1^{1} / 2 \mathrm{br}$, penultimate segment $\mathrm{L}=\mathrm{I}^{1} / 3 \mathrm{br}$, with a pointed opposing spine, $\mathrm{h}={ }^{1 / 2}$ of the br of the segment. T'erminal claw curved, somewhat longer than the preceding segment.

I $\mathrm{Br} 1$ almost concealed by $\mathrm{Cd}$. Axillary rhombic, $h=2 / 3 \quad \mathrm{br}^{\circ}$ with a slight synarthrial tubercle in the proximal part. Arms $\mathrm{X}, 30-$ $35 \mathrm{~mm}$. Br-s 1 basally united inside. Br 22 with a small, backward directed synarthrial tuberele; this ossicle is narrower than Br I, by which a broad interspace $\left(={ }^{1 / 2}\right.$ of the br of the arm) arises between the arm-bases. Syzygies: $3+4,9+10,14+15$ ete. with an interval 


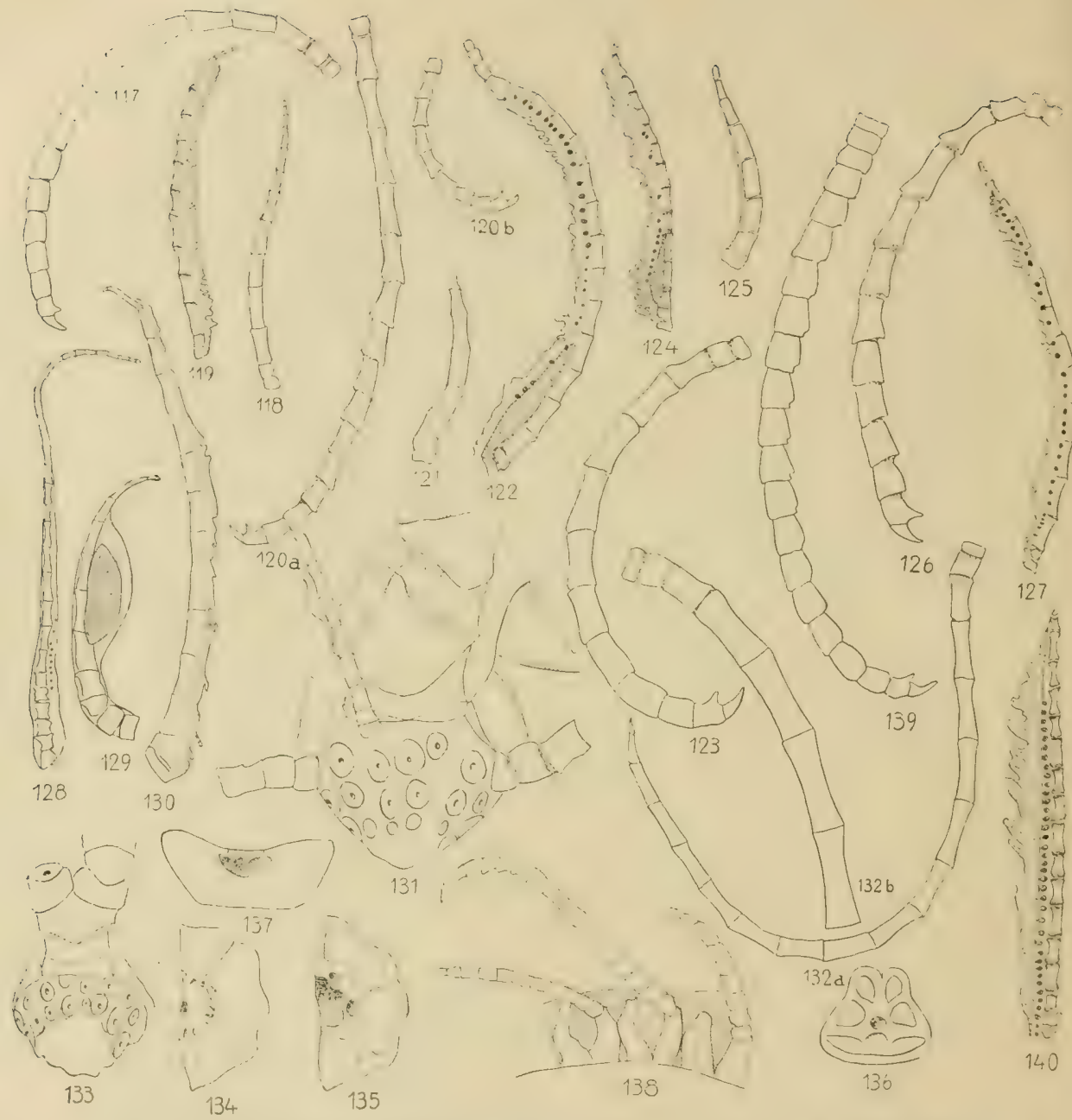

Fig. 117-119 Iridometra melpomene (St. 32) 117) Cirrus $\% / 1,118$ ) $P_{1} \%$, 119) Distal pinnule $\%$; 120122 Dorometra briseis (St. 37) 120) Cirrus a) long one (from the ventral whorl), b) short one (from the dorsal whorl) $9 / 1,12 L) P_{1} 14 / s, 122$ ) Distal pinnule $14 / 1 ; 123,124$ Dorometra nana (St. 41) 123 Cirrus . 16/1, 124) Distal pinnule $/ 1$; 125-127 Dorometra parvicirra 125) $\mathrm{P}_{1}$ (St. 53), $\left.\times 17^{1 / 2}, 126\right)$ Cirrus (St. 47) 14, 127) Distal pinnule (St. 53) 14, 12; 128-132 Psathyrometra Wireni (st. 6) 128) $\left.\mathbf{P}_{2} 14 / 1,129\right) P_{2}$ with a genital gland from the 5th-8th segments it $s, 130$ ) Distal pimule $14 / 2$, 131) Cd with the cirrus-groups and the bases of the arms 14,1 . 132 a) $\mathrm{A}$ younger and more slender but complete cirrus, b) the 7 first segfinents of an out-grown eiruts ${ }^{14 / 1}$; $133-140$ Cyllometra pulchella (St. 13) 133) Cu with the cirrus-sockets and an arm-base $9 / 1,13.1$ ) The proximal faces of the radinls and half of the rosette $14 / 1$. 135) Half $\mathrm{Cd}$ seen from the vertral side ${ }^{1+1} 1,136$ ) 'The distal articulation of the

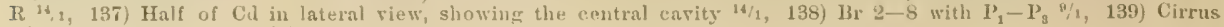
$14 / 1,140$ ) Distal pinuule $11 / 1$. 


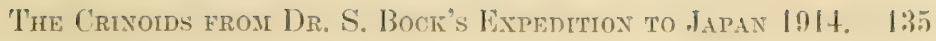

of 3 oblique articulations. 'The segments are smooth, rather short, never much longer than broad.

$\mathrm{P}_{1} 11 ; 3 \mathrm{~mm}$. $\mathrm{P}_{2}$ and $\mathrm{P}_{3}$ broken, $\mathrm{P}_{3:} 9: 2,5 \mathrm{~mm}, \mathrm{P}_{\mathrm{h}} 10$, of about the same length or a little longer. $P_{c} 13 ; 5 \mathrm{~mm}$. much larger and coarser than $P_{1}$ and $P_{2}$, like these $p-s$ rather smooth. $P_{c}$ with a small genital gland. $P_{d}$ and the following ones about $3 \mathrm{~mm}$. Distal p. $15-17 ; 4,5-5,5 \mathrm{~mm}$.

Disk somewhat swollen with a smooth, ungranulated skin, pentagonal, $5 \mathrm{~mm}$. Colour: like the specimens of the Siboga Expedition with close, small spots of violet-brown on white ground, the soft parts olive-brown (specimens in spirits).

Sp. 2 (St. 41) C. XLIX 12-14; 4-9 mm. Arms X, broken.

$\mathrm{P}_{1} 10 ; 3 \mathrm{~mm}$. For the rest as the preceding specimen.

Sp. 3 (St. 41) C. about L 10-12; t-8 mm. Arms X, $35 \mathrm{~mm}$. Syzygies as before. $\mathrm{P}_{1} 8 ; 3 \mathrm{~mm} . \mathrm{P}_{2} 6-8 ; 2,7 \mathrm{~mm}, \mathrm{P}_{3} 15 ; 6 \mathrm{~mm}, \mathrm{P}_{4}$ $12 ; 3,7 \mathrm{~mm}$. Distal p. $\pm 16 ; 5 \mathrm{~mm}$.

Disk $5 \mathrm{~mm}$. Somewhat smaller spots, appearing only at the articulations, by which the specimen seems to be lighter.

Differs from $D$. nana only by greater number of cirri and by

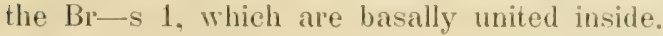

Dorometra briseis A. II. Cr.sкK.

Fig. $120-122$.

Syn.: Antedon briscis 1907 A. II. Cuark Proe. U. S. Nat. Mus. Vol. 33, p. 8:3.

Iridometra briseis 1908 A. II. Chank Wash. Proc Biol. Soc. Vol. 21, p. 131; 1912 Crin. Ind. Oc., p. 231; 1915 Wash. Journ. Aead. Sei. Vol. 5, p. 215

Dorometra briseis 1918 A. II. CLanK Siboga Exp. Vol. 42 B, 1) 216.

From St. $35(1), 37(2)=3$ specimens.

Sp. 1 (St. 37) C. XLVII 10-17;3-11 mm. $1^{\text {st }}$ segment $L_{i}=b$ b. $2^{\mathrm{d}}$ one $\mathrm{L}=2 \mathrm{br}, 3^{\mathrm{d}}-5^{\text {th }}$ segments the longest, $\mathrm{L}=3-3^{1 / 2} \mathrm{br}$. The segments somewhat hour-glass-shaped, specially widened distally.

$\mathrm{R}-\mathrm{S}$ indistinetly visible in the corners. I $\mathrm{Br} 1 \mathrm{~h}={ }^{1 / 6}$ br', partly concealed at the middle by the tongue-like prominence from the axillary, laterally free and provided with a small tubercle. I $\mathrm{Br}^{\mathrm{r}}$ ㄴ about rhombic, $h={ }^{2} / 3 \mathrm{br}$, with concave distal margins and a backward directed 
tongue. Br-S 1 free inside. Br 2 with a backward projecting prominence, similar to that of the axillary. Arms X, $40 \mathrm{~mm}$. smooth; the syzygies: $3+4,9+10,16+17$ ete. with an interval of 3 oblique articulations. The longer side of the proximal $\mathrm{Br}-\mathrm{S} \mathrm{L}$ about $=\mathrm{br}$, on the distal segments $L=1{ }^{1 / 2} \mathrm{br}$.

$P_{1} 8 ; 2,7 \mathrm{~mm} ., P_{2} 8 ; 2,5 \mathrm{~mm} ., \mathrm{P}_{3} 13 ; 4,7 \mathrm{~mm} ., \mathrm{P}_{6} \quad 14 ; 5,5 \mathrm{~mm}$. Distal $\mathrm{p}-\mathrm{S} \pm 18 ; 6,5 \mathrm{~mm}$.

Colour: yellow-white; the arms with transverse bands of brownred large spots.

Sp. 2 (St. 37) C. XXXIV 9-12; 2-7 mm. Arms X, $20 \mathrm{~mm}$.

$\mathrm{P}_{1} 7 ; 2,2 \mathrm{~mm} ., \mathrm{P}_{2} 7 ; 2 \mathrm{~mm} . \mathrm{P}_{3} 10 ; 3 \mathrm{~mm}$. Distal $\mathrm{p}-\mathrm{s} 15 ; 5 \mathrm{~mm}$.

Sp. 3 (St. 35) C. about XXXV $11-14 ; 6-10 \mathrm{~mm}$, built as before. II of the opposing spine ${ }^{2 / 3}$ of the br of the segment.

Axillary with concave distal margins, $\mathrm{h}={ }^{2} / 3 \mathrm{br}$. $\mathrm{Br}-\mathrm{S}$ almost free inside, twice as broad on the outer side; the outer half partly hidden by the backward directed tongue from Br. 2. Arms $\mathrm{X}, 45 \mathrm{~mm}$. Syzygies with an interval of $3(-4)$ oblique articulations.

$\mathrm{P}_{1} 9-10 ; 3-3,5 \mathrm{~mm} ., \mathrm{P}_{2} \mathrm{~s}-9 ; 2,5-3 \mathrm{~mm} . \mathrm{P}_{3} 11-12 ; 4,2-5 \mathrm{~mm}$. $\mathrm{P}_{4} 10 ; 4,5 \mathrm{~mm}$. with a genital gland. Distal p. $17 ; 5,5 \mathrm{~mm}$.

Disk $5 \mathrm{~mm}$. Colour as before.

All these specimens differ from $D$. briseis by having more cirri and by longer $\mathrm{P}_{3}$, by which they resemble $D$. nana. Nevertheless the size of $\mathrm{P}_{3}$ in the latter species always differs much more from the other $\mathrm{p}-\mathrm{s}$ than in $D$. briseis, the cirrals are shorter in $D$. nana (cf, the descriptions of the two species), and the colour seems to be consistently different, as $D$. nana has small, closely-arranged spots, while $D$. briseis has some few, large dark flecks separated by large white parts of the arms and pinnules.

\section{Dorometra parvicirra (I'. H. CARP.)}

Fig. 125-127.

Syn: See 1918 A. II. Crakk Siboga Exp. Vol. 42 B, p. 216.

From St. $47(1), 53(1)=2$ specimens.

Sp. 1 (St. 53) Cd hemispherical, C. about XXX, fallen. Cirrussockets arranged in two irregular whorls. A loose cirrus 14; 5,5 $\mathrm{mm}$. 
$3^{d}$ and $t^{\text {th }}$ segments the longest ones, $L=2-2^{1 / 2}$ br', like the preceding ones a little hour-glass-shaped. Antepenultimate segment $\mathrm{L}_{2}={ }^{1} / 2$ br. Opposing spine $\mathrm{h}=1 / 2$ of the br of the segment. Terminal elaw narrow, pointed, somewhat curved, as long as the penultimate segment. $\mathrm{R}-\mathrm{S} \mathrm{h}={ }^{1 / 7} \mathrm{br}$. I $\mathrm{Bl}-\mathrm{S} \mid \mathrm{h}={ }^{1 / 3} \mathrm{C}^{1 / 5} \mathrm{br}$, laterally free, but in close contact by a small, lateral tuberele, at the middle partly hidden by the synarthrial tubercle from the axillary. Axillary rhombie, $h=b r$. The lateral angles a little pointed by a small prominence. Arms X, broken, probably between 20 and $30 \mathrm{~mm}$. Br-s 1 united on the inside, twice as broad on the outside, medio-laterally narrower by the tubercle from $\mathrm{Br}$ 2. Ex. of syzygies: $3+4,9+10,1++15$ ete. with an interval of 3 oblique articulations. First 10 segments about discoidal, then oblique joints. Arms rather smooth.

$P_{1} 8 ; 2 \mathrm{~mm}$. (1 ${ }^{\text {st }}$ segment short, $2^{\mathrm{d}}$ one cubical, $3^{\mathrm{n}} \mathrm{L}=1^{1 / 2} \mathrm{br}$, $4^{\text {th }}$ - $7^{\text {th }}$ segment $\left.\mathrm{L}=2-3 \times \mathrm{br}\right), \mathrm{P}_{\mathrm{a}} 7 ; 1,5 \mathrm{~mm} ., \mathrm{P}_{2}$ S; $2,5 \mathrm{~mm} ., \mathrm{P}_{3} 10$; $4 \mathrm{~mm}$. (The segments somewhat hour-glass-shaped, $\mathrm{L}=3-4 \mathrm{br}$ ), $\mathrm{P}_{4} 7$; $2 \mathrm{~mm} ., \mathrm{P}_{5} \pm 9 ; 3 \mathrm{~mm}$. Distal $\mathrm{p}-\mathrm{s}$ about $15 ; 5 \mathrm{~mm}$. (Longest segments $\mathrm{L}=3-3^{1 / 2} \mathrm{br}$ ).

Disk $3 \mathrm{~mm}$., rather much incised, granulated both IR and interbrachially. Colour: brown. - With some large IIyzostomas.

S. p. 2 (St. 47) Cd rounded, dome-shaped, dorsally papillated. C. $\pm \mathrm{XXV}, 11-14 ; 2,5-7 \mathrm{~mm}$. in 2 or 3 whorls, $3^{4}-6^{\text {th }}$ segments the longest, $\mathrm{L}=1^{1} / 2,2$ and $2^{1 / 2} \times$ br. Opposing spine $h=2 / 3$ of the br of the segment, directed obliquely outwards.

Axillary rhombic, $h-2 / 3$ br, with a low synarthrial tuberele. located somewhat in front of the tongue-like posterior prominence (the same in sp. 1). Arms $X, 35 \mathrm{~mm}$. Syzygies as before.

$P_{1} 9 ; 2,7 \mathrm{~mm}$. (The $\mathrm{L}$ of the segments $3-3{ }^{1 / 2} \mathrm{br}$ ), $\mathrm{P}_{2} 7 ; 2 \mathrm{~mm}$., $\mathrm{P}_{2} \quad 10 ; 3,5 \mathrm{~mm} ., \mathrm{P}_{3} 14 ; 5,5 \mathrm{~mm} ., \mathrm{P}_{4} 9 ; 2,5 \mathrm{~mm}$. Distal p. $16 ; 5 \mathrm{~mm}$. (Longest segments $\mathrm{L}= \pm 4 \times \mathrm{br}$ ). The genital glands not very prominent.

Disk smooth, somewhat ineised, without granules. Colour: brown. - With Myzostomas.

l'roperly speaking, the above-described specimens only differ from D. parvicira (P. H. CARP.) by their smaller proportions. 'Therefore I have not separated them as a special variety, though the axillaries 
and $\mathrm{I} \mathrm{Br} 1$ are of somewhat different form, not so much pronounced, however, in the larger specimen. These differences are therefore probably due to the animals' different ages.

Zenometrinæ A. II. CLARK.

Psathyrometra A. H. Chark.

Ps. Wireni n. sp.

Fig. 128-132. Photo 12.

From St. $6: 1$ specimen.

Sp. 1 (St. 6) Cd pointedly conical, $\mathrm{h}=2 \mathrm{~mm} ., \mathrm{br}=2,2 \mathrm{~mm}$. The cirrus-sockets in 5 radial groups, separated by narrow, interradial interspaces. Each radial group with $7-8$ cirri. (The most dorsal cirrus-sockets more or less indistinct or disappeared). In each group there are two rows (with $\ddot{b-4}$ cirrus-sockets), forming an angle with each other, and between these rows there is an incomplete one with $1-2$ eirri.

Cirri fallen or broken, marks after XXXIX. A young, complete, fallen cirrus with 18 segments, $10 \mathrm{~mm}$. $1^{\text {st }}$ segment short, $2^{\mathrm{d}}$ cubical, $3^{\mathrm{d}} \mathrm{L}=1^{3} / 4 \mathrm{br}, 4^{\text {th }}$ segment $\mathrm{L}=2^{1 / 2} \mathrm{br}$, $5^{\text {th }}-7^{\text {th }}$ cirral $\mathrm{L}=3-3^{1 / 2} \mathrm{br}$ then slowly decreasing; antepenultimate segment $\mathrm{L}=2{ }^{1 / 4} \mathrm{br}$; penultimate one $\mathrm{L}=2 \mathrm{br}$. 'Terminal claw almost straight, $\mathrm{L}=1 / 2$ of the preceding segment (ef. the figure). The first 7 segments of a full-grown cirrus also remaining. These are larger and coarser, but otherwise of about the same proportions as in the young cirrus. (Except the $3^{d}$ segment, where $\mathrm{L}=1^{1 / 3} \mathrm{br}$. This cirrus has probably been of a $\mathrm{L}$ of about $15 \mathrm{~mm}$.

$\mathrm{R}-\mathrm{S}$ somewhat visible in the corners. I Br--S I laterally free, latero-distally a little squeezed together, $h={ }^{1} / 4 \mathrm{br}$. Axillary $\mathrm{h}={ }^{3} / 4 \mathrm{br}$, broader than the preceding ossicle, rhombic, the posterior margin slightly curved, because of the low, backward directed, synarthrial tubercle; distal tongue narrow, very much prolonged. Arms X, $40 \mathrm{~mm}$., (broken, probably about $60 \mathrm{~mm}$.) $\mathrm{Br}-\mathrm{S} 1$ basally contiguous inside, the outer border twice or three times as broad as the inner one. 13r 2 
also very much more narrow on the inside; slight synathrial tuberele between $\mathrm{Br} I$ and 2 . The distance from the $R-S$ to the first syzygy is $3,2 \mathrm{~mm}$. After Br 12 oblique joints. Ex, of syzygies: $3+t_{2} 9+10$, $14+15,21+22$ or $3+4,9+10,16+17,20+21$ ete. with an interval of 3 oblique articulations. The first $10 \mathrm{Br}-\mathrm{s}$ with the distal margins somewhat thickened and bent outwards; distally the arms are smooth.

$P_{1} \pm 30 ; 6 \mathrm{~mm}$. The 5 first segments with notehes (as in for instance PS. mira), shorter than long to eubical; then the segments are slender, more or less hour-glass-shaped, $L=1^{1 / 2}-2 \mathrm{br}$, the whole pinnule very slender and whip-shaped, $I_{i 1}$ similar, $\pm 25 ; P_{2} 11-12 ; 3,5-4$ mm. (First 3 segments shorter than long, the following ones $\mathrm{L}=2$ $2^{1} / 2$ br. From the $5^{\text {th }}$ - the $8^{\text {th }}$ segment a large genital gland; $P_{2}$ stouter than $\left.P_{1}\right)$. $P_{b}$ similar, 11 segments. $P_{3} 11 ; 3,7 \mathrm{~mm}$. Distal $p .16 ; 5,5 \mathrm{~mm}$. $\left(1^{\text {st }}\right.$ and 2 segments short, $3^{\text {d }}$ and the following ones long and slender, $\mathrm{L}=2^{1 / 2-3} \mathrm{br}$, the articulations somewhat swollen).

Disk a little incised, $4,5 \mathrm{~mm}$., without granules. Anal tube $2,3 \mathrm{~mm}$. The ossicles white, the weak parts yellowish (on the preserved specimen).

The above-described new species is a rather interesting type. By the formation of $\mathrm{Cd}$ it documents its relationship to the subfam. Zenometrince. The formation of cirri and $\mathrm{P}_{1}$ both hint at the abovementioned subfamily as well as the subfam. Thysanometrince (Both these characteristies are however common both to Thysanometrince and to a couple of genera in Zenometrince). And fually - and this is the really strange condition - the animal has a large genital gland on $P_{2}$, a phenomenon elsewhere found in $P_{S}$. anomala, in Bathymetrince, and exceptionally in Antedonince (Compare Compsometra parviflora). Of late A. H. Cuark has shown that a genital gland on $\mathrm{P}_{2}$ does not occur in all species of Baflymetrince (as he at first supposed), though it is a very usual characteristic in the subfamily mentioned.

It is perhaps not an accident that this characteristic, otherwise common to the Bathymetrince, is found in Zenometrin forms. This is an additional support for $\mathrm{A}$. II. CLark's supposition (though possibly not a very important one, considering that a genital gland is also found exceptionally in the Antedonina) that the two first-mentioned subfamilies might be more elosely related. 'T'o be correctly understood. I will say, however, that, contrary to A. II. CLARK, I am more inclined to think 
the Zenometrince to be the original type because of the formation of the $\mathrm{Cd}$ which probably more than that of the Bathymetrince, resembles the $\mathrm{Cd}$ of the more primitive (Atelecrinoid?) forms from which the Macrophreats originate.

The new species, which I have named after Prof. A. Wirén of Uppsala, is in other respects approaches closest to $P$ s. inusitata and Ps. anomala.

\section{Perometrinæ A, H. ClakK.}

Erythrometra $\Lambda$. I1. Crikr.

E. rubra $\Lambda$. II. CLiRK.

Fig. $150-152$. p. 146 .

Syn.: Antedon ruber 1907 A. II. Cu.nk Proc. U. S. Nat. Mus. Vol. 33,

Erythrometra nuber 1908 A. H. Chark Wash. Proc. Biol. Soc. Vol. 121, p. 126; Proc. U. S. Nat. Mus. Vol. 34, p. 316; 1909 Kobenhavn, Videnskabl. Meddel. p. 190; 1912 Crin. Ind. Oc. p. 233; 1915 Wash. Journ. Acad. Sci. Vol. 5, p. 215; 1918 Sibogi Exp. Vol. 42 B, p. 236.

From St: $11=3$ specimens.

Sp. 1 (St. 11) C. XX 24-25 (D), 34-36 (V); 7-11 mm. Ist and 2 segments short, $3^{\text {d }}$ cubical, $5^{\text {th }}$ the longest, $L=1^{1 / 2}-1^{2} / 3$ br, then slowly decreasing, $10^{\text {th }}$ segment about cubical. From this segment a dorso-distal swelling on the cirrals, and this prominence gradually develops into a blunt, longitudinal erista (most prominent about 9-10 segments from the last one). Antepenultimate segment almost smooth. Opposing spine stout, $\mathrm{h}={ }^{2} / 3$ of the br of the segment. Terminal claw curved, $L$ about the same as the penultimate segment.

$\mathrm{R}-\mathrm{S} \mathrm{h}={ }^{1 / 6} \mathrm{br}$. I $\mathrm{Br} 1 \mathrm{~h}=1 / 2 \mathrm{br}$, laterally almosi free, though nearly standing, distally somewhat incised in the middle by the obtuse-angled proximal border of the axillary. The synarthrial swelling inconspicuous. Axillary rhombic, $h={ }^{3} / 4 \mathrm{br}$, lateral angles with very slight, small spines. Arms $\mathrm{X}, 25 \mathrm{~mm} .+. \mathrm{Br}-\mathrm{s} 1$ inwardly united by pairs, outwardly $1^{1 / 2} \times$ broader. The proximal border of $\mathrm{Br} 2$ 
similar to that of $\mathrm{I} \mathrm{Br} 2$. Joints after $\mathrm{Br} 10$ triangular, smooth. Syzygies: $3+4,(9+10), 15+16,21+22$, distally with an interval of usually $3-4$ oblique articulations.

$P_{1} 11-12 ; 4,2 \mathrm{~mm}$. (1 $1^{\text {st }}$ and last segments short, the other ones $\mathrm{L}=2-2{ }^{1 / 2} \mathrm{br}$, smooth cirrals), $\mathrm{P}_{2} 11 ;+\mathrm{mm}$. (Distal segments slightly swollen and spiny), $P_{3} S-9 ; 2,2 \mathrm{~mm} ., P_{4}$ still a little shorter, then again longer $\mathrm{p}-\mathrm{s}$. Distal $\mathrm{p} \pm 13$; $3 \mathrm{~mm}$. ( $1^{\text {st }}$ and $2^{\mathrm{t}}$ segments somewhat stouter than the following ones), $P_{i}$ usually absent. The proximal pinnules are stiff.

Colour (on preserved material) yellow-brown. Cirri white. Disk $2,5 \mathrm{~mm}$, finely papillous. Anal cone narrow, $\mathrm{L}=0,8 \mathrm{~mm}$.

Sp. 2 (St. 11) C. XXXII 15-16 (D), 25-28 (V); 2,5 and $7 \mathrm{~mm}$. respectively.

I $\mathrm{Br} 1$ with 3 small lateral tubereles on each side. Arms $\mathrm{X}$. broken. After $\mathrm{Br} 7$ wedge-shaped segments. Lx, of syzygies: $3+4$, () $10,14-15$.

$\mathrm{P}_{1} 9 ; 3,5 \mathrm{~mm}$. (Distal segments slightly collar-shaped and a little spiny). $P_{2} 8 ; 2,5 \mathrm{~mm}$. Similar to $P_{1} ; P_{3} 9$, about as long as $P_{2}$. $P_{a}$ absent.

Disk with large calcareous granules also interbrachially, where the perisome reaches to $\mathrm{Br}^{-} \mathrm{t}$. Colour salmon-red. Cirri white.

Sp. 3 (St. 11) The free dorsal surface of Cd small-grained, 0.8 mm. C. XIV $17-19$ in a single whorl. $4^{\text {th }}$ segment the longest, with a dorsal tubercle, which at the $7^{\text {th }}$ segment passes over to at stout dorsal spine, less developed on the antepenultimate segment.

Arms $\mathrm{X}$, broken. Syzygies with an interval of $3-4$ oblique articulations.

$P_{1} 11 ; 3 \mathrm{~mm} . \mathrm{P}_{2} 11 ; 4,2 \mathrm{~mm}$. (the distal borders of the pinnular's with small spines), $\mathrm{P}_{3} 9 ; 3 \mathrm{~mm} ., \mathrm{P}_{4} 10 ; 2 \mathrm{~mm}, \mathrm{P}_{\mathrm{a}}$ absent.

Colour white, with pale pink spots on the arms.

Though the above-deseribed specimens differ from Erylthometre mora by having almost smooth arm-bases and proximal pinnules, I have referred them to this species, as the other characteristics coincide. and considered the differences to be ascribable to different ages in my specimens and those described of A. II. CLaRK.

A. II. CLarK originally called the species Antedon mber. When a little later he created his new elassification of the Comatulids and 
referred the species to a new genus of feminine gender, he still preserved the second name mber with a masculine inflection. 'To adapt the adjectival second name to the genus-name, I have therefore called the species E. rubra.

\section{Clarkometra n. gुen.}

In all morphological chararacteristics this new genus proves to be a Macropheat form and is to be included in the subfamily Perometrinc. (Nevertheless I will call attention to the fact that the dorsal prominence on $5^{\text {th }}-S^{\text {th }}$ cirral is a transversely curved, even crista. This reminds one of the condition in the family Colobometride, where the crista is, however, always forked or serrate.)

Clarkometra agrees with the Central-American genus Hypalometra in the absence of $\mathrm{P}_{1}$ and $\mathrm{P}_{\mathrm{a}}$, but differs from this one by a low, flattened $\mathrm{Cd}$, by short cirri, which are composed of a rather small number of about cubical segments, and by the occurrence of 2 pairs of oral pinnules. Of the other distinguishing marks I ought, perhaps, to mention the appearance of the cirrus-sockets on Cd. (T'he perforation for the central canal is situated in the middle of a relatively large calcareous wart located in the central part of the cavity in which the cirrus is fixed) - A. H. CuARK in a letter to me has supposed that the species described below might possibly be identical with, or nearly related to, "Antedon impinnata» mentioned by P. H. CARPENTER from Mauritius (Chall. Exp. p. 206). It is possible, though not very likely, that the new species might be nearly related to CARPENTER's species - from his very incomplete description one only learns that $P_{a}, P_{b}$ and $P_{2}$ are absent - that it is identical with my species I consider to be out of the question, partly because of the statements about the number of cirri and cirrals, partly on account of the geographical distribution. Besides, the statements about the pinnulation rather point to a young animal than to a full-grown individual. For in connection with the notice of absence of $P_{2}, P_{n}$ and $P_{b}$ nothing is said about $P_{1}$, and one must therefore suppose that this pinnula is present.

This new, very interesting genus $I$ have called after A. I. CLark, who has done such very meritorious work on the systemisation of the Comatulids. 


$$
\text { Cl. elegans } 11, \mathrm{sp} \text {. }
$$

Fig. $1+1-149$, Photo 8 .

From St. 43 (15 sp.), $53(2)=17$ specimens.

Sp. 1 (St. 43) Cd low, arehed, br=1,8 mm., free dorsal surface $1 \mathrm{~mm}$. , somewhat granulated. II of Cd $1 \mathrm{~mm}$. (from the $\mathrm{R}-\mathrm{s}$ to the dorsal pole).

C. XXX $15-18 ; 3,5-5 \mathrm{~mm}$. in two close, alternating whorls. $1^{\text {st }}$ segment shorter than long, $2^{\mathrm{d}}$ and $3^{\mathrm{d}}$ cubical, $4^{\text {th }} \mathrm{L}=1^{1 / 4} \times \mathrm{br}$, then slowly decreasing. $5^{\text {th }}-7^{\text {th }}\left(\right.$ or $\left.S^{\text {th }}\right)$ segment with a low, transverse, curved crista which from the $8^{\text {th }}$ cirral concentrates to a small, simple dorsal tubercle. Opposing spine pointed, rather large $(h=1 / 2$ of the br of the segment.). Terminal claw eurved, rather stout, length about the same as the preceding segment. The whole cirrus rather stout.

$\mathrm{R}-\mathrm{S}$ almost concealed at the middle by $\mathrm{Cd}$, a little tongue-like in the corners. I Br-s 1 baso-laterally contiguous or free, $h=t^{1 / 4}$ br, with a small medio-dorsal tuberele. Axillary $h=3 / 4$ br, almost hexagonal with a low, synarthrial, longitudial erista (rather slightly bordered) in the proximal $2 / 3$. Arms $\mathrm{X}, 30 \ldots 35 \mathrm{~mm}$., smooth. Br-s 1 united inwardly to $2 / 3 . \mathrm{Br} 2$ on the outside twice as broad. Br 1 and 2 with a slight synarthrial prominence similar to that of the I Br series. Ex of syzygies: $3+4,9+10 \ldots$ distally with an interval of 3 oblique articulations. The proximal segments rather long.

$\mathrm{P}_{1}$ and $\mathrm{P}_{\mathrm{a}}$ absent. $\mathrm{P}_{2} 12 ; 6,5 \mathrm{~mm}$. (1 $1^{\text {st }}$ segment short, $2^{\mathrm{d}}$ a little longer than broad, $3^{\text {t }} \mathrm{L}=2 \mathrm{br}, 4^{\text {th }}$ and $5^{\text {th }}$ segment $\mathrm{L}=3-4 \times \mathrm{br}$, slender, at the ends somewhat widened. From the $3^{\text {t }}$ segment the distal ends are indistinctly collar-shaped and have spiny borders), $P_{\mathrm{b}}$ $6 \mathrm{~mm} . \mathrm{P}_{3} 11 ; 5 \mathrm{~mm} . \mathrm{P}_{4} 10 ; 3,2 \mathrm{~mm}$. with a genital gland and considerably shorter segments. Distal p-s. $16 ; 5,5 \mathrm{~mm} .\left(1^{\text {st }}, 2^{\mathrm{d}}\right.$ and the last segments short, the other ones $\mathrm{L}=2 \mathrm{br}$ ).

Disk without calcareous granules, incised, longest diameter 4, shortest $2,5 \mathrm{~mm}$. Anal cone long, $\pm 2 \mathrm{~mm}$.

Cirri white. the arms red-violet.

Sp. 2 (St. 43) The size of the disk as before. Anal cone 1,5 mm. Colour a little lighter: red-grey with a light, dorsal, longitudinal band. For further details compare the table. 
SP. 3 (St. 43) $\mathrm{R}-\mathrm{s}$ narrow bands. I Br-s 1 laterally free. The synarthrial tuberele indistinct. $P_{k}, 9 ; 3 \mathrm{~mm}$.

Sp. 4 (St. 43) $\mathrm{R}-\mathrm{s}$ well visible, $\mathrm{h}=1 / 6 \mathrm{br}$. No synarthrial tuberele. Broken arms.

Sp. 5 (St. 43) R-S as in Sp. 4. P $\mathrm{P}_{\mathrm{k}}, 7 ; 2,7 \mathrm{~mm}$.

Sp). 6 (St. 43) $\mathrm{P}_{\mathrm{b}}, 9 ; 4,2 \mathrm{~mm}$.

Sp. 7 (St. 43) $P_{\mathrm{b}}, 8 ; 3,3 \mathrm{~mm}$. Disk : longest diameter 3,5 , shortest one $2 \mathrm{~mm}$.

Sp. 16 (St. 53) Opposing spine $\mathrm{h}=2 / 3$ of the br of the segment. $\mathrm{P}_{\mathrm{h}} 8 ; 3 \mathrm{~mm}$. Disk $3 \mathrm{~mm}$., not so distinctly incised. Anal cone $2 \mathrm{~mm}$. Sp. 17 (St. 53) Disk 2,5 mm.

\begin{tabular}{|c|c|c|c|c|c|c|c|c|c|c|c|c|c|}
\hline \multirow{2}{*}{$\begin{array}{l}\text { Number of speci- } \\
\text { mens \& stations }\end{array}$} & \multicolumn{3}{|c|}{ Girri } & \multicolumn{2}{|c|}{ Arms } & \multicolumn{2}{|c|}{$\mathrm{P}_{2}$} & \multicolumn{2}{|c|}{$\mathrm{P}_{3}$} & \multicolumn{2}{|c|}{$\mathrm{P}_{4}$} & \multicolumn{2}{|c|}{ Dist. $p$. } \\
\hline & $\mathrm{N}$ & $\mathrm{S}$ & $\mathrm{L}$ & $\mathrm{N}$ & $L$ & $\mathrm{~S}$ & $\mathrm{~L}$ & $\mathrm{~S}$ & L & $\mathrm{S}$ & $\mathrm{L}$ & $\mathrm{s}$ & $\mathrm{L}$ \\
\hline Sp. 1 (St. 43.) & $\mathrm{XXX}$ & $15-18$ & $3,5-5$ & X & $30-35$ & 12 & 6,5 & 11 & 5 & 10 & 3,2 & 16 & 5,5 \\
\hline Sp. 2 (St. 43.) & XXVIII & $16-19$ & $3,5-5,5$ & $\mathrm{X}$ & 25 & 12 & 5,5 & 10 & 4,7 & 10 & 3 & $15-17$ & 5 \\
\hline Sp. 3 (St. 43.) & - & $14-15$ & 4,5 & $\mathrm{X}$ & 20 & 9 & 4 & 8 & 3,5 & 7 & 2,3 & 12 & 4 \\
\hline Si. 4 (St. 43.) & $\mathrm{XV}$ & 13 & $3-3$. & $x$ & & & - & _ & - & - & - & & - \\
\hline Sp. 5 (St. 43.) & XVII & 13 & $3-3,5$ & $\mathrm{X}$ & 12 & $8-9$ & 2,7 & $7-8$ & 2,5 & 8 & & 10 & 2,5 \\
\hline Si. 6 (St. 43.) & XXVIII & $13-16$ & $3,5-6$ & $\mathrm{X}$ & 27 & 9 & 4,2 & $7-8$ & 3,2 & s & 2,5 & 16 & 5 \\
\hline Sp. 7 (St. 43.) & XXIII & $14-16$ & $2,5-3,5$ & $5 \mathrm{X}$ & - & 8 & 3,3 & 8 & 3 & $\ldots$ & - & - & - \\
\hline Sp. 16 (St. 53.) & $\mathrm{XXV}$ & 15 & $4-5$ & $\mathrm{X}$ & 27 & 8 & 3,5 & 8 & 3 & 8 & 2,7 & 15 & 4 \\
\hline Sp. 17 (St. 53.) & XIV & $\mid 2-15$ & $3-4$, & $5 X$ & $15-20$ & 9 & 3 & 9 & $\mathbf{Q}_{, 5}$ & & - & \pm 15 & 4 \\
\hline
\end{tabular}

Bathymetrinæ A. II. ClaAr.

Thaumatometra A. II. CLAkK.

Th. comaster $\Lambda$. IJ. Crukk.

Fig. $153-156$.

Syn: Thaumatometra comuster 1908 A. II. CL.SR Proc. U. S. Nat. MIus, Vol. 34, p. 232; 1912 Crin. Ind. Oc. p. 246; 1915 Wash. Journ. Acard. Sci. Vol. 5 p. 215; 1918 Siboga Exp. Vol. 42 B, 1. 256.

From St. 37 (and 4$)=2$ specimens.

Sp. 1 (St. 37) Cd very low and flattened, conieal, br $=2 \mathrm{~mm}$., h about $0,6 \mathrm{~mm}$. The free, dorsal surface $1,1 \mathrm{~mm}$. C. \pm XXXV 12-15;

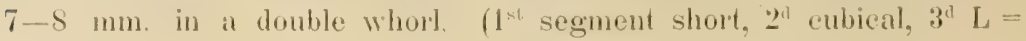


The Crinoids from Dr. S. Bock's Expentrion to dapax 1914. 145

$2 \mathrm{br}, 4^{\text {th }}-6^{\text {th }} \mathrm{L}=3 \times \mathrm{br}$, rather much hour-glass-shaped, $7^{\text {th }}$ segment $\mathrm{L}=2{ }^{1 / 2} \mathrm{br}$, antepenultimate one $\mathrm{L}$ very slightly greater than br. Terminal claw curved, about as long as the preceding segment). The distal cirrals smoother. in side view thickened.

$\mathrm{R}-\mathrm{s}$ concealed. I Br-s 1 laterally free, in the middle incised by the backward projection from the axillary. Their lateral $h=1 / 4-1 / 3$ of the br of the segments. Axillary $h=b r$, with a tongue-Jike prominence both proximally and distally; the proximal projection is longer than the distal one. The side-angles of the axillary overlapping the $1 \mathrm{Br}-\mathrm{s} 1$. Arms $\mathrm{X}, 45-50 \mathrm{~mm}$. Br-s 1 inwardy contiguous basally, on the outside three times as wide. Br 2 with a stout synarthrial tongue. 'The first syzygial pair $(3+4)$ a little broader inside than outside. The following segments irregularly squarish. The distal Br-s knotty and swollen, somewhat longer than broad. lix. of syzygies: $3+t, 9+10,14+15$ ete. with an interval of 3 oblique articulations.

$P_{1} \quad 15 ; 7 \mathrm{~mm}\left(1^{\text {st }}\right.$ and $2^{\mathrm{d}}$ segments short, $3^{\mathrm{d}} \mathrm{L}=2-2^{1} / 2 \mathrm{br}, 4^{\text {th }}$ and the following ones $\mathrm{L}=3-4$ br), $\mathrm{P}_{2} 8 ; 4 \mathrm{~mm}$. (with a genital gland from the $3^{\text {d }}$ or $4^{\text {th }}$ to the $7^{\text {th }}$ segment), $P_{3} 9 ; 4,5 \mathrm{~mm}$. (a gonad from the $3^{\text {in }}$ to the $7^{\text {th }}$ segment). The distal segments a little spiny distally. Distal p-s. $\pm 16 ; 6-7 \mathrm{~mm}$.

Disk 3,8 mm., smooth, without stouter granules. Anal cone $3,2 \mathrm{~mm}$.

Sp. 2 (St. 4) A very young specimen, probably belonging to this species.

C. + XXVI 7-10; 2-3 mm. in 2 whorls. Cd low, flattened, almost hidden by cirri. (29 cirral $\mathrm{L}=1^{3 / 4} \mathrm{br}$, the following segments $\mathrm{L}=4 \times \mathrm{br}$, distally somewhat expanded. Antepenultimate segment $\mathrm{L}=\mathrm{I}^{3} / 4$ br. Penultimate segment $\mathrm{L}=\mathrm{br}$, with an indistinct opposing spine).

I $\mathrm{Br} / \mathrm{h}=1 / 3 \mathrm{br}$. Axillary $\mathrm{h}=3 / 4 \mathrm{hr}$, the backward directed corner with a large synarthrial tongue, about twice as long as the distal angle. Arms $\mathrm{X}, 10 \mathrm{~mm}$. + . Br-s 1 almost free inside. Br 2 with a synarthrial tongue, $-P_{1}+10 ; 1,8 \mathrm{~mm}$. ( $L$ of the segments $2^{1 / 2}$ br). Between $P_{1}$ and the distal pinnules a gap. Disk $1,3 \mathrm{~mm}$. Anal cone $1 \mathrm{~mm}$. narrowly suusige-shaped. 


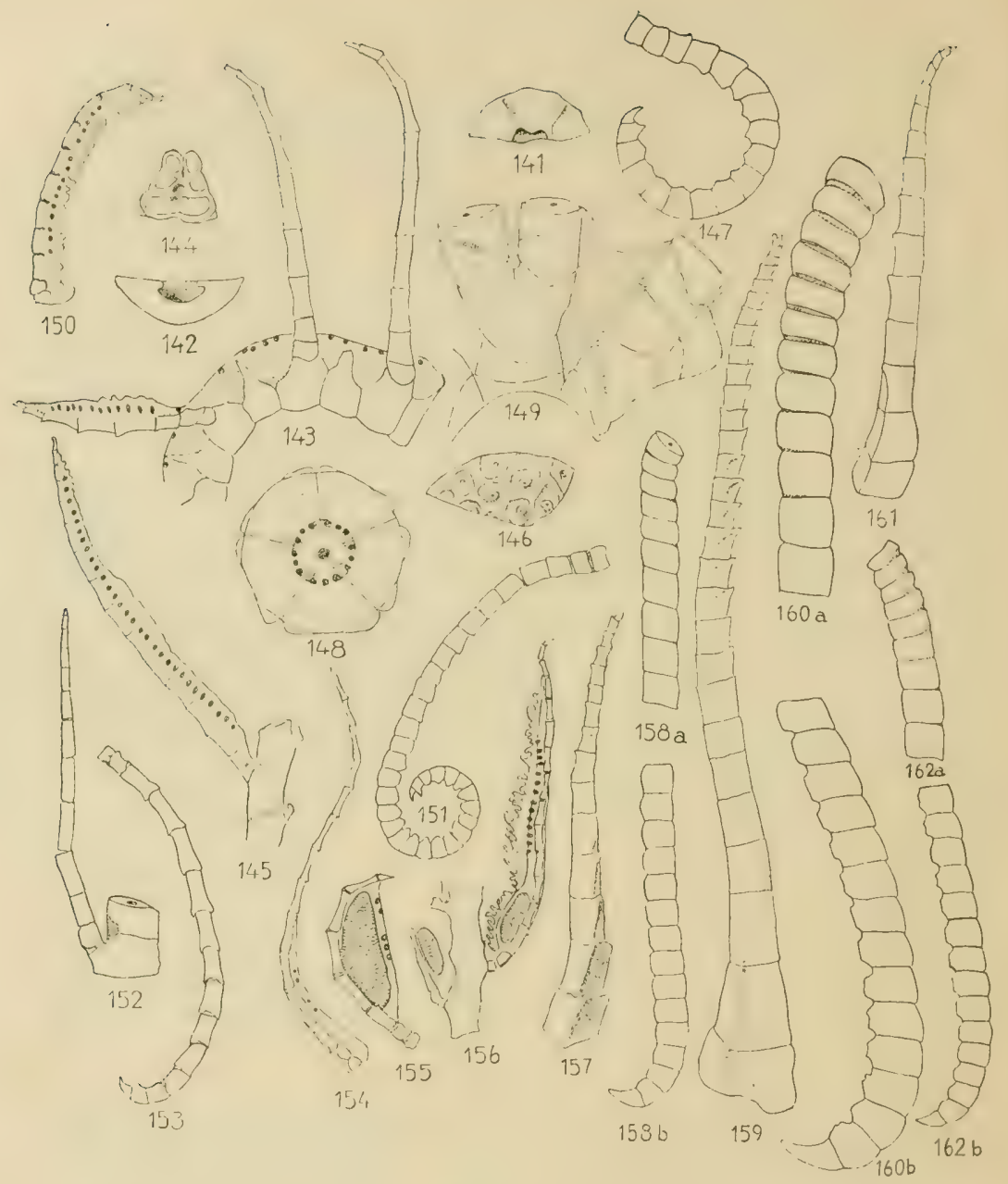

Fig. 141-149 Clarkometra elegans (St. 43) 141) Half Cd viewed from the ventral side 1s/1, 142) Half $\mathrm{Cd}$ viewed laterally, showing the extention of the central cavity $14 / 1,143) 13 \mathrm{k}-11$ with $\mathrm{P}_{2}-\mathrm{P}_{4} 14 / 1$, 14k) The distal face of the $\left.\mathrm{R} 14 / 1,145\right)$ Some $\mathrm{Br}$ segments and $n$ distal pinnule 14/1, 146) A part of Cd viewed from the dorsal side (observe the calcareous warts at the bottom of the cirrus-sockets), $\times 17^{1 / 2}, 147$ ) Cirrus 14/1, 148) Proximal radial faces with the rosette in situ, $\times 173 / 2$, 149) The arm-bases out to $\mathrm{Br} 3^{14 / 1}$; $150-152$ Frythometra rubra (St. 11) 150) Distal pinnule $16 / 1$, 


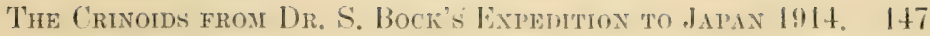

It seems to me as if 'Th. cymmis were rather indistinctly separated from the above-described species.

The dorsal prominences of the cirrals are not developed in the above specimens. Is this condition, perhaps, common to all small species of the genus tham Antedonine, and the dorsal prominences of the cirrals may be absent in Bathymetrince the limit between the two sub-families becomes rather vague.

\section{Pentacrinidæ (D'OrBigny).}

Metacrinus P. H. Carpenter (WY. 'l'homs. M. S.).

M. nobilis var tenuis 11 , var:

Fig. 161, 162.

From St 7 (2), $9(5), 56(1), 58(1)=9$ specimens. Also a stemless crown without indication of the locality.

Sp. 1 (St. 9) Full-grown internodes with 10-13 internodal joints, 13-18,5 mm. (8, 9 and 10 internodals each 1 case, $11: 5$ cases, $12: 5$ cases, $13: 4$ cases). Interarticular pores to the $12^{\text {th }}$ internode. The 3 most proximal nodals without eirri. Full number of internodal joints in the $6^{\text {th }}$ internode. The stem with 22 internodes; total length 275 $\mathrm{mm}$. Diameter of the stem $3,5-4,5 \mathrm{~mm}$. The segments are pentagonal, smooth; the 10 most distal internodes, however, with the joints in the radial line a little concave and provided with small tubereles. Here and there on the internodals tubercles also $1 \mathrm{R}$.

Cirri reaching over $2-2^{\frac{1}{2}}$ internodes. 50 segments (IX ${ }^{\text {th }}$ nodal) $44 \mathrm{~mm}$., 44 (XIII) $36 \mathrm{~mm} ., 44$ (XVI) $36 \mathrm{~mm} ., 40$ (XVII) $31 \mathrm{~mm} .40$ (XVlII) $30 \mathrm{~mm}$. $7^{\text {th }}$ segment $\mathrm{L}=$ br; 15 last segments with dorsal spines. $L$ of the terminal claw $=1^{1 / 2}$ times the preceding segment.

151) Cirrus $\% \frac{1}{152)} \mathrm{Br} 2$ and 3 with $\mathrm{P}_{1}$ 14/1; 153-15̄6 Thammatometra comaster. (St. 37), 153) Cirrus $\% \frac{1}{1}$, 151) $\left.P_{1} 14 / 1,155\right) P_{2}$ with a genital gland $14 / 1,156$ ) An arm-stump with distal pinules (a small genital gland from the 3d-the 5 th segments) 9/1; 157, 158 Metacrinus interruptus ( $\mathrm{Sp} .10)$ 157) $\mathrm{P}_{1}$ (I $\mathrm{Br} 3$ ) viewed somewhat more laterally than in the two following species, $\left.\times 4^{1 / 2}, 158\right)$ Cirrus a) Proximal part b) Distal part, $\times 4^{1}{ }^{1 / 8} ; 159,160$ Mefacrinus rotundus (Sp. 2) 159) $\mathrm{P}_{1} \times 4^{1 / 2}, 160$ ) Cirrus a) Proximal b) Distal part, $\times 1 \frac{1 / 2}{161,162}$ Metacrinus nobilis tenuis (Sp. 1) 161) $P_{1} \times 4^{1 / z}, 162$ ) Cirrus a) Proximal part (observe: by the position of the basal cirrals the cirrus is bent downwarls, not, as in the two preceding species, up wards) b) Distal part, $\times 11 / 2$. 
No opposing spine. The cirrus-socket entering somewhat into the supra- and infra-nodal joint.

B-s contiguous, shield-shaped, $\mathrm{h}: 1,3, \mathrm{br}: 3,5 \mathrm{~mm} . \mathrm{R}-\mathrm{s}$ soldered together laterally, $h=1,3 \mathrm{~mm}$., br $=4 \mathrm{~mm}$. I Br-s $4(1+2) ; 7 \mathrm{~mm}$. Il Br-s $7(2+3)$ or $7(3+4)$ each in + arses, $9 \mathrm{~mm}$. The two remaining divisions broken. III Bl-s $11(3+4) 3$ cases, $13(3+4) 2$ eases, $15(3+4) 2$ cases; $11-15 \mathrm{~mm}$., the other ones broken. IV $131 \mathrm{r}-\mathrm{s}$ $13(3+4), 15(3+t)$ each in one case. The Br-s smooth. The perfeet specimen probably with $L V$ arms; the total arm-length is $95 \mathrm{~mm}$. L of an unramified arm from III Brax $65 \mathrm{~mm}$.

$\mathrm{P}_{1}$ (to the right on $\mathrm{I} \mathrm{Br}^{\circ} 2$ and to the left on $\mathrm{I} \mathrm{Br}^{\circ} 3$ in 2 cases. the reverse condition in :3 eases) $14-15: 13 \mathrm{~mm}^{2}\left(1^{\text {st }}\right.$ and $2^{\text {at }}$ segments stout, square, the $L$ in total $3 \mathrm{~mm}$., the rest of the segments strongly compressed), $\mathrm{P}_{2}$ 17; $18 \mathrm{~mm} . \mathrm{P}_{3} 17-1 \mathrm{~s} ; 18 \mathrm{~mm}, \mathrm{P}_{4}$ 14; 12 mm. - Disk with small calcareous granules, - Colour, in spirits, white with a green-bluish tinge.

Sp. 2 (St. 9) 18 Internodes; $240 \mathrm{~mm}$. Internodal joints 13 (1 case), 14 ( 12 eases); $15,5-18 \mathrm{~mm}$. Interarticular pores to the $10^{\text {th }}$ internode. Full number of internoral joints and number of proximal nodals without cirri as in Sp. 1. Diameter of the stem $4,5-4,8 \mathrm{~mm}$.

Cirri extending over 2 internodes. Length on the $\mathrm{X}^{\text {th }}$ nodal 40 mm., 43 (XII th nodal) $38 \mathrm{~mm}$. , 48 (XIII) $35 \mathrm{~mm}$. The fixing point for the cirrus just touching the supranodal. The infranodal joint sloping towards the fixing point. I Br-s $+(1+2) 9 \mathrm{~mm}$. only remaining in one case. II Br-s $7(3+4) 11 \mathrm{~mm}$. (1 case).

$\mathrm{P}_{1}$ to the right on $\mathrm{I} \mathrm{Br}^{\circ} 2$, to the left on $\mathrm{I} \mathrm{Br} 3 \mathrm{3}$ in the only occurring case.

Sp. 3 (St.9) 23 internodes, $295 \mathrm{~mm}$. Internodal joints 12 (1 case), 13 (11 cases), 14 (5 cases); 12,8-16,2 mm. Interarticular pores to the $10^{\text {th }}$ or $11^{\text {th }}$ internode. The joints are pentagonally rounded, smooth. Diameter of the stem $4,8-5,5 \mathrm{~mm}$.

Cirri 55 ( $\mathrm{A}^{\text {th }}$ node) $59 \mathrm{~mm}, 53$ (XIII) $58 \mathrm{~mm} .51$ (XX) $55 \mathrm{~mm}$. extending over ${ }^{3} / 4-3^{1} / 2$ internodes. From the $S^{\text {th }}$ segment the cirrals are as long as broad The 20 last joints with a slight dorsal carination. The crown thrown off from the B-s.

Sp. 4 (St. 9) 17 internodes, $225 \mathrm{~mm}$. Internodal joints 13 (6 cases), 14 ( 0 cases), 15 ( 1 case); $15--18 \mathrm{~mm}$. Interarticular pores to 
the $7^{\text {th }}$ internode. Diameter of the stem $4,7-5,0 \mathrm{~mm}$. The segments are smooth, distally almost perfectly round or 10-agonal by a slightly developed radial tuberele. The interradial tubereles usually smaller than the radial ones, all of them very inconspienous.

Cirri 47 (ISth node) ts mm., th (XI) $46 \mathrm{~mm}$., t6 (XIV) $46 . \mathrm{mm}$. Reaching over $2^{1 / 2}$ internodes. - Crown thrown off.

Sp. jo (St. (1) 13 internodes: 125 $\mathrm{mm}$. Internodal joints 13 in all the full-grown internodes; $14,7-15 \mathrm{~mm}$. Interarticular pores to the $10^{\text {th }}$ internode. Diameter of the stem $4,0-4,4 \mathrm{~mm}$. 3 proximal nodal joints without cirri. Full number of nodal joints in the $6^{\text {th }}$ internode. 'The segments as before smooth or slightly swollen in the middle. Cirri $t+$ (IX), t3 (XII) 40 (XIII), 35- $40 \mathrm{~mm}$. Extending over $21 / 4$ internodes. The crown thrown off.

\section{Loose crowns (St.9)}

1) $\mathrm{R}-\mathrm{s} \mathrm{h}: 1,3, \mathrm{br}: 4,5 \mathrm{~mm}$. I Br-s $+(1+2) ; 13 \mathrm{~mm}$, occurring in 5 curses. II Br-s $5(3+4) 2$ cases, 6 ( 1 case $), 7$ (7 eases) with syzygies between the $2^{d}$ and $3^{\prime \prime}$ segment in 4 cases, between the $3^{\mathrm{d}}$ and $4^{\text {th }}$ in 3 cases: $7-10 \mathrm{~mm}$. III Br-s $9(3+4)+$ cases, 10: 1 case, $11(3+t) 8$ cases, $13(3+t) 5$ cases; $9-11$ mm. The higher figures usually on the inner side. IV Br-s $11(3+t)+$ cases, $13(3+4) 3$ cases, $15(3+4) 5$ cases, $17(3+4) 2$ cases, $19(3+4) 5$ cases, 21 $(3+4) 3$ cases: $10-20 \mathrm{~mm}$. Arms LX, $140 \mathrm{~mm}$., smooth. Length of an undivided arm from IV Brax $90 \mathrm{~mm}$. 40-50 last $\mathrm{mm}-\mathrm{s}$, with rudimentary p-s. Syzygies: $3+4,17+18,37+38,56+57$ ete.

$\mathrm{P}_{1}$ to the right on $\mathrm{I} \mathrm{Br}^{\circ} 2$ in 5 cases. Distal $\mathrm{p}-\mathrm{s} \pm 15 ; 10 \mathrm{~mm}$.

Disk $+1+\mathrm{mm}$., coarsely granulated. Anal tube $12 \mathrm{~min}$. Colour lightly red-grey.

2) A very broken specimen. I $B l^{\circ}-\mathrm{s}+(1+2) 1$ case; $8,5 \mathrm{~mm}$. II $\mathrm{Br}-\mathrm{S} 8(2+3,5+6)$ or $\mathrm{S}(1+2,++5) 2$ cases; $12 \mathrm{~mm}$. - III $\mathrm{Br}-\mathrm{s}$ $15(3+4) 1$ case; $17 \mathrm{~mm} . \mathrm{P}_{1}$ to the right on I Br 2 in the only occurring ease.

Rixample of pinnulation:

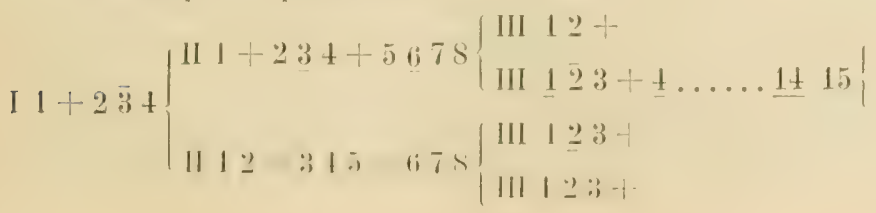


Sp. 6 (St. 7) A stemless crown. - R-s $1 \times 3 \mathrm{~mm}$. $1 \mathrm{Br}-\mathrm{s} 4$ $(1+2) ; 7$ mm.; present i 4 cases. Il Br-s $7(2+3) 4$ cases, $8: 3$ cases, of which the syzygies between $1+2,4+5$ in 1 case, between $2+3$, $5+6$ in 2 cases; $10 \mathrm{~mm}$. The other ones broken. III Br-s $9(3+4)$ 1 case, $11(3+4) 7$ cases, $13(3+4) 6$ eases; $8-11 \mathrm{~mm}$. IV Br-s 11 $(3+4) 3$ cases, $13(3+4) 10$ cases, $15(3+4) 1$ case, $17(3+4) 1$ case, $18(3+4,8+9$, or $3+4,13+14) 2$ cases, $20(3+4,12+13) 1$ case, $22(3+4,15+16) 2$ cases, $23 \cdot(3+4,6+7,16+17)$ 3 cases, 25 $(3+4,6+7,17+18$ or $3+4,10+11,20+21$ the former condition in 2, the latter in 1 case), $27(3+4,11+12,23+24)$ i case; $10-22$ $\mathrm{mm}$. The higher figures on the inner sides, e. g. 13--22-25-13: 13-23-22-11; 15-27-25-11 Arms LVI (probably about LXXV in the complete specimen), total length $115 \mathrm{~mm} .+$. The length of a free arm after a IV Brax $75 \mathrm{~mm}$. Rudimentary pinnules on the last $30 \mathrm{~mm}$. The distal Br-s somewhat collar-shaped.

$P_{1} 12 ; 10 \mathrm{~mm}$. (to the left on $\mathrm{I} \mathrm{Br} 2$ in 3 cases of 4 ), $P_{2} 14 ; P_{3} 14$; $15 \mathrm{~mm} . \mathrm{P}_{7}$ and the following ones $12-15 ; 10 \mathrm{~mm}$. At the transition to the rudimentary pinnules the number of segments are $14 \ldots 12$, $9,8, ., 7,7,8, ., 16,6,5,4,3,3,3,2,2, \ldots$

Sp. 7 (St. 7) A stemless chalice. I Br-s $4(1+2) ; 7 \mathrm{~mm}$. II Br-s $6(3+4) 1$ case, $7(3+4) 5$ cases, $7(2+3) 1$ case; $8-9 \mathrm{~mm}$. III Br-s $9(3+4) 1$ case, $11(3+4) 3$ cases, $13(3+4) 1$ case; $10-12,5 \mathrm{~mm}$. IV Br-s $11(3+4) 2$ cases, $13(3+4) 2$ cases, $17(3+4) 1$ case; $10-$ $14 \mathrm{~mm}$. A perfect specimen, probably, with about LXX arms; total length $105 \mathrm{~mm}$. L of the unramified arm after IV Brax $65 \mathrm{~mm}$. Part of the arm with rudimentary p-s $35 \mathrm{~mm}$. Syzygies after a IV Brax: $3+4,29+30,41+42$ or $3+4,23+24,42+43 \ldots$

$\mathrm{P}_{1} 8-10$ (to the right on $\mathrm{I} \mathrm{Br} 2$ in 2 eases, to the left in 3 cases); $7 \mathrm{~mm}$. Distal $\mathrm{p}-\mathrm{s} \pm 12 ; 9,5 \mathrm{~mm}$.

A loose crown without indication of the locality: I Br-s $4(1+2) ; 7$ mm. II Br-s $5(2+3) 1$ case, 7 in 9 cases, of which in 1 ease the syzygies between $1+2$, in 3 cases between $2+3$, and in 5 cases between $3+4 ; 8-10 \mathrm{~mm}$. III Br-s $9(3+4) 2$ cases, 11: 9 cases the syzygy in 1 case $2+3$, in 8 cases $3+4), 13(3+t) 8$ cases; $10,5-13$ mm. IV Br-s $11(3+4) 1$ case, 13 in 12 cases (2 cases: $4+5 ; 10$ cases: $3+4), 15(3+4) 7$ cases, $17(3+4) 1$ ease, $19(3+4)+$ cases, $20(3+4,14+15$ or $3+4,16+17: 2$ cases, or $3+4,17+18$ or 
The Crinords from Dr. S. Boch's Expedition to Japan 1914. 151

$3+4,18+19) 5$ cases, $21(3+4) 1$ case, $22(3+4,13+14$ or $3+4$, $15+16) 2$ eases, $2+(3+4,15+16) 1$ case; $10-17,5 \mathrm{~mm}$. V Br-s $13(3+t) 1$ case. - Arms LXXIV. Total length $135 \mathrm{~mm}$. Free armlength after IV Brax $75 \mathrm{~mm}$. The arm-part with rudimentary p-s $35 \mathrm{~mm}$. $\mathrm{P}_{1}$ (to the right on $1 \mathrm{Br}^{2} 2$ in 5 cases) $10 ; 13 \mathrm{~mm} ., \mathrm{P}_{3} 14 ; 17$ mm. Distal p. 13; 11-12 mm. Disk $10 \mathrm{~mm}$. Anal cone $7 \mathrm{~mm}$.

Sp. 8 (St. 56) 15 internodes, $160 \mathrm{~mm}$. Internodal joints 11: 3 cases, 12: 3 cases, 13:6 cases; 9-13 $\mathrm{mm}$. Interarticular pores to the $7^{\text {th }}$ internode. 3 proximal nodals without cirri. F'ull number of internodals at the $4^{\text {th }}$ internode. Diameter of the stem $2,5-2,8 \mathrm{~mm}$.

Cirri 38 (VI) 28 mm., 37 (VII) 29 mm., 36 (IX) 30 mm., 34 (XI) 26 mm., 36 (XIII) $21 \mathrm{~mm} ., 35$ (XV). Cirri extending over 2 internodes.

B-s $1 \times 2 \mathrm{~mm}$. R-s $1 \times 3 \mathrm{~mm}$. I Br-s $4(1+2) ; 6 \mathrm{~mm}$., in 4 cases. II Br-s $7(2+3) ; 6 \mathrm{~mm}$. in 1 case. III Br-s $11(3+4) 2$ cases; $9 \mathrm{~mm}$. IV Br-s $11(3+4) 1$ case, $15(3+4) 1$ case, $21(3+4) 2$ cases. The other arm-divisions broken. Total $\mathrm{L}$ of the arms $80 \mathrm{~mm}$. Free part from a III Brax $55 \mathrm{~mm}$. Part of the arm with rudimentary p-s about $10 \mathrm{~mm}$. Ex, of syzygies: $4+5,24+25,34+35 \ldots$

$P_{1}$ (to the right in 2 cases of 4 ) $12-14 ; 10-11 \mathrm{~mm} . \mathrm{P}_{2} 15 ; 11$ $\mathrm{mm}$. Distal $\mathrm{p}-\mathrm{S} 11 ; 6 \mathrm{~mm}$.

Sp. 9 (St. 58) 14 internodes, $100 \mathrm{~mm}$. Number of internodals $6-11 ; 5,5-10 \mathrm{~mm}$. Interarticular pores to the $6^{\text {th }}$ internode. Diameter of the stem $0,8-1,6 \mathrm{~mm}$. Number of internodal joints, counted proximo-distally (from the chalice), are: $0,0,0,1,3,7,9(6 \mathrm{~mm}$.) $10(8,2$ mm.) $11(9), 10(8), 11(9), 10(8,5), 9(7), 7(5,5), 6(5), 11(10), 10(9)$. Stem smooth.

Cirri 26 (VII) $18 \mathrm{~mm} ., 25$ (X) $16 \mathrm{~mm} ., 23$ (XIII) $14 \mathrm{~mm} ., 21$ (XV). From the $4^{\text {th }}$ segment the $L$ of the segments are $=1^{1 / 2}$ br, last 7 segments $\mathrm{L}=\mathrm{br}$ or shorter. A dorsal spine scarcely developed. Cirri extending over 2 internodes.

I Br-s $4(1+2)$ in 4 cases, $5(1+23+4) 1$ case; $5 \mathrm{~mm}$. II Br-s $7(2+3) 5$ cases, $8(1+2,4+5$ or $2+3,6+7$, the former condition in 1 case, the latter one in 3$)+$ cases; 6 mm. III Br-s $11(3+4$ : 8 cases, $2+3: 1$ case) 9 cases, $13(3+4) 7$ cases, $15(3+4) 2$ cases; $8-10 \mathrm{~mm}$. IV Br-s $11(3+4) 1$ ease, $13(3+4) 12$ cases, $14(3+4$, $10+11) 1$ case, $15(3+4) 3$ cases, $17(3+4) 7$ cases, $19(3+4) 1$ case; 6-7 mm. Arms LXII +, total length $30 \mathrm{~mm}$. Free $\mathrm{L}$ after a III Brax 
10-12 $\mathrm{mm}$. The part of the arm that supports the rudimentary pinnules $3 \mathrm{~mm}$. The arms derived from IV Brax of very different lengths, cf. the table below:

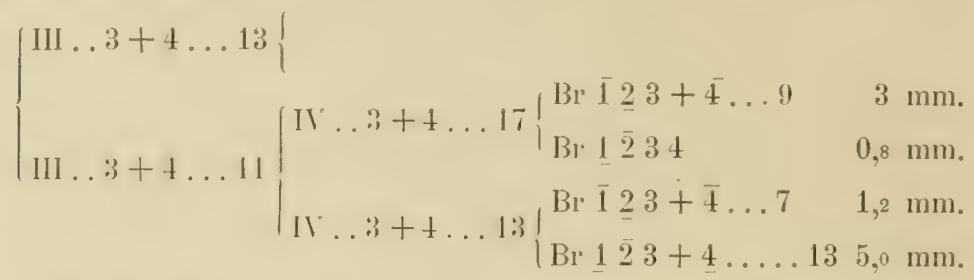

$\mathrm{P}_{1}$ (to the right on $\mathrm{I} \mathrm{Br} 2$ in 5 cases) $9 ; 5 \mathrm{~mm} ., \mathrm{P}_{2} 10 ; \mathrm{P}_{3} 10$; $P_{\text {IV Br }}, 7 ; 2 \mathrm{~mm}$.

Disk coarsely granulated, with a long, plated anal tube. No orals remaining.

As is evident from the deseriptions given above the number of cirrals and cirri is to a certain degree proportional to the thickness of the stem, that is to the age of the specimen. The different stages of age that the present specimens represent permit a rough estimate of the $\mathrm{L}$ of the stem in a full-grown specimen. Specimen 3 .has a $\mathrm{L}$ of the stem of $295 \mathrm{~mm}$. and an increase of $4,8-5,5 \mathrm{~mm}$. of the stem-diameter. Sp. 2 has a $240 \mathrm{~mm}$. long stem and a diameter of $4,5-4,8 \mathrm{~mm}$. Sp. 1 has a stem length of $275 \mathrm{~mm}$, and a stem-diameter of $3,5-4,5 \mathrm{~mm}$. In $S p$. 8 the stem on a $\mathrm{L}$ of $160 \mathrm{~mm}$. has increased from $2,5-2,8 \mathrm{~mm}$. and in Sp. 9 from $0,8-1,6 \mathrm{~mm}$. on a $\mathrm{L}$ of $100 \mathrm{~mm}$. To judge from these specimens the increase of the diameter of the stem is thus rapid to $1,5 \mathrm{~mm}$. rather slow at about $2,5 \mathrm{~mm}$, again somewhat more rapid between $33_{5}$ and $t_{, 5} \mathrm{~mm}$. retarded between $4_{.5}$ and $4,8 \mathrm{~mm}$., and a little faster between 5,0 and $5,5 \mathrm{~mm}$. Nevertheless there is a general decrease in the rapidity of the thickness-growth of the stem, i. e. younger specimens grow faster, older ones usually more slowly. The total length of the stem, judging from the above figures, might be between 1,5 and 2,0 metres.

To the so-called nobilis-group DöDERLEIx has assigned 4 species: M. nobilis, varians, suluensis and superbus. I can here leave the two last-mentioned ones out of the question, as they are well separated from the 2 preceding species and from the above-described varicty. Metacri- 
The Crinoms from Dr. S. Bock's lexpentuton to Japan 1914. $15 \%$

mus nobitis with varieties and M. varians DöDERLEIN has distinguished according to the below combined scheme:

I Large species. Diameter of the stem $5-7,5 \mathrm{~mm}$. IV Brachials ordinary. Internodals smooth, without distinct furrows between the joints.

\section{M. nobilis}

1) 8 internodal joints. Cirri extending over 4 internodes. Diameter of the stem 5-6 mm. 5 》Radials» M. nob. tar. sumatrams

2) 9--10 internodal joints. Cirri extending orer 3-4 internodes. Diameter of the stem $(i-7,5 \mathrm{~mm}, 6(-7) \gg$ Radials» NI. nob. var . timoriensis

3) 10-12 internodal joints. Cirri extending over 3 internodes. Diameter of the stem $6-7 \mathrm{~mm}$. 5) $\gg$ Radials» $M . n 0 b$. var. nobilis.

4) 13-15 Internodal joints, otherwise as in the preceding variety. Here is to be mentioned also the sp. from Siboga Stat 251, $253,25 t$.

M. nob. var. murangi.

II Small species. Diameter of the stem 4 -5 mm. Rarely II Br-s. Internodal joints $6-8$. Distinet furrows between the intemodals. Cirri extending over $4-5$ internodes.

H. vertians.

To which species ought the above-described specimens then to be referred: From the point of view of the diameter of the stem and the number of pinnulars they are most elosely related to M. varians, but by the number of internodals, $\mathrm{L}$ of cirri and number of eirrals, by the occurrence of IV Br-s, by the number of internodes with interarticular pores they approach M. nobilis and especially the varieties nobilis and murayi of this species. Why have I not referred them to these two varieties, which moreover may searcely be considered as more than types of individual variation? 'The smaller diameter' of the stem in my specimens is an important distinguishing mark, but merely because of this I would not establish a new variety, as the difference might be due to a difference in age. Is I have pointed out above, the number of the cirrals is to a certain degree in proportion to the size of the animal. When therefore, in spite of the delicate stem, the Bockian specimens have a number of cirrals reaching or exceeding that stated for M. nobilis, the different diameters of the stems cannot be considered as due to differenees of age. Besides, the proximal pinnules in the new variety are shorter than both in M. nobilis and varians.

'Two of the previously described varieties of $M$. nobilis show in separate characteristics an approach to M. varians: $M$. n. var'. sumu- 
tianus by the number of internodal joints, by the diameter of the stem. by the $L$ of the cirri when compared with the $L$ of the internodes; MI. $n$. var, timoriensis by the variability of the I Br-s. It ought therefore not to be so surprising that the new variety of $M$. nobilis established here approaches $\mathbf{H}$. varians in a couple of characteristics: a slender stem and short pimnules.

Metacrinus rotundus P'. II. CARP.

Fig. $159,160$.

Syn: Aletacrimus rotundus 1884 P. If. Carpexter Chall. Exp. Vol.11, p. 34 ; 1885 Trans. Linn. Soc. Ser. 2 Vol. 2, p. 436; 1902 (04) Frank Spenry Proc. Mich. Aead. Sei., p. 195; 1908 A. H. Clamk Proc. U. S. Nat. Mus. Vol. 34, p. 529; 1911 Proc. U. S. Nat. Mus. Vol. 39, p. 487; Notes from the Leyden Mlus. Vol. 33, p. 192; 1912 Crin. Ind. Oc. p. 270; Proc. U. S. Nat. Mus. Yol. 43, p. 408; Smiths. Nise. Coll. Vol. 60, N:o 10, p. 33; 1913 Smiths. Nise. Coll Vol. 61, N:o 15, p. 69; 1915 Monograph p. 89.

Jetaerinus Stewarti 1884 P. 11. Carpexter Chall. Exp. Vol. 11, p. 34t; $188 \bar{~}$ Trans. Linn. Soc. Ser. 2. Vol. 2, p. 443; 1908 A. II. Clark Proc. U. S. Nat. Alus. Vol. 24 , p. 529; 1912 Crin. Ind. Oc., p. 270.

The Vega spocimen $188 \pm$ P. H. Carpester Chall. Exp. Vol. 11, p. $34 t$.

From St. 10 (1 sp.), 24 (1), 29 (1), 30 (1), 31 (2), 32 (1)=7 specimens.

Sp. 1 (St. 30) 24 Internodes; total length of the stem $400 \mathrm{~mm} .3$ nodal joints before the first cirrus-bearing node. Full number of internodals in the $5^{\text {th }}$ internode. Interarticular pores to the $12^{\text {th }}$ internode. Internodal joints $11: 3$ eases, $12: 9$ eases, $13: 3$ cases, $1+: 3$ cases, $15: 2$ cases; $14-17 \mathrm{~mm}$. Stem after the $16^{\text {th }}$ node decumbent in the bed-ooze. Full-grown segments rounded. The socket for the cirrus extending to the supra-, but not to the infranodal joint. Interradial swellings or tubereles on the nodals (slightly developed distally).

Cirri 44 (VIII $^{\text {th }}$ node), 48 (XI), 37 (XII), 44 (XV); $49-56 \mathrm{~mm}$. L of the 5 first segments $=1 / 3$ br, about the $12^{\text {th }}$ cirral $L=b r$. A dorsal longitudinal carination, more or less divided intó 2 prominences, on each ossicle appearing after the $20^{\text {th }}$ cirral. Cirri extending over $21 / 2-$ $3^{1 / 4}$ internodes.

$\mathrm{B}-\mathrm{S}$ contiguous, $\mathrm{L}=2 / 3$ br. I Br-s $7(1+2,4+5)$ in 5 cases; $16 \mathrm{~mm}$. Primipostaxillaries free inside. II Br-s $7(3+4) 1$ case, $10: 1$ 
case, $11(3+4) 6$ cases, $13(3+4) 1$ case, $21(3+4) 1$ case; $19-32 \mathrm{~mm}$. III Br-s. $9(3+t) 1$ ease, $10: 1$ case, $11(3+4) 2$ cases, 12:1 case. $13(3+4) 9$ cases, $15(3+4) 1$ case, $16(3+t, 6+7) 1$ ease, $17(3+4)$ 1 ease, $18: 1$ case, $25(3+t) 1$ case: $17-32 \mathrm{~mm}$. IV Br-s 13$)(3+4)$ 1 case, $15(3+4) 1$ ease, $16(t+5), s+9) 1$ case. $17(3+4) 1$ case. $18(3+4.13+14: 1$ case, $4+5: 1$ case) 2 cases, $19(3)+t: 2$ cases. $t+5: 1$ case) 3 cases, $21(3+4) 1$ case, $25(3+4) 1$ case, $26(3+4$, $12+13) 1$ case. $Y$ Br-s $19(t+5) 1$ case, 23) $(8+9) 1$ case. Arms LIII. Total length $180 \mathrm{~mm}$. Arm-length after a $111 \mathrm{Brax} 110 \mathrm{~mm}$. with $107-116$ Br-s. The arms proximally wall-sided thus, that the lateral borders of $\mathrm{I} \mathrm{Br} \quad 1$ are contiguous, and the left side of $\mathrm{I} \mathrm{Br}$ $2+$ the first segment of the pinnule correspond to the right side of I Br 2 and 3. Syzygies after a III Brax $3+4,37+38,52+53$, $70+71,107$ or $3+4.26+27.50+51,74+75.87+88.113+11+$. 116. After a IV Brax the figures are: $3+4,20+21,45+46,79+50$. or $3+4,8+9,18+19,28+29,38+39 \ldots$

$\mathrm{P}_{1} 2432 ; 30-35 \mathrm{~mm}$. The 10 most proximal segments sharply quadrangular, strongly compressed laterally after the ${ }^{4}$ segment, with ambulacral furrow, (to the right on $1 \mathrm{Br}^{2} 2$ in 5 cases), $\mathrm{P}_{2} 2+30$; $P_{7}-P_{10}$ the shortest ones, then longer p-s again. The most distal segments on $\mathrm{P}_{1}-\mathrm{P}_{4}$ with collars with small spines, from $P_{5}$ smooth segments. The p-s from the middle parts of the arms $12-15 \mathrm{~mm}$. The last 20 pairs of $\mathrm{p}-\mathrm{S}$ rudimentary with $2-4$ segments.

Chalice in transverse section about $20 \mathrm{~mm}$. Colour (in spirits) whitish, the arms light brown. Syzygial pairs white. - Disk with coarse granules. - The specimen handed over to the museum at Gothenburg.

Sp. 2 (St. 31) 23 Internodes, $350 \mathrm{~mm}$. Interarticular pores to the $11^{\text {th }}$ internode. 4 nodal joints without cirri. Full number of internodals in the $6^{\text {th }}$ internode. Internodal joints $11: 10$ cases, 12:6 cases, $13: 2$ cases (11 distally, 12 proximally); $15-18$ mm. Diameter of the stem $6.0-6.2 \mathrm{~mm}$.

Cirri 53 (IX th node), $55 \mathrm{~mm} ., 49$ (X) $53 \mathrm{~mm} ., 46$ (XIX) $50 \mathrm{~mm}$. 49 (XXII) $50 \mathrm{~mm}$. Extending over $2^{1 / 2}-3$ internodes. Cirrals $1,5-1,8$ $\mathrm{mm}$. in cross section. The last 20 - 30 segments with a double dorsal spine as in Sp. 1. The facet for the cirrus extending over ${ }^{3 / 4}$ of the nodal and over ${ }^{1 / 4}$ of the supranodal joint. Interradial tubereles on 
the nodals stoutly developed often as far as the XX ${ }^{\text {th }}$ node. Internodal joint with slight interradial swellings and indistinct ring-ridges, often disappearing radially.

$\mathrm{B}-\mathrm{s} 3 \times 6 \mathrm{~mm}$. hardly contiguous. $\mathrm{R}-\mathrm{s} 1,7 \times 8 \mathrm{~mm}$, bandshaped, with a concave distal margin. I Br-s 7 with syzygies between $1+2,4+5$ in 4 eases, between $1+2,4+5,6+7$ in 1 case; $17-19$ mm. II Br-s $2(1+2) 1$ case, $6(1+2,5+6) 1$ case $7(1+2): 1$ case, $3+4: 5$ cases, $5+6: 1$ case) 7 cases, $8(3+4) 1$ case; $5-15 \mathrm{~mm}$. III Br-s $7(3+4$ or $5+6) 2$ cases, $9(3+4) 3$ cases, $11(3+4) 6$ cases, $12: 1$ case, $13(3+4: 3$ cases, $1+2: 1$ case 4 cases, $15(3+4) 3$ cases, $17(3+4) 1$ case; $12-24 \mathrm{~mm}$. IV Br-s $9(3+4) 1$ case, 11 $(3+4) 1$ case, 13$)(1+2: 2$ cases, $3+4: 3$ cases $) 5$ cases, $15(3+4)$ 2 cases, $17(1+2$ or $4+5) 2$ cases, $18(5+6,11+12) 1$ case. $20(3+4,9+10) 1$ case, $23(3+4) 1$ case, $25(3+4) 1$ case, $26(3+4$, $15+16) 1$ case, $29(3+4,14+15,19+20) 1$ case, $32(3+4,21+22)$ 1 case; $12-34 \mathrm{~mm}$. V Br-s $10(7+8) 1$ case, $14(3+4,10+11), 17(3+$ $4), 18(3+4,8+9), 22(3+4,15+16), 24(3+4,13+14)$ each in one case; $16-26 \mathrm{~mm}$. Arms LIV, total L $170 \mathrm{~mm}$. Free, undivided part $80-120 \mathrm{~mm}$. The distal parts of the Br-s somewhat overlapping and provided with small spines.

$\mathrm{P}_{1}$ (to the right on $\mathrm{I} \mathrm{Br} 2$ in 5 cases) $32 ; 35 \mathrm{~mm}$. Disk finely granular. Colour: uniformly duskish grey. The arms regenerated from the III Br.

Sp. 3 (St. 31) 25 internodes, $375 \mathrm{~mm}$. 3 proximal nodal joints without cirri. Full number of internodal joints in the $6^{\text {th }}$ internode. Number of internodals $10: 4$ cases, $11: 13$ cases, 12:3 cases: 14-17 $\mathrm{mm}$. Interarticular pores to the $9^{\text {th }}$ internode. Diameter of the stem $6,3-6,5 \mathrm{~mm}$. The intercirral tubercle not very prominent after the $7^{\text {th }}$ node. The ring-ridge slightly developed.

Cirri 46 (IX) 54 mm., 53 (XII) 54 mm., 50 (XXI) $52 \mathrm{~mm}$. Extending over $3-3^{1 / 2}$ internodes.

B-S $3 \times 5 \mathrm{~mm}$. R-S: $2,5 \times 6,5 \mathrm{~mm}$. I Br-s $7(1+2,4+5)$ 4 cases, $8(1+2,4+5) 1$ case; $18-21 \mathrm{~mm}$. II Br-s $5(2+3) 1$ case, $7(3+4) 1$ case, $8: 1$ case, $9(3+4$ or $4+5$ or $5+6$ or $6+7) 4$ cases, $11(4+5) 1$ case, $12(1+2,11+12$ or $1+2,4+5) 2$ cases: $10-20 \mathrm{~mm}$. III Br-s $13(3+4) 3$ cases, $15(3+4 ; 1$ case $2+3) 9$ cases, $16: 1$ case, $17(3+4) 5$ cases, $18(3+4,13+14) 1$ case, 19 
Thie Crixoids from Dr. S. Bock's Expenitiox to Japax 1914. 157

$(3+4) 1$ case; $19-28 \mathrm{~mm}$. IN Br-s $13(5+6) 1$ case. $17(3+4$ or $3+4,12+13) 2$ cases, $18(3+t, 1++15) 1$ case, $19(3+4$ or $3+4$. $9+10,15+16) 2$ cases, $20(3+4.9+10$ or $3+4.15+16$ or $3+4$. $16+17$ or $3++, 17+18)+$ cases, $22(3+4,19+20$ or $3+4,20+21)$ 2 cases, $2+(3+4,17+18) 1$ case, $25(3+4,12+13,20+21) 1$ case. $26(3++, 22+23) 1$ case, 28 or $29(12(3)++56+78 .)$.1 case the 31 segment rudimentary): $17-32 \mathrm{~mm}$. Arms LVI, total L $175 \mathrm{~mm}$. a regenerated part only $140 \mathrm{~mm}$. The undivided part of the arm $75-110 \mathrm{~mm}$. Example of the decrease in the number of pinnulars: $13,10,10,8,7,5,4,4,3,3, \ldots(7-1,5 \mathrm{~mm}$.$) .$

$P_{1}$ (to the right on I $\mathrm{Br}^{2} 2$ in + eases of 5 ) 22-24: $P_{5}$ fon II Br 5) $15: 15 \mathrm{~mm} . \mathrm{P}_{15} 17 ; 12 \mathrm{~mm}$.

Sp. 4 (St. 32) 28 internodes, $460 \mathrm{~mm}$. 3 nodal joints withoui cirri. Full number of internodals at the $6^{\text {th }}$ internode. Internodal joints 11: 1t cases, 12:8 cases, 14: I case; $14-17 \mathrm{~mm}$. (distally the shortesi indernodes). Interarticular pores to the $9^{\text {th }}$ internode. Diameter of the stem $6,7-6,0 \mathrm{~mm}$. ! (Thus a more slender stem proximally. Slight, incomplete ridges on the internodals.)

Cirri 45 (VII), 4 (XII), 43 (XV), 45 (XXV); $46-49 \mathrm{~mm}$. Extending over $2{ }^{1}$ is 3 ; internodes.

B-s $2 \times 6 \mathrm{~mm}$, R-s $2 \times 7 \mathrm{~mm}$. I Br-s $7(1+2,++5:+$ cases: $1+2,3+t: 1$ case $) 5$ cases; 18 $-19 \mathrm{~mm}$. II Br-s $6: 1$ case, $7(3+t$; 1 case $4+5) 9$ cases; $13-15 \mathrm{~mm}$. III B1-s $11(5+6) 1$ case, 13 $(3+4 ; 1$ case $5+6) 9$ cases, $15(3+4) 5$ cases, $17(3+4: 2$ cases. $1+2,4+5,14+15: 1$ case) 3 cases, $19(3+4) 1$ case, $20(3+4$. $17+18) \quad 1$ ease; $19-26 \mathrm{~mm}$. IV Br-s $18(3+4,7+5) 1$ case, 19 $(3+4,7+8,15+16$ or $5+6) 2$ eases, $20(3+4$ or $3+4,16+17)$ 2 cases. $22(3+4,9+10$ or $5+6,18+19) 2$ cases, $24(6+7) 1$ case, $30(3+4,18+19) 1$ case; $19-25 \mathrm{~mm}$. Arms XLLX, total L 185 $\mathrm{mm}$. Free arm-length $90-120 \mathrm{~mm}$. $\Lambda$ lot of new regenerated arms. Ex of syzygies: $3+4.23+24 \ldots$

$\mathrm{P}_{1}$ (to the right on $\mathrm{I} \mathrm{Br}_{2} 2$ in 3 cases of $5 \mathrm{f}^{18}-19 ; 2+\mathrm{mm}, \mathrm{P}_{2}$ 17; $P_{4} 18 ; P_{15} 18: 15 \mathrm{~mm}^{2}$

One radiat branch shows an irregular pinnulation: 


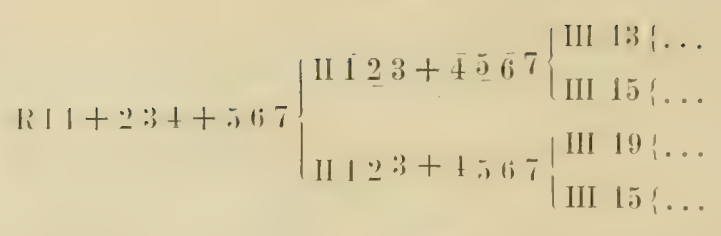

Sp. 5 (St. 24) 17 internodes, 220 mm. 4 nodal joints without cirri. Full number of internodals in the $5^{\text {th }}$ internode. Internodal joints $9: 1$ case $10: 3$ cases, $11: 9$ cases; $12-15 \mathrm{~mm}$. Interarticular pores to the $10^{\text {th }}$ internode. Diameter of the stem: $5,1-5,4 \mathrm{~mm}$. Every second internodal joint somewhat lower as far as the $10^{\text {th }}$ internode.

Cirri 44 (IX). 47 (X), 45 (Xl), 44 (XVIl), 32 (XVIH); $37-46 \mathrm{~mm}$. Extending over $2^{1 / 2}-3$ internodes.

$\mathrm{B}-\mathrm{s}$ heart-shaped, not contiguous laterally, I Br-s $7(1+2$. $4+5: 3$ cases, $1+2,3+4: 1$ case $)+$ cases, $8(1+2,4+5) 1$ case; $15-17 \mathrm{~mm}$. II Br-s $9(3+4) 1$ case, $11(3+4) 8$ cases, $13(3+4)$ 1 case; $15-21 \mathrm{~mm}$. III Br-s $11(3+4) 1$ case. $13(3+4) 3$ cases, $15(3+4) 5$ cases. $16(3+4,14+15) 1$ case, $17(3+4) 1$ case, 18 $(3+4.13+14$ or $3+4,14+15$ or $3+4,15+16) 3$ cases, $20(3+4$. $16+17: 2$ cases $3+4,13+14: 2$ cases $) 4$ cases, $21(3+4,13+14)$ 1 case, $22(3+4,18+19) 1$ case. Arms XL, total L $155-175 \mathrm{~mm}$. Br-s about 115. Ex. of syzygies: $3+4,13+14,22+23$ ete. with an interval of $6-10$ oblique articulations. The arm-segments distally somewhat spiny and overlapping.

$\mathrm{P}_{1}$ (to the right on $\mathrm{I} \mathrm{Br}^{2} 2$ in 4 cases of 5) $18 ; 22 \mathrm{~mm} . \mathrm{I}_{2}$ $22+; 27 \mathrm{~mm} . \mathrm{P}_{3} 23 ; 23 \mathrm{~mm} ., \mathrm{P}_{4} 20 ; 18 \mathrm{~mm} ., \mathrm{P}_{5} 23 ; 19 \mathrm{~mm}$. (smoother), $\mathrm{P}_{6} 20 ; 17 \mathrm{~mm} . \mathrm{P}_{1}$ (to the left on $1 \mathrm{Br} 2: 1$ case) $24 ; 25 \mathrm{~mm}$. $P_{10} 21 ; 16 \mathrm{~mm}$. Disk coarsely granular. Light spots at the syzygial pairs.

Sp. 6 (St. 29) 23 internodes, $370 \mathrm{~mm}$. Interarticular pores to the internode. 4 nodes without cirri. Full number of internodals in the $5^{\text {th }}$ or $6^{\text {th }}$ internode. Number of internodal joints $10: 2$ cases, $11: 4$ cases, $12: 7$ cases, $13: 1$ case, $16: 1$ case, $17: 2$ cases, $19: 1$ case; length of the internodes $14-24 \mathrm{~mm}$. Diameter of the stem $6,5-6,5 \mathrm{~mm}$. The ring-ridge of the internodals divided in a radial middle tubercle and a low ridge on each side of the tubercle. A similar condition also often in the preceding specimens. 
The Crinotos from Dr. S. Bock's lixpenition to Jap'Ax 1914. 159

Cirri 52 (IX) $53 \mathrm{~mm} .49$ (XI) $50 \mathrm{~mm} .47$ (XV) $50 \mathrm{~mm}$. Extending over $2^{1 / 2-3}$ internodes.

$\mathrm{B}-\mathrm{s} 3 \times 6 \mathrm{~mm}, \mathrm{R}-\mathrm{s} 1.3 \times 6 \mathrm{~mm} . \quad 1 \mathrm{Br}-\mathrm{s} 7(1+2.4+5) 2$ cases, $8\left(1+2,4+5,7+80 r^{\circ} 1+2,3+4,6+7\right) 2$ cases, $10(1+2$. $3+4.6+7.9+10)$ I case: $21-2.5 \mathrm{~mm}$. II Br-s $7(3+4)+$ cases, $8(3+4$ or $2+3,7+8) \underline{2}$ cases, $9(3+4) 3$ cases, $10(1+2,6+7)$ 1 case; $12-17 \mathrm{~mm}$. $111 \mathrm{Br}-\mathrm{s} 11(3+4) 1$ case, $12(3+4,7+8) 1$ case, $13(3+4) 8$ cases, $14(3+4.8+9) 1$ case, $15(3+4) 3$ cases. $16(3+t .12+13$ or $3+t .13+14) 2$ cases, $17(3+t) 4$ cases: $17-26 \mathrm{~mm}$. IV Br-s 15$)(3+t) \underline{2}$ cases, $16(3+t .14+15) 1$ case. 17 $(3+t: t$ cases, $5+6: 1$ case, $10+11: 1$ case $)(3$ cases, 19$)(3+4) 1$ case. $20(3+t .6+7) 1$ case. $21(3+t .15+16,20+21) 1$ case, $23(3+t)$ 1 case, $24\left(3+4,8+9^{1}\right.$ or $\left.3+4,16+17\right) 2$ cases, $26(3+4,6+7)$ 1 ease; $20-29 \mathrm{~mm}$. Arms LVI, total L $205 \mathrm{~mm}$., Free undivided part of the arm $95-140 \mathrm{~mm}$. 35-40 $\mathrm{mm}$. of the distal parts of the arms with rudimentary $\mathrm{p}-\mathrm{s}$. The number of pinnulars in the transition region is $14,13,15,12,9,10,10,7,4,4,3,3, \ldots$

$\mathrm{P}_{1}$ (to the right on $\mathrm{I} \mathrm{Br} 2$ in 5 eases) $23 ; \mathrm{P}_{2} 2+$. Disk stoutly granulated. The arms light-brown, darker in the proximal parts (the transition usually at II or III $\mathrm{Br} 3+4$ ). Syzygial pairs white.

Sp. 7 (St. 10) 30 internodes, $360 \mathrm{~mm}$. 6 nodal joints without cirri. Full number of internodals in the $6^{\text {th }}$ or $7^{\text {th }}$ internode. Internodal joints: $9: 2$ cases, $10: 14$ cases, $11: 9$ cases (in 2 of the cases an internodal joint visible only on one side of the stem). Length of the internodes $11.5-14 \mathrm{~mm}$. Interarticular pores to the $11^{\text {th }}$ internode. Diameter of the stem $5.5-6.5 \mathrm{~mm}$. The stem with somewhat stouter ridges than in the preceding specimens (similar to the distal part of the stem i Sp. 2).

Cirri 48 (XI) 51 mm., 54 (XIV), 56 mm., 40 (XIX) 16 mm., 37 (XX) 42 mm.. 47 (XX) 52 mm.. 33 (XXI) 38 mm., 4 (XXil) 46 mm., 47 (XXI) $51 \mathrm{~mm} ., 43$ (XXII), 46 (XXIV) $50 \mathrm{~mm}$. Extending over $2^{3} / 4-3^{1} / 4$ internodes. The thickness of the cirrus $1,5-1,8 \mathrm{~mm}$.

B-s $2^{1 / 2} \times 5$ mm. R-s 1 or $2 \times 5$ or $7 \mathrm{~mm}, 1 \mathrm{Br}^{\mathrm{r}-\mathrm{s}^{1)}}+(\mathrm{L}+2)$. 2) $5(4+5), 3,4,5)(1+2,4+5)$, $12(9+10$ or perhaps $13: 1+2$. $10+, 11$ the two first ossicles in this case almost completely grown

\footnotetext{
$18+9$ almost grown together.
} 
together', probably I + II Bl-s, see below); 15-30 mm. II Br-s 7 $(3+4: 2$ cases, $2+3: 1$ case) 3 cases, $8(3+4) 1$ case, $9(3+4) 3$ cases, $11(3+4) 2$ cases, $13(3+4$ or $5+6) 2$ cases, $20(3+4,14+15)$ 1 case; $18-34 \mathrm{~mm}$. III Br-s $11(3+t) 1$ case, $13(3+4) 5$ cases, $14(3+4,11+12) 1$ case, $15(3+4) 3$ cases, $17(3+4: 2$ cases, $5+6: 1$ case) :3 cases, $18(16+17) 1$ case, $19(3+4) \geq$ eases, 21 $(3+4) 4$ cases; $20-28 \mathrm{~mm}$. Arms XLIV, total L $170 \mathrm{~mm}$. Undivided part of the arm $100-110 \mathrm{~mm}$. The transition to rudimentary p-s rapid: $13,12,5,4,4,3,2 \ldots 6,5-1,5 \mathrm{~mm}$. The arm-part with short. p-s $30-40 \mathrm{~mm}$.

$\mathrm{P}_{1}$ (to the right on $\mathrm{I} \mathrm{Br} 2$ in 1 case and on $\mathrm{I} \mathrm{Br} 1: 2$ cases; on I Br 3 in 3 cases; therefore the first p. 3 times to the right, 3 times to the left) $26 ; 35 \mathrm{~mm}$. (on I Br 2), $\mathrm{P}_{2}, 25 ; 29 \mathrm{~mm} ., \mathrm{P}_{3} 24,25$ mm., $P_{4} 25 ; 23 \mathrm{~mm} . \mathrm{P}_{5} 21 ; 19 \mathrm{~mm} . \mathrm{P}_{6} 20 ; 17 \mathrm{~mm}$. $\mathrm{P}_{1}$ (on I Br 3) 23; $27 \mathrm{~mm}$. The distal segments with rather strong. distal collars, $\mathrm{P}_{10}$ 13: $19 \mathrm{~mm}$.

Disk $15-20 \mathrm{~mm}$., coarsely granular. Colour in spirits white.

The $\mathrm{XX}^{\text {th }}$ node has a short, deformed cirrus in the same radius as $\mathrm{I} B \mathrm{r}=12$. The XXI and XXII nodes have no cirrus in this radius. The infranodal facet of the last node is not newly broken, but overgrown by some Bryozoan colony, which also occurs in the empty cirrus-facets on the XXI ${ }^{\text {st }}$ and XXII nodes. The internodal joints at. the $\mathrm{XX}^{\text {th }}$ node are a little shorter than in the other parts of the stem. The I Br-series with 4 and 12 components stand alongside of each other and are normally directed upwards; the bases of the other ones are horizontally directed and 2 (the $4^{\text {th }}$ and $5^{\text {th }}$ ) are a double-arm standing on 4 radial small ossicles. Thus the whole crown turns, as if it had been lying on the side on the $t^{\text {th }}$ and $5^{\text {th }}$ radius and by the continued growth had tried to rise into a vertical position. Possibly one might infer from what is said above that the crown was injured. when it was on the present $\mathrm{XX}^{\text {th }}$ node and that at the same time the stem was broken at the present $\mathrm{XXX}^{\text {thl }}$ (last) node. If this is the case the abnormal divergences are to be explained by this accident.

In some specimens there occurs a large Myzostoma. probably M. cirvipectium, v. GrafF. 
The Crinolds from Dr. S. Bock's Expedition to Japan 1914. 161 Example of arm-division and distribution of syzygies from Sp. 2:

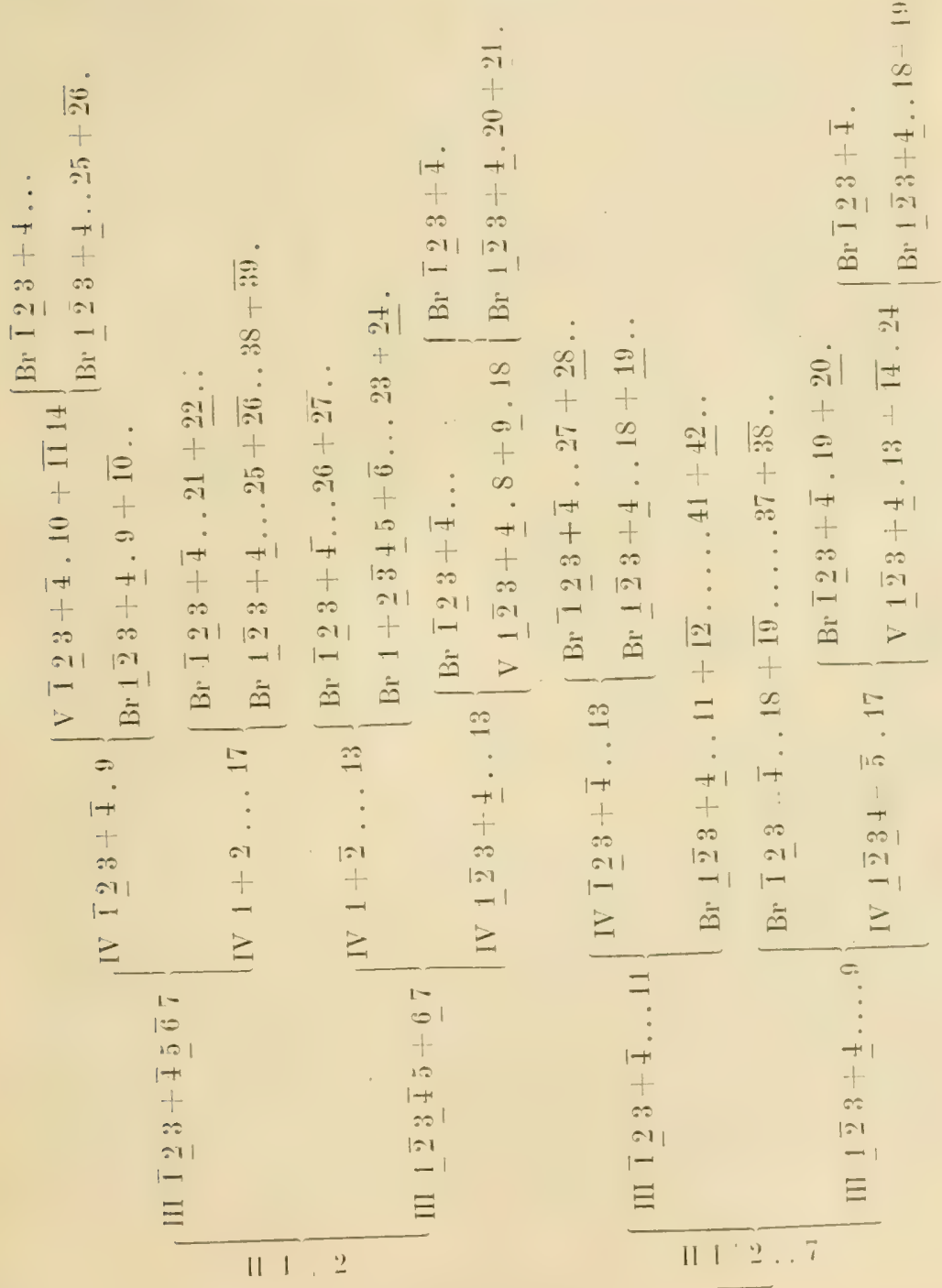

R $11+2 \overline{3}+1+567$

Nova Aeta liog. Sone. Sce. Ups., Ser. 4, Vol. 5. Nin 6. Impr. "i/s 1922. 
In 1884 P. H. Carpenter in the Challenger Exp. mentioned the so called Vega-specimen as a separate species (in the table p. 344), and then the following year (Trans. Linn. Soc.) he discussed its separate position. According to him the species in question had higher internodal joints (both relatively and absolutely), which was of less diameter than in M. intermptus and regularly 6 radials, that is according to a more modern indication $\mathrm{I} \mathrm{Br} 7(1+2,4+5)$. In the collections of the Uppsala museum there is also a specimen of a Metacrinus taken by the Vega-expedition in the Yedo-Bay at a depth of 65 fath. With regard to the diameter of the stem it approaches most to $M$. rotundus (the diameter is $6,0-5,8 \mathrm{~mm}$.) The internodal joints are really somewhat higher $(1,4-1,55 \mathrm{~mm}$.) than in. M. rotundus, where, according to $\mathrm{my}$ calculations, the $\mathrm{h}$ of the segments is $1,3-1,4 \mathrm{~mm}$. (The last described specimen 7 differs by the segment being only $1,15-1,35 \mathrm{~mm}.)^{1}$. Nevertheless it does not seem advisable to distinguish the Vega-Specimen even as a variety on the basis of such vague features. (Observe that the original Vega-specimen is said to have a slender stem. If it is a young specimen of $M$. rotundus it is perfectly natural that the joints are rather high, at least relatively.) As to the $\gg$ Radials» they are in the Vega-specimen at my disposal: $6: 4$ cases, $7: 1$ case (according to Carpenter's indication) or I $\mathrm{Br} 5: 1$ case, $6(3+4) 3$ cases, $7(3+4)$ 1: ease (modern indication). II $\mathrm{Br}-\mathrm{s}$ are in the case at hand $7(3+4)$ 3 cases, $9(3+4$ or $4+5) 2$ cases, $11(3+4$ or $2+3) 2$ cases, the other ones broken. Thus it differ's in no essential way from $M$. rotundus, to which species I therefore refer the $\gg$ Vega-specimen» of P. H. Carpenter.

In the same work as he described $M$. rotundus $\mathrm{P} . \mathrm{H}$. CARPEnter gives an account of the appearance of a stem-fragment of a Metacrinus from Singapore, which he calls M. Stewarti. This species is said to be distinguished from M. rotumdus and interrupturs (which it approaches most closely) by the statement that, »the joints have much more distinct horizontal ridges (p. 443). They give it a certain amount of resemblance to the stems of $M$. Wyvilli and cingulatus». The separate position of the species is evidently considered by the author to be most clearly demonstrated by the different appearance of the infranodal

1 The $h$. of the joints is obtained by measuring the whole internode and dividing its $\mathbf{L}$ by the number of internodal joints. 
faces of the nodal joint in M. rotundus (P']. 52, fig. 3, not as stated in the description fig. 2) and in the debated stem-fragment (Pl. 52, fig. 15). According to the description this face in M. Stewarti (p. 44t) is »quite different from the circular syzygial surface in M. rotundus (I'l. LII, fig. 3) and resembles that of $M$. internuptus. 'The syzygial surface of the nodal joint, however, is somewhat lobate as in the Vega-specimen». It appears from the figures that this stem very much resembles that of the above-described $S_{p}$. 7 , which has more angular internodal joints with stronger ring-ridges than the typical M. rotundus. The importance that CARPENTER attached to the appearance of the nodals and internodals has proved to be a little exaggerated and to some extent is subject to individual variation as well as the tubercles and ridges on the sides of the segments. At first I supposed that M. Stowarti ought to be considered a variety of $M$. rotundus and referred to Sp. 7 here. By a comparison of the different stems in the collection I become, however, convinced that one ought not to separate M. Stewwiti even as a variety. With regard to appearance and formation of ridges and tubercles the most distal part of the stem in $S_{p}$ ). 2 agrees completely with $S p$. 7 , on the other hand the $11^{\text {th }}-17^{\text {th }}$ internodes are rounded, without radial ridges or corner-tubercles and therefore of the usual $M$. rotundus-type. SP. 3 has indistinet ring-ridges and sharply pentagonal segments in the $10^{\text {th }}-16^{\text {th }}$ internodes, but in the most distal internodes rounded segments without ridges again.

H. L. ClarK in 1916 described a new species most closely related to M. rotundus as M. cyaneus. (Commonwealth of Austral. Fisheries Vol. 4, part. 1 p. 9). 'The Radials in this species are usually $6(1+$ $2,4+5)$ but often $7(1+2,4+5) ; \mathrm{P}_{1} 20 \mathrm{~mm}$. $<\mathrm{P}_{2}<\mathrm{P}_{3} ; \mathrm{P}_{4} 25 \mathrm{~mm}$. $=\mathrm{P}_{5}, \mathrm{P}_{6}$ shorter; the Br-s a little overlapping in the middle of the arm, the longest cirri with $60-64$ cirrals, internodals $7-15$ (usually 9-14). These are the most important features that the author gives to characterize the species. The only real differences between my specimens of $M$. rotundus and $M$. cyaneus are the number of cirrals and radials. The number of internodals are about the same in both species, the arms are in M. rotundus (the type) »tolerably smooth», in my specimens a little serrate in lateral profile, in $M$. cyaneus $\gg$ the brachials have somewhat flaring distal margins .. beeoming smooth near the armtip.» The L 
of the proximal $\mathrm{p}-\mathrm{s}$ is subject to too great a variation to be given any great importance (compare S.j. 5 and 7 ). Considering that the localities for the two species are widely separated, it is highly probable that the differences in the number of cirrals $[45$ in the type specimen, 47 $\mathrm{mm}$.; (32-)43-53 in my specimens (37-)46-57 $\mathrm{mm}$.; ?-60 or 64 in MI- cyaneus, $50-65 \mathrm{~mm}$.) and radials (5-6 in $M$. rotundus type; $4-12$, usually 7 , occasionally 5 or 8 , in my specimens; and $4-7$, usually 6 , often 7 , occasionally 5 , in $M$. cyaneus will turn out in the future to be deviations of merely edafic value. For the present $M$. cyaneus ought to be considered as a variety of $M$. rotundus.

Metacrinus interruptus P. I. CArpenter.

Fig. 157, 158; Photo 13-15.

Syn. Metacrinus interruptus 1884 P. H. Carpenter Chall. Exp. Vol. 11, p. 367; Trans. Linn. Soc. London Ser. 2. Vol. 2, p. 438 ff.; 1902 (04) Sperry Proc. Mich. Acad. Sei, p. 195; 1908 A. H. Clark Proc. U. S. Nat. Mus. Vol. 34; p. 528; 1912 Crin. Ind. Oc. p. 269.

From St. 9 (1 sp.), $45(10), 56(4), 58$ (2), 59 (3) = 20 specimens.

Sp. 1 (St. 45) For the $\mathrm{L}$ of the stem, the number and $\mathrm{L}$ of the internodes and internodal joints, and the thickness of the stem in this as in the following specimens see the table. The medium height of the internodal joints $1,1-1,3 \mathrm{~mm} .3$ proximal nodals without eirri. Full number of internodals in the $4^{\text {th }}$ internode. The distal face of the nodal round. The intercirral tubercle on some nodals slightly prominent. Stem rounded, tolerably smooth, but with small radial prominences. Interarticular pores to the $8^{\text {th }}$ internode.

Cirri 36 (VIII $^{\text {th }}$ cirrus-bearing node) $32 \mathrm{~mm} ., 37$ (XI) $32 \mathrm{~mm}$., 37 (XV). Extending over $2-2^{1 / 4}$ internodes. I $\mathrm{Br}-\mathrm{S} 7(1+2,4+5)$ 5 cases; $9 \mathrm{~mm}$. II Br-s $9(3+4) 1$ case, $10: 1$ case, $11(3+4) 8$ cases; 10-12 mm. III Br-s $11(3+4) 4$ cases, $13(3+4) 8$ cases, $15(3+4) 5$ cases, $17(3+4) 2$ cases, $18(3+4,14+15) 1$ case; $10-$ $14 \mathrm{~mm}$. IV $\mathrm{Br} 17(3+4) 1$ case; $13 \mathrm{~mm}$. Arms XLI, total L $90 \mathrm{~mm}$. $\mathrm{L}$ of the undivided arm $55 \mathrm{~mm}$. Part of the arm with rudimentary $\mathrm{p}-\mathrm{s} 20 \mathrm{~mm}$. I $\mathrm{Br}$ series smooth. II $\mathrm{Br}^{2}-\mathrm{s}$ and the following segment a little overlapping distally. 
'T'He Crinoids from Dr. S. Bock's lixpentrion to JaPAx 1914. 165

$\mathrm{P}_{1}$ (in 5 cases to the right on $\left.1 \mathrm{Br}^{2}\right) 14 ; 12 \mathrm{~mm}$. (1 $1^{\mathrm{st}}$ segment short, $2^{\mathrm{d}}$ one largest), $\mathrm{P}_{2} 14 ; 10 \mathrm{~mm} ., \mathrm{P}_{3} 13 ; 8 \mathrm{~mm}$. Brachial $\mathrm{p}-\mathrm{s}$ 10; $6 \mathrm{~mm}$. Disk coarsely granulated, $11,5 \mathrm{~mm}$.

Sp. 2 (St. 45) The medium h of the internodals $1,3-1,45 \mathrm{~mm}$. 4 nodal joints without cirri. Full number of internodals in the $5^{\text {th }}$ internode. Internodal joints with rather prominent interradial swellings, which disappear in the $8^{\text {th }}$ internode, and low ring-ridges on the sharply pentagonal stem. Interarticular pores to the $7^{\text {th }}$ internode. Cirri 37 ; $32 \mathrm{~mm}$.

I Br-s $7(1+2,4+5) 5$ cases; $10 \mathrm{~mm}$. Il Br-s $9(3+t)$ I case, 10: 1 case, $11(3+4) 8$ cases; $11 \mathrm{~mm}$. III Br-s $11(3+4) 1$ case, 12: 1 case, $13(3+4) 7$ cases, $15(3+4) 1$ case, $19(3+4) 3$ cases, $20(4+5,13+14) 1$ case, $21(3+4: 2$ cases, $4+5: 1$ case, $5+6: 1$ case 4 cases, $23(3+4) 1$ case, $24(3+4,19+20) 1$ case: 12-17 mm. Arms. XL, total L $100 \mathrm{~mm}$. Undivided part of the arm $60 \mathrm{~mm}$.; $20 \mathrm{~mm}$. with rudimentary $\mathrm{p}-\mathrm{s}$.

$\mathrm{P}_{1}$ (to the right on $1 \mathrm{Br}_{2} 2$ in 5 cases) $17 ; \mathrm{P}_{2}$ and $\mathrm{P}_{3} 17 ; \mathrm{P}_{5} 14$. Br-p. 14;9 mm. One pinnule swollen by an entoparasitic Myzostoma. Sp. 3 (St. 45) 5 nodals without eirri. Full number of internodal joints in the $3^{\mathrm{d}}$ internode. The segments tolerably smooth. The syzygial face of the nodal rounded. Interarticular pores to the $7^{\text {th }}$ internode. Cirri $35(1 \mathrm{~V}) 28 \mathrm{~mm}$., 36 (VII) $32 \mathrm{~mm}$., 35 (IX) $29 \mathrm{~mm} . \mathrm{S}^{\text {th }}-11^{\text {th }}$ segments the longest $\mathrm{L}=1^{1} / 2 \mathrm{br}$.

$\mathrm{B}-\mathrm{s} 1 \times 1,5 \mathrm{~mm}, \mathrm{R}-\mathrm{s} 1,8 \times 2,5 \mathrm{~mm} . \quad \mathrm{I} \mathrm{Br}-\mathrm{s} 7(1+2,4+5)$ 5 cases; $10 \mathrm{~mm}$. II Br-s $9(3+4) 7$ cases, $11(3+4) 3$ cases; $10-$ $12 \mathrm{~mm}$. III Br-s $11(3+4) 2$ cases, $13(3+4) \mathrm{S}$ cases, $15(3+4) 2$ cases, $17(3+4) 3$ cases, $18(3+4$, the outer arm more weakly developed) 1 case, $19(3+4) 3$ cases, $20(3+4$, the new arm bending outwards on the outer side) 1 case; $10-15 \mathrm{~mm}$. IV Br-s $15(3+4) 3$ cáses, $17(8+9) 1$ case; $12-13 \mathrm{~mm}$. Arms XLIV, total L $95 \mathrm{~mm}$. Unbranched arm $55 \mathrm{~mm}$. Part of the arm with rudimentary p-s $20-22 \mathrm{~mm}$.

$\mathrm{P}_{1}$ (to the right on $1 \mathrm{Br} 2$ in 4 cases) $11 ; 9 \mathrm{~mm}, \mathrm{Br}-\mathrm{p} 10$; $6 \mathrm{~mm}$.

In the same pot also 2 stem-fragments, one with 4 internodes. 11 internodals, $\mathrm{L}$ of the internodes $14 \mathrm{~mm}$; diameter of the stem $3 \mathrm{~mm}$. Cirri $36 ; 32 \mathrm{~mm}$; the other with 6 internodes, 11 - 13 interno- 
dals; $L$ of the internodes $15-17 \mathrm{~mm}$. Diameter of the stem $3,5-4,0$ mm., Cirri $39 ; 36 \mathrm{~mm}$.

Sp. 4 (St. 45) Infranodal joint pentagonally rounded. The cirrus socket hardly touches the supranodal joint. Interarticular pores to the $7^{\text {th }}$ internode. 4 nodals without cirri. Full number of internodals in the $4^{\text {th }}$ or $5^{\text {th }}$ internode.

Cirri 41 (V) 26 mm., 39 (VIII) 31 mm.. 42 (XI) 32 mm., 41 (XII) $31 \mathrm{~mm} ., 37(\mathrm{XV}), 35$ (XVIII) $28 \mathrm{~mm}$. A dorsal carination from the $20^{\text {th }}$ or $25^{\text {th }}$ cirral.

$\mathrm{B}-\mathrm{s} 1,3 \times 1,8 \mathrm{~mm} . \mathrm{R}-\mathrm{s} 1,8 \times 3,2 \mathrm{~mm} . \quad \mathrm{I} \mathrm{Br}-\mathrm{s} 7(1+2,4+5)$ 5 cases; $10,5 \mathrm{~mm}$. II Br $-\mathrm{s} 9(3+4) 1$ case, $11(2+3: 6$ cases, $3+$ 4 ; 3 cases) 9 cases; $9,5-11,5 \mathrm{~mm}$. III Br-s $9(3+4) 1$ case, 13 (3 $+4) 7$ cases, $15(3+4) 3$ cases, $19(3+4) 1$ case, $20(3+4,14+15$ or $3+4,17+18) 2$ cases, $21(3+4) 2$ cases, $23(3+4) 1$ case, 24 $(3+4,14+15) 1$ case; $7,5-21,5 \mathrm{~mm}$. Arms XXXVIII, total L $90 \mathrm{~mm}$. Unbranched pait of the arm 50-55 mm., $15-20 \mathrm{~mm}$. with rudimentary pinnules. Ex. of syzygies: $3+4,34+35$ or $3+4,23+24,36+$ $37,59+60 \ldots$

$\mathrm{P}_{1}$ (to the right on $\mathrm{I} \mathrm{Br} 2$ in 5 cases) $13 ; 11 \mathrm{~mm} . \mathrm{P}_{2}$ similar. $\mathrm{Br}-\mathrm{p} .11 ; 7 \mathrm{~mm}$. One $\mathrm{P}_{2}$ with an entoparasitic Myzostoma.

Sp. 5 (St 45) 3 nodal joints without cirri. F'ull number of internodals in the $5^{\text {th }}$ internode. Interarticular pores to the $9^{\text {th }}$ internode. Stem rounded.

Cirri 45 (VIII) $35 \mathrm{~mm}, 45$ (IX) $42 \mathrm{~mm} ., 43$ (XI) $40 \mathrm{~mm} ., 42$ (XIII) 37 mm., 42 (XVII) 36 mm., 40 (XX) 34 mm., 39 (XXII) 33 mm., 38 (XXVI) $27 \mathrm{~mm}$.

$\mathrm{B}-\mathrm{s} 1 \times 2 \mathrm{~mm} . \mathrm{R}-\mathrm{s} 1,3-3 \mathrm{~mm} . \quad \mathrm{I} \mathrm{Br}-\mathrm{s} 6(1+2,4+5) \mathrm{I}$ case, $7(1+2,4+5) 4$ cases; $10-12 \mathrm{~mm}$. II Br-s $7(3+4) 1$ case, $11(3+4) 9$ cases; $10-13 \mathrm{~mm}$. III Br-s $10(6+7$, peculiar pinuula-

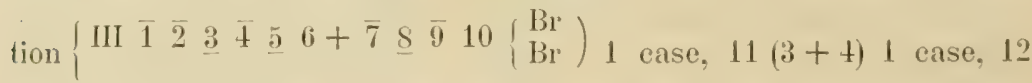
$(3+4,8+9) 1$ case, $13(3+4) 5$ cases, $14(3+4,10+11) 1$ case, $15(3+4) 1$ case, $16(3+4,11+12) 1$ case, $17(3+4) 3$ cases, 18 $(3+4,1++15: 2$ cases or $3+4,15+16: 1$ case $) 3$ cases, $19(3+4$, $14+15) 1$ case: $9-16 \mathrm{~mm}$. IV Br-s $13(3+4) 1$ case, $1+(3+4$. $11+12) 1$ case, $18(3+4,15+10) 1$ case; $13-16 \mathrm{~mm}$. Arms XLI + , 
'The Crinoids fron Dr. S. Bock's Expentition to Japan 1914. 167

total L. $130 \mathrm{~mm}$. Unbranched arms $100 \mathrm{~mm}$., $30-40 \mathrm{~mm}$. with rudinentary $\mathrm{p}-\mathrm{s}$.

$P_{1}$ (to the right on I $\mathrm{Bl}^{\circ} 2$ in 4 cases) 19 ; many $\mathrm{p}-\mathrm{s}$ with eneysted Myzostomas.

Sp. 6 (St. 45 ) 4 nodals without cirri. Full number of internodal joints in the $5^{\text {th }}$ internode. Interarticular pores to the $9^{\text {th }}$ internode. Stem somewhat more rounded and smoother than in the preceding specimens.

Cirri 43 (X) 37 mm., 44 (XII) 40 mm., 42 (XV) 38 mm. First (i) cirrals short, $\mathrm{L}=1 / 3$ br.

I Br-s $5(1+2,4+5) 1$ case, $7(1+2,4+5) 4$ cases; $9-11$ mm. II Br-s $9(3+4) 5$ cases, $11(3+4) 5$ eases; $\pm 10 \mathrm{~mm}$. III and IV Br-s bent down, impossible to count. Arms XLIV, total L $110 \mathrm{~mm}$. Unbranched part of the arms $80 \mathrm{~mm}$.

$\mathrm{P}_{1}$ (to the right on I Br 2 in 4 eases) $14-17 ; 12-13 \mathrm{~mm}$. $\mathrm{P}_{2} \quad 16-19 ; \mathrm{P}_{3} 16 ; 10 \mathrm{~mm}$. Br-p. 13; $7 \mathrm{~mm}$. Disk $10-12 \mathrm{~mm}$. Anal tubus $4 \mathrm{~mm}$.

Sp. 7 (St. 45) 6 nodal joints without cirri. Full number of internodals in the $4^{\text {th }}$ internode. Average height of internodal joints $1,3-1,5$ $\mathrm{mm}$. A slight intercirral tubercle to about the $\mathrm{XV}^{\text {th }}$ node. The distal face of the nodal joint lobated. Ring-ridge inconspicuous. Interarticular pores to the $\mathrm{S}^{\text {th }}$ internode.

Cirri 41 (VI) 35 mm., 42 (IX) 37 mm., 41 (XI) 34 mm., 41 (XIV) $36 \mathrm{~mm} ., 39$ (XVII) $35 \mathrm{~mm} ., 40$ (XIX) $3+\mathrm{mm}$.

B-S $1,3 \times 2 \mathrm{~mm}$, contiguous. R-s $2 \times 4 \mathrm{~mm}$. I Br-s $7(1+2$, $4+5) 5$ cases; $12 \mathrm{~mm}$. II Bl'-s $11(3+4) 10$ cases; $1+\mathrm{mm}$. III Bl-s $11(3+4) 3$ cases, $13(3+4) 3$ cases, $15(3+4) 4$ cases, $17(3+4)$ 3) cases, $19(3+4) 5$ cases, $21(3+4) 2$ cases; $11-19 \mathrm{~mm}$. IV Br-s 13:1 case, $15: 2$ cases, $17: 1$ case, $21: 1$ case, all with a syzygy between $3+4 ; 12-14 \mathrm{~mm}$. Arms XLV, total L $115 \mathrm{~mm}$. Unbranched part of the arm $75 \mathrm{~mm}$.. Syzygies with an interval of $17-25$ oblique articulations.

$\mathrm{P}_{1}$ (to the right on $1 \mathrm{Br} 2 \mathrm{in}+$ eases) $16 ; 1+\mathrm{mm}$. Br-p. 13; $7 \mathrm{~mm}$.

Sp. 8 (St. 45) 3 nodals without cirri. Full number of internodals in the $5^{\text {th }}$ internode. Interarticular pores to the $9^{\text {th }}$ internode. Infranodal joint rounded. The segments are remarkably smooth and rounded. 
Cirri 44 (IX) 36 mm., 41 (XIII) 35 mm., 41 (XVI) 32 mm., 39 (XVIII) $31 \mathrm{~mm} ., 38$ (XX) $28 \mathrm{~mm}$.

B-s $1 \times 2$ mm., R-s $1,3 \times 3 \mathrm{~mm}$. I Br-s $7(1+2,4+5) 4$ cases, $8(1+2,4+5) 1$ case; $11-13 \mathrm{~mm}$. Il Br-s $9(3+4: 2$ cases, $5+61$ case) 3 cases, $10: 1$ case, $11(3+4) 6$ cases; $11-13 \mathrm{~mm}$. III Br-s $13(2+3: 1$ case, $3+4: 8$ cases $) 9$ cases, $15: 1$ case, $17: 4$ cases, $19: 0$ cases, syzygies between $3+4 ; 12-18 \mathrm{~mm}$. IV $\mathrm{Br}-\mathrm{s}$ $13(3+4) 1$ case, $17(3+4) 1$ case, $28(3+4,15+16) 1$ case; $12-$ $+25 \mathrm{~mm}$. Arms XLIII, total L $130 \mathrm{~mm}$. Unbranched part of the arms $95 \mathrm{~mm}$, with about $120 \mathrm{Br}-\mathrm{s}$. Syzygies with an interval of $8-23$ oblique articulations. $30-35 \mathrm{~mm}$, with rudimentary $\mathrm{p}-\mathrm{s}$.

$\mathrm{P}_{1}$ (to the right on $\mathrm{I} \mathrm{Br}^{2} 2$ in 3 cases) $20-21 ; 18 \mathrm{~mm} . \mathrm{P}_{2} 22$; $17 \mathrm{~mm} . \mathrm{P}_{3} 21 ; 1+\mathrm{mm}$. Br-p. 16;8,5 mm. The syzygial pairs lighter coloured.

Sp. 9 (St. 45) 4 nodals without cirri. Full number of internodals in the $4^{\text {th }}$ internode. Interarticular pores to the $7^{\text {th }}$ internode.

Cirri 42 (VII) $35 \mathrm{~mm} ., 42$ (IX) 34 mm., 41 (XIll) $35 \mathrm{~mm} ., 38$ (XV) $30 \mathrm{~mm}$. Extending orer $1^{1 / 2}-2$ internodes.

I Br-s $7(1+2,4+5) 5$ cases; $11 \mathrm{~mm}$. II Br-s $9(3+4) 4$ cases, $11(3+4: 3 ; 4+5: 2 ; 0+7: 1) 6$ cases; $10-12 \mathrm{~mm}$. III Br-s $11(3+4) 1$ case, $12: 2$ cases, $13(3+4: 3 ; 4+5: 1 ; 5+6: 1) 5$ cases, $14: 1$ case, $15(3+4) 2$ cases, $17(3+4) 2$ cases, $19(3+4) 1$ case, $22(3+4,20+21) 1$ case, $23(3+4) 2$ cases, $25(3+4) 1$ case; $10-23 \mathrm{~mm}$. IV Br-s $17(3+4: 2 ; 11+12: 1) 3$ cases, $19(5+6) 1$ case: $12-14 \mathrm{~mm}$. Arms XLII,$+ 110 \mathrm{~mm}$. Unbranched part of the arms $70 \mathrm{~mm}$. Syzygies with an interval of 12-30 oblique articulations.

$\mathrm{P}_{1}$ (to the right on $\mathrm{I} \mathrm{Br}^{\circ} 2 \mathrm{in} 5$ cases) $15 ; 11 \mathrm{~mm}$. Br-p. 14; $6.5 \mathrm{~mm}$.

Sp. 10 (St, 59) 2 nodals without cirri. Full number of internodals in the $6^{\text {th }}$ internode. Interarticular pores to the $10^{\text {th }}$ internode. lnternodal joints pentagonally rounded with a slight ring-ridge. No intercirral tubercle.

Cirri 38 (XI) 37 mm., 39 (XIII), 37 (XIV) 34 mm., 39 (XVII), 38 (XX) 35 mm., 38 (XXII), 37 (XXIII) 33 mm. The dorsal longitudinal carination is indistinet. 
T'me Crinotns from Dr. S. Bock's Expedition to Japan 1914. 169

$\mathrm{B}-\mathrm{s} 1 \times 2 \mathrm{~mm} . \quad \mathrm{R}-\mathrm{s} 1,5 \times 4 \mathrm{~mm}$. I Br-s $7(1+2,4+5) 5$ cases; $10 \mathrm{~mm}$. Breadth $5 \mathrm{~mm}$. II Br-s $9(3+4) 2$ eases, $13(3+4)$ 3 cases; $11-12 \mathrm{~mm}$. The other ones broken. III Br-s $11(3+4)$ I case, $13(3+4) 3$ cases, $16(3+4$, the outer arm somewhat weaker $)$ 1 case, $19(3+4) 1$ case, $26(3+4,22+23) 1$ case: $13-25 \mathrm{~mm}$. IV Br-s $13(3+4) 1$ case, $17(3+4) 2$ eases; $12-16 \mathrm{~mm}$. The arms partly broken, total $\mathrm{L} 120 \mathrm{~mm}$. $\Lambda$ complete radius with $\mathrm{X}$ arms. Unbranched part of the arms $85 \mathrm{~mm}$.

$P_{1}$ (to the right on $1 \mathrm{Br} 2$ in 3 eases) $17 ; 16 \mathrm{~mm}$; $P_{1}$ (to the right on $\mathrm{I} \mathrm{Br}$ '3 in 2 eases) 15;14 mm. Br-p. 14; $9 \mathrm{~mm}$.

Sp. 11 (St. 59) 4 nodal joints without cirri. Full number of internodals in the $7^{\text {th }}$ internode. Interarticular pores to the $12^{\text {th }}$ internode.

Cirri 48 (IX) $47 \mathrm{~mm} ., 46$ (XII) $50 \mathrm{~mm} ., 44$ (XVI) $49 \mathrm{~mm} ., 45$ (XVIII) $49 \mathrm{~mm} ., 41$ (XXI) $42 \mathrm{~mm}$. Cirri extending over $2^{1} / 2$-3 internodes.

B-s $1 \times 1,5 \mathrm{~mm}$., small, not contiguous. R--S $2 \times 4 \mathrm{~mm}$. I Br-s $7(1+2,4+5) 4$ cases; 12 mm. One radius broken. II Br-s 7 $(3+4) 1$ case, $11(3+4) 2$ cases; $9-13 \mathrm{~mm}$. The other ones broken. III Br-s $11(3+4) 1$ case, $13(3+4) 2$ cases, $20(3+4,13+14$ or $3+4,15+16) 2$ cases; $13-22 \mathrm{~mm}$. IV Br-s $16(3+4,11+12)$ 1 case, $19(1+2,4+5,15+16) 1$ ease: $15-16 \mathrm{~mm}$. Arms $155 \mathrm{~mm}$. ( $\Lambda$ complete radius with IX arms.) Unbranched part of the arms 100 mm.; 25-30 mm. with rudimentary $p-S$. Syzygies with an interval of 5-8 oblique articulations.

$P_{1}$ (to the right on I Br' 2 in 4 eases) broken. $P_{1}$ (to the left on I $\mathrm{Br}^{\circ}$ 3) 24; $23 \mathrm{~mm}$., P 27; $23 \mathrm{~mm}$. Br-p. $15 ; 10 \mathrm{~mm}$.

Sp. 12 (St. 59) 6 nodal joints without eirri. Full number of internodals in the $5^{\text {th }}$ internode. Interarticular pores to the $\mathrm{S}^{\text {th }}$ internode. Stem smooth, pentagonal, the joints proximally with a slight radial concavity. The distal face of the nodal joint almost round. Cirri $38-39$; $28-2$ ? $\mathrm{mm}$.

B-s $1 \times 1,2 \mathrm{~mm}$., laterally contiguous. $\mathrm{R}-\mathrm{s} 1 \times 2,5 \mathrm{~mm}$. I Br-s $5(1+2,4+5) 1$ case, $7(1+2,++5)+$ cases; $8-11$ mm. II Br-s $9(3+4) 5$ cases, $11(3+4) 4$ cases; $11-13 \mathrm{~mm}$. The $10^{\text {th }}$ radius broken. III Br-s $11(3+4) 2$ cases, $13(3+4) 7$ cases, 15 $(3+4) 2$ cases, $16(3+4) 1$ case, $17(3+4) 2$ cases, $19(3+4: 2$;

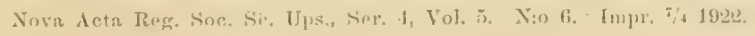


$3+4,7+8: 1$ case) 3 cases; $13-18 \mathrm{~mm}$. IV Br-s $17(3+4) 1$ case, 18 $(3+4) 1$ case, $23(3+4,13+14,20+21) 1$ case; $15-20 \mathrm{~mm}$. Alms on a perfect specimen probably $+\mathrm{XLV}$; total $\mathrm{L} 115 \mathrm{~mm}$. Unbranched part of the arm $80 \mathrm{~mm}$. Syzygies with an interval of $6-12$ oblicque articulations. The $\mathrm{Br}$ segments after II Brax with somewhat overlapping distal margins.

$\mathrm{P}_{1}$ (to the right on $1 \mathrm{Br} 2$ in 5 eases) $20 ; 16 \mathrm{~mm}$., $\left[\mathrm{P}_{1}\right.$ (on I $\mathrm{Br}$ 3) $16 ; 13 \mathrm{~mm}.] \mathrm{P}_{2} 19 ; 14 \mathrm{~mm}$. Br-p. 14;6-7 mm.

Sp. 13. (St. 56) 4 nodal joints without cirri. Full number of internodals in the $4^{\text {th }}$ internode. Interarticular pores to the $7^{\text {th }}$ internode. The distal face of the nodal joint pentagonally rounded.

Cirri 29 (V) 27 (VI) 28 (VII); $21-22 \mathrm{~mm} . \quad 4^{\text {th }}$ segment $\mathrm{L}=$ br, $5^{\text {th }}$ - $S^{\text {th }}$ segments $\mathrm{L}=1^{2 / 3}$ br. Cirri extending over $1^{1 / 2}-2$ internodes.

$\mathrm{B}-\mathrm{S} 0,6 \times 1,0 \mathrm{~mm}$. soldered together laterally. R-s $1 \times 2 \mathrm{~mm}$. a little bent outwards, thus forming an angle with the basals. I $\mathrm{Br}-\mathrm{s}$ $7(1+2,4+5) ; 8 \mathrm{~mm}$. in the 3 perfect radii. II $\mathrm{Br}-\mathrm{s} 11(3+4) 2$ cases, $13(3+4) 1$ case, $14(3+4) 1$ case; $10-11 \mathrm{~mm}$; the other ones broken. III $\mathrm{Br}-\mathrm{S} 13(3+4) 3$ cases, $15(3+4) 1$ case, $19(3+4)$ 2 cases, $20(3+4,16+17) 2$ cases; $9-14 \mathrm{~mm}$. IV Br-s $18(3+4$, $13+14: 1 ; 3+4,14+15: 1 ; 3+4,16+17: 1) 3$ cases. All new arms on the inside of IV Brax reinforeed $p-s$, very small with $5-6$ segments, $2 \mathrm{~mm}$. The outer arms = the original arms: $12 \mathrm{~mm}$.

Arms in the complete specimen probably XLV, total L $55 \mathrm{~mm}$.: $12 \mathrm{~mm}$. with rudimentary $\mathrm{p}-\mathrm{s}$. The small, new arms appear on the border to the rudimentary pinnules. (The preceding pinnule of the original arm with 7 , the succeeding one with 3 , and the ones that then follow with 2 segments; the young arm itself with $6-7$ segments). These new arms differ from the other adjacent $\mathrm{p}-\mathrm{s}$ by the distal spinosity and by supporting one or two small $\mathrm{p}-\mathrm{s}$ with $2-3$ segments: The syzygy between $\mathrm{Br} 3$ and 4 is usually developed.

$\mathrm{P}_{1}$ (to the right on $\mathrm{I} \mathrm{Br} 2$ in 5 cases) $9 ; 6 \mathrm{~mm}$. Br-po, 9; 5,5 $\mathrm{mm}$. Lxample of arm-branching: 
The Crinoms mom Dr. S. Bock's lixpedition to dapax 1914. 171

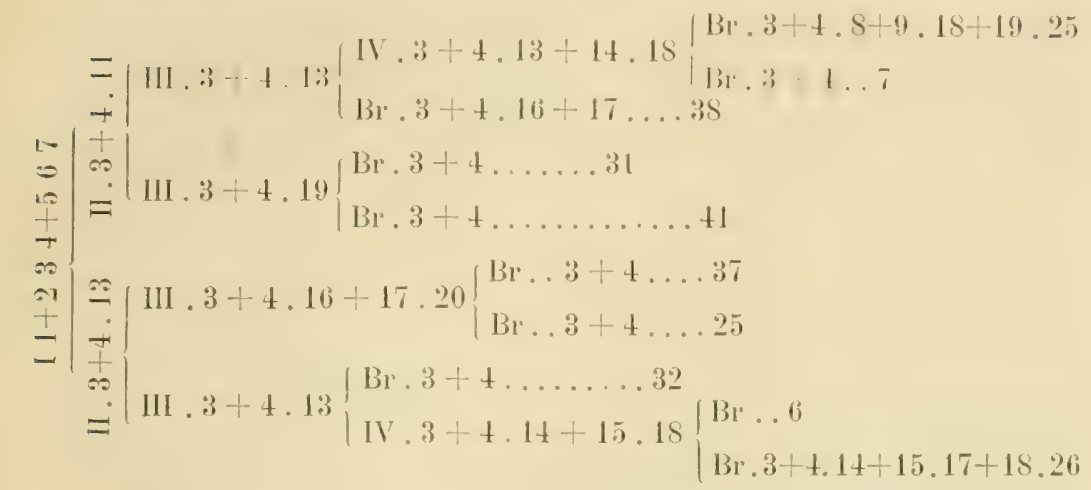

Sp. 14 (St. 56) Interarticular pores to the $6^{\text {th }}$ internode. 5 internodals without cirri. Full number of internodals in the $3^{d}$ internode.

Cirri 34 (VII th cirrus-provided node); 34 (IX) $22 \mathrm{~mm}$. 32 (XII).

$\mathrm{B}-\mathrm{s} 1 \times 1,3 \mathrm{~mm}$. R--s $1 \times 3 \mathrm{~mm}$. forming an angle with the $\mathrm{B} \rightarrow \mathrm{s}$. The arms broken. $\mathrm{P}_{1}$ (to the right on $\mathrm{I} \mathrm{Br} 22$ in 5 cases) 12; $9 \mathrm{~mm}$. Disk $7 \mathrm{~mm}$. Anal cone $5 \mathrm{~mm}$.

Sp. 15 (St. 56) 3 nodal joints without cirri. Full number of internodals in the $3^{\text {d }}$ internode. Interarticular pores to the $6^{\text {th }}$ internode. The distal internodes often have one of the middle internodal joints provided with tubercles; this is an indication of the formation of a nodal joint. One such middle node is perfectly developed between the $2^{\text {d }}$ and $3^{\mathrm{d}}$ internodes, counted from the distal end of the stem. (Here therefore only 4 and 3 internodal joints appear.) The distal stem-joints almost perfectly round.

Cirri 34 (IV) 22 mm., 32 (VII), 30 (XI), 30 (XII) 17 mm., 28 (XV). The cirrus-sockets of the distal nodals do not quite reach to the proximal border of the joint. Nevertheless, the usual type is to be found already at the $1 \mathrm{X}^{\text {th }}$ node, where the joints also begin to become somewhat pentagonal.

The arms broken. $P_{1}$ (to the right on $1 \mathrm{Br}^{2}$ in 3 cases) 12; $7 \mathrm{~mm}$. Disk $6 \mathrm{~mm}$. Anal cone $5 \mathrm{~mm}$.

Sp. 16 (St. 56) 8 nodals without cirri. Full number of internodals in the first internode. Interartieular pores to the $2^{\text {internode. }}$ The number of internodals when counted proximo-distally runs as fol- 
lows: $12,11,11,9,8,7,7,7,5$. The internodal joints are longer than broad. Also the nodal joints are long (compare photo 14). The cirrus-sockets do not reach the proximal border of the nodal. The two most distal internodes with attempts at formation of nodal joints on some joints.

Cirri 22 (II) $9,5 \mathrm{~mm} ., 19$ (III) $11 \mathrm{~mm}, 19$ (V) $10 \mathrm{~mm} .2^{\mathrm{u}}$ eirral $\mathrm{L}=\mathrm{br}, \quad 4^{\text {th }}-8^{\text {th }}$ one $\mathrm{L}=2 \mathrm{br}$.

$\mathrm{B}-\mathrm{S} \cdot 0,5 \times 0,5 \mathrm{~mm}$. R-S $\mathrm{h}=1,3 \mathrm{~mm}$., br (at the base) $1 \mathrm{~mm}$., forming an angle with the basals. I Br-s $7:(1+2,4+5) 2$ cases, 8 $(1+2,3+4) 1$ case, $9(1+2,4+5) 2$ cases; $5-7 \mathrm{~mm}$. II Br-s 10 : 4 cases, $11(2+3: 1 ; 3+t: 3 ; 4+5: 1) 5$ cases, $12: 1$ case; $7-8 \mathrm{~mm}$. Arms XX; $18 \mathrm{~mm}$. Unbranched part of the arm $1-4 \mathrm{~mm}$. $\mathrm{P}_{\mathrm{I}}$ (to the right on $1 \mathrm{Br} 2$ in 5 cases) $9 ; 3,7 \mathrm{~mm} . \mathrm{P}_{2} 11 ; 4,2 \mathrm{~mm}$.

Example of arm-branching:

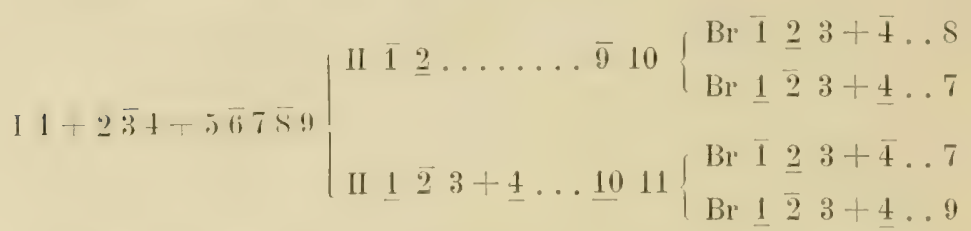

The inner arms a little shorter, $2 \mathrm{~mm}$., the outer arms about $3 \mathrm{~mm}$. Disk reaching to $\mathrm{I} \mathrm{Br} 2$.

Sp. 17 (St. 5s) 6 nodal joints without cirri. Full number of internodals in the $3^{\text {d }}$ internode. Interarticular pores to the $t^{\text {th }}$ internode. Number of internodal joints counted proximo-distally as follows: $6,9,10,9,5,8,9,8,7,8,7,6$.

Cirri 27 (IV) 15 mm., 23 (VI) 13 mm., $2+$ (VIIl) 11 mm., 21 (X) $10 \mathrm{~mm} ., 19$ (XIl) $8 \mathrm{~mm}$.

$\mathrm{B}-\mathrm{S}$ pentagonal, directed straight upwards. $\mathrm{R}-\mathrm{s}$ forming with the $\mathrm{B}-\mathrm{s}$ an angle of about $135^{\circ}$. I Br-s $7(1+2,4+5) 5$ cases; $(6 \mathrm{~mm}$. II $\mathrm{Br}-\mathrm{S} 11(3+4: 2 ; 2+3: 1) 3$ cases; $12(2+3,7+8: 1 ; 2+3,5+6: 1$ : $2+3,6+7: 1 ; 3+4,6+7: 1)+$ eases, $13(3+4) 1$ case, $1+(3+4$ $8+9) 1$ case; $7-10 \mathrm{~mm}$. III Br-s $14(3+t, 10+11: 2 ; 3+4,11$ $+12: 1 ; 3+4,12+13: 1 ; 3+4,13+14: 1) 5$ cases, $15(3+4) 2$ cases, $10(3+4,8+9) 1$ case, $20(3+4,10+11) 1$ case; $7-9 \mathrm{~mm}$. Arms XXVIII, in the complete specimen, probably, XXIX; total L 30 
The Chromos from Dr. S. Bock's Expedition to dapan 1914. 17:3

mm.; last $5 \mathrm{~mm}$ :s with rudimentary $\mathrm{p}-\mathrm{s}$. The new arms on the inside of III Brax very short, about $1 \mathrm{~mm}$. (the main arm from the same III Brax $5 \mathrm{~mm}$.) An outer ramification in one case shorter, though with normal pinnulation, elsewhere always shorter branches on the inside. Example of arm-branching:

$$
\begin{aligned}
& |\mathrm{III} \ldots 3+4 \ldots 10+11 \ldots 14| \begin{array}{l}
\mathrm{Br} \ldots 3+4 \ldots 12 \\
\mathrm{Br} 12345
\end{array} \\
& \mathrm{Br}^{1} \ldots 3+4 \ldots 12+13 \ldots 22
\end{aligned}
$$

$\mathrm{P}_{1}$ (to the right on $\mathrm{I} \mathrm{Br} 2$ in $t$ eases) $9 ; 4,5 \mathrm{~mm} . \mathrm{P}_{2} 9 ; \mathrm{P}_{3} \quad 10$ $\mathrm{P}_{6} 10 ; 5 \mathrm{~mm}$.

Disk 2-3 mm. in diameter with calcareous plates. No orals. Sp. 18 (St. 58) 3 nodals without eirri. Full number of internodals in the $4^{\text {th }}$ internode. Interarticular pores to the $7^{\text {th }}$ internode.

Cirri 32 (VI) $21 \mathrm{~mm}$, 30 (VIII) $19 \mathrm{~mm}$. $4^{\text {th }}$ segment cubical.

I Br $-\mathrm{s} 7(1+2,4+5$ : 3 cases; $1+2,3+4: 2$ cases $) 5$ cases: $8 \mathrm{~mm}$. II Br-s $9(3+4) 4$ cases, $11(3+4: 4 ; 2+3:-2) 6$ cases: S-10 mm. III Br-s 11:1 case. 13: 7 cases. 15: 2 cases. 17: 7 cases. $18(3+4) 1$ case, 19: 2 cases, everywhere the syzygies $3+4 ; 8-12$ $\mathrm{mm}$. Arms $\mathrm{XL}$, total L $55 \mathrm{~mm}$. Rudimentary $\mathrm{p}-\mathrm{S}$ on the last $12-$ $15 \mathrm{~mm}$.

$P_{1}$ (to the right on $1 \mathrm{Br}^{2}$ in 4 eases) $11 ; 7 \mathrm{~mm} . \mathrm{P}_{3} 11 ; 5 \mathrm{~mm}$. $\mathrm{Br}-\mathrm{p} .9 ; 5 \mathrm{~mm}$.

To this species probably also belongs S Sp. 19 (St. 9) 3 nodals without eirri. Full number of internodals in the $6^{\text {th }}$ internode. Interarticular pores to the $10^{\text {th }}$ internode. The segments are rounded with a slight ring-ridge. Distally of the fixing point for the cirral there is a slight, swollen ridge effaced at the middle. The cirrus-socket extends up' over the distal part of the supranodal but does not reach the infranodal joint.

Cirri 43 (Xl) $45 \mathrm{~mm}$, 40 (XVIII) $40 \mathrm{~mm}$. Extending over ㄴ$2^{1 / 4}$ internodes.

B-s $1,8 \times 3,7$ mm., laterally not contiguous, except on the supernumerary side. There are $6 \mathrm{R}-\mathrm{s}$.

I Br-S $4(1+2)$ or $1+234+$; the other ones broken in the $1^{\text {st }}$ syzygy. 
Sp. 20 (St. 45) 4 nodal joints without eirri. Full number of internodal joints in the $5^{\text {th }}$ internode. Interarticular pores to the $10^{\text {th }}$ internode. Between the internodal joints there are in several cases incomplete internodals, only visible, however, on one side of the stem. The joints pentagonally rounded with low ring-ridges.

Cirri $45-48 ; 37-45 \mathrm{~mm}$. The $\mathrm{S}^{\text {th }}$ segment cubical.

I $\mathrm{Br} 7(1+2,4+5), 1$ case, $8(1+2,4+5), 1$ case, the other arms bent downwards and their dorsal parts hidden.

Arms LII; $160 \mathrm{~mm}$. Rudimentary $\mathrm{p}-\mathrm{S}$ on the most distal 30 $\mathrm{mm}$. of the arms.

$\mathrm{P}_{1}$ to the right on $\mathrm{I} \mathrm{Br} 2$ in 4 cases; in one case the reverse. Disk $14 \mathrm{~mm}$. Anal funnel $\overline{\mathrm{g}} \mathrm{mm}$. Colour in life bright green.

To a certain extent forming a transition to the form ornatus.

Metacrinus interruptus forma ornatus.

From St. $9(1), 59(1)=2$ specimens.

Sp. 21 (St. 9) 4 nodals without cirri. Full number of internodals in the $7^{\text {th }}$ internode. Interarticular pores to the $11^{\text {th }}$ internode. Stem proximally narrower. The joints, especially the distal ones, markedly pentagonal. Every second internodal joint provided with an unbroken ring-crista. The infranodal face of the nodal joint lobate. The supranodal joint somewhat ineised by the cirrus socket. The nodal joint a little thicker than the other joints. No distinct intercirral tuberele.

Cirri 41 (XI) 42 mm., 41 ( $\mathrm{NV}$ ) $40 \mathrm{~mm}$. Extending over 3 internodes. Sth $^{\text {th }}$ cirral $\mathrm{L}=\mathrm{br}$. The dorsal carination divided in a distinct proximal and distal portion.

$B-S$ laterally not contiguous. $R-S 1,7 \times 4,8 \mathrm{~mm}$. The arms broken at the first syzygy ( $\mathrm{Br} 1+$ ).

Sp. 22 (St. 59) 5 nodals without cirri. Full number of internodals in the $5^{\text {th }}$ internode. Interarticular pores to the $8^{\text {th }}$ internode. The joints decidedly pentagonal. Intercirral tuberele well developed. Every second internodal joint with interradial tubercles. $8^{\text {th }}-10^{\text {th }}$ internodes a little smoother.

Cirri 39 (IX) 32 mm., 40 (X) 34 mm., 34 (XII) $28 \mathrm{~mm}$. lixtending over 2 internodes. $6^{\text {th }}$ cirral $\mathrm{L}=\mathrm{br}$.

$\mathrm{B}-\mathrm{S} 1,5 \times 2,5 \mathrm{~mm} ., \mathrm{R}-\mathrm{S} 1,5 \times 3,5 \mathrm{~mm} . \quad$ i Br-s $6(1+2) 1$ case, 
The Crtworns from Dr. S. Bock's lixpentitox to dapax 1914. 175

$7(1+2,4+5)+$ cases; $12 \mathrm{~mm}$. II Br-s $7(3+4) 3$ cases, $9(3+4)$ 2 cases, $11(3+4: 2 ; 2+2: 1)$ 3 cases; $9-13 \mathrm{~mm}$. III Br-s 9 $(3+4) 1$ case, $11(3+4) 3$ cases, 12 : 1 case, $13(3+4) 5$ cases, 15 $(3+4) 3$ cases, $17(3+4)$ I case, $19(3+4)$ 2 cases; $9-17 \mathrm{~mm}$. IV Br-s $15(3+4) 4$ eases, $16(t+5,10+11)$ I case, $17(3+4) \stackrel{2}{2}$ cases, $19(3+4) 1$ case, $21(3+4) 1$ case, $23(3+4) 1$ case, 25 $(3+t) 1$ case, $27(3+t) 1$ case: $14-2+\mathrm{mm}$. V Br-s 15:1, 17:1. 19: 2 eases (syzygy between $3+4$ ); $15-19$ mm. Arms partly broken. in a complete specimen probably about LX; total L $105 \mathrm{~mm}$. Unbranched arms $60 \mathrm{~mm}$; $10 \sim 20 \mathrm{~mm}$. with rudimentary $\mathrm{p}-\mathrm{s}$. The number of the segments of the $p-s$ at the transition $11,11,9,8,7$. $4, \ddot{3}, 2,2$. Syzygies with an interval of about 20 oblique articulations. $P_{1}$ (to the right on I B1 '2 in 3 cases) $16-17$; $12 \mathrm{~mm}^{2}, \mathrm{P}_{5}, 15$; $9 \mathrm{~mm} ., \mathrm{P}_{10} 14 ; 8 \mathrm{~mm}$.

Disk $13 \mathrm{~mm}$. Anal cone $t_{0} .5 \mathrm{~mm}$.

The present material of $M$. interreptus forms an extraordinarily fine and interesting series. Sp. 16 may be the youngest known stage of recent pentacrinoids ${ }^{1}$ or at least of the genus Metacrinus.

As to the thickness-growth of the stem one can observe that the increase is most rapid among the young speeimens and generally decreases with growing age. When the diameter of the stem is less than $1 \mathrm{~mm}$. the stem thickens with $0,1 \mathrm{~mm}$. for a length-growth of about $15 \mathrm{~mm}$. From $1,0-2,5 \mathrm{~mm}$. generally the same enlargement of the diameter of the stem is reached with an length-growth of $25 \mathrm{~mm}$. (An exception is, however, Sp. 13, but one must notice that the preserved part of the stem is relatively short and the whole thickness-growth only $0,1 \mathrm{~mm}$; the divergence might therefore be ascribed to errors of measurement.) From 2,5-3,0 $\mathrm{mm}$. the diameter of the stem inereases with $0,1 \mathrm{~mm}$. on $30-35 \mathrm{~mm}$. Between 3,0 and $t, 0 \mathrm{~mm}$. the same growth takes place on $60-120 \mathrm{~mm}$. and over $t_{9}, \mathrm{~mm}$. an equivalent thickening is attained on a length-growth of about $80 \mathrm{~mm}$. Exceptions are Sp) 11 with a thick stem, but rapid growth $(0,1 \mathrm{~mm}$. pro $33 \mathrm{~mm}$.) and Sp. 21, where the diameter of the stem is proximally decreasing. A

1 A figure of a very young specimen of Isocrinus decorns of about the same size is also presented by A H. Clark in 1908 (Proc. U. S. Nat. Mlus. Vol. 35, p. 88; a stem fragment) and in 1915 (Monograph p. 205; the same stem, here the figure is correctly placed) and by H. L. Chank in 1918 (Bull. Lab. Nat. Hist. lowa Vol. 7, Rep. C'rin id Echin. of the Baliama Exp.). 


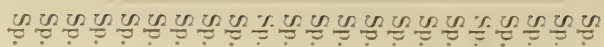

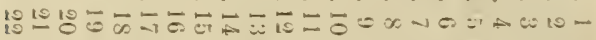

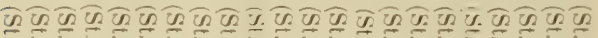
ध 可

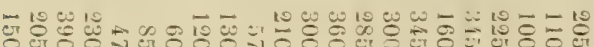

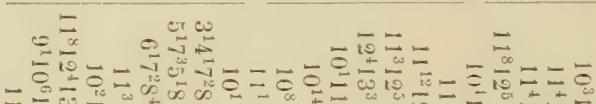
ㄴ,

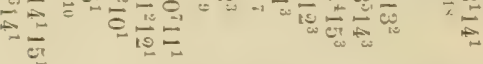

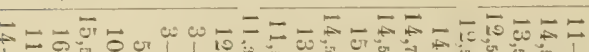

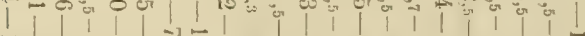

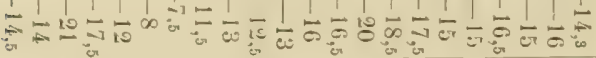

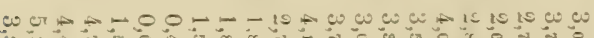
wa

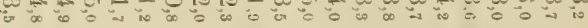
車

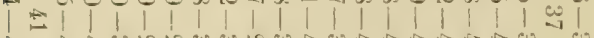

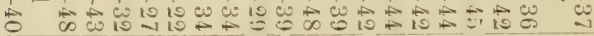

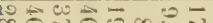
की

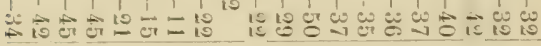

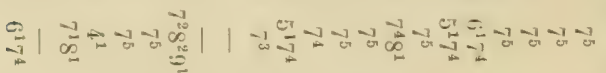

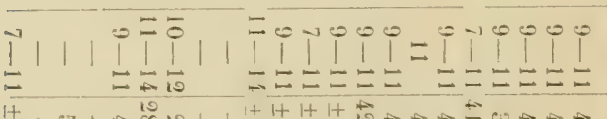

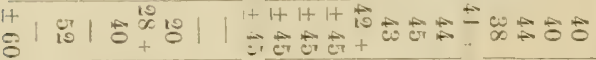

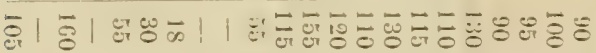

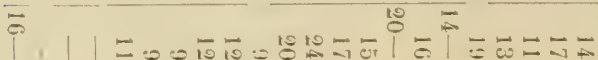
$-1$

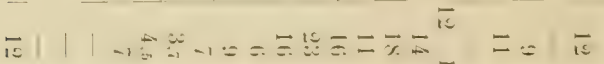

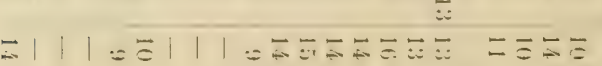

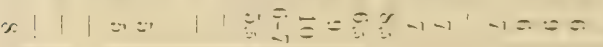

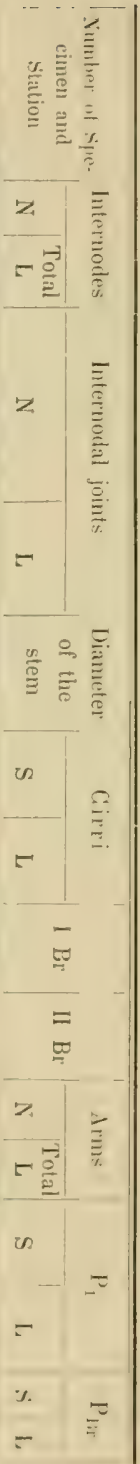


full-grown specimen therefore continues the length-growth of the stem, but the diameter of the stem is very little or not at all increased and might (in old specimens:) even decrease. An full-grown M. intermutus migth thus have a total stem-length of 2-2,5 metres, but from what is mentioned above it is probable that in older specimens it might be considerably larger. The previously described speeimens of M. rotundus probably have much longer stems, for these only show an inconspicuous $\mathrm{or}^{\circ}$ no increase of the diameter. The fact that large specimens exhibit a decrease of the diameter of the stem (cf. Mr. rotundus Sp. t, M. interruptus Sp. 21) has also been observed by DöderLeiN (Siboga Exp. Vol. 42 A, p. 29 ff.). I have not established any periodicity in the growth of the stem-diameter in $M$. intermptus.

The proximal segments of the cirrals are short and discoidal, but the number of these short segments is evidently a function of the age of the animal. In e.g. Sp. 16 cirral. 2 is already as long as broad, in Sp. 17 the $3^{\mathrm{d}}$, in $\mathrm{Sp} .18$ the $4^{\text {th }}$, in Sp. 14 the $5^{\text {th }}$, in Sp. 5 the $6^{\text {th }}$, in Sp. 6 the $7^{\text {th }}$ and in Sp. 19 the $9^{\text {th }}$ segment is cubical. In the corresponding specimens the number of cirrals and their $\mathrm{L}$ are on an average $20(10 \mathrm{~mm}),. 23(12 \mathrm{~mm}),. 31(20 \mathrm{~mm}),. 33(22 \mathrm{~mm}$.), $42(35 \mathrm{~mm}), 41(38 \mathrm{~mm}),. 42(43 \mathrm{~mm}$.). - The distal cirrals are, as in the comatulids, longer in younger specimens; e. g. Sp. 16 has the L of the $4^{\text {th }}-8^{\text {th }}$ cirrals $=2$ br (cf. Sp. 3). The same prolongation is also seen in the stem-joints, which in the youngest specimens are longer than broad. 'Therefore the cirrus-sockets on the nodals in the young specimens do not reach the proximal border.

The interarticular pores cease very constantly at the $7^{\text {th }}$ or $S^{\text {th }}$, in some rare cases in large specimens $(10,19,20,21)$ not until the $9^{\text {th }}$ or $10^{\text {th }}$ internodes. In the very young specimens $14-17$ the pores have disappeared already at the $2^{\text {to }}$ "ith internodes - a manifestation af more rapid stem-growth.

Full number of internodal joints in the largest specimens $(6,10$, $11,19,20,21)$ appears in the $\left(5^{\text {th }}-\right) 6^{\text {th }}-7^{\text {th }}$ internodes, on the other hand in the smallest specimens already in the $\left(t^{\text {th }}-\right) 3^{4}$ or even in the first internode (Sp. 3, 13-18).

SPERrY has doubted whether $M$. rotundus and $M$. interruptus should be considered as different species. I grant he is right inasmuch as there is no essential difference in the number of components 
of the II and III Br-series in the two species. The number of II $\mathrm{Br}-\mathrm{s}$, however, in $M$. rotundus is somewhat more variable $(2-7-11$ -21) than in $M$. intervuptus, where, with rare exceptions, it stops between 9 and 11. Further I quite agree with SPERry in his statement about the variability of the infranodal face.

But - nevertheless - there are some differences. In the original specimens of $M$. rotundus and interruptus there was measured a stem-diameter of 5,0 and $t, 25 \mathrm{~mm}$. respectively. This difference might seem slight, but my measurements of both the species show that it is of rather great importance: only 4 of the 22 specimens of $M$. internetus have a stem-diameter of more than $4,2 \mathrm{~mm}$., and these 4 , evidently very old specimens, do not attain a stem-thickness of more than $5,1 \mathrm{~mm}$. In M. rotundus, on the other hand, there are only 2 specimens (with relatively rapid growth of the stem) which do not come up to $6 \mathrm{~mm}$. (CARPENTER's specimen is evidently to be compared with the Bockian Sp. 5); all the full-grown ones have a diameter of the stem of $6,0-6,7 \mathrm{~mm}$.

M. rotundus is therefore a larger species and from this some other differences also follow. Thus the cirrals often number 50-55, contrary to $M$. internuptis, where they very seldom exceed 45 . The interarticalur pores in the latter species disappear at the $7^{\text {th }}$ or the $8^{\text {th }}$ internodes (seldom at the $9^{\text {th }}$ or $10^{\text {th }}$ ), in the former species they disappear first at the $9^{\text {th }}-12^{\text {th }}$ internodes.

As to the number of the ossicles in the I Br-series a comparison between the two species turns out thus: M. rotundus has 7 I Br-s in 26 cases, 8 or 5 each in 4 eases; 4,10 or 12 each in 1 case. (It is, however, to be noticed that here are included the figures from the abnormal Sp. 7). M. interruptus has $7 \mathrm{I} \mathrm{Br-s}$ in 76 cases, 8 in 5 cases, 5 and 6 each in 2 cases, $t$ and 9 each in 1 case. (Here the young specimen 16, however, contributes 3 figures differing from 7 ). 'T'hus it is impossible to deny that in $M$. rotundus there is a somewhat greater variability in the number of the $1 \mathrm{Br}^{\mathrm{r}} \mathrm{-S}$.

The cirri extend over $2^{1 / 2}-3^{1 / 2}$ internodes in $M . r o t u n d u s$, over $11 / 2-2^{2} / 3$ internodes, only exceptionally over 3 internodes, in $M$. intermoptus (Sp. 11, 21). (The last-mentioned L only occurs in the largest specimens). 
The Crivoms from Dr. S. Bock's Expertion to Japan 1914 . 179

I have therefore preserved the two species as different types of species value.

The newly proposed form ormatus I might possibly have been able to consider as a variety, if I had had more plentiful material at my disposal. It differs from the ehief speeies by the well developed ornamentation of the internodal joints and, probably, by a somewhat greater number of arms (Sp. 22. with about LX arms). Nevertheless it might be considered that the greater number of arms is a mere chance; ef. the $20^{\text {th }}$ specimen (observe also that Sp. 20-22 are rather large specimens). Therefore, keeping in view the appearance of the stems in M. rotundus, I will not set up a new variety based only onthe ornation of the internodals and because of that I have preferred only to note the new type as a $\gg$ form».

I do not consider that the ehange in the number of internodals in the above-deseribed specimens causes any sub-dividing into varieties. (Sp. 8, 9 and 20 show specially high figures). It is to be noticed that the very youngest speeimens have a smaller number of internodal joints. That is because the middlemost internodal joints have got a complete cirrus-whorl. There are often on the other internodals too small prominences where the cirrus ought to have been inserted if the joint had been a nodal. I do not doubt that the still unknown, very small young forms of this family will turn out to have all or most internodal joints provided with cirrus-like prominences, thus appoaching the type that is shown in the distal part of the stems of Rhizocrinus. The differentiation into nodal and internodal joints is certainly a secondary phenomenon. - 


\section{List of the stations where Crinoids were obtained.}

Chronologically arranged and numbered.

Station 1 Japan, Shimonoseki, on the slore at low tide, $30 / 31914$; formol-spirit. Compsometra serruta $4 \mathrm{sp}$.

St. 2 Japan, Sagami, Misaki, Aburazubo 2-3 Metres, ${ }^{19} / 1$ 1914. Compsometra serrala 3 sp.

St. 3 Japan, Sagami, Misaki, on the shore, low tide t's. Formol-spirit. Compsometra serrata $1 \mathrm{sp}$.

St. 4 Japan, Sagami, Misaki, 150 fathoms (the Metacrinus-shoal) $5 / 5 ; 96 \%$ Alc. Comissia partula $1 \mathrm{sp.}$ Toxometra oquipinna $2 \mathrm{sp}$. Thamatometra comaster sp. juv? $1 \mathrm{sp}$. St. 5 Japan, Kiu Shiu, Kagoshima, 135 fathoms ${ }^{13} / 5$. Formol. Catoptometra Hartlaubi $1 \mathrm{sp}$.

St. 6 Japan, Kiu Shiu, Kagoshima and Okinoshima, Scraper I and II, 13-14/5 and 18/5 (In the same pot). Formol-spirit (60 or 110 -220 fathoms). Cyllometra pulchella $7 \mathrm{sp}$. Psathyrometra Wireni 1 sp.

St. 7 Japan, Kiu Shiu, Golo Islands, 23 Miles N. W. $\left(128^{\circ} 11^{\prime}\right.$ East; $\left.32^{\circ} 17^{\prime} \mathrm{N}\right)$. 110 Fath. Oseaki, Trawl 111 14/5. Formol. Metacrimus nobilis var, temis 2 sp.

St. 7 a Japan, Kiu Shiu, Goto Islands, Trawl. IV, 110 fathoms, ${ }^{14} / 5$. Formol. Peris. - sometra aranea $1 \mathrm{sp}$.

St. 8 Japan, Kiu Shiu, Goto Islands, Trawl II, Bottom-temp. $13,7^{\circ} \mathrm{C}, 115$ Fathoms 14/5. Formol-spirit. Comissia parrula $1 \mathrm{sp}$.

St. I Japan, Kiu Shitu, Goto Islands, 90-115 fathoms, ${ }^{1+15} / 5$. Formol. Metacrinus nobilis var. tenuis $5 \mathrm{sp}$, Metacrinus intermptus $1 \mathrm{sp} .$, Metucrinus interruplus form ornatus $1 \mathrm{sp}$.

St. 10 Japan, Kiu Shiu, Goto Islands, about 100 fathoms. May. Metacrinus rotundus I sp.

St. 11 Japan, Kiu Shiu, Goto Islands. Scraper, Pallas rock, 5 Miles E. to S. 90 fathoms. 15/5. Formol spirit. Evylhometra rubre 3 sp.

St. 12 Japan, Kiu Shiu, Goto Islands, the coral bank. 90 Fathoms ${ }^{15} / 5$. Formolspirit. Cyllometra disciformis 1 sp., Cyllometra pulchella 1 sp., Asterometra macropoda 2 sp., Neometra multicolor 2 sp.

St. 13 Japan, Kiu Shiu, Goto Islands. $128^{\circ} 50^{\prime} \mathrm{E}, 33^{\circ} 41^{\prime} \mathrm{N}$. Trawl 11,75 fathoms. Sand. Bottom-temp. $15,9^{\circ}$ C., ${ }^{17} / 5$. Formol or Formol-spirit. Cyllometra pulchella 33 sp.

St. 14 Japan, Kiu Shiu, Goto lshands, $128^{\circ} 50^{\prime}$ E, $33^{\circ} 41^{\prime}$ N. Trawl III, 75 fathoms. Sand. ${ }^{17} / 5$. Formol. Comanthus pinguis $2 \mathrm{sp}$.

St. 15 Japan, Kiu Sliu, Golo Islands. The same locality, Trawl IV. ${ }^{17}$; 8 . Formol. Comanthus pinguis $1 \mathrm{sp}$. 


\section{'The Crinotos from Dr. S. Bock's Exiention to Japan 1914. 181}

St. 16 Japan, Kiu Shiu, Goto Islands, The same locality. Trawl VII, ${ }^{17 / 5}$. Formol. Cyllometra pulchella $2 \mathrm{sp}$.

St. 17 Japan, Kiu Shiu, Goto Islands, The same locality. 'Trawl 1, 17/5. Formol-spirit. Cyllometra pulchella $3 \mathrm{sp}$.

St. 18 Japan, Kiu Shiu, Okinoshima, Scraper 1 and II, 50-60 fathoms, Bottom-temp. $16,6^{\circ} \mathrm{C}$., $18 / 5$. Formol-spirit. cf. Comanthus pinguis sp. juv. $1 \mathrm{sp}$.

St. 19 Japan, Kiu Shiu, Okinoshima, Scraper V, 26 fathoms. Bottom temp. $17^{\circ}$ C., ${ }^{18 / 5}$. Cyllometra manca $1 \mathrm{sp}$.

St. 20 Japan, Sagami, Misaki, 2 Metres, ${ }^{13} / 5$. Formol. Comanthns solaster $1 \mathrm{sp}$.

St. 21 Japan, Sagami, Misaki, on the shore at low tide, ${ }^{28} / 5.70 \%$ spirit. Compsometra serrata sp. juv. 1 sp.

St. 22 Japan, Sagami, Mlisaki, $0-2$ Metres, ${ }^{28} / 5,96 \%$ alcohol. Compsometice ser. rata $3 \mathrm{sp}$.

St. 23 Japan, Sagami, Misaki, Corallina, 5/6, spirit. - Compsometra serratı 1 sp.

St. 24 Japan, Sagami, Misaki, straight off the shore, 140 fathoms, $6 / 6,70 \%$ Alc. Metacrinus rotundus $1 \mathrm{sp}$.

St. 25 Japan, Sagami, Misaki, on the shore at low tide, ${ }^{13} / 6,70 \%$ Alc. Compsometra serratu 3 sp.

St. 26 Japan, Sagami, Misaki, on the shore at low tide (Corallina) 14/6, spirit. Compsometra serrata 2 sp.

St. 27 Japan, Sagami, Misaki, Diver, 3-5 Metres, 14/6. Tropiometra afra vas. ma. crodiscus $8 \mathrm{sp}$.

St. 28 Japan, Sagami, Misaki, Rocky bottom, 2-3 M. 14/6, formol-spirit. Comanthus solaster" $1 \mathrm{sp}$.

St. 29 Japan, Sagami, Misaki, mud, 200 Metres, ${ }^{23} / 6$. Metacrinus rolundus 1 sp.

St. 30 Japan, Sagami, Misaki, straight outside the shore, sandy bottom, 200 M. ${ }^{23} / 6$. Metacrinus rotundus $1 \mathrm{sp}$.

St. 31 Japan, Sagami, Misaki, straight outside the shore, 100 falhoms ${ }^{23} / 6$. Alcohol. Metacrinus rotundus $2 \mathrm{sp}$.

St. 32 Japan, Sagami, Misaki, Okinose, 100 fathoms, ${ }^{26} ; 6$. Alcohol. Iridometra melpamene $1 \mathrm{sp}$., Metacrinus rotundus $1 \mathrm{sp}$.

St. 33 Japan, Sagami, Misaki, Okinose, 100-200 fathoms, ${ }^{26} / 6$. . Alcohol. C'yllometra disciformis? sp. juv. 1 sp.

St. $3 \pm$ Japan, Sagami, Misaki, Okinose, 400 fathoms, ${ }^{26}, 6$. Alcohol. I'ectinometru favopurpurea $5 \mathrm{sp}$.

St. 35 Japan, Sagami, Misaki, Okinose, 400 fathoms ${ }^{28 / 6}$. Alcohol. Comissia gracilipes $2 \mathrm{sp}$., Cyllometra disciformis 1 sp., Pectinometra Alaopurparea 1 sp., Dorometra briseis 1 sp.

St. 36 Japan, Sagami, Misaki, straight off the shore, 200 fathoms ${ }^{1 / 7}$. Alcohol. Comissia parcula 1 sp., Pectinometra faropurparea 1 sp., Crossometra septentrionalis 1 sp.

St. 37 Japan, Sagami, Misaki, Okinose, 400 fathoms ${ }^{8 / 7}$. Alcohol. Comissin partula 1 sp., ?Comalulides decameros sp. juv. 1 sp., Iridometra melpomene 1 sp., Dorometra briseis 2 sp., Thanmatometra comaster $1 \mathrm{sp.}$ 
St. 38 Japan, Sagami, Misaki, rocky boltom, 2-4 Metres, $9 / 7$. Alcohol. Comanthus solaster $1 \mathrm{sp}$.

St. 38 A. Japan, Sagami, Misaki, rocky crevices, $3-5$ Metres. Comanthus solaster $1 \mathrm{sp}$.

St. 39 Japan, Sagami, Misaki, Liparometra grandis 1 sp.

St. 40 Japan, Bonin Islands (Ogasawara), Taki Ura, Diver, coral-bottom. ${ }^{28}$ ir. Alcohol. Comanthus parvicirra $2 \mathrm{sp.}$

St. $\$ 1$ Bonin Islands, Taki Ura, Diver, coral-hottom, ${ }^{28} ;$. Alcohol. Dorometre nana $3 \mathrm{sp}$.

st. 42 Bonin Islands, West from Port Lloyd, 65 fathoms, ${ }^{31} ; 7$. Alcohol. Comissia ignota minuta $1 \mathrm{sp.}$

St. $42 \mathrm{~A}$. Bonin Islands, West from Port Lloyd, 70 fathoms, ${ }^{31 / 7}$. Alcohol, Comanthus anmulata $1 \mathrm{sp}$.

St. 43 Bonin Islands, NW from Otolojima, 80 fathoms, ${ }^{\text {11 }} /$ ?. Alcohol. Comatella stelligera 1 sp., Clarkometra elegans $15 \mathrm{sp}$.

St. 14 Bonin Islands, NW from Olotojima, 70 fathoms, ${ }^{31 / 7}$. Young Comasteritl 1 sp., Compsometra parviflora $1 \mathrm{sp}$.

St. 45 Bonin Islands, East from Chichijima, 80 falhoms, ${ }^{31}$;7. Alcohol. Comissia ignotu minuta 9 sp., Comaster delicata grandis $3 \mathrm{sp}$., Comaster serrata $1 \mathrm{sp}$., Young Comasterids $15 \mathrm{sp}$., Eudiocrinus gracilis pulchellus $5 \mathrm{sp}$., Pterometra trichopoda $1 \mathrm{sp}$., Asterometra anthus sp. juv. 5 sp., Compsometra partiflora 2 sp., Metacrinus internutus $10 \mathrm{sp}$.

St. $45 \mathrm{~A}$. Bonin Islands, East from Chichijima, 90 fathoms ${ }^{91} / \mathrm{r}$. Alcohol. Comissia ignota minuta 1 sp., Tropiometra encrims $1 \mathrm{sp.}$

St. 46 Bonin Islands, East from the Chrannel, 70 fathoms, ${ }^{1} / 8$. Alcohol. Eudiocrimus gracilis pulchellus 2 sp., Catoptometra magnifica minor sp. juv. 1 sp., Asterometra anthus 2 sp., Compsometra parviflora $1 \mathrm{sp}$.

St. 47 Bonin Islands, East from Channel, 80 fathoms, $1 / 8$ (August). Alcohol. Comissiu ignota minuta $5 \mathrm{sp}$, Young Comasterills $6 \mathrm{sp}$, Eudiocrinus gracilis pulchellus $2 \mathrm{sp}$., Eudiocrinus Loveni $1 \mathrm{sp}$, Catoptometra magnifica minor spp. juv. 3 sp., Liparometra grandis sp. juv. 1 sp., Asterometra anthus spp. juv 5 sp., Compsometra parviflora 2 sp., Dorometra par. vicirra $1 \mathrm{sp}$.

St. 48 Bonin Islands, East from Chichijima, 100 Metres, ${ }^{1 / 8}$. Formol. Eudiocrinus gracilis pulchellus $1 \mathrm{sp} .$, Pterometra trichopoda $1 \mathrm{sp}$.

St. 49 Bonin Islands, the Channel, 35 fath. $\% / 8$. Alcohol and formol. Comanthus par. vicirra a comasteripinna, broken arms, Cenometra bella $1 \mathrm{sp.}$

St. 50 Bonin Islands, Chio-ta-jima, on the shore at low tide, ${ }^{3}, 8$. Alcohol. Young Comasterid $1 \mathrm{sp.}$

St. 51 Bonin Islands, the Channel, 10 fath. $3 / 8$. Alcohol. Comaster delicutu grandis 1 sp.

St. $51 \mathrm{~A}$. Bonin Islands, the Channel, 35 fath. ${ }^{3 / 8}$ Formol. Comantheria grandicalyx var. Aagellipinna $1 \mathrm{sp}$.

St. 52 Bonin Islands, Taki-no-ura Channel, 30-40 fath. ${ }^{3-4} / 8$. Aicohol. Comantheria grandicalyx $2 \mathrm{sp}$.

St. 53 Bonin lslands, Higashijima (2 Miles East), sand + broken shells, 90 fath., $7 / 8$. Alcohol. Comatella brachycirra 5 sp., Comatelle maculata 1 sp., Young Comasterid 1 sp., 


\section{The Crinoms from Dr. S. Boctís Expedition to Japax 1914. 183}

Eudiocrinus gracilis pulchellus sp. juv. 1 sp., Cyllometra albopurpureu spp. juv. $2 \mathrm{sp}$., Asterometra anthus (some young ones) II sp., Lorometra parcicirra is sp., Clarlometra elegans $2 \mathrm{sp}$.

St. 54 Bonin Islands, East from Chichijima, 70 fath., ${ }^{7 / 8}$, broken shells + sand. Young Comasterid $1 \mathrm{sp}$., Asterometra anthus spp juv. I sp, Compsometra parviflora $1 \mathrm{sp}$.

St. 55 Bonin Islands, ENE. from Chichijima, 115 fath., shells + sand, 15/8. Alcohol. Comatella brachycira 2 sp., Comissia ignota minuta 11 sp., Comasler serrata $1 \mathrm{sp}$., Asterometra anthus sp. juv. 1 sp., Stenometra dentata sp. juv. $1 \mathrm{sp}$.

St. 56 Bonin Islants, East from the Chiannel, 115 fath. ${ }^{15} / 8$. Alcohol. Comatella brachycirra $2 \mathrm{sp}$., Comatella stelligera 1 sp., Asterometra anthus 7 sp., Stenometra dentata 5 sp., Diodonlometra Bocki 1 sp., Metacrinus nobilis tenuis $1 \mathrm{sp}$., Metacrinus interruptus $4 \mathrm{sp}$.

St. 57 Bonin Islands, East from Chichijima, 100 fath., ${ }^{85}{ }_{8}$. Asterometra anthus sp. juv $1 \mathrm{sp}$.

St. 58 Bonin Islands, the islands East from Chichimima, 180 Metres, ${ }^{15} / 8$. Metacrinus nobilis tenuis $1 \mathrm{sp}$, Metacrinus interruptus $2 \mathrm{sp}$.

St. 59 Bonin Islands, LNE from Anojima, 100 fath. ${ }^{15}, 8$, formol or alcohol. Comatella brachycirra 7 sp., Comatella maculata 2 sp., Comatella stelligera 2 sp., Comissia per'egrina magnifica $2 \mathrm{sp}$, Comaster delicata grandis sp. ad. $1 \mathrm{sp}$. , Comaster serrata $1 \mathrm{sp}, \mathrm{Ca}$ toptometra magnifica minor $3 \mathrm{sp}$., Eudiocrinus inlivisus 1 sp., Cyllometra albopurpurea $2 \mathrm{sp}$., Pterometra trichopoda 3 sp., Asterometra anthus 20 sp., Stenometra dentata 3 sp., Metacri. uns interruptus $4 \mathrm{sp}$.

St. 60 Bonin Islands, ENE from the Chanizel, 100 fathoms, ${ }^{15} / 8$. Formol. Comaster delicata grandis $1 \mathrm{sp}$.

St. 61 Bonin Islands, ESE from the Channel, 83 fath., ${ }^{16}$ ' 8 . Formol. Comissiu ignola minuta 2 sp., Young Comasterid 1 sp., Catoptometra magnifica minor sp. juv 1 sp.

St. 62 Bonin-Islands, the Channel between Chichijima and Anojima, 20 Metres, August. Comantheria grandicalyx var. flagellipinna. $1 \mathrm{sp.}$

St. 63 Japan, Sagami, Misaki, on the shore at low tide, ${ }^{14 / 9}$. Alcohol. Comanthus parvicima a comasteripinua sp. juv. $1 \mathrm{sp}$.

\section{Misprints.}

p. $66,3^{\text {d }}$ line from below for able-formed l'ead table-formed.

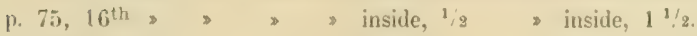

p. $99,6^{\text {th }}$ » $\geqslant \geqslant 75$ » 45 .

p. $123,1^{\text {st }}$, above , bifucation , bifurcation.

p. $159,7^{\text {th }}$ \& $\$$ below $>54$ (XIV) 56 mm. 51 (XIV) $56 \mathrm{~mm}$. 


\section{Photos: Plate I.}

1) Comatella brachycira (St. 56 Sp. 1 and 2; 1 in lateral view) about $\times 2$.

2) Comissia peregrina magnifica (St. 59 Sp. 1 and 2) nat. size.

3) Comissia ignota minuta (St. 47) $2 / 1$.

4) Comaster delicata grandis (St. 45 Sp. 3) nat. size.

5) Eudiocrinus gracilis pulchellus (St. 45) ${ }^{2 / 1}$.

6) Eudiocrinus Loveni (St. $47 \mathrm{Sp} .1)^{2 / 1}$.

7) Stenometra dentata (St. 56) ${ }^{2 / 1}$.

8) Clarkometra elegans (St. 43 Sp. 1) "/1.

9) Cyllometra pulchella (St. 13) $9 / 1$.

\section{Plate II.}

10) Diodontometra Bocki (St. 56 Sp. 1) $2 / 1$.

11) Toxometra cequipinna (St. 4, Sp. 1) $\mathrm{P}_{3}$ visible to the left, ${ }^{2 / 1}$.

12) Psathyrometra Wireni (St. 6, Sp. 1) $2 / \mathrm{s}$.

13) Metacrinus intermptus (St. 56 Sp. 16) the newly formed arms of sometvlat unequal size; about $\times 1^{3 / 4}$.

14) Metacrims intermutus (Sp. 16) the same specimen viewed from another side, ${ }^{2} / 1$.

15) Metacrimus intermptus (St. $56 \mathrm{Sp.} \mathrm{13)} \mathrm{the} \mathrm{ne} \mathrm{warms} \mathrm{of} \mathrm{very} \mathrm{different} \mathrm{length,} 2 / 1$.

16) Asterometra anthus (St. $55 \mathrm{Sp} .53$ ) a very young specimen, 4/1. 
Nova Acta Reg. Soc. Sc. Ups. Sel. 4. YJl. E. il. E

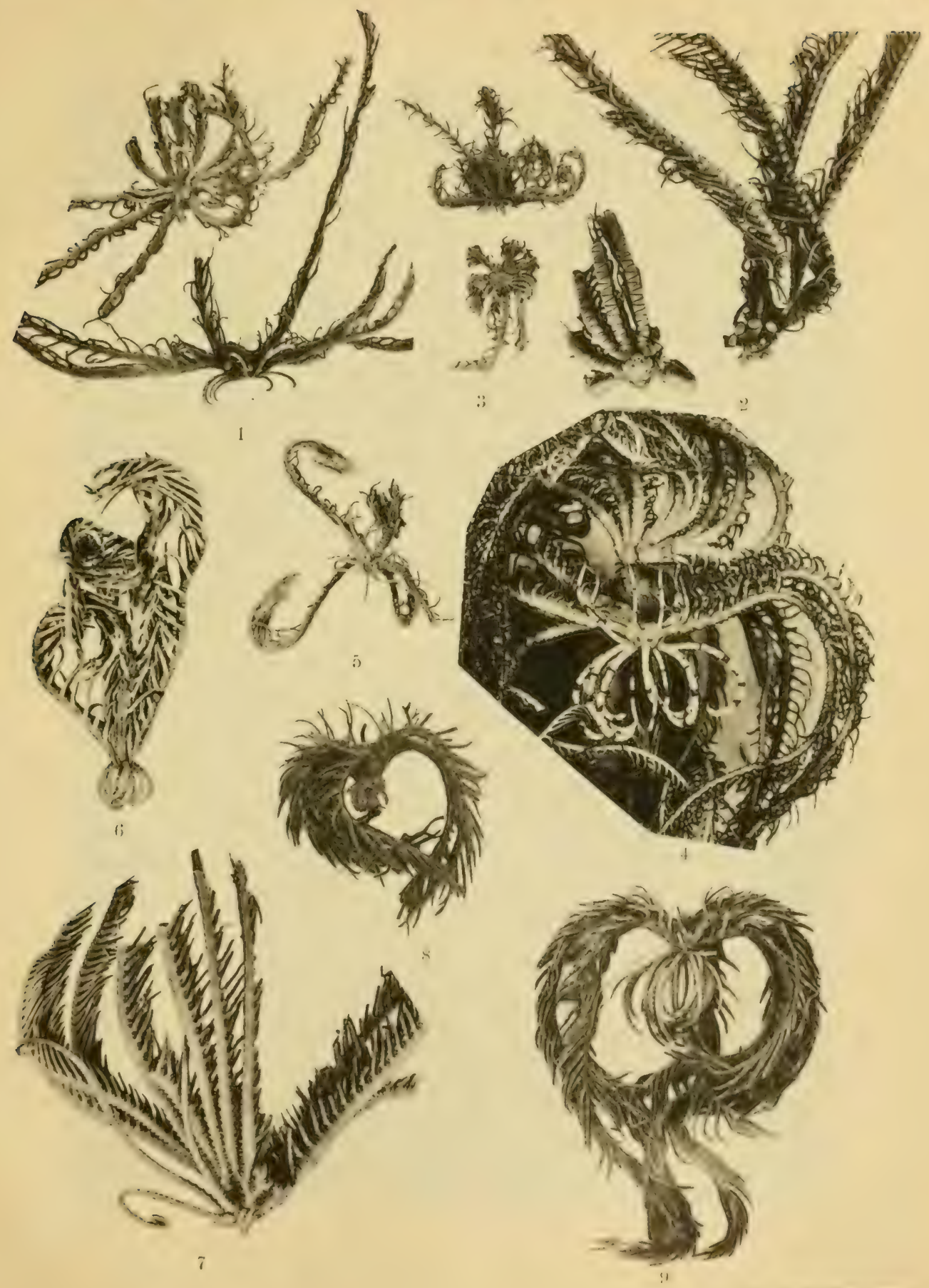



Nova Acta ReE. Soa. Sz. Upu. Ser. A. "Ol.

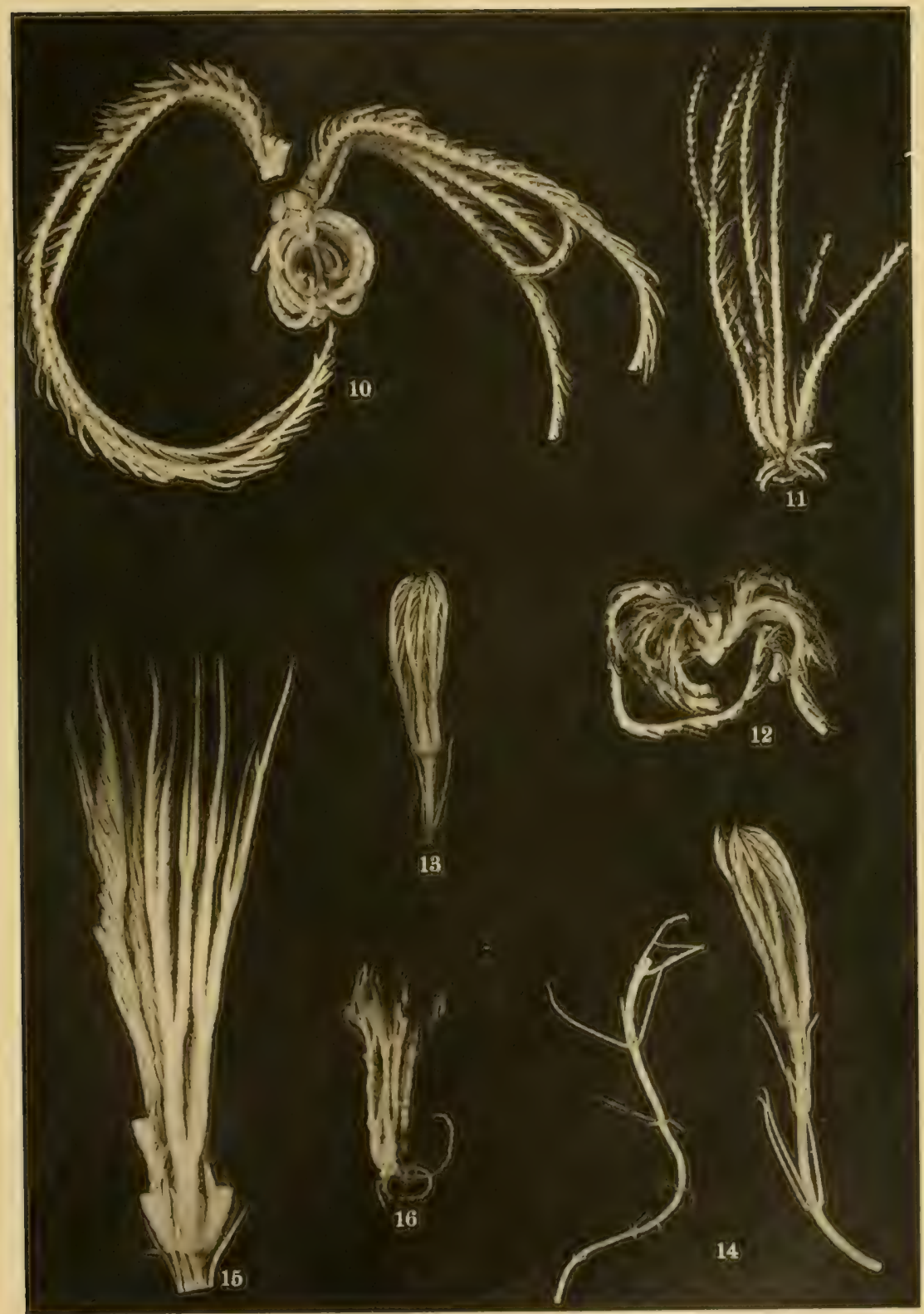




5
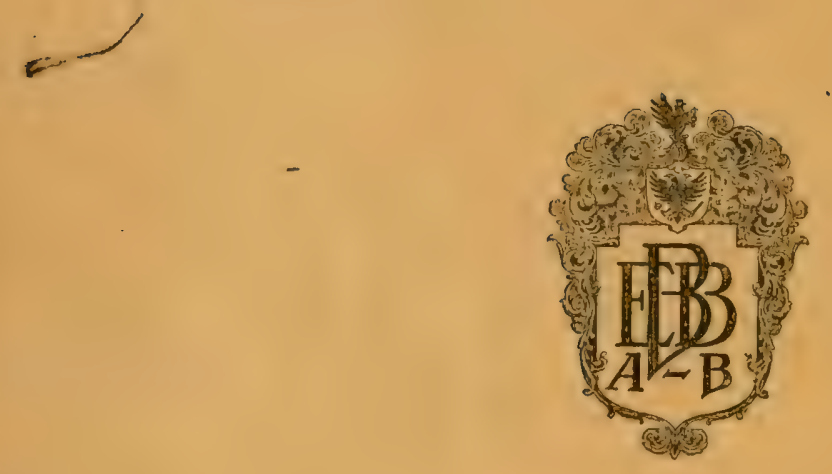



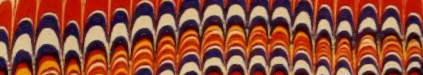

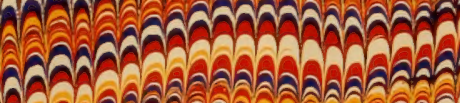

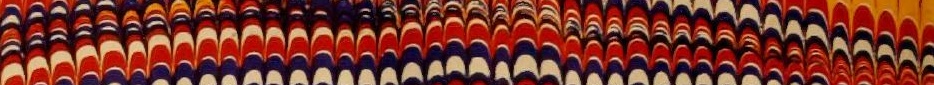

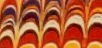

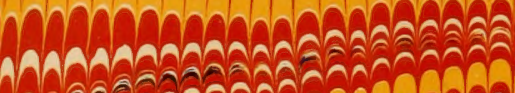

Aिר तैरी

AीA

बิe

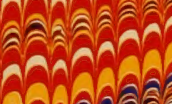

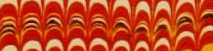




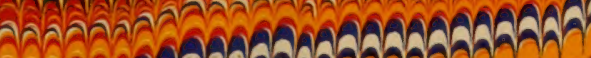

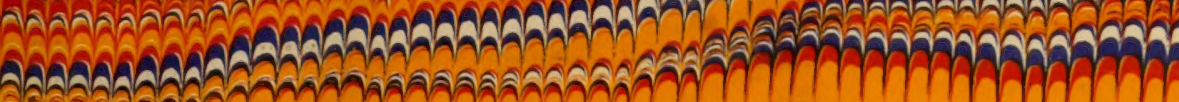

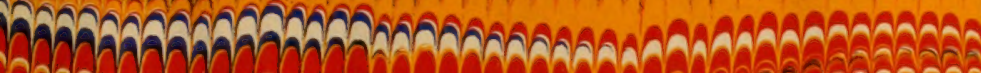

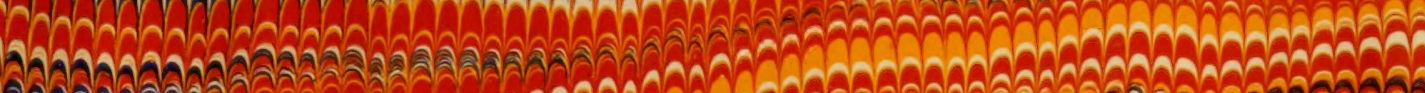

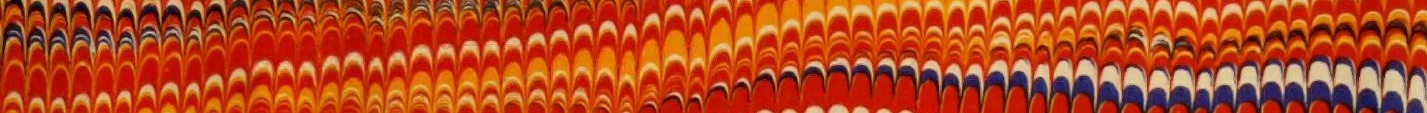

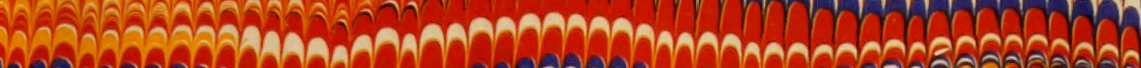
Whâ,

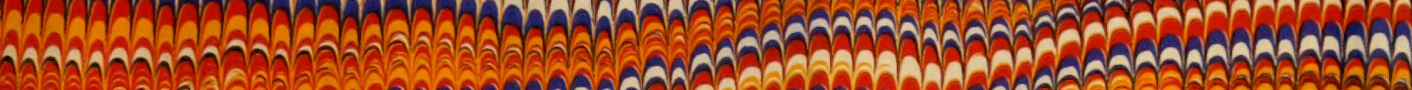

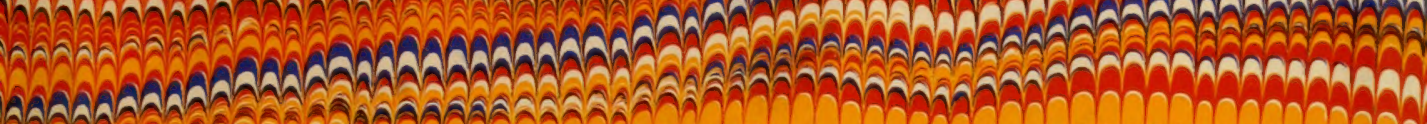

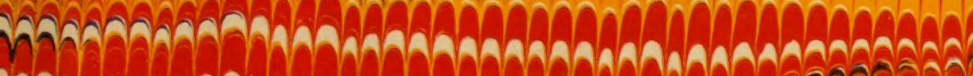

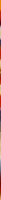

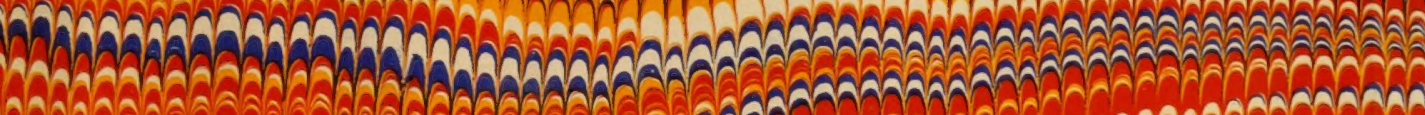

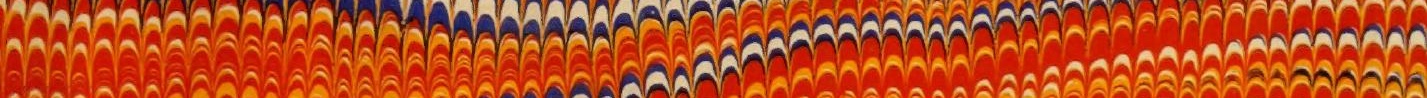
1. 1.

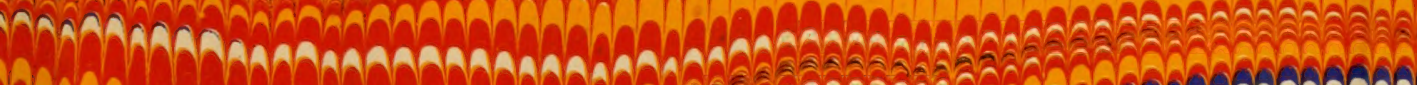

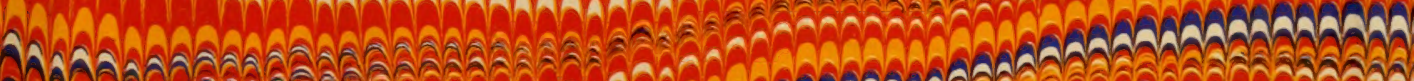


